Luiz Alexandre Kulay

\title{
Aplicações da técnica de Avaliação de Ciclo de Vida como recurso para o aprimoramento de processos e transformações que se desenvolvem no âmbito da Indústria Química
}

Tese apresentado à Escola Politécnica da Universidade de São Paulo - EPUSP como requisito obrigatório para inscrição no Concurso Publico de Provas e Títulos para Professor Livre Docente junto ao Departamento de Engenharia Química na especialidade Meio Ambiente

São Paulo 
Kulay, Luiz Alexandre

Aplicações da técnica de Avaliação de Ciclo de Vida como recurso para o aprimoramento de processos e transformações que se desenvolvem no âmbito da Indústria Química / L.A. Kulay -- São Paulo, 2020.173 p.

Tese (Livre-Docência) - Escola Politécnica da Universidade de São Paulo. Departamento de Engenharia Química.

1.Avaliação de Ciclo de Vida 2.Desempenho Ambiental 3.0timização 4.Modelos matemáticos 5.Processos Químicos 6.Dimensionamento 7.Projeto de Processo I.Universidade de São Paulo. Escola Politécnica. Departamento de Engenharia Química II.t. 
À Alice e ao Dante:

A geração de vocês tem nas mãos as receitas do sucesso e do fracasso. Ela precisa ser capaz de reconhecer a melhor opção e colocá-la em prática com a urgência que pede a situação. Tudo que foi pensado, discutido, implementado, enfim, tudo que ocorreu anteriormente a isso terá valido a pena, tão somente, se puder transmitir aos que se propuserem a fazer isso as serenidade e sabedoria que a decisão predispõe. 

Plantar árvores faz bem a saúde, observá-las faz bem a alma.

É que as plantando, você exercita o corpo; observando-as, você nota a grandeza da criação divina.

(Zé Ambientalista)

The more clearly we can focus our attention on the wonders and realities of the universe about us, the less taste we shall have for destruction.

(Rachel Carson) 



\section{Agradecimentos}

Muitas foram as pessoas que me ajudaram a compor (e formatar) esse texto. Não apenas por conta do esforço dedicado, mas pelas ideias, conversas, debates, e pontos de vista. E não poderia ser de outra forma, trata-se de uma coletânea sistematizada de parte da produção científica de um docente. Há sem dúvida uma curva de amadurecimento que leva seu tempo natural para ser cumprida. E cá entre nós, não acho que fosse capaz de percorrer essa trajetória sozinho.

Agradecer aos orientados, supervisores, formadores, colegas e claro, aos estudantes ('O que eu seria sem eles?') é mais do que externar um reconhecimento pelos esforço e tempo dedicado: é uma questão de respeio, merecido e adquirido com o tempo nas mais diversas e, às vezes, inusitadas, situações.

Mas, a cautela, aquela mesma para o qual apelamos quando submetidos a situações inesperadas e expositivas, me impede de citar individualmente a todos aqueles que colaboraram para que esta tese fosse escrita: é certo que me escaparia alguém, trazendo equívocos e injustiças lamentáveis. Me permito não correr tal risco exatamente pelos respeito e consideração que devo a todos eles e elas.

Mas não me furtarei a externar a gratidão de forma coletiva: inicio com meus orientadores e supervisores, no país e fora dele, pela dedicação (e talvez até, a paciência) e colocar bases consistentes para minha formação, nos âmbitos do ensio e da pesquisa. E principalmente, por incutir em mim (todos eles) a busca pelo fazer apreder, e por sempre procurar discípulos, ao invés de me contentar apenas, com estudantes.

Passo imediatamente aos orientados, a quem escuto muito mais do que eles imaginam. E sem dúvidas: muitoembora possa não lhes parecer, sinto-me realizado quando eles avançam, superam seus limites, concluem o processo árido de qualquer dos níveis de pós-graduação identificando que amadureceram. Não são muitas as realizações nessa carreira, mas por lidarmos com algo tão caro quanto a forma, sem dúvida que quando atingidos, os dividendos são intensos. 
Gratificantemente intensos. As vitórias são deles. Que deixem nossa convivência sempre com mais bagagem científica e pessoal do que portavam ao chegar. E que as ideias que construímos nesse interegno frutifiquem, multipliquem, sempre pautadas por seus estilos individuais. É um trabalho de responsabilidade e confiança individual. Logo, se (ou quando) isso ocorre, me vem o sentido de dever cumprido. É ambém chegada a hora deles. Estão prontos novos desafios. E que venham outros! Nossa vida é assim; impiedosamente transitória.

Não posso esquecer também os colegas, docentes e pesquisadores das investigações que realizamos, algumas delas usadas nesta mesma narrativa para fundamentar a tese que escolhi expor. Ao mencioná-los, me permito uma digressão para também citar àqueles com que interajo no departamento. Trata-se de uma oportunidade ímpar poder olhar de perto seus estilos e ouvir seus pontos de vista. A USP de forma geral, e a Escola Politécnica, no mérito mais específico, oferecem, de fato, um elenco de possibilidades de interação, criação, e aprimoramento muito maior do que jamais poderia imaginar (ou aproveitar). Essas instituições merecem apreço por muito mais do que as condições físicas e materiais (excelentes) que puderam me oferecer para que avançasse até aqui. Registro por fim, mas nem por isso, com tom de menor importância, meus agradecimentos aos órgãos de fomento à pesquisa - FAPESP, CNPq e CAPES, - cujo apoio financeiro foi essencial para que as ideias se tornassem contribuições consistentes.

Termino agradecendo às pessoas externas à academia, mas nem por isso deixam de fazer parte daquele cotidiano, às vezes forçadamente. Nesse grupo estão meu Pai, irmãs, sogro e sogra, além do Dante e da Alice. São eles dois, a razão de seguir me debruçando sobre problemas ambientais. Acredito que podemos (esta geração) lhes entregar uma condição melhor, mais sutentável na acepção mais pura do termo, em termos de opções de vida. E está também a Gisele, a mamãe! Se me pedissem para definí-la em um termo, diria sem pensar: companheira! Com ela (e todos eles) me apoiando tenho por obrigação que seguir enfrente. Isso e mais do que um obrigação: trata-se de um privilégio! 


\section{Resumo}

Este arrazoado se ocupa em testar a hipótese de que a Avaliação de Ciclo de Vida (ACV) pode contribuir para o aprimoramento de atividades e transformações que ocorrem no âmbito da Indústria de Processos Químicos (IPQ). Para cumprir com tal propósito são apresentadas e discutidas seis aplicações da técnica, todas voltadas a uma perspectiva específica de sua potencial interface com a IPQ. Na primeira dessas situações a ACV investigar possíveis desdobramentos energéticos e ambientais derivados de ações de scale up de processo em uma unidade de cogeração de energia lotada em destilaria autônoma de etanol. A seguir, a técnica fornece elementos para a concepção de uma embalagem mais sustentáveis, obtida a partir de fécula de mandioca pela tecnologia de casting. Em outra intervenção a ACV verifica a efetividade ambiental de se recuperar efluente com vistas a torná-lo um fluido de processo em uma refinaria de petróleo. 0 caso seguinte irá testar o desempenho ambiental da tecnologia de Carbon Capture and Storage no tocante, exatamente, à redução de emissões de gases de efeito estufa no contexto da geração de energia em usinas termelétricas operadas com carvão e gás natural, que mais recentemente vêm ganhando participação na matriz elétrica brasileira. Depois, a ACV é testada em sua habilidade de selecionar a rota mais adequada - entre os leitos arrastado e fluidizado - para produção de gás de síntese a partir de biomassa de cana-de-açúcar. No contexto em questão, impactos ambientais e energéticos associados a sucessivas adições de palha em substituição ao bagaço são também quantificados e analisados. A narrativa se encerra com uma experiência na qual a ACV produz um indicador ambiental que será aplicado a equivalentes para as dimensões técnica e econômica no sentido de propor um arranjo otimizado, segundo esses enfoques, de distribuição de fontes, mais uma vez para o grid brasileiro de eletricidade. Em todas as situações avaliadas os resultados obtidos a partir da aplicação da técnica foram robustos o suficiente para atender às expectativas de que se cercavam. Esse desfecho ratifica a condição de artifício de suporte para gestão de processos que se desenvolvem no âmbito da IPQ.

Palavras chave: Avaliação de Ciclo de Vida. desempenho ambiental. Otimização. Modelos matemáticos. processos químicos. Dimensionamento. projeto de processo. 


\begin{abstract}
This buchar content tests the hypothesis that the Life Cycle Assessment (LCA) can contribute to the improvement of activities and transformations that occur within the Chemical Process Industry (CPI). To accomplish this purpose, six applications of the technique are presented and discussed, all focused on a specific perspective of its interface with the CPI. In the first of these situations, LCA investigates possible energy and environmental effects derived from process scale-up actions in an energy cogeneration unit located in an autonomous ethanol distillery. Next, the technique provides elements for the design of a more sustainable packaging, obtained from cassava starch by casting technology. In another intervention, LCA checks the environmental effectiveness of recovering effluent to make it an oil refinery process fluid. The following case will test the environmental performance of Carbon Capture and Storage technology with respect, exactly, to the reduction of greenhouse gas emissions in the context of the generation of energy in thermoelectric plants operated with coal and natural gas, which more recently have been gaining participation in the Brazilian electrical matrix. Then, LCA is tested on its ability to select the most suitable route - between the entrained and fluidized beds - for the production of syngas from sugarcane biomass. Environmental and energy impacts associated with successive additions of straw to replace bagasse are also quantified and analyzed in the same context. The narrative ends with an experience in which the LCA produces an environmental indicator that will be associated with others for the technical and economic dimensions - in the sense of proposing an optimized arrangement for the distribution of sources, also for the Brazilian electricity grid. In all situations evaluated, the results obtained from the application of the technique were robust enough to meet the expectations they were surrounded by. This outcome confirms the condition of the LCA as a support metric for the management of processes that are developed within the scope of CPI.
\end{abstract}

Keyword: Life Cycle Assessment. environmental performance. Optimization. mathematical models. chemical processes. sizing. process design 


\section{Sumário}

Agradecimentos

Resumo iii

Abstract

Sumário

$\begin{array}{ll}\text { 1. Introdução } & 1\end{array}$

2. Aplicação de indicadores ambientais a processo de scale up de planta de cogeração instalada 9 em destilaria de etanol

2.1. Introdução $\quad 9$

$\begin{array}{lr}2.2 \text { Descrição do Processo } & 9\end{array}$

$\begin{array}{lr}2.2 .1 \text { Etapa Agrícola } & 12\end{array}$

$\begin{array}{ll}\text { 2.2.2 Etapa Industrial } & 13\end{array}$

2.3. Metodologia $r$

$\begin{array}{lr}\text { 2.3.1 Definição dos cenários } & 15\end{array}$

$\begin{array}{lr}2.32 \text { Análise Termodinâmica } & 17\end{array}$

$\begin{array}{ll}\text { 2.3.3 Análise Ambiental } & 21\end{array}$

2.3.4 Efeito da sinergia entre indicadores termodinâmicos e ambientais no scale up do 23 processo 23

$\begin{array}{ll}2.4 \text { Modelagem do ciclo de vida } & 24\end{array}$

$\begin{array}{lr}2.5 \text { Resultados e Discussão } & 28\end{array}$

$\begin{array}{lr}2.5 .1 \text { Análise Termodinâmica } & 28\end{array}$

2.5.2 Análise Ambiental $\quad 32$

$\begin{array}{ll}2.5 .3 \text { Análise combinada termo-ambiental } & 37\end{array}$

$\begin{array}{ll}2.6 \text { Conclusões } & 38\end{array}$

$\begin{array}{ll}2.7 \text { Referências } & 39\end{array}$

3. Projeto de produto baseado em conceitos de Produção mais Limpa e Design for
Environment (DfE)

3.1. Introdução $\quad 45$

$\begin{array}{ll}\text { 3.2. Metodologia } & 47\end{array}$

3.3. Processamento de filme de amido de mandioca a partir da técnica de casting 48

3.4. ACV da produção do filme pela técnica de casting $\quad 49$

$\begin{array}{lr}3.4 .1 \text { Requisito gerais para a definição de escopo } & 49\end{array}$

$\begin{array}{ll}\text { 3.4.2 Premissas Específicas } & 50\end{array}$

3.4.3 Inventário de Ciclo de Vida (ICV) - fontes e qualidade dos dados $\quad 51$

3.4.4 Avaliação de Impacto do Ciclo de Vida (AICV)

3.5 Desempenho Ambiental e Energético da manufatura de biofilme 55

$\begin{array}{ll}\text { 3.5.1 Perfil Energético } & 55\end{array}$

3.5.2 Perfil de Impactos associados a emissões 5

$\begin{array}{lr}3.6 \text { Discussão } & 58\end{array}$

3.7 Proposição de cenários baseados em Produção mais Limpa (P+L) 60

3.7.1 Descrição de cenários alternativos $\quad 62$

3.8 Comparação de Perfis Energéticos e de Impactos de Emissões entre Cenários 64

3.8.1 Análise de Cenário Individual $\quad 64$

$\begin{array}{ll}\text { 3.8.2 Cenário Combinado } & 68\end{array}$ 
$\begin{array}{ll}3.9 \text { Considerações acerca do Balanço de Carbono } & 72\end{array}$

$\begin{array}{lr}3.10 \text { Conclusões } & 74\end{array}$

$\begin{array}{ll}3.11 \text { Referências } & 76\end{array}$

4. Uso de ACV na seleção de rotas para reúso de água em refinaria de petróleo 84

$\begin{array}{ll}4.1 \text { Introdução } & 84\end{array}$

$\begin{array}{ll}4.2 \text { Metodologia } & 87\end{array}$

4.2.1 Caracterização do efluente e destinação da água recuperada $\quad 87$

4.2.2 Definição de cenários de análise e descrição dos sistemas de recuperação 90

$\begin{array}{ll}4.3 \text { Modelagem do sistema } & 92\end{array}$

$\begin{array}{ll}\text { 4.4 Modelagem do ciclo de vida } & 94\end{array}$

$\begin{array}{ll}\text { 4.4.1 Definição de escopo } & 94\end{array}$

4.4.2 Invetário de Ciclo de Vida (ICV) 95

$\begin{array}{lr}4.5 \text { Resultados } & 96\end{array}$

$\begin{array}{lr}4.6 \text { Conclusões } & 102\end{array}$

$\begin{array}{lr}4.7 \text { Referências } & 103\end{array}$

5. Avaliação da efetividade de tecnologias de abatimento de impactos ambientais 107

$\begin{array}{ll}5.1 \text { Introdução } & 107\end{array}$

$\begin{array}{ll}5.2 \text { Metodologia } & 110\end{array}$

5.2.1 Visão Geral da Matriz Energética Brasileira 110

5.2.2 Carbon Capture and Storage: tecnologia Calcium Looping (CaL) 112

5.2.3 Definição de cenários 113

5.2.4 Simulação do Processo de CaL: condições de processo e premissas 114

$\begin{array}{ll}5.2 .5 \text { Avaliação Ambiental } & 117\end{array}$

$\begin{array}{lr}\text { 5.2.6 Análise Econômica } & 120\end{array}$

5.2.7 Combinação de indicadores ambientais, energéticos e econômicos 122

$\begin{array}{lr}5.3 \text { Resutados e Discussão } & 123\end{array}$

$\begin{array}{lr}\text { 5.3.1 Avaliação Ambiental } & 124\end{array}$

$\begin{array}{lr}\text { 5.3.2 Análise Econômica } & 128\end{array}$

5.3.3 Análises Combinadas: Ambiental, Energética e Econômica 129

$\begin{array}{lr}5.4 \text { Conclusões } & 130\end{array}$

$\begin{array}{ll}5.5 \text { Referências } & 131\end{array}$

6. Especificação de unidade de produção de gás de síntese derivado de biomassa de 136

$\begin{array}{ll}\text { cana-de-açúcar a partir de critério ambiental } & 136 \\ 6.1 \text { Introdução } & 136\end{array}$

$\begin{array}{ll}6.2 \text { Metodologia } & 138\end{array}$

6.2.1 Descrição das tecnologias em análise $\quad 139$

$\begin{array}{lr}\text { 6.2.2 Modelagem do Ciclo de Vida } & 140\end{array}$

$\begin{array}{lr}6.3 \text { Resultados } & 141\end{array}$

6.3.1 Desempenho Ambiental: GFA vs GLFB 141

6.3.2 Efeito ambiental da cogaseificação de bagaço e palha no sistema GLFB 144

$\begin{array}{ll}6.4 \text { Conclusões } & 146\end{array}$

$\begin{array}{lr}6.5 \text { Referências } & 147\end{array}$

7. Otimização de processos tendo em conta parâmetros ambientais 149

$\begin{array}{lr}7.1 \text { Introdução } & 149\end{array}$

$\begin{array}{lr}7.2 \text { Metodologia } & 154\end{array}$

$\begin{array}{ll}\text { 7.2.1 Projeção da Matriz Elétrica Brasileira } & 154\end{array}$

$\begin{array}{ll}\text { 7.2.2 Modelagem de ACV } & 156\end{array}$

7.2.2.1 Inventário de Ciclo de Vida (ICV) 158

$\begin{array}{ll}\text { 7.2.2.2 Avaliação de Impacto de Ciclo de Vida (AICV) } & 158\end{array}$ 
7.3 Resultados e Discussão

7.4 Conclusões

7.5 Referências

166

8. Considerações Finais 



\section{Introdução}

A sociedade atual dispõe de um volume expressivo de informações a respeito de Sustentabilidade, não apenas quanto ao conceito, mas com relação a suas especificidades e dimensões constituintes. Muito embora o termo Triple Bottom Line (TBL) tenha sido criado por John Elkington em 1997, apenas recentemente sua acepção mais ampla tem deixado de estar restrita, apenas, a dimensão ambiental e, dentro desta, aos impactos gerados sobre o entorno na forma de Mudanças Climáticas.

Uma das argumentações usadas para justificar essa analogia enviesada baseia-se no grau de reconhecimento, e a partir disso, de importância dado pela sociedade para cada uma das vertentes consideradas pelo TBL. Dentre estas, a que atenta para aspectos econômico é, sem sombra de dúvida, a mais consolidada. A associação entre seu caráter naturalmente quantitativo e (potencial) de riqueza do indivíduo, ou da coletividade, faz com que a dimensão econômica seja usada incontáveis vezes ao dia durante processos decisórios - individuais e coletivos - nos níveis de gestão, tático e até estratégico. E, em muitos dos casos será este o único critério adotado para aquela deliberação.

No extremo oposto àquele ocupado pela dimensão econômica dentro do espectro de valorização se encontra a dimensão social. Muito embora essa constatação possa soar como antagônica, as ações sociais ocorrem com mais frequência por iniciativas individuais, ou de pequenos grupos, do que em nível coletivista. Outras características das decisões (e ações) que ocorre no domínio da dimensão social são a regionalidade e a sazonalidade. Estas costumam ser motivadas por condições específicas e circunstanciais, que variam desde o auxílio a um município ou comunidade onde um empreendimento empresarial será instalado, até a solidariedade do cidadão comum diante dos efeitos de epidemias ou catástrofes naturais que resultam em dados coletivos irreparáveis a curto e médio prazos.

Um dos obstáculos a ser removido para que a dimensão social passasse a também ser observada como critério de gestão está na dificuldade de mensurá-la. A diversidade de valores, culturas e opções tornará específico qualquer conjunto de indicadores criado para esse fim. Sequer aqueles mais conhecidos, e de uso frequente - tais como, nível de formação, taxa de empregabilidade, riqueza acumulada, ou níveis de riqueza e pobreza fazem sentido para avaliar todas as situações, comunidades, ou nações, para os fins de gestão supramencionados. 
No entanto, importantes esforços acadêmicos empreendidos nesse campo vêm mudando o quadro e assim, é cada vez mais frequente o uso de perfis sistêmicos e precisos que são derivados de análises sociais, em processos e gestão pública e privada.

Entre os dois limites se encontra a vertente ambiental, uma posição improvável a há alguns anos devido à dificuldade sociedade em reconhecê-la como dimensão a ser sustentada e assim, de criar e desenvolver métricas que fossem capazes de converter seu abstratíssismo inerente em indicadores quantitativos. E como comenta Peter Drucker em uma de suas frases mais famosas e apropriadas: '(...) apenas o que pode ser medido, pode ser melhorado (...)'.

Também nesse caso, a academia teve função decisiva no processo de reversão do conceito arraigado de forma conveniente pelo Movimento Desenvolvimentista, de que o planeta seria, simultaneamente, fonte inesgotável de recursos, e receptáculo infinito de rejeitos. No bojo da superação desse desvio, chega também o alerta emitido no Relatório Brundtland (Our Common Future) em 1987, de que a sociedade moderna tem por dever interagir com o entorno para satisfazer suas necessidades, (apenas) na medida suficiente para que as geração futuras possam exercitar esse mesmo direito.

Desde então, muitas ações coletivas e individuais têm ocorrido. Tais movimentos tornaram-se mais orientados, a partir do momento em que as formas de interação entre o ser humano e o ambiente puderam ser descritas, particularmente em termos de seus efeitos; ou seja, quando tornou-se enfim possível, fazer estimativas da magnitude dos impactos ambientais.

É exatamente nesse contexto que surge a Avaliação de Ciclo de Vida (ACV). Desde a gênese, em 1969, ainda como Resource Environmental Profile Analysis (REPA), que nos países europeus se desenvolveu com Ecobalence Method, até chegar aos dias atuais, essa abordagem conserva duas características essenciais: (i) ser capaz de praticar o caráter sistêmico em suas avaliações, e (ii) gerar indicadores que quantifiquem da atuação de um produto, serviço ou processo em termos de desempenho ambiental no exercício de funções para as quais foram concebidos.

Seria precipitado, e até insensato, afirmar que a ACV é a única técnica de suporte a gestão a gerar indicadores. Há outras métricas que cumprem essa mesma atribuição de maneira bastante competente. E foi devido a essa variabilidade tão necessária, oportuna e bem-vinda que a vertente ambiental obteve a posição que ocupa na hierarquia de importância que a sociedade criou para as dimensões componentes da Sustentabilidade. 
Os impalpáveis impactos ambientais de a princípio, que se tornaram concretos e, talvez por isso mesmo, temidos, em poucas décadas poderiam finalmente ser compreendidos, quantificados e reduzidos (ou melhorados...).

Mas o empenho da comunidade científica que se dedica a ACV, reduzindo, quando não, eliminando, algumas de inconsistências, propondo abordagens metodológicas mais atuais, gerando bancos de dados variados, realistas e robustos, e concebendo modelos matemáticos capazes de descrever com precisão cada vez maior o binômio instalado entre aspecto ambiental - impacto ambiental, trouxe frutos.

Nos dias que correm, a ACV ocupa um espaço próprio, de apoio às mais variadas facetas da gestão. Tal como relata de forma apropriada a norma 14040 da International Organization for Standardization (ISO) seus diagnósticos ACV se prestam a desenvolver e melhorar produtos, apoiar planejamentos estratégicos, elaborar políticas pública, dar respaldo a ações de marketing. Todas essas aplicações são fundamentais, sobretudo se observadas dentro da perspectiva mais básica a indispensável de suas atuações: de criar, ou incutir, um valor ambiental da sociedade.

A Indústria de Processos Químicos (IPQ) figura entre os setores antrópicos mais promissores para disseminação do enfoque oferecido pela ACV. Tratada no passado com mal necessário para a vida moderna em virtude das exacerbadas taxas de depleção de recursos e de poluição que proporcionava, a IPQ precisou rever conceitos e se atualizar. Essa remodelação passou, sem dúvida, pela incorporação de recursos tecnológicos, mas avanços nos campos da formação de competências e, principalmente, da gestão, foram também introduzidos. E foi exatamente na interface com o entorno imediato, ou não, em que surgiu um espaço para que a ACV pudesse contribuir com essas intervenções de aprimoramento de processos e transformações que se desenvolvem no âmbito da IPQ. Essa é a tese que se pretende comprovar com o presente arrazoado.

Para tanto, além deste - que exerce o papel de introduzir a temática, e apresentar formalmente seus objetivos -, o presente documento se compõe também de outros sete capítulos, sendo seis descritivos e um, o último deles, que traz considerações finais sobre a matéria antes tratada. Os capítulos descritivos reúnem relatos de investigações, que selecionados com o propósito de respaldar a proposição declarada no parágrafo anterior.

Antes de partir para uma descrição preambular do conteúdo de cada capítulo, é importante destacar certa particularidade que é comum a essas situações: a despeito de seu caráter de realidade - já que algumas delas ocorrem apenas no campo das propostas - essas experiências foram publicadas em periódicos científicos de expressões diversas. 
O Capítulo 2 descreve um caso em que a ACV é aplicada para investigar possíveis desdobramentos energéticos e ambientais derivados de ações de scale up de processo. 0 sistema em análise compreende uma destilaria autônoma de etanol cujo ciclo Rankine de cogeração tem potencial para atender às necessidades da planta, e ainda, ser capaz de exportar a energia elétrica excedente para a concessionária. A etapa agrícola de cultivo da cana-de-açúcar, assim como os transportes (de cana, palha, cinzas, vinhaça e torta de filtro) que interligam os núcleos produtivos são também parte integrante do sistema. As ações de scale up ocorrem no ciclo combinado, por meio de elevação paulatina da pressão de operação da caldeira desde 20 bar até 100 bar. A adição de palha como combustível auxiliar ao bagaço na caldeira também foi examinada.

O comportamento termodinâmico de ciclo Rankine é verificada em cada situação por meio de análise exergética, ao passo que a análise ambiental ocorre averiguando-se o desempenho do sistema quanto a Mudanças Climáticas, Formação de Particulado, bem como das Depleções Hídrica e de Fósseis. $\mathrm{O}$ caso se torna interessante à medida que os comportamentos ambientais e exergética mostram confluência de tendências para cada situação analisada. Isso se dá quando os resultados obtidos por uma das abordagens corroboram, confirmam, ou até colaboram para elucidar especificidades destacadas pela outra dimensão. A pesquisa se conclui com a integração das duas dimensões, a partir do que se torna possível calcular um indicador exergo-ambiental. 0 procedimento, que aliás se repete em outros momentos deste documento, permite identificar possíveis sinergias e discrepâncias que ocorrem a partir da conjugação da dimensão ambiental com outras verificadas pelas análises. Além disso, essa ação abre a perspectiva de que as alternativas em avaliação sejam hierarquizadas com base em seus resultados para aqueles domínios.

A expectativa com aquela aplicação é demostrar que a ACV é capaz de fornecer elementos que condicionem a operação de sistemas já implantado, ou mesmo, que possa proporcionar elementos que orientem projetos de futuras instalações. Essas aplicações não são triviais. Diferentemente do ocorre quando a ACV é aplicada na identificação de focos impacto, esta situação se ocupa de estabelecer relações entre as condições em que um processo opera e seu desempenho ambiental. A ação é bem-sucedida, na medida que os resultados ambientais respaldam e são respaldados pela avaliação exergética, de fundo essencialmente termodinâmico.

Já o terceiro capitulo traz uma aplicação clássica da ACV, em que a técnica fornece elementos para concepção de um produto mais sustentável, ao menos no que se refere à dimensão ambiental. 
O exercício de Design for Environment (DfE) acontece no âmbito do desenvolvimento de um biofilme estruturado a partir de fécula de mandioca, que além da função original de acondicionar alimentos, é capaz de trazer indicações quanto ao seu grau de preservação, ao longo do tempo de prateleira.

Como não poderia deixar de ser, um dos aspectos diferenciais da circunstância em que transcorre a análise reside na transitoriedade da tecnologia, que muito embora conceitualmente consolidada, permanecia sendo ainda explorada em escala laboratorial. A influência dessa circunstância sobre a atividade de coleta de dados para elaboração do diagnóstico ambiental é inerente, a situações de DfE. No entanto, a investigação pôde proporcionar resultados com variedade e precisão suficientes para orientar o projeto do biofilme no momento em que este se encontrava à época da realização da ACV.

As experiências descritas nos Capítulos 2 e 3 foram capazes de ratificar algumas das expectativas que cercam a ACV. A primeira delas reside na efetividade da técnica na consecução de seus propósitos, não apenas no âmbito da gestão reativa, que se apoia em diagnósticos para corrigir distorções e assim conter impactos que sempre existiram, mas que até a aplicação da técnica eram desconhecidos. Nestes estudos a ACV atua de forma proativa, mostrando ao projetista caminhos que merecem ser explorados e quais alternativas devem ser deixadas de lado naquele momento, sob a ótica peculiar, mas absolutamente oportuna, do desempenho ambiental.

Outra comprovação importante é a de que a técnica pode ser usada com dados de empíricos. A lógica natural do desenvolvimento de um produto, ou talvez antes, de uma tecnologia, predispõe o uso de escalas crescentes de exploração, que naturalmente trazem associados graus de incerteza. Isso é inerente aos modelos e também aos métodos, tal como ocorre com a própria ACV. No entanto, caso a técnica seja aplicada em um momento adequado, em que os valores de consumos e emissões estejam consolidados para a escala correspondente, o diagnóstico ambiental oferece os dividendos que dele se espera para o contexto, mesmo que esses se restrinjam a apontar rotas, procedimentos e condutas a não serem seguidas. Isso per se já pode ser visto como de grande valia, inclusive em termos econômicos e de administração de tempo.

De maneira algo proposital, ficou para o fim desta argumentação a confirmação mais importante: de que os resultados obtidos pela ACV podem, na prática, condicionar a concepção de produto, e por decorrência, também de processos e serviços. Isso se dá por intermédio da adequação de sua eficiência ambiental ao grau de avanço de tecnologia e a disponibilidade de recursos disponíveis à época da instalação desse desenvolvimento. 
O Capítulo 4 relata uma prática da ACV para verificação de rotas processuais algo diferentes entre si, mas que prestam a atingir um objetivo comum. Este consiste do reuso de efluentes de processo como fluído de troca térmica em torre de resfriamento de uma refinaria petroquímica. Para que o efluente atingisse os padrões requeridos para aquela função, um arranjo composto por osmose inversa (OI), evaporação (EV) e cristalização (CR) foi projetado para realizar sua dessalinização. Esse encadeamento de operações era comum a todos os cenários constituídos para análise, que acontece via comparação entre seus efeitos ambientais e energéticos. As diferenças entre as situações são explicitadas no tipo de tratamento dispensado ao efluente previamente à sua alimentação na osmose, e a fonte de energia térmica utilizada pelos sistemas.

Aparentemente, esta seria mais uma aplicação trivial da ACV, não fosse pelo fato de o objeto de estudo ser um arranjo de processo que, à época, se encontrava ainda em fase de implantação. $O$ objetivo que norteou a escolha desse caso foi de ilustrar que a ACV se presta perfeitamente a também identificar esquemas de processo que, na plenitude (ou seja, sob a perspectiva de ciclo de vida) sejam mais adequados para as circunstâncias e condições pleiteadas. Um dividendo compulsório dessa ação estava também em avaliar como diferentes formas de pré-tratamento poderiam influenciar os resultados globais de impactos energéticos e ambientais. Isso porque, se por um lado, cada uma das estratégias aporta ao desempenho coletivo uma parcela própria de impactos que inerente ao se ciclo de vida individual, por outro, tais operações conferem diferentes graus de eficiências de recuperação de água na OI, que tanto mais elevados forem, menos impactos imporão ao funcionamento da CR. O problema torna-se atraente em virtude desse balanço. Raciocínio semelhante orienta a análise que envolve a fonte de provimento de calor para CR. Assim como espera-se, tenha ficado claro na descrição daquele enredo, também neste caso a ACV mostrou ser um meio efetivo de geração de critérios para o projeto de processos.

O Capitulo 5 narra uma situação cuja efetividade ambiental da prática de Carbon Capture and Storage (CCS) - concebida especificamente para reduzir impactos na forma de Mudanças Climáticas - é examinada pela ACV. 0 caso difere dos anteriores, ou mais especificamente daquele tratado no Capítulo 3 - em virtude de as concepção e aplicação do CCS serem disciplinadas pelo requisito de trazer um resultado ambiental favorável. E em primeira instância isso de fato ocorre, para um domínio de aplicação restrito apenas à tecnologia. 0 caso ganha contornos de especificado por ampliar o escopo de avaliação até os limites do ciclo de vida de cada qual dos fluxos de matéria e energia, e dos recursos físicos, envolvidos no processo de abatimento de $\mathrm{CO}_{2}$. 
O pano de fundo de aplicação do CCS é a matriz elétrica brasileira. Este panorama foi escolhido de maneira intencional por dois motivos. A eletricidade é uma utilidade de uso constante, e em muitos casos, intenso, em processos químicos. Assim, conhecer que impactos serão incorporados ao processo a partir de sua utilização é sempre oportuno, sobretudo, para uma circunstância que sinaliza redução desses efeitos.

O segundo motivo se relaciona ao caso. 0 grid brasileiro apresenta uma parcela significante de energias derivadas de fonte renovável. No entanto, já há alguns anos, por motivos diversos, a participação de fósseis naquele arranjo vem aumentando de maneira algo preocupante. 0 resultado imediato desse movimento de carbonização da matriz foi a elevação de seus índices de contribuição para o Aquecimento Global. 0 acoplamento de Carbono Looping - talvez a modalidade mais frequente de CCS - às usinas termelétricas operadas com carvão e gás natural pode equacionar esse problema. É exatamente essa a possibilidade examinada no estudo em questão, tanto sob a perspectiva de emissões de Gases de Efeito Estufa (GEE), como de Demanda de Energia Primária (DEP), que passou a fazer parte da análise de dados os requerimentos energéticos do Carbon Looping.

O Capítulo 6 associa em um só caso, diversas variantes testadas isoladamente nas investigações que a precedem neste documento. Nessa situação, a habilidade da ACV em selecionar um processo foi posta à prova. Dado que arranjos envolvendo leito fluidizado e leito arrastado atendem satisfatoriamente e de forma semelhante a requisitos técnicos, e supondo que seus custos globais se equivalessem, coube a ACV apontar a tecnologia mais adequada para obtenção de gás de síntese a partir de biomassa de cana-de-açúcar.

O título do capítulo faz referência a especificação de uma unidade de gaseificação em virtude de a segunda etapa da análise se debruçar sobre a biomassa. Selecionada uma abordagem processual, o objetivo da intervenção que se segue é compreender como se comporta o perfil ambiental do processo conforme o bagaço de cana vai dando lugar para a palha dentro do reator. Assim, além de atuar como critério de seleção de tecnologia, a ACV foi usada também como um artifício para inter-relacionar parâmetros de processo ao desempenho ambiental do conjunto, na busca de um eventual equilíbrio entre condições operacionais e efeitos sobre o entorno. Assim como já havia sido destacado no texto introdutório ao Capitulo 2, esta não é também uma aplicação trivial da técnica de ACV.

Outro foco incorporado a análise reside no pseudo-ineditismo do caso. A prática de gaseificação visando a produção de gás de síntese pode ainda ser considerada uma tecnologia com campo para avançar nos casos em que a biomassa de cana-de-açúcar em particular, a palha - seja a matéria prima principal. 
Por fim, no Capítulo 7 a ACV volta mais uma vez suas atenções para a matriz energética brasileira, assim como já havia ocorrido no caso descrito no Capítulo 5. No entanto, ao invés de verificar a compatibilidade ambiental de uma solução inovadora, esta análise eleva o nível de suas pretensões ao especificar as bases de uma proposta de arranjo otimizado para o grid do país. Tal como se poderia esperar de antemão, o papel da ACV nesse enredo é gerar um indicador ambiental com características e consistência condizentes às dos congêneres para as dimensões técnica e econômica, com que este será associado.

O fato de as dimensões consideradas para solução do problema - demanda, custo e desempenho ambiental descrito em termos de contribuição para o Aquecimento Global - não se comportarem de forma regrada e harmônica cria uma perspectiva interessante em termos de abordagem do problema, dada a necessidade original de coordenar todos esses recortes de maneira equilibrada.

0 afã de associar as três vertentes acaba, no entanto, tendo de desconsiderar outras interações do sistema em análise com o ambiente. A ACV volta então à cena para avaliar os efeitos modificações, ajustes e aprimoramentos implementados sobre o grid sobre o desempenho de outras categorias de impacto. 0 resultado dessa experiência acaba por configurar um alerta com relação aos riscos de restringir a Sustentabilidade à dimensão ambiental e, esta, exclusivamente às emissões de GEE. Ou seja: não basta equiparar todas as dimensões do TBL em termos de reconhecimento (e grau prioridade) para a sociedade moderna.

Esta é apenas a primeira das etapas a serem percorridas, ao que se seguirá uma especificação dos conteúdos mais importantes de cada recorte. Essa tarefa, precede de sua parte, a inclusão de dimensões de importância equivalente às ambiental, econômica e social, mas que, para o momento, se apresentam tão incomensuráveis quanto aquelas pareciam quando Elkington propôs o TBL. E feito isso, virão outros ajustes.

Há de fato muito trabalho a ser feito. Resta saber se teremos tempo para que tudo isso possa ser implementado com chances reais de obtermos algum sucesso. 


\section{Aplicação de indicadores ambientais a processo de scale up de planta de cogeração instalada em destilaria de etanol}

\section{Resumo}

Este capítulo descreve e discute efeitos termodinâmicos e ambientais gerados em decorrência da expansão de sistemas de cogeração que operem de acordo com o ciclo de Rankine com o reaquecimento, e estejam instalados em destilarias autônomas de etanol. A verificação termodinâmica foi realizada por meio de análise exergética, ao passo que a análise ambiental ocorreu por meio de ACV. Dez cenários foram projetados considerando diferentes níveis de pressão de vapor e taxas de adição de palha remanescente no cultivo da cana-de-açúcar. A análise termodinâmica revelou uma melhoria de 37\% na eficiência exergética, bem como, aumento de $63 \%$ na geração de energia a partir do aumento da pressão de operação do sistema de 20 para 100 bar. Além disso, o uso de 50\%m/m de palha em unidades que geram vapor a 100 bar pode mais do que dobrar a quantidade de eletricidade exportada. Quando observado sob uma perspectiva sistêmica, o uso da palha reduz impactos ambientais provocados pela cogeração na forma de Mudanças Climáticas e Formação de Material Particulado; no entanto, a ação acarreta impactos adicionais em termos de Depleção de Recursos Hídricos e Fósseis.

\subsection{Introdução}

A produção de açúcar e álcool figura como das principais atividades produtivas do Brasil. A expansão do setor teve início a partir duas ações: (i) o mercado internacional se abriu para aquele combustível; e, (ii) o governo brasileiro criou diversos mecanismos para comercialização de excedentes de eletricidade derivados da queima da biomassa para a concessionária (SEABRA e MACEDO, 2011; ALVES et al., 2015). Essas perspectivas motivam as empresas do setor sucroalcooleiro a elevar seus níveis de competitividade tomando ações que, por exemplo, melhorem a produtividade agrícola e o rendimento das unidades industriais, ou mesmo, que reduzam perdas distribuídas pela cadeia produtiva. Nessa segunda vertente destaca-se como prática regular o reaproveitamento de resíduos agrícolas, principalmente, na forma de bagaço e palha.

Por não estar consolidada como fonte complementar de obtenção de etanol, essa biomassa é utilizada com frequência nos ciclos de cogeração, com o objetivo de aumentar o suprimento de energia elétrica, com vistas a sua exportação para a rede concessionária (CARDOSO et al., 2013; ALVES et al., 2015). Aliás, é esperada uma tendência expressiva de expansão nessa direção para os próximos anos. Isso ocorre porque: (i) o Brasil ainda 
não conseguiu explorar completamente seu potencial energético na biomassa da cana de açúcar (CARDOSO et al., 2015; MENANDRO et al., 2017); (ii) a capacidade instalada de cogeração a partir de biomassa é de 143 GW, representando 9,3\% do suprimento interno de energia em 2014, e o compromisso nacional é aumentar essa contribuição para 23\% até 2030 (EPE, 2015); e (iii) o país se comprometeu, ao assinar acordos internacionais, em reduzir emissões de Gases de Efeito Estufa (GEE) (CASTILLA, 2016). E a cogeração a partir de biomassa é, portanto, uma opção promissora dentro da estratégia brasileira para alcançar tais objetivos (MOORE et al., 2017).

Outro motivo para expandir a "bioeletricidade" está na crescente disponibilidade da biomassa que abastece o processo. As ofertas de palha vêm aumentando devido ao Protocolo Agroambiental, um acordo firmado em 2017 entre o Governo do Estado de São Paulo, maior produtor de cana-de-açúcar do país, e os principais produtores rurais da região, ali representados pela União da Agroindústria de Cana-de-Açúcar (UNICA). De acordo com o protocolo, fica proibida a limpeza de áreas cultivadas por meio de queima de biomassa em locais que podem ser mecanicamente colhidos. Além disso, nas áreas em que não há tecnologia apropriada para mecanização, a queima da cana-de-açúcar deveria ser extinta até o início de 2020 (LISBOA et al., 2017; RAMOS e NACHILUK, 2017).

Mesmo com tantos benefícios, o uso de fontes renováveis em usinas de cogeração pode ser aprimorado em termos de geração simultânea de eletricidade e calor (EBOH et al., 2017). A análise exergética, abordagem baseada na $2^{\underline{a}}$ Lei da Termodinâmica, tem sido utilizada para esse fim, obtendo resultados expressivos em comparação à análise clássica, restrita à $1^{a}$ Lei (GUPTA et al., 2015). A análise exergética permite identificar as principais fontes de irreversibilidade em um sistema de energia térmica (ou seja, suas ineficiências) (DINCER e ROSEAN, 2013).

Uma pesquisa da literatura técnica sobre o assunto mostra a existência de muitos trabalhos recentes sobre a avaliação termodinâmica de sistemas de cogeração. Dewulf et al. (2008) e Torchio (2013) analisaram potenciais vantagens do uso da análise exergética na seleção de indicadores de desempenho técnico em sistemas de cogeração. Da mesma forma, Ensinas et al. (2009) e Dias et al. (2011) aplicaram um indicador exergoeconômico para avaliar o desempenho termodinâmico do processamento de etanol de cana, para identificar oportunidades de menor irreversibilidade associada a esse mesmo processo. Cabe ressaltar, no entanto, que todas essas pesquisas se limitam ao uso de bagaço como combustível do ciclo de cogeração. 
A elevação das demandas por etanol e energia elétrica levou alguns autores a investigar o comportamento termodinâmico das modernas tecnologias de cogeração, em que as turbinas a vapor de contrapressão são substituídas pelas homólogas, de extraçãocondensação, capazes de operar segundo condições severas de pressão e temperatura. Pellegrini e Oliveira Jr. (2011) abordaram o tema verificando o desempenho energético das unidades de cogeração instaladas em usinas de etanol cuja pressão de vapor de saída da caldeira variava de 21 a 120 bar. Análises semelhantes também foram realizadas por Bechara et al. (2016), Colombo et al., (2014), Dias et al. (2013) e por Olivério e Ferreira (2010).

Embora o aumento da disponibilidade de palha seja um corolário previsível do fim das queimadas (HASSUANI et al., 2005; SARTORI e FLORENTINO, 2007; CARDOSO et al., 2013; LISBOA et al., 2017), as implicações do uso dessa biomassa, por exemplo, em associação com bagaço, sobre o desempenho termodinâmico dos sistemas de cogeração, ainda não foram suficientemente exploradas (LEAL et al., 2013; MENANDRO et al., 2017). Alves et al. (2015) e Cardoso et al. (2015) avaliaram o potencial de exportação da energia elétrica do ciclo Rankine, gerada a partir de diferentes taxas de adição de bagaço e palha. Seguindo diferentes abordagens, esses autores chegaram à conclusão de que a eficácia elétrica da cogeração varia linearmente com o aumento da palha para níveis específicos de operação do sistema. Menandro et al. (2017) apontaram como é importante manter uma quantidade de palha no campo para reciclar nutrientes e regular a umidade do solo.

A recuperação da palha foi também objeto de análise exergéticas efetuadas por Palacios-Bereche et al., (2013), Bechara et al., (2016) e Modesto et al. (2016), revelandose uma alternativa promissora, mas com potencial a ser ainda explorado. Esses estudos também se concentram em processos e operações industriais específicos.

Contrariamente a essa perspectiva, Dewulf et al., (2008) e Murphy et al., (2016) adotaram escopos de ciclo de vida, a fim de avaliar sistemas energéticos. Gil et al., (2013), Moya et al. (2013), Nogueira et al. (2014) e Ometto e Roma (2010) aplicaram abordagens sistêmicas para verificar a conversão de calor em trabalho na indústria de açúcar e álcool.

Kakiyala et al., (2016) e Shen et al., (2015) recorreram a um domínio extenso para quantificar o impacto ambiental da geração de eletricidade a partir de diferentes fontes de biomassa; nesses casos, a análise termodinâmica centrou-se na quantificação da Demanda Acumulada de Exergia. Guerra et al., (2014) e Silva et al. (2014) usaram uma abordagem mais rigorosa de ACV associada a análise exergética para investigar aspectos ambientais e termodinâmicos da cogeração elétrica por bagaço de cana-de-açúcar. 
Até onde foi possível saber, não há pesquisas que verificassem, simultaneamente, as consequências termodinâmicas e ambientais da cogeração usando bagaço e palha para diferentes condições de operação do sistema. Este estudo aborda tais efeitos a partir do aumento da escala de produção de sistemas dessa natureza, operados com biomassa de cana-de-açúcar. Para tanto, foram projetados cenários que levassem em conta diferentes condições de processo. A opção pela técnica de reaquecimento no ciclo Rankine é outra característica única da pesquisa, pois essa abordagem é típica das usinas termelétricas (MORAN e SHAPIRO, 2010) e apenas mais recentemente foi testada em condições como as pleiteadas por essa pesquisa. Espera-se que a iniciativa possa fornecer elementos para o projeto de unidades de cogeração tecnicamente eficientes e menos agressivas ao meio ambiente, além de subsidiar políticas públicas orientadas a planejamento energético no Brasil.

\subsection{Descrição do processo}

\subsubsection{Etapa Agrícola}

Para efeito de condução desse estudo, a produção agrícola de cana-de-açúcar foi baseada na tecnologia utilizada mais frequentemente no estado de São Paulo, principal produtor do Brasil, nas últimas três décadas. No período entre 2005 e 2014, as culturas cultivadas na região registraram uma produtividade agrícola média de 82 t/ha (MAPA, 2015). Fertilizantes químicos - cloreto de potássio ( $\mathrm{KCl}$ ), superfosfato simples (SSP) e uréia - são usados para atender necessidades nutricionais da cana-de-açúcar. A vinhaça, torta de filtro, e cinzas geradas no estágio industrial também são aplicadas ao solo como fontes complementares de macro e micronutrientes. Além disso, ajustar a acidez do solo por calagem e uso de agroquímicos - como carbofuranos, diuron, glifosato, hexazinona e tebuthiuron - para controle de pragas são práticas usuais e necessárias (RODRIGUES; ALMEIDA, 2011). Além disso, o processo mecanizado foi usado para colher cerca de $95 \%$ da produção na região entre 2009 e 2013 (FREDO et al., 2014).

Após ser transportada até a unidade industrial, a cana é lavada, picada e triturada antes de ocorrer a moagem. A extração de caldo ocorre por via úmida (taxa de embebição de $46 \% \mathrm{~m} / \mathrm{m}$ ) e tem como coproduto o bagaço. Antes da fermentação, o caldo é aquecido e

purificado ao circular em filtro rotativo (que gera a torta) e concentrado em um conjunto de evaporadores de contato indireto (NOGUEIRA et al., 2014). Uma produtividade industrial média de $83 \mathrm{~L} \mathrm{C}_{2} \mathrm{H}_{6} \mathrm{O} / \mathrm{t}$ cana pode ser obtida usando Saccharomyces cerevisiae para fermentação alcoólica do caldo. 0 processo é realizado em reatores em batelada a temperaturas, níveis de acidez e concentrações de oxigênio controlados. 
A destilação fracionada se desenvolve a pressão atmosférica e segue até antes de ser atingido o ponto azeotrópico. A forma anidra do álcool $(99,5 \% \mathrm{v} / \mathrm{v})$ é obtida somente após a solução hidratada $\left(95 \% \%_{v} / v\right)$ ser submetida a uma coluna de retificação. A vinhaça é gerada durante essas operações (destilação e retificação), na proporção de 10-13 L/L de etanol anidro (OMETTO e ROMA, 2010; KOSARIC et al., 2005).

\subsubsection{Etapa Industrial}

A maioria das usinas brasileiras de cogeração opera segundo ciclos Rankine sem reaquecimento. A novidade introduzida por essa técnica aparece detalhada na Figura 2.1. A base teórica para propor tal abordagem deriva de iniciativas anteriores descritas por Moran e Shapiro (2010) para melhorar a eficiência em usinas termelétricas.

0 reaquecimento consiste em extrair vapor superaquecido após expansão parcial no primeiro estágio da turbina de contrapressão e reaquecê-lo no gerador de vapor para depois reinjetá-lo no segundo estágio do equipamento. A pressão ótima de extração varia de 20 a 25 bar, dependendo das propriedades termodinâmicas do vapor de alta pressão em cada cenário (OLIVEIRA JR, 2013).

Após ter sido realizado o reaquecimento, o vapor é reinjetado no segundo estágio da turbina se expande até que a pressão do condensador seja atingida. Um gerador converte a energia mecânica proporcionada pela expansão do vapor em eletricidade. Segundo Silva et al. (2014), a eficiência energética do ciclo que se vale de reaquecimento pode alcançar $\eta_{\mathrm{e}} \approx 95 \%$.

Vapor saturado seco é extraído da turbina com $\mathrm{P}=2,5$ bar para suprir a demanda térmica da destilaria e atingir o ponto de desaeração $\left(110^{\circ} \mathrm{C}\right.$ ) (GUERRA et al., 2014). A bomba de alimentação de água da caldeira deve ser projetada para superar o máximo fluxo de fluido possível previsto pelas condições de projeto. Em cada cenário de análise, considerou-se uma pressão de descarga em $20 \%$ maior que a pressão da caldeira, para superar a pressão operacional do vaso, as perdas de carga nos tubos e, além disso, incluir uma margem de segurança.

Esse fator de correção é geralmente aplicado em sistemas de caldeiras, e uma válvula de controle de água de alimentação ajusta o fluxo (OLIVEIRA JR, 2013). 0 vapor de exaustão da turbina alimenta uma unidade de condensação a uma pressão $\mathrm{P} \sim 0,1$ bar. 0 condensado passa pelo desaerador antes de ser reintroduzida na caldeira, fechando o ciclo (DIAS et al., 2011; GUERRA et al., 2014). 
Figura 2.1 - Esquema geral de ciclo Rankine com reaquecimento

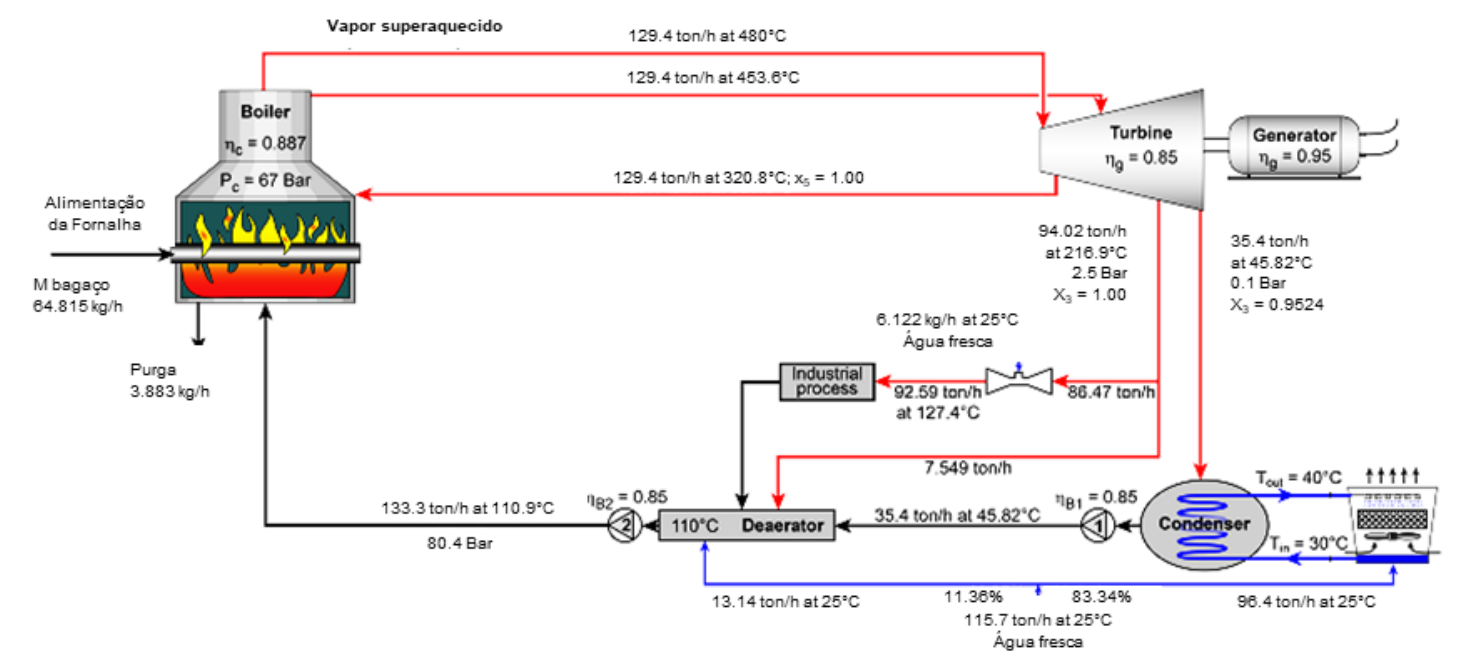

Tabela 2.1 - Parâmetros operacionais típicos da produção de etanol com destaque para a relação entre pressão de operação vs eficiência do sistema do sistema de cogeração

\begin{tabular}{|c|c|c|c|}
\hline Estágio de processo & Parâmetro (Unidade) & \multicolumn{2}{|c|}{ Valor } \\
\hline & Cana moída total $\left(\mathrm{t}_{\mathrm{sc}}\right)$ & \multicolumn{2}{|c|}{2000000} \\
\hline & Dias de safra (destilaria em operação) & \multicolumn{2}{|c|}{210} \\
\hline & Total de bagaço produzido (base úmida) $\left(\mathrm{kg} / \mathrm{t}_{\mathrm{sc}}\right)$ & \multicolumn{2}{|c|}{280} \\
\hline & Dia de trabalho $(\mathrm{h})$ & \multicolumn{2}{|c|}{24} \\
\hline Destilaria & Produção de etanol anidro $\left(\mathrm{kg} / \mathrm{t}_{\mathrm{sc}}\right)$ & \multicolumn{2}{|c|}{65} \\
\hline & Umidade do bagaço (\%) & \multicolumn{2}{|c|}{50} \\
\hline & Poder calorífico inferior do bagaço $(\mathrm{kJ} / \mathrm{kg})$ & \multicolumn{2}{|c|}{7565} \\
\hline & Consumo de vapor $\left(\mathrm{kg} / \mathrm{t}_{\mathrm{sc}}\right)$ & \multicolumn{2}{|c|}{400} \\
\hline & Consumo de eletricidade $\left(\mathrm{kWh} / \mathrm{t}_{\mathrm{sc}}\right)$ & \multicolumn{2}{|c|}{30} \\
\hline \multirow{13}{*}{$\begin{array}{l}\text { Sistema de } \\
\text { Cogeração }\end{array}$} & Consumo de bagaço (base úmida) $(\mathrm{t} / \mathrm{h})$ & \multicolumn{2}{|c|}{129} \\
\hline & Consumo de palha (base úmida) $(\mathrm{t} / \mathrm{h})$ & \multicolumn{2}{|c|}{38} \\
\hline & \multirow{6}{*}{$\begin{array}{l}\text { Pressão do vapor } \\
\text { vs. } \\
\text { Eficiência térmica (caldeira) }\end{array}$} & $\mathrm{P}$ (bar) & $\eta(\%)$ \\
\hline & & 20 & 78 \\
\hline & & 45 & 82 \\
\hline & & 67 & 86 \\
\hline & & 80 & 88 \\
\hline & & 100 & 88 \\
\hline & Eficiência de geração elétrica (a,b) (\%) & \multicolumn{2}{|c|}{95} \\
\hline & Pressão do vapor (destilaria) (bar) & \multicolumn{2}{|c|}{2,50} \\
\hline & Pressão do vapor (condensador) (bar) & \multicolumn{2}{|c|}{0,10} \\
\hline & Temperatura de condensação no desaerador $\left({ }^{\circ} \mathrm{C}\right)$ & \multicolumn{2}{|c|}{110} \\
\hline & Eficiência isentrópica da bomba (b) (\%) & \multicolumn{2}{|c|}{85} \\
\hline \multirow{4}{*}{ Produção palha } & Total de palha produzida (base úmida) $\left(\mathrm{kg} / \mathrm{t}_{\mathrm{sc}}\right)$ & \multicolumn{2}{|c|}{165} \\
\hline & Umidade da palha (\%) & \multicolumn{2}{|c|}{15} \\
\hline & Poder calorífico inferior (a) (kJ/kg) & \multicolumn{2}{|c|}{12960} \\
\hline & Consumo de eletricidade $\left(\mathrm{kWh} / \mathrm{t}_{\mathrm{sc}}\right)$ & \multicolumn{2}{|c|}{5,60} \\
\hline
\end{tabular}

Legendas/Referências: (a) (DIAS et al., 2009, 2010); (b) As eficiências do gerador a vapor, gerador elétrico, bombas e turbina a vapor são baseadas em Guerra et al. (2014), (DIAS et al., 2010, 2011b). 
Segundo Cortez (2010) 57\% do consumo elétrico na destilaria será atribuído ao preparo e moagem da cana. 0 restante aciona equipamentos auxiliares (sopradores de caldeiras, bombas, injetores e agitadores), sistemas de automação e a instrumentação industrial. 0 excedente de eletricidade é comercializado com os proprietários da rede. Ainda no campo, a palha a ser utilizada na unidade de cogeração é comprimida em fardos (250 a $500 \mathrm{~kg}$ ) para ser transportada até destilaria, onde será cortada em pedações menores, que serão depois picados em moinhos de martelos (HASSUANI et al., 2005). Nessas condições, a palha segue para a caldeira para então ser adicionada ao bagaço. A Tabela 2.1 descreve os principais parâmetros do processo do sistema de cogeração. Tais dados também foram utilizados para modelar a cogeração e sua interface com a usina de etanol, a fim de avaliar os perfis termodinâmico e ambiental de cada cenário.

\subsection{Metodologia}

A metodologia aplicada para alcançar os objetivos do estudo compreende cinco etapas: (i) formulação de cenários que representem diferentes escalas operacionais de cogeração a partir da biomassa da cana-de-açúcar (bagaço e palha); (ii) verificação do perfil de desempenho termodinâmico de cada cenário por análise exergética; (iii) uso da ACV para determinar o desempenho ambiental dos cenários; (iv) análise dos resultados obtidos, com vistas a identificar agentes causadores de impactos nas duas dimensões da análise; e (v) análise da sinergia dos indicadores termodinâmicos e ambientais quando aplicados sob a perspectiva de ampliação da capacidade produtiva da cogeração.

\subsubsection{Definição dos cenários}

A formulação de cenários foi baseada no padrão tecnológico médio praticado em destilarias autônomas localizadas no estado de São Paulo que exportam eletricidade para a concessionária. Essa cobertura geográfica foi escolhida devido a (já mencionada) expressão da região em termos da produção de cana-de-açúcar, que variou de 56 a 61\% do total gerado no país entre 2011 e 2015 (MOORE et al., 2016).

A definição do padrão tecnológico médio de cogeração levou em consideração dois critérios: (i) as escalas operacionais das unidades; e, (ii) as especificações do ciclo termodinâmico. A escala operacional foi definida em função da pressão do vapor à saída da caldeira, que, em geral, oscila entre 20 e 100 bar (DIAS et al., 2011b). Segundo Guerra et al. (2014) a maioria das unidades de cogeração situadas em São Paulo aplica o ciclo Rankine sem reaquecimento naquela faixa de pressão. 
A especificação do ciclo termodinâmico varia em função de fatores diversos; no entanto, as quantidades e características da biomassa adicionada ao sistema estão entre os mais importantes. Além do bagaço produzido na moagem de cana, instalações de alto desempenho também consomem palha de cana (folhas e ponteira) como fonte de calor (SILVA et al., 2014). Por outro lado, a aplicação de palha na proteção do solo agrícola (SEABRA e MACEDO, 2011), e as elevadas taxas de cloretos e sílica a ela associadas - que podem causar, respectivamente, corrosão nas tubulações e incrustações no interior da caldeira (OLIVÉRIO e FERREIRA, 2010) - restringiram a dosagem dessa fonte renovável pelo sistema de cogeração. Tendo em conta todas essas circunstâncias, o estudo avaliou duas condições em termos de utilização da palha: (i) ausência de adição; e (ii) uso de $50 \% \mathrm{~m} / \mathrm{m}$ da quantidade total produzida nos campos.

Tabela 2.2 Cenários de cogeração estabelecidos em função da pressão de operação da caldeira, e da taxa de adição de palha

\begin{tabular}{cccc}
\hline \multirow{2}{*}{ Cenário } & Adição de palha & \multicolumn{2}{c}{ Características do vapor superaquecido } \\
\cline { 3 - 4 } & & $\mathrm{P}(\mathrm{bar})$ & $\mathrm{T}\left({ }^{\circ} \mathrm{C}\right)$ \\
\hline I & $(-)$ & 20 & 412 \\
II & $(-)$ & 45 & 457 \\
III & $(-)$ & 67 & 483 \\
IV & $(-)$ & 80 & 495 \\
V & $(-)$ & 100 & 511 \\
VI & $(+)$ & 20 & 412 \\
VII & $(+)$ & 45 & 457 \\
VIII & $(+)$ & 67 & 483 \\
IX & $(+)$ & 80 & 495 \\
X & $(+)$ & 100 & 511 \\
\hline
\end{tabular}

A Tabela 2.2 traz dez cenários realistas estabelecidos para apoiar a investigação após o cumprimento das condições mencionadas. 0 sinal (+) indica presença de palha na alimentação da caldeira, à taxa de $50 \% \mathrm{~m} / \mathrm{m}$ do total deixado no campo após a colheita; e o sinal (-) representa a não adição dessa biomassa. As demais etapas da cogeração de eletricidade a partir de biomassa permaneceram inalteradas, independentemente do cenário analisado. 


\subsubsection{Análise Termodinâmica}

Exergia pode ser entendida como o trabalho máximo obtido por determinado fluxo de matéria, calor ou trabalho, quando este converge para a condição de equilíbrio termodinâmico com componentes do ambiente (KOTAS, 2012). 0 ambiente de referência está em equilíbrio estável, tendo por isso seu estado intensivo de temperatura, pressão e composição química inalterado, e onde as substâncias são encontradas em abundância na natureza (OLIVEIRA JR, 2013). No sistema de cogeração que encontra-se sob análise, o fluido de trabalho é a água, sendo as temperatura e pressão do ambiente de referência, respectivamente, de $25^{\circ} \mathrm{C}$ e 1,0 bar.

No caso presente a análise termodinâmica compreende um balanço exergético a ser realizado exclusivamente para o sistema de cogeração. Essa abordagem foi adotada para estimar a distribuição do perfil de irreversibilidade (isto é, a destruição da exergia) ao longo dos estágios que constituem o ciclo Rankine: caldeira, turbina, condensador, e equipamento auxiliar.

O balanço exergético foi aplicado para os cenários descritos na Tabela 2.2. Nesses processos tais arranjos foram descritos com auxílio do software Engineering Equation Solver (EES)® (F-Chart Software, Madison, WI, EUA) (KLEIN, 2002). O EES pode gerar soluções termodinamicamente robustos para sistemas energéticos, sendo bastante útil no projeto de problemas multivariados. Neste estudo, o EES foi empregado para avaliar os efeitos das variações de parâmetros, dentro de limites pré-definidos, com o intuito de identificar condições ótimas de processo. As equações algébricas usadas para modelar o comportamento termodinâmico em cada etapa do ciclo Ranking seguem os princípios de conservação de massa e energia (GUERRA et al., 2014). 0 balanço de massa para um sistema de estado estacionário pode ser representado na forma de taxa, como indicado pela Equação (1):

$$
\sum_{i} \dot{m}_{l}=\sum_{e} \dot{m}_{e}
$$

onde $\dot{m}_{l}$ e $\dot{m}_{e}$ representam taxas de fluxo de massa do fluido de trabalho que, entram e saem do sistema. Da mesma forma, o balanço, em estado estacionário, de taxas de energia de um certo sistema está descrito na Equação (2): 


$$
\sum_{i} \dot{E}_{i}+\dot{Q}=\sum_{e} \dot{E}_{e}+\dot{W}
$$

sendo $\dot{E}_{i}$ e $\dot{E}_{e}$ as taxas de energia que, da mesma forma, circulam entrando e saindo pelas fronteiras. A taxa de calor fornecida ao sistema é $\dot{Q}$, enquanto a taxa de transferência de trabalho foi definida como $\dot{W}$.

O balanço de exergia é realizado combinando-se as equações de massa e energia de fluxo constante com a expressão para a geração de entropia (ou seja, envolvendo a $1^{\text {a }}$ e a $2^{\text {a }}$ Leis da Termodinâmica). 0 balanço entrópico referente a um sistema de estado estacionário está indicado na Equação (3):

$$
\sum_{j} \frac{\dot{Q}}{T_{j}}+\sum_{i} \dot{m}_{i} s_{i}+\dot{S}_{g e r}=\sum_{e} \dot{m}_{e} s_{e}
$$

onde $\dot{S}_{g e r}$ e $T_{j}$ são a taxa de geração de entropia e a temperatura do volume de controle. Os parâmetros $s_{i}$ e $s_{e}$ são taxas de entropia específicas dos fluxos de entrada e saída que circulam pelos limites do sistema. A taxa de destruição da exergia $E x_{\text {dest }}$ dos estágios do ciclo Rankine foi calculada aplicando o saldo da taxa de exergia considerando o sistema de estado estacionário (Equação (4)).

$$
\dot{E} x_{d e s t}=\dot{E} x^{Q}-\dot{E} x^{W}+\sum_{i} \dot{E} x_{i}-\sum_{e} \dot{E} x_{e}
$$

$\dot{E} x^{W}$ corresponde a taxa de transferência de trabalho $(\dot{W})$ para cada etapa do ciclo, enquanto $E x_{i}$ e $E x_{e}$ referem-se às taxas de exergia que circulam pelo sistema. A exergia associada à transferência de calor $\left(E x^{Q}\right)$ foi calculada usando a Equação (5):

$$
\dot{E} x^{Q}=\sum_{j}\left(1-\frac{T_{0}}{T_{j}}\right) \dot{Q}_{j}
$$


No contexto, $T_{0}$ é a temperatura ambiente de referência e $T_{j}$ a temperatura limite do sistema. Segundo Kotas (2012), a expressão geral da taxa de exergia é obtida a partir da soma de quatro componentes, ou seja, cinético, potencial, químico e físico (Equação (6)):

$$
\dot{E} x=\dot{E} x_{k e}+\dot{E} x_{p e}+\dot{E} x_{c h}+E x_{p h}
$$

A exergia cinética $E x_{k e}$ representa às tendências de ordenação das partículas, ao passo que a exergia potencial $\dot{E} x_{p e}$ refere-se à sua elevação. A exergia química $\dot{E} x_{c h}$ leva em consideração as diferenças de concentração e estrutura molecular (OLIVEIRA JR, 2013). Nesse estudo, os componentes cinéticos e potenciais foram omitidos devido aos efeitos insignificantes em cada etapa única analisada. Como o fluido de trabalho é água que não sofre reação ao longo do processo, não há exergia química envolvida nesse caso; portanto, a taxa de exergia associada a um fluxo de matéria será estimada por sua taxa de exergia física $E x_{p h}$ que pode ser calculada pela Equação (7):

$$
\dot{E} x=\dot{E} x_{p h}=\dot{m}\left[\left(h-h_{0}\right)-T_{0}\left(s-s_{0}\right)\right]
$$

Os parâmetros $h_{0}$ e $s_{0}$ são, respectivamente, a entalpia e entropia específicas na temperatura ambiente de referência. As taxas de destruição de exergia associadas a bombas de água e condensado, vaso desaerador e sistema de superaquecedor foram calculadas separadamente, usando as Equações (1) - (7). Nesse estudo, esse conjunto de unidades e equipamentos foi definido genericamente como 'equipamento auxiliar'.

A análise termodinâmica foi realizada a partir dos seguintes indicadores de processo: (i) eficiência de energia (\%); (ii) Potência útil específica e quantidade de eletricidade exportada para a rede (kWh/t cana); e (iii) consumo de água de reposição para a torre de resfriamento e de água deionizada para as caldeiras ( $\mathrm{kg} / \mathrm{t}$ de cana).

Definiu-se como eficiência de exergia do sistema $\left(\eta_{e x}\right)$ a razão entre a exergia útil que ele fornece (ou seja, o conteúdo exergético associado a energia térmica a ser demandada pelos processos industriais, e também a potência útil de cogeração) e a exergia total fornecida à caldeira (Equação (8)) (GUERRA et al., 2014). Eboh et al. (2017) concordam que $\eta_{e x}$ é o parâmetro mais adequado para avaliar o desempenho do sistema térmico: 


$$
\eta_{\text {ex }}=\frac{\dot{E} x_{\text {útil }}}{\dot{E} x_{\text {combustível }}}=\frac{\dot{E} x_{p s}+\dot{E} x_{n p o}}{\dot{E} x_{\text {combustível }}}
$$

$\dot{E} x_{p s}$ representa a taxa de exergia do vapor de processo a ser consumido para a produção de etanol (Equação (7)), enquanto $\dot{E} x_{n p o}$ e $\dot{E} x_{f u e l}$ referem-se, à produção útil de cogeração e à taxa de exergia de combustível.

Segundo Oliveira Jr. (2013), o conteúdo exergético de um certo combustível pode ser estimado a partir de seu Poder Calorífico Inferior. No presente estudo, a alimentação da caldeira se compõe de bagaço e palha. Suas taxas de exergia foram avaliadas a partir da Equação (9) e tendo em conta os dados descritos na Tabela 2.1.

$$
\dot{E} x_{f u e l}=\dot{m}_{\text {bagasse }} L H V_{\text {bagasse }}+\dot{m}_{\text {straw }} L H V_{\text {straw }}
$$

$\dot{E} x_{n p o}$ consiste na diferença entre a energia total gerada e a energia consumida pelo bombeamento de água e a condensação que ocorrem no ciclo Rankine. A energia total gerada pelo grupo gerador de turbinas é calculada combinando-se a eficiência do gerador elétrico (Tabela 2.1) e os balanços de massa e energia (Equações (1) e (2)) com a eficiência isentrópica $\left(\eta_{t}\right)$, que pode ser avaliada pela Equação (10) para cada estágio da turbina a vapor

$$
\eta_{t}=\frac{\text { Actual Work }}{\text { Isentropic Work }}=\frac{h_{i}-h_{e}}{h_{i}-h_{e}^{i s e}}
$$

$h_{i}$ e $h_{e}$ são entalpias específicas dos fluxos que entram e saem do sistema. A entalpia específica para o processo isentrópico é $h_{e}^{i s e}$. Para todos os cenários, foi adotada uma turbina a vapor com eficiência isentrópica $\eta_{t}=85 \%$. Da mesma forma, usando a eficiência isentrópica da bomba, é possível estimar seu consumo de energia combinando as Equações (1) e (2). Turbinas e bombas foram modeladas como sendo adiabáticos.

A energia útil exportada para a rede concessionária pode ser entendida como a diferença entre a produção útil de energia e aquela que segue para a destilaria de etanol, e que aparece indicada na Tabela 2.1. 
Além disso, a qualidade do vapor de exaustão da turbina é avaliada conhecendo suas entalpia e temperatura específicas. Para tal especificação fez-se uso do banco de dados do EES (KLEIN, 2002). A Figura 2.1 descreve os resultados gerados pela simulação no EES para um cenário em que a caldeira foi alimentada somente com bagaço, o vapor superaquecido deixa a unidade a 67 bar e, a qualidade do vapor de exaustão (à saída da turbina, quando se encontra a $45,8{ }^{\circ} \mathrm{C}$ e 0,1 bar) atinge $95,2 \%$.

Os consumos de água de reposição da torre de resfriamento e água deionizada na caldeira puderam ser avaliados aplicando-se as Equações (1) e (2) para o superaquecedor, o desaerador e a própria torre. No caso presente, água deionizada é usada apenas nos dessuperaquecedor e desaerador. Admitiu-se que $90 \%$ do vapor saturado total que serve a produção de etanol retorna como condensado para o desaerador e que 5,0\% do fluxo de água recirculante da torre de resfriamento se perde via purga, evaporação, ou mesmo, na remoção de sólidos (GUERRA et al., 2014).

\subsubsection{Análise Ambiental}

O desempenho ambiental foi determinado por ACV, uma técnica de diagnóstico, capaz de avaliarem os impactos ambientais de um produto (ou processo) ao longo de todo o seu ciclo de vida. Essa abordagem compreende todas as interferências antrópicas sobre o meio ambiente, desde a extração de recursos naturais, necessários para sua produção (ou instalação), até seu descarte final (ou descomissionamento) (ISO, 2016a).

Uma ACV é composta por quatro fases: definição de objetivos e escopo, análise de inventário do ciclo de vida (ICV), avaliação de impacto (AICV) e interpretação (ISO, 2016b). 0 objetivo do estudo, assim como alguns de seus elementos estruturais (tais como a base de cálculo, ou unidade funcional, usada na análise, as dimensões do sistema, os critérios para coleta e que definem a qualidade dos dados; a forma de tratamento de situações multifuncionais, e os métodos e categorias para a avaliação de impacto) são estabelecidos durante a fase de Definição de Objetivo e Escopo.

O ICV identifica e coleta dados que possa quantificam aspectos ambientais; isto é, fluxos de matéria e energia que entram e saem de cada estágio do ciclo de vida, cruzando a fronteira definida entre estes e o ambiente. Na AICV, os efeitos potenciais sobre o meio ambiente e a saúde humana acarretados pelos aspectos ambientais, serão quantificados expressos em termos de descritores de impactos. Esse diagnóstico é chamado no jargão da ACV de Perfil de Impacto Ambiental do objeto de análise (ISO, 2016a). 
Os perfis de impacto ambiental para os cenários definidos neste estudo foram determinados por ACV atribucional, seguindo uma abordagem do tipo "berço ao portão", em que apenas o processo produtivo é considerado. Também nessa situação, o sistema em análise (Sistema de Produto) se compõe de duas etapas: (i) o cultivo da cana; e (ii) a produção de etanol, à qual a cogeração está diretamente associada.

Embora o foco da pesquisa recaia sobre a geração de excedente de eletricidade, o produto principal da destilaria autônoma segue sendo o etanol anidro. Assim, para evitar uma eventual influência desse parâmetro sobre as análises termodinâmica e ambiental, decidiu-se manter constante a taxa de produção desse combustível. Essa decisão reduziu o número de graus de liberdade do estudo uma vez que: (i) a quantidade de cana-deaçúcar produzida na etapa agrícola torna-se fixa; e, portanto; (ii) a quantidade de bagaço gerado na moagem passa também a ser invariável para todos os cenários. Durante a fase de ICV, os aspectos ambientais foram estimados de acordo com a Equação (11). A Figura 2.2 mostra os estágios de uma cadeia de suprimentos genérica.

Figura 2.2 - Descrição genérica de um Sistema de Produto a ser submetido a ACV

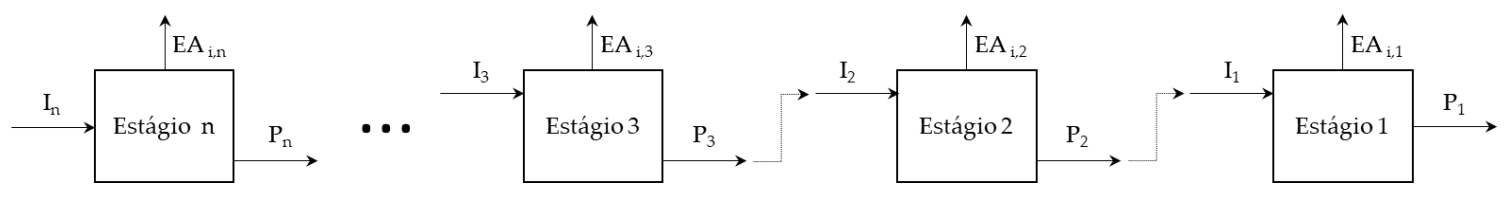

Nesse arranjo, o 'Estágio 1' refere-se à última etapa do ciclo industrial de produção de etanol, enquanto 'Estágio $n$ ' consiste da primeira ação antrópica realizada para extrair recursos materiais e energéticos do ambiente

$$
E A_{i, \text { total }}=\frac{E A_{i, 1}}{P_{1}}+\sum_{s=2}^{n}\left[\frac{E A_{i, s}}{P_{s}} \times \prod_{k=1}^{s-1}\left(\frac{I}{P}\right)_{k}\right]
$$

$E A_{i, \text { total }}$ representa a soma das ocorrências de um certo aspecto ambiental (i) em toda a cadeia de suprimentos; $E A_{i, s}$ consiste do consumo (ou a emissão) de certo aspecto ambiental (i) em um estágio do processo, e $P_{S}$ indica a quantidade de produto obtido no mesmo estágio. $(I / P)_{k}$ é um fator que quantifica à razão entre os insumos consumidos $(I)$ e o produto $(P)$ gerado em certo estágio da cadeia de suprimentos. 
Uma vez que cada aspecto ambiental tenha sido estimado, a fase AICV realiza o cálculo dos indicadores da categoria de impacto ambiental usando a Equação (12)

$$
I_{c, j}=\sum_{i}\left(E A_{i, t o t a l} \times I F_{i, c}\right)
$$

$I_{c, j}$ é o indicador que representa determinada categoria de impacto ambiental (c) e $I F_{i, c}$, o fator de impacto (ou fator de caracterização) a ser aplicado sobre a contribuição de $E A_{i, t o t a l}$ para magnificar o impacto proporcionado por esse aspecto ambiental para a categoria de impacto a que ele está associado.

\subsubsection{Efeito da sinergia entre indicadores termodinâmicos e ambientais no scale up do processo}

Na fase final do estudo as dimensões termodinâmica e ambiental foram associadas sob a forma de uma verificação coordenada (ou sinérgica) das tendências de scale up da cogeração. Tal como sugere a norma ISO 14044 (ISO, 2016b), esse desenvolvimento se deu a partir de indicadores normalizados e adimensionais para cada vertente, que foram obtidos a partir da aplicação das Equações (13) e (14):

$$
\begin{array}{r}
N E x_{\text {dest }, j}=\frac{\left(\frac{T \dot{E} x_{\text {dest }, j}}{\dot{E} x_{n p o}}\right)}{\dot{E} x_{d e s t, \max }} \\
N I_{c, j}=\frac{I_{c, j}}{I_{c, \max }}
\end{array}
$$

$N E x_{\text {dest }, j}$ é o indicador normalizado de destruição de exergia para o cenário (j). Esse valor é obtido a partir da razão entre o quociente de $T \dot{E} x_{d e s t, j}$ - de destruição total de exergia pelo ciclo de cogeração de (j) - e $\dot{E} x_{\text {npo }}$, e $\dot{E} x_{\text {dest,max }}$ que se refere a destruição máxima de exergia entre todos os cenários. 
Da mesma forma, $N I_{c, j}$ corresponde ao indicador normalizado para determinada categoria de impacto (c) sob as premissas consideradas para cada cenário (j), enquanto $I_{c, \max }$ refere-se ao valor máximo dos indicadores em relação a impacto ambiental (c) considerando todos os cenários. $O$ indicador combinado $C I_{c, j}$ para o cenário (j) pode ser calculado conforme descrito na Equação (15)

$$
C I_{c, j}=N E x_{d e s t, j} \times N I_{c, j}
$$

$C I_{C, j}$ foi determinado para cada situação em estudo a partir do produto simples entre os indicadores ambiental e termodinâmico normalizados. Essa decisão foi tomada para evitar possíveis distorções decorrentes da aplicação de agentes externos (como pesos, ou operadores matemáticos) que poderiam eventualmente vir a superestimar (ou amortecer) qualquer dessas dimensões.

\subsection{Modelagem do ciclo de vida}

Este estudo seguiu as diretrizes da norma ISO 14044 (ISO, 2016b). 0 software SimaPro 8 - versão 8.1.1.16 de PRé Consultants $®$ foi aplicado na elaboração do ICV e para conduzir a AICV. Os cálculos realizados para cada cenário foram baseados em requisitos tecnológicos e operacionais de uma destilaria autônoma típica de etanol anidro (Tabela 2.1). A Unidade Funcional (UF), base de cálculo para a qual estão relacionados o consumo de recursos e as emissões que ocorrem ao longo do ciclo de vida em análise, estabelecida para esta ACV foi 'fornecer 1,0 MWh de eletricidade à rede elétrica brasileira a partir da cogeração com cana-de-açúcar como biomassa em um ciclo Rankine com reaquecimento de vapor de alta pressão'.

O Sistema do Produto (Figura 2.3) inclui o estágio agrícola do cultivo da cana de açúcar, além dos subsistemas industriais de síntese de $\mathrm{C}_{2} \mathrm{H}_{6} \mathrm{O}(99,5 \% \mathrm{v} / \mathrm{v})$ e cogeração de energia. Os transportes de cana e palha desde os campos de cultivo até as instalações industriais é também uma etapa do arranjo, assim como os retornos de vinhaça, torta de filtro e cinzas da destilaria para as fazendas. Com relação às fontes de dados, foram coletados dados secundários para modelar a maioria dos estágios incluídos nos sistemas do produto. O ICV construído para a etapa agrícola considerou os dados obtidos em GREET (2000), IPCC (2006), Nemececk e Kägi (2007), Ometto et al. (2009); Nemecek e Schnetzer (2011), Seabra et al. (2011), Bonomi (2012), Cavalett et al. (2012, 2013), Sugawara (2012) e Guerra et al. (2014). 
Fabricações de ureia, SSP e KCl foram adaptadas dos seguintes bancos de dados: 'Urea, as $N$, at regional storehouse/RER $U$ ', 'Single superphosphate, as $\mathrm{P}_{2} \mathrm{O}_{5}$, at regional storehouse/RER $U$ ', and 'Potassium chloride, as $K_{2} O$, at regional storehouse/RER $U$ ' que são, todos eles, pertencentes à base de dados Ecoinvent (NEMECECK e KÄGI, 2007).

As sínteses de agroquímicos foram tratadas através de abordagens semelhante: carbofurano: 'Carbofuran, at regional storehouse/RER $U$ ', diuron: 'Diuron, at regional storehouse/RER $U$ ', e glifosato: 'Glyphosate, at regional storehouse/RER $U$ ' são também bancos de dados disponíveis em Ecoinvent (NEMECECK e KÄGI, 2007). Por outro lado, as sínteses de hexazinona e tebuthiuron foram modeladas a partir do inventário genérico 'Pesticides unspecified, at regional storehouse/RER U'. Além desses, os ICVs para cal: 'Limestone, milled, loose, at plant/CH U (de Ecoinvent) e diesel: 'Diesel, at refinery/I/US" de U.S. Life Cycle Inventory Database (USLCI) foram também adaptados para representar insumos associados à produção de materiais auxiliares no Brasil (MOORE et al 2016).

Os transportes de fertilizantes químicos, e de outros insumos foram descritos considerando-se valores médios de distâncias de deslocamento. No caso específico de importação, que predispusesse transporte transoceânicos, como ocorre com o $\mathrm{KCl}$, foram utilizados dados de SeaRates (C) (SeaRates LP, Edinburgh, Reino Unido) para descrever os trajetos de maneira realista. Por fim, a modelagem da geração de eletricidade considerou dados de Hansen et al (2015), ajustados para a rede brasileira de 2015, tendo em conta considerações feitas por Moore et al. (2016), que foram aplicadas a dados coletados junto a Balanço Energético Nacional daqueles período (EPE, 2016).

As etapas de produção e cogeração de etanol receberam tratamento diferenciado, sendo modeladas a partir de dados primários obtidos de uma destilaria cujas condições operacionais correspondiam, satisfatoriamente, ao padrão tecnológico da maioria das usinas de porte similar localizadas no Estado de São Paulo. Esse conjunto de dados foi também comparado a indicadores típicos do setor de cana-de-açúcar, obtidos de Ensinas et al. (2007, 2009), Pellegrini et al. (2010), Bonomi (2012) Cavalett et al. $(2012,2013)$ e Shen et al. (2015) para aferir sua confiabilidade.

Os aspectos de infraestrutura e outros bens de capital foram desconsiderados, depois que uma análise que indicou serem esses elementos de influência insignificante sobre o desempenho ambiental global do sistema, a despeito do cenário que estava sendo analisado. 
A Cobertura Temporal para coleta de dados compreendeu o período entre 2013 a 2015. Pelos motivos já mencionados, a Cobertura Geográfica incluiu o estado de São Paulo, e a Cobertura Tecnológica foi retratada pelo status técnico-operacional descrito e discutido nas seções 2.2 .1 e 2.2.2.

Uma distância de $32 \mathrm{~km}$ foi definida com percurso médio a ser cumprido entre as áreas de cultivo e a instalação industrial (Sugawara, 2012). Além do transporte de canade-açúcar e palha, essa especificação foi usada ainda para modelar outros deslocamentos entre aqueles extremos do sistema, casos de vinhaça, torta de filtro e cinzas. Quaisquer fluxos cuja contribuição cumulativa fosse inferior a 2,0\% da massa (ou energia) total que entra, ou sai, de um estágio desse ciclo de vida foram desconsiderados. A significância ambiental também foi aplicada como critério de exclusão de aspectos ambientais para efeito de modelagem do sistema, conforme especifica a norma ISO 14044 (ISO, 2006b).

As situações de multifuncionalidade identificadas ao longo do sistema do produto foram tratadas sempre por procedimentos de alocação (ISO, 2006b). Para os cenários IV$\mathrm{X}$, a alocação das cargas ambientais geradas na etapa agrícola da cana-de-açúcar e palha ocorreu por critério de massa, resultando em uma partição de proporções [92,4: 7,60]. 0 mesmo procedimento foi também aplicado à moagem de cana, sendo as cargas ambientais acumuladas até essa etapa divididas entre bagaço e caldo a razão de [21,5: 78,5]. Os produtos de destilaria (etanol, vinhaça e torta de filtro) foram tratados de maneira algo diferente. Dado o elevado interesse do mercado pelo $\mathrm{C}_{2} \mathrm{H}_{6} \mathrm{O}$ anidro, decidiuse que as cargas acumuladas até o estágio de destilação (e inclusive este) seria integralmente a ele atribuídas.

Na cogeração, a distribuição de cargas ambientais foi realizada via alocação por critério energético. Com isso, os fatores de compartilhamento de carga entre eletricidade excedente, eletricidade consumida na destilaria e vapor de processo foram determinados especificamente para cada cenário, variando respectivamente entre (16,8 - 40,4), (7,60 - 9,20) e $(51,9-74,0)$. A escolha do critério, excluiu as cinzas dessa atribuição de cargas ambientais.

Os impactos ambientais potenciais devido às emissões que ocorrem por todo o sistema foram calculados pelo método ReCiPe - midpoint $(\mathrm{H}$ ) versão 1.11 (GOEDKOOP et al., 2013), para as categorias de impacto de Mudanças Climáticas (MC), Formação de Material Particulado (PMF), Depleção Hídrica (WD) e Depleção Fóssil (FD). 
Figura 2.3. Descrição esquemática do sistema de produtos em estudo

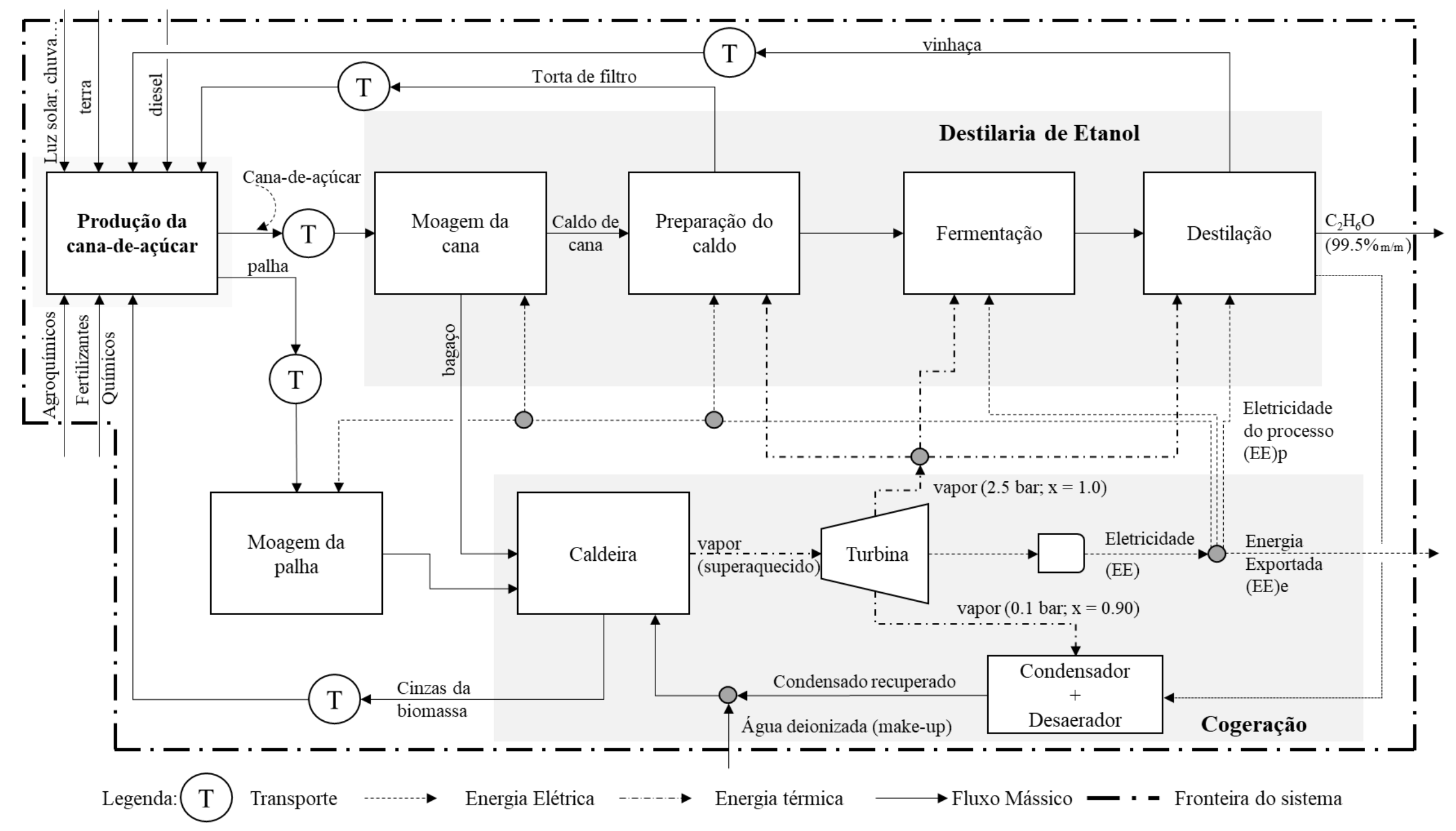


A inexistência de métodos de avaliação de impacto voltados especificamente para biomas brasileiros (SILVA et al., 2015) motivou uma pesquisa sobre o assunto, que apontou ser a abordagem metodológica exercitada pelo método ReCiPe consistente com as expectativas desta investigação. Além disso, as categorias de impacto selecionadas são coerentes com um arranjo processual que associa transformações nos domínios agrícola e industrial, como é o caso da cogeração em uma destilaria autônoma de etanol.

\subsection{Resultados e Discussão}

\subsubsection{Análise Termodinâmica}

A Figura 2.4 traz resultados dos indicadores termodinâmicos para cada cenário analisado. A despeito do tipo de biomassa a ser queimado na caldeira, tanto a eficiência exergética, como a potência útil do conjunto tendem a se aumentar conforme se eleva a pressão de extração de vapor. Um incremento desse parâmetro em ciclos Rankine com reaquecimento pode se reverter em ganhos na eficiência de exergia para o conjunto de até 37\% em cenários sem palha adicional ( $\mathrm{I}-\mathrm{V}$ ). Além disso, a eletricidade total gerada à pressão máxima de operação da caldeira, de 100 bar (cenário V), atingiu 143 kWh/tsc, crescimento de cerca de $63 \%$ em relação ao observado no cenário I, em que o vapor sai da caldeira a 20 bar. Esses achados podem ser explicados pelo diagnóstico de exergia a ser descrito e discutido abaixo.

Figura 2.4 - Indicadores termodinâmicos para cada cenário em termos de: (a) Potência útil; e (b) consumo de água

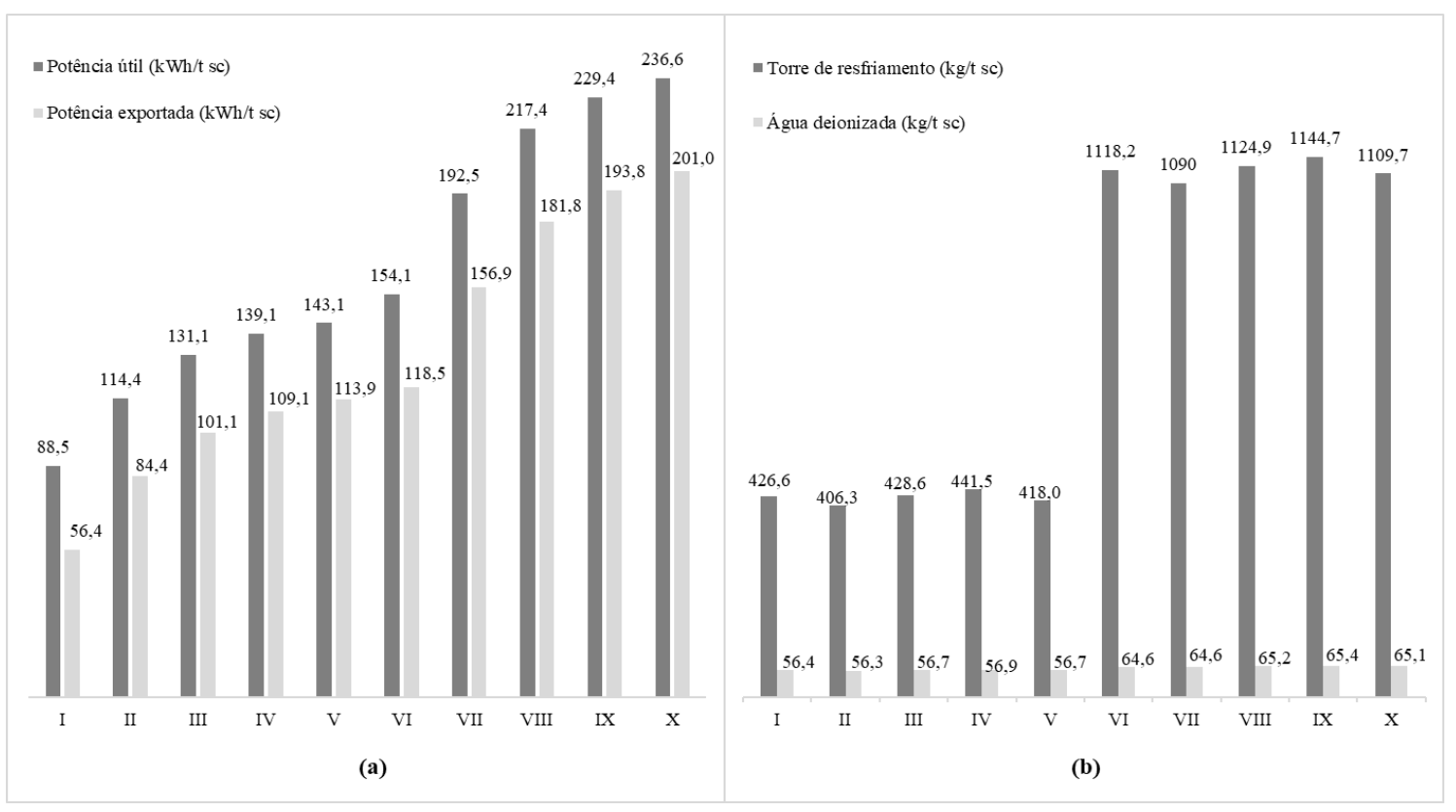


A diferença entre $\mathrm{V}$ e I é ainda mais notável se observada sob a perspectiva de energia útil exportada. Quando o consumo específico da destilaria é deduzido do total de eletricidade produzida, essa desigualdade chega a 102\%. Nos cenários em que o bagaço é fornecido à caldeira juntamente com $50 \% \mathrm{~m} / \mathrm{m}$ da palha (VI - X), as taxas de produção específica da eletricidade total e exportada são maiores que as do conjunto anterior. Essa descoberta advém da comparação direta entre cenários que operam sob condições idênticas de pressão e temperatura para o vapor extraído da caldeira. Em termos de produção de energia, a adição de palha foi convertida em aumentos que variam de 65\% (cenários IV $\rightarrow$ IX e V $\rightarrow \mathrm{X}$ ) a 74\% (I $\rightarrow$ VI), enquanto para a energia exportada para a rede, os benefícios oscilam de $76 \%(\mathrm{~V} \rightarrow \mathrm{X})$ a $110 \%(\mathrm{I} \rightarrow \mathrm{VI})$.

Por outro lado, o uso de palha para alimentar a cogeração, traz ganhos de energia entre pressões extremas (VI e X) - 54\% para produção de energia útil, e 69\% em eletricidade exportada -, reduzidos se comparados aos das contrapartes que operam

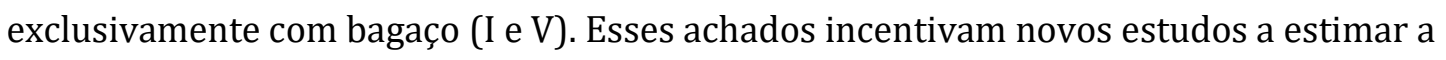
taxa de retorno dos investimentos realizados em sistemas de cogeração com reaquecimento, projetados para operar a altas pressões.

O consumo de água não foi influenciado de maneira significante pelas variações de pressão da caldeira. Uma redução no consumo de água para a torre de resfriamento ocorreria apenas, caso a eficiência exergética do ciclo Rankine fosse elevada. Esse efeito é, no entanto, bastante dependente da rejeição de calor no conjunto torre-condensador. O fenômeno ocorre em função do aumento de taxa de transferência térmica da biomassa para o fluido de trabalho do ciclo, conforme a pressão da caldeira, e sua eficiência térmica, se elevam. Vale ressaltar que os ganhos de transferência de energia e na eficiência da caldeira resultam em maior geração de eletricidade, mas também acarretam taxas importantes de rejeição de calor, fazendo com que, invariavelmente, mais água seja consumida para repor as perdas na torre por evaporação, por arraste e purga (OLIVEIRA JR, 2013). Por outro lado, a adição de palha ao sistema afeta significativamente o consumo de água. Quando comparados aos seus equivalentes ( $-\mathrm{V}$ ), os cenários VI - X registram aumentos de cerca de $15 \%$ na demanda de água deionizada, além de consumir 2,6 vezes mais água de reposição na torre de resfriamento.

Esse efeito não chega a surpreender, uma vez que a energia adicional fornecida pela palha foi usada para a produção de energia no ciclo, com o vapor circulando pelos estágios da turbina e rejeitando o calor através do conjunto do condensador e da torre evaporativa, e causando, assim, um aumento que já deveria ser esperado do suprimento de água de reposição. 
De fato, o uso de uma fonte adicional de energia na caldeira resulta em maior transferência de calor da biomassa para o fluido de trabalho o que, consequentemente, aumenta a geração de eletricidade. No entanto, e mais uma vez, este causa também mais rejeição de calor e, portanto, dispende mais água de reposição para suprir as perdas que ocorrem na torre de resfriamento (KAMATE e GANGAVATI, 2009; DINCER e ROSEAN, 2013). A Tabela 2.3 detalha a destruição de exergia para cada cenário proposto com base nos balanços exergéticos aplicados em cada etapa do ciclo Rankine e na unidade geral de cogeração.

Tabela 2.3 - Destruição da Exergia para cada estágio do ciclo de cogeração

\begin{tabular}{|c|c|c|c|c|c|c|c|c|c|c|}
\hline \multirow{2}{*}{$\begin{array}{l}\text { Destruição de exergia } \\
\left(\mathrm{kWh} / \mathrm{t}_{\mathrm{sc}}\right)\end{array}$} & \multicolumn{10}{|c|}{ Cenários } \\
\hline & I & II & III & IV & $\mathrm{V}$ & VI & VII & VIII & IX & $\mathrm{X}$ \\
\hline Caldeira & 405 & 376 & 355 & 345 & 340 & 609 & 565 & 534 & 519 & 511 \\
\hline Turbina & 11,2 & 14,1 & 16,5 & 17,7 & 18,3 & 21,3 & 26,6 & 30,1 & 31,0 & 32,8 \\
\hline Condensador & 6,51 & 5,90 & 6,48 & 6,49 & 6,52 & 16,8 & 16,8 & 16,8 & 17,7 & 16,8 \\
\hline Equipamentos auxiliares & 8,82 & 10,0 & 10,6 & 11,8 & 11,8 & 15,1 & 15,9 & 18,6 & 19,5 & 19,5 \\
\hline Exergia útil & 157 & 183 & 200 & 208 & 213 & 223 & 261 & 286 & 298 & 306 \\
\hline
\end{tabular}

A maior destruição de exergia ocorre da caldeira, devido à irreversibilidade gerada pela transferência térmica e à natureza intrínseca do processo de combustão que ocorre na fornalha. Se tal irreversibilidade não puder ser eliminada, uma vez que esse processo está ligado a um aumento da entropia, seria ao menos possível tentar reduzi-la implementando três ações: (i) aprimoramento do sistema de controle de purga; (ii) ajuste da razão ar-combustível; e (iii) revisão do conceito tecnológico adotado para a configuração pressão-isolamento. A implementação dessas práticas pode resultar em menores perdas de energia, e maiores eficiências térmicas (GUERRA et al., 2014). Essas conclusões ajudam a explicar a diminuição da destruição da exergia da caldeira em sistemas de cogeração de alta pressão. Todas essas opções podem reduzir perdas na forma de convecção e radiação, que ocorrem tanto no vaso de pressão quanto nos tubos (SZARGUT, 2005; EBOH et al., 2017). Segundo Oliveira Jr. (2013), um aumento da pressão de trabalho do vapor, coaduna o conceito adotado atualmente na construção de caldeiras de alta pressão, além de reduzir perdas de energia e irreversibilidades. 0 resultado justifica as reduções em relação à exergia total introduzida pela biomassa de 69\% para $58 \%$ à medida que a pressão da caldeira aumenta, tanto no conjunto $\mathrm{I}-\mathrm{V}$, quanto entre VI - X. 
Para os cenários I - V, a destruição de exergia na turbina aumentou 63\% (1,90\% $\rightarrow 3,10 \%)$. Esse efeito está associado à maior conversão de energia nos estágios da turbina, por conta do incremento do fluxo de vapor que gera também mais trabalho no eixo. Comportamento semelhante foi observado na turbina com adição de palha, que resultou em aumento de 54\% na depleção de exergia de VI a X. A Figura 2.5 estratifica os diagnósticos exergéticos indicados na Tabela 2.3. As contribuições relacionadas ao condensador não foram indicadas na esta imagem; no entanto, esses valores podem ser estimados por diferença em relação à totalidade.

Figura 2.5 - Análise exergética consolidada para cada cenário

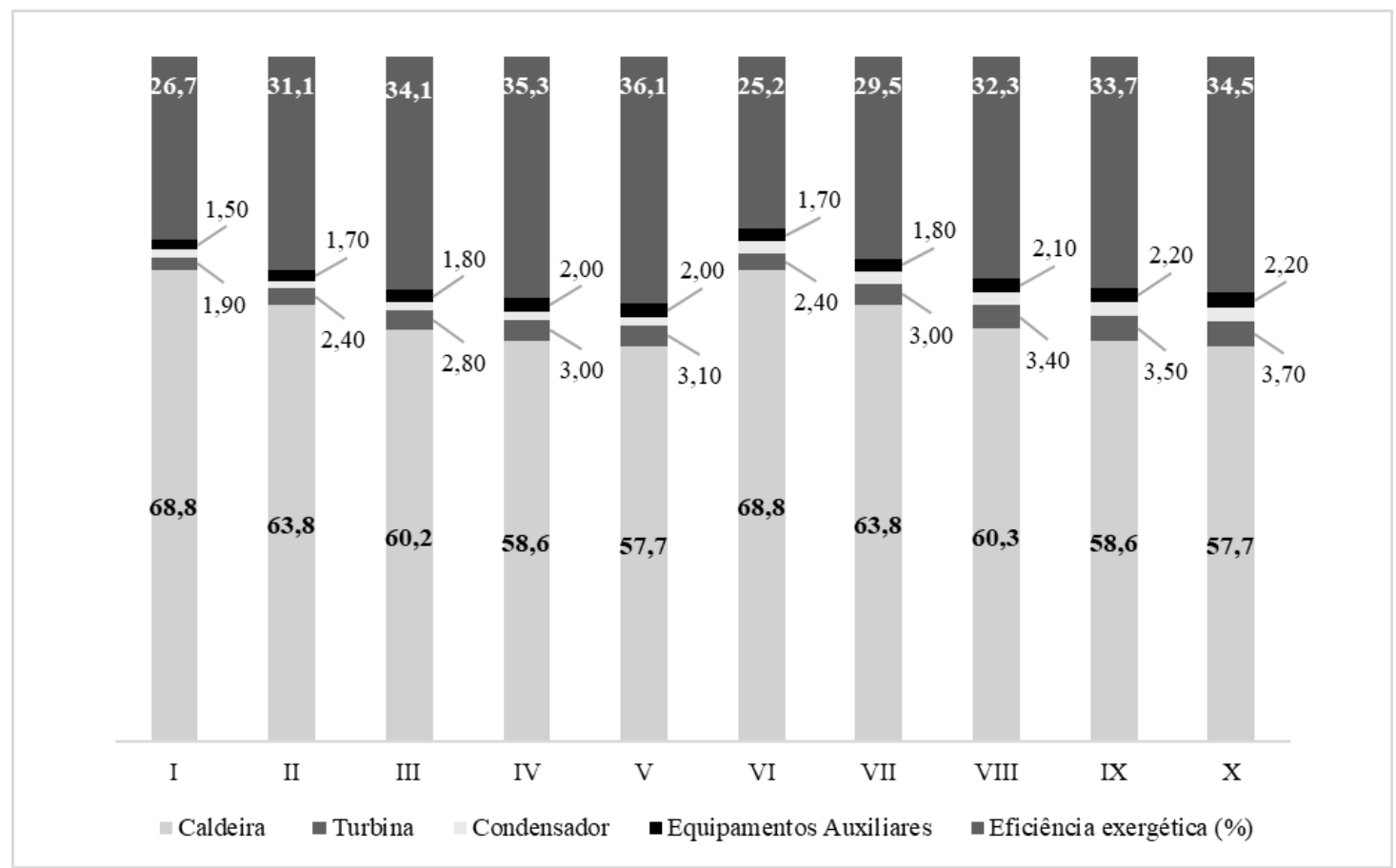

A eficiência exergética global do sistema se eleva com o aumento da pressão da caldeira, independentemente de a palha ser ou não incorporada à biomassa. No entanto, para condições similares de pressão e temperatura, a eficiência de exergia com uma mistura de bagaço e palha foi sempre menor do que a obtida apenas com bagaço. Isso ocorre porque a estimativa desses parâmetros depende do equilíbrio entre fontes de energia, calor (vapor de processo) e eletricidade, no sistema de geração. Assim, sob as mesmas condições de operação, quanto maior a fração de energia utilizada na forma de vapor, maior a eficiência do ciclo Rankine. No caso da cogeração, o vapor é produto final, e quando extraído da turbina para ser usado na destilaria, este não mais participa dos processos de conversão do ciclo (na turbina e no gerador), nos quais há irreversibilidade associada e taxas significativas de destruição da exergia. 
Neste estudo, o consumo de vapor para a produção de etanol foi o mesmo para todos os cenários (400 kg/tsc). A energia térmica adicional na caldeira resultante da queima da palha foi amplamente transferida para o fluido de trabalho (água), convertida em energia mecânica na turbina e, em seguida, em eletricidade no gerador. Cada etapa desse arranjo causa uma irreversibilidade adicional ao processo. Examinando mais de perto essa abordagem, as comparações entre eficiências exergética para sistemas de cogeração se tornam ainda mais razoáveis para cenários com a mesma alimentação de energia térmica na caldeira e consumo de vapor no processo.

Não foram observadas flutuações significativas na destruição de exergia que se dá no condensador conforme são elevadas a pressão e a temperatura da caldeira. 0 parâmetro permaneceu estável - em torno de 1,10\% - para os cenários I - V e em cerca de 2,00\% para VI - X. Esses resultados indicam que as perdas ocorridas no condensador são de "energia de baixa qualidade" e, portanto, têm pouco potencial para provocar mudanças. Essa energia está, portanto, em condições termodinâmicas e químicas, bem próximas da forma do ambiente energético, quase atingindo o 'estado morto'. Com base nesse diagnóstico, não seria recomendável recuperar a energia perdida no condensador. Finalmente, para todos os cenários avaliados, a destruição de exergia no equipamento auxiliar aumentou gradualmente à medida que a pressão da caldeira foi elevada.

Como mencionado anteriormente, aumentar a pressão de trabalho e melhorar o conceito tecnológico da caldeira proporcionam maior transferência de calor para o fluido de trabalho. Isso gera também uma capacidade considerável de recirculação de água e, consequentemente, mais trabalho será consumido pelas bombas de condensado, e de alimentação, resultando assim em taxas importantes de destruição de exergia. Embora se tenha assinalado que tanto maior a pressão operacional, mais alta será também a taxa de destruição de exergia nas turbinas e equipamentos acessórios, o balanço energético global para o sistema de cogeração é positivo. Além disso, é possível projetar um ganho de melhoria na eficiência exergética do ciclo, compensada pela menor taxa de destruição de exergia na caldeira.

\subsubsection{Análise Ambiental}

A ACV realizada nesta investigação permitiu identificar estágios do ciclo de vida, com grande contribuição nos impactos ambientais. A Tabela 2.4 traz uma visão geral dos perfis de desempenho ambiental para geração de 1,0 MWh de eletricidade nos diferentes cenários analisados. 
A Figura 2.6 reorganiza esses mesmos dados, a fim de destacar as consequências da incorporação de palha à biomassa. Geralmente, um aumento na pressão de vapor é acompanhado pela redução dos impactos ambientais em relação a todas as categorias avaliadas. Apesar de a inclusão da palha como agente provedor de energia, as reduções de impacto variaram de $26 \%(\mathrm{I}-\mathrm{V}$ ) a $27 \%$ (VI - X) para todas as categorias analisadas.

A diminuição sistêmica de impactos pode ser explicada pela análise exergética que foi apresentada e discutida na seção 2.5.1. Uma pressão mais alta de operação do sistema trouxe redução ampla da irreversibilidade do ciclo, melhorando assim sua eficiência exergética. Isso permitiu que um excedente ainda maior de eletricidade fosse exportado para a concessionária, partindo-se do mesmo consumo de biomassa.

Dentro ainda desta abordagem inicial, é importante observar como os resultados da Tabela 2.4 são altamente dependentes dos critérios de alocação adotados para efeito de tratamento de situações multifuncionais. Como os consumos de vapor e eletricidade na destilaria são constates para todos os cenários, uma vez que a produção de etanol foi fixada para efeito de modelagem, as cargas ambientais associadas a esses fluxos serão menores, sempre em termos específicos, à medida que a geração de eletricidade excedente se intensifica.

Tabela 2.4 - Perfis do desempenho ambiental para cada cenário avaliado.

\begin{tabular}{lllllllllllll}
\hline \multirow{2}{*}{$\begin{array}{l}\text { Categoria } \\
\text { impacto }\end{array}$} & Unidade & \multicolumn{10}{c}{ Cenários } \\
\cline { 3 - 11 } & & I & II & III & IV & V & VI & VII & VIII & IX & X \\
\hline MC & kg CO2eq & 165 & 142 & 130 & 125 & 122 & 151 & 129 & 118 & 113 & 110 \\
PMF & kg PM10 eq & 19,7 & 16,9 & 15,5 & 14,9 & 14,6 & 17,4 & 14,8 & 13,5 & 13,0 & 12,7 \\
WD & $\mathrm{m}^{3}$ & 4,27 & 3,54 & 3,37 & 3,37 & 3,12 & 6,81 & 5,69 & 5,33 & 5,19 & 4,93 \\
FD & kg óleoeq & 7,81 & 6,71 & 6,15 & 5,91 & 5,78 & 8,02 & 6,84 & 6,24 & 5,99 & 5,88 \\
\hline
\end{tabular}

Ao comparar resultados obtidos com e sem palha, percebem-se comportamentos diferentes em cada categoria de impacto (Figura 2.6). Em relação ao MC, o uso de palha reduziu as emissões de GEE para todas as condições de pressão. Esses efeitos foram reforçados de acordo com o aumento da pressão ( $\rightarrow$ V e VI $\rightarrow \mathrm{X}$ ). Assim, a comparação de desempenho quando o sistema opera em 20 bar (I vs. VI) projetou uma redução de impacto de 8,4\% da adição da palha, enquanto que em 100 bar (V vs. X) esse esgotamento foi de $9,7 \%$. 
Isso ocorre porque não há mais palha de cana queimada nos campos e parte dela é usada na caldeira em condições controladas para converter energia térmica em trabalho útil no sistema de cogeração. 0 processo de colheita manual da cana inclui uma limpeza prévia do campo. Isso ocorre pela queima da palha, e é justificado por várias razões, incluindo: (i) causar um aumento de sólidos solúveis ( ${ }^{\circ}$ Brix) e fibras vegetais devido à secagem dos caules; e (ii) facilitar a colheita e torná-la menos onerosa (CORTEZ, 2010). As condições sob as quais a queima da palha é realizada no campo favorecem a formação de compostos de carbono reduzido, também de origem biogênica, em particular compostos orgânicos voláteis não metânicos (NMVOC $\mathrm{b})$, monóxido de carbono $\left(\mathrm{CO}_{\mathrm{b}}\right)$ e metano $\left(\mathrm{CH}_{4, \mathrm{~b}}\right)$ - sendo este último um gás que integra o elenco de precursores de MC.

Por outro lado, quando a queima da palha ocorre na caldeira, melhora as emissões de dióxido de carbono biogênico $\left(\mathrm{CO}_{2, \mathrm{~b}}\right)$, formado a partir de carbono fixado na atmosfera $\left(\mathrm{CO}_{2, \text { arr }}\right)$ por meio da fotossíntese da cana-de-açúcar. $\mathrm{O}$ método utilizado pelo IPCC para quantificação de $\mathrm{MC}$ não reconhece $\mathrm{CO}_{2, \mathrm{~b}}$ como precursor de $\mathrm{MC}$, considerando sua taxa de emissão em equilíbrio com aquela de $\mathrm{CO}_{2, \text { ar }}$ (IPCC, 2006). Por fim, deve-se destacar que os benefícios proporcionados pela queima da palha na caldeira superam os impactos adicionais causados pelo enfardamento, transporte e moagem.

A etapa agrícola, a cogeração e o transporte de cana foram responsáveis pelos impactos do MC, com contribuições respectivas de 72\%, 16\% e 5,4\%, para os cenários de I - V. Quando a palha é consumida no processo (VI - X), confirma-se uma diminuição (68\%) na contribuição da etapa agrícola, ao mesmo tempo em que ocorrem aumentos na cogeração (19\%) e transporte (5,7\%). Por fim, o enfardamento de palha foi responsável por $1,3 \%$ dos impactos do MC.

O precursor mais importante do $\mathrm{MC}$ em todos os cenários foi $\mathrm{CO}_{2}$ originado da transformação do solo, que contribuiu com $51 \%$ do impacto total. Também existem emissões atmosféricas de óxido nitroso $\left(\mathrm{N}_{2} \mathrm{O}\right)$ devido à oxidação de adubos nitrogenados, queima de cana-de-açúcar, aplicação de vinhaça e torta de filtro, e à combustão de diesel em máquinas agrícolas. Somados, os efeitos dessas ações representam $22 \%$ dos impactos para a categoria. A eles se seguem emissões de $\mathrm{CO}_{2}$ fóssil (19\%) da combustão do diesel em máquinas agrícolas, caminhões, e na aplicação de ureia e cal. Finalmente, as emissões atmosféricas de $\mathrm{CH}_{4, \mathrm{~b}}$, que nos cenários I a $\mathrm{V}$ são devidas à queima das culturas de canade-açúcar, somam 3,3\% dos impactos da MC. 
Em relação ao PMF, o uso de palha na caldeira proporcionou melhores resultados para todas as condições de pressão. As reduções de $12 \%$ de I vs. IV e $13 \%$ para V vs. X estão relacionadas às condições controladas nas quais a energia intrínseca da palha é convertida em trabalho útil na caldeira. Os precursores do PMF estão concentrados tanto no estágio agrícola quanto no sistema de cogeração. No conjunto I a V, esses processos representaram $90 \%$ e 9,4\% respectivamente, e em VI a X, a etapa agrícola participou com $88 \%$, enquanto a contribuição da cogeração chegou a quase $12 \%$.

As liberações de material particulado com diâmetro $\Phi<2,5$ m $(\mathrm{PM}<2,5)$ são os principais precursores de impacto para PMF em todos os cenários. Esses poluentes representaram 89\% das contribuições em I - V e 91\% daquelas para VI - X. A queima de palha para colheita manual e combustão de diesel em máquinas agrícolas foi responsável por $97 \%$ e 96\% das emissões em cada caso. A cogeração contribuiu com 3,2\% em I - V e $3,8 \%$ em VI - X. Se a palha é usada na caldeira, essas emissões se reduzem devido ao controle de combustão. Nesse caso, a emissão de particulados com diâmetro $\Phi<10 \mu \mathrm{m}$ (PM < 10), típico de cogeração, cai de 9,2\% para 6,9\% de contribuição. As emissões de óxido de nitrogênio $\left(\mathrm{NO}_{\mathrm{x}}\right)$ foram responsáveis por 1,7\% e 1,6\% dos impactos de PMF em I - V e VI - X. Os resultados sugerem haver tanto uma baixa contribuição de $\mathrm{NO}_{\mathrm{x}}$ para $\mathrm{PMF}$, como pequena influência da palha na emissão desse poluente.

O uso de palha na cogeração trouxe reduções significativas dos impactos para MC e PMF. No entanto, a Figura 2.6 mostra que esta opção piorou os impactos para WD e FD. Em relação à WD, houve um aumento médio de 59\% no consumo de água. Esse efeito está associado principalmente ao sistema de cogeração e pode ser explicado através da análise termodinâmica. Conforme discutido antes na Seção 2.5.1, a transferência de calor adicional da biomassa (bagaço + palha) para o fluido de trabalho aumenta a potência útil, mas também eleva a taxa de calor rejeitado no condensador. Consequentemente, faz-se necessário um fluxo maior de água de reposição para substituir as perdas na torre de resfriamento. A WD está, portanto, baseada no consumo de águas superficiais (91\%) para atender à demanda da torre de resfriamento.

Em termos de FD, o uso de palha não trouxe aumento substancial nos impactos ambientais. Para essa categoria, foram estimados impactos de 7,81 e 8,02 kg óleo ${ }_{\text {eq }} / \mathrm{MWh}$ excedente de eletricidade para os cenários I e VI, respectivamente. A pequena diferença $(2,6 \%)$ entre esses resultados não é tão significativa. Além disso, aumentando a pressão de trabalho, os impactos do FD tendem a se aproximar. 
A análise exergética pode explica claramente esse fenômeno, uma vez que o aumento da eficiência exergética global leva a maior geração de eletricidade, fenômeno capaz de compensar consumos fósseis adicionais causados pelas etapas de enfardamento, transporte e moagem da palha. Portanto, e como se poderia esperar, nos cenários V e X, a diferença de impacto para FD resultou em um aumento ainda menor $(1,1 \%)$.

Figura 2.6 - Comparação dos efeitos do uso da palha na cogeração para condições equivalentes de processo em termos de (a) Mudanças Climáticas (MC); (b) Formação de Material Particulado (PMF); (c) Depleção Hídrica (WD); e (d) Depleção Fóssil (FD).

(a) $\mathrm{MC}\left(\mathrm{kg} \mathrm{CO}_{2 \mathrm{eq}} / \mathrm{MWh}\right)$

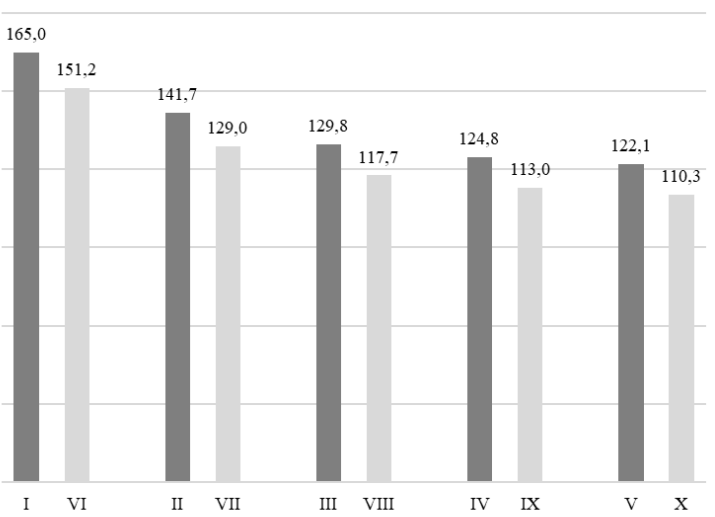

(c) $\quad \mathrm{WD}\left(\mathrm{m}^{3} / \mathrm{MWh}\right)$

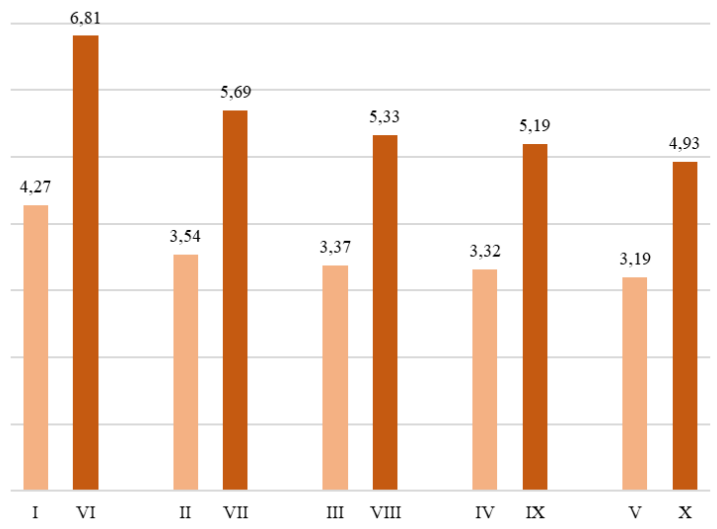

(b) PMF (kg PM 10 eq $/ \mathrm{MWh})$

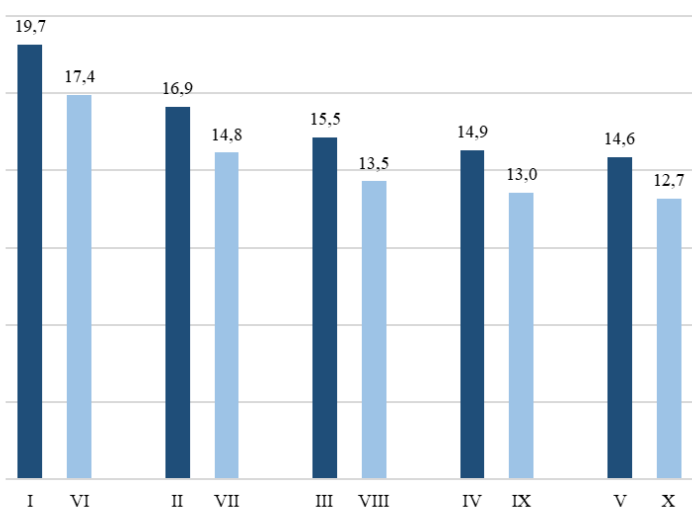

(d) $\quad \mathrm{FD}\left(\mathrm{kg}\right.$ oil $\left.{ }_{\mathrm{eq}} / \mathrm{MWh}\right)$

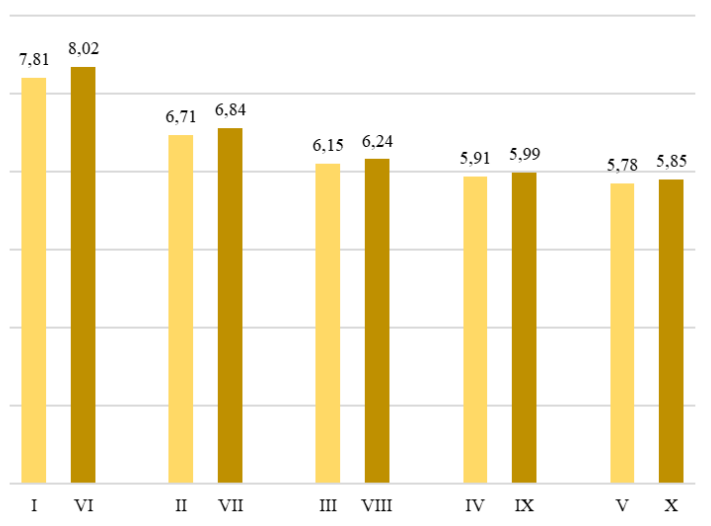

Do ponto de vista do processo, o gasto de combustíveis fósseis nos cenários de I - V concentra-se no estágio agrícola (73\%) e no transporte de cana (27\%). Por outro lado, em VI a X, há um aumento desses mesmos consumos em valor absoluto, devido ao arranjo processual introduzido pela palha no sistema do produto. Assim, a contribuição da etapa agrícola diminui para $69 \%$, enquanto a do transporte de cana chega a $25 \%$. As etapas adicionais de enfardamento, transporte e moagem de palha agora representam $2,6 \%, 2,1 \%$ e $0,7 \%$. 0 principal recurso natural associado a essa categoria é o petróleo bruto (99\%), que entra no sistema via diesel consumido em máquinas e caminhões. 


\subsubsection{Análise combinada termo-ambiental}

A Tabela 2.5 mostra os resultados do indicador combinado $\left(C I_{c, j}\right)$, que foi gerado a partir da correlação entre os indicadores ambientais normalizados de cada categoria de impacto analisada ( $\mathrm{N}_{\mathrm{MC}}, \mathrm{N}_{\mathrm{PMF}}, \mathrm{N}_{\mathrm{WD}}$ e $\mathrm{N}_{\mathrm{FD}}$ ) e seu homólogo, para exergia, que descreve a dimensão termodinâmica da análise $\left(\mathrm{N}_{\mathrm{ExD}}\right)$, para os cenários I-X.

Tabela 2.5 - Indicador combinado $\left(C I_{c, j}\right)$ para os cenários I - X

\begin{tabular}{cccccccccccc}
\hline & \multicolumn{10}{c}{$C I_{c, j}$} & \multicolumn{1}{c}{ Cenário } \\
\cline { 2 - 11 } & I & II & III & IV & V & VI & VII & VIII & IX & X \\
\hline $\mathrm{N}_{\mathrm{MC}} \times \mathrm{N}_{\text {ExD }}$ & 1,000 & 0,561 & 0,410 & 0,359 & 0,331 & 0,693 & 0,422 & 0,320 & 0,281 & 0,261 \\
$\mathrm{~N}_{\mathrm{PMF}} \times \mathrm{N}_{\mathrm{ExD}}$ & 1,000 & 0,559 & 0,410 & 0,358 & 0,332 & 0,669 & 0,405 & 0,306 & 0,271 & 0,252 \\
$\mathrm{~N}_{\mathrm{WD}} \times \mathrm{N}_{\mathrm{ExD}}$ & 0,627 & 0,339 & 0,258 & 0,234 & 0,205 & 0,758 & 0,451 & 0,350 & 0,313 & 0,283 \\
$\mathrm{~N}_{\mathrm{FD}} \times \mathrm{N}_{\mathrm{ExD}}$ & 0,974 & 0,545 & 0,400 & 0,349 & 0,323 & 0,758 & 0,460 & 0,348 & 0,307 & 0,287 \\
\hline
\end{tabular}

Uma observação preliminar dos dados, revela que $C I_{c, j}$ diminuiu à medida que a pressão do vapor extraído da caldeira se eleva, independentemente de haver adição de palha. A tendência se confirma para qualquer uma das categorias de impacto analisadas; portanto, os piores desempenhos sinérgicos de cada série são obtidos se o ciclo Rankine opera a 20 bar (I e VI). Os ganhos de desempenho são mais notados ao passar de pressões de 20 bar para 45 bar (I $\rightarrow$ II e VI $\rightarrow$ VII). A partir daí, as oscilações $C I_{c, j}=\mathrm{f}(\Delta \mathrm{P})$ tornamse cada vez menores, fazendo com que os resultados de $C I_{c, j}$ tendam a se comportar de maneira constante.

Observa-se também grande similaridade entre os resultados de $C I_{c, j}$ derivados da sinergia entre $\mathrm{N}_{\mathrm{ExD}}$ e $\mathrm{N}_{\mathrm{MC}}, \mathrm{N}_{\mathrm{PMF}}$ e $\mathrm{N}_{\mathrm{FD}}$ para o conjunto de I - V. Isso sugere que os valores normalizados de seus indicadores ambientais são de fato semelhantes. Tendência algo semelhante ocorre também entre $\mathrm{N}_{\mathrm{MC}}$ e $\mathrm{N}_{\mathrm{PMF}}, \mathrm{N}_{\mathrm{WD}}$ e $\mathrm{N}_{\mathrm{FD}}$ para o grupo VI - X.

O indicador que descreve a sinergia entre destruição da exergia e WD (ou seja, $\mathrm{N}_{\text {ExD }}$ e $\mathrm{N}_{\mathrm{WD}}$ ) mostra comportamento distinto do manifestado pelos demais. Nesse caso, observa-se aumento gradual dos valores para uma mesma pressão, de $21 \%$ entre I vs VI, a 38\% para V vs. X, devido à adição de palha. Nesse caso, a melhoria observada em termos de elevação de eficiência energética não foi suficiente para compensar a maior demanda de água de resfriamento. 


\subsection{Conclusões}

Este estudo tratou de investigar a forma como se comportam os desempenhos termodinâmico e ambiental de um sistema de cogeração operado com biomassa de canade-açúcar, diante do aumento da escala de produção. Foram elaborados cenários a partir de diferentes pressões operacionais da caldeira; além disso, o efeito do uso da palha de cana como fonte adicional de biomassa para o sistema também foi examinado.

A análise termodinâmica indicou que a elevação da pressão e temperatura do vapor extraído da caldeira pode significar uma melhoria na eficiência de exergia de até $37 \%$ nos cenários de pressão alta (a partir de 67 bar). Além disso, os resultados mostram um impacto direto na conversão de energia térmica de combustíveis em trabalho útil, resultando em melhoria de até $63 \%$ da produção líquida de energia da mesma fonte de calor. Os ganhos de desempenho termodinâmico associados ao sistema quando este opera a pressões altas também significou redução de impactos ambientais em todas as categorias analisadas. Para pressões superiores a 67 bar a análise mostra reduções potenciais de impacto nessa dimensão de até $27 \%$. Com relação ao uso da palha, a análise termodinâmica identificou que a incorporação de $50 \% \mathrm{~m} / \mathrm{m}$ da palha gerada no campo na biomassa utilizada na cogeração tem o potencial de dobrar a energia excedente se o sistema operar a pressões próximas a 100 bar.

A análise ambiental revelou desdobramentos positivos e negativos em relação ao uso da palha. A partir da adoção dessa fonte de energia renovável, é possível esperar diminuições de impactos quanto a Mudanças Climáticas (MC) e Formação de Material Particulado (PMF); por outro lado, efeitos em termos de Depleção Hídrica e Fóssil (WD e FD) se elevam. Se o sistema opera em 100 bar, as reduções de impacto para MC e PMF atingem 9,7\% e 13\%, respectivamente. Para a mesma condição operacional, no entanto, houve aumentos em danos ambientais de 58\% e 1,1\% para WD e FD. Assim sendo, ao comparar o desempenho ambiental dos cenários de cogeração com e sem palha, deve-se considerar as categorias de impacto a serem priorizadas antes da concepção do projeto.

A avaliação dos cenários propostos sob uma perspectiva ambiental forneceu uma percepção diferente e sistêmica para a análise. A partir do diagnóstico fornecido pela ACV, foi possível perceber que a implementação de medidas efetivas de melhoria de processos, pode levar a reduções sistêmicas de efeitos adversos causados por atividades antropogênicas, mesmo que essas intervenções se limitem a estágios específicos do ciclo de vida de um processo (ou produto). Para tal caso em específico, os resultados também indicaram haver melhorias ambientais potenciais associados a produção de etanol. 


\subsection{Referências}

Alves M., Ponce G. H. S. F., Silva M. A., Ensinas A. V., 2015, Surplus electricity production in sugarcane mills using residual bagasse and straw as fuel. Energy, 91: 751-757. DOI: 10.1016/j.energy.2015.08.101.

Bechara R., Gomez A., Saint-Antonin V., Schweitzer J.-M., Maréchal F., 2016, Methodology for the optimal design of an integrated sugarcane distillery and cogeneration process for ethanol and power production. Energy, 117: 540-549. DOI: 10.1016/j.energy.2016.07.018.

Bonomi A., The Virtual Sugarcane Biorefinery (VSB)—Report 2011. CTBE/CNPEMBrazilian Bioethanol Science and Technology Laboratory/Brazilian Center of Research in Energy and Materials. Campinas, Brazil. 2012.124p.

Cardoso T. F., Cavalett O., Chagas M. F., Morais E. R., Carvalho J. L. N., Franco H. C. J., Galdos M. V., Scarpare F. V., Braunbeck O. A., Cortez L. A. B., Bonomi A., 2013, Technical and economic assessment of trash recovery in the sugarcane bioenergy production system. Scientia Agricola, 70(5): 353-360. DOI: 10.1590/S010390162013000500010.

Cardoso T. F., Chagas M. F., Rivera E. C., Cavalett O., Morais E. R., Geraldo V. C., Braunbeck O., Cunha M. P., Cortez L. A. B., Bonomi A., 2015, A vertical integration simplified model for straw recovery as feedstock in sugarcane biorefineries. Biomass and Bioenergy, 81: 216-223. DOI: 10.1016/j.biombioe.2015.07.003.

Castilla L.R.C., Bioeletricidade como fonte de energia no Brasil In. Proceedings: XVIII ENGEMA-Encontro Internacional sobre Gestão Empresarial e Meio Ambiente. 2016.

Cavalett O., Chagas M. F., Seabra J. E. A., Bonomi A., 2013, Comparative LCA of ethanol versus gasoline in Brazil using different LCIA methods. The International Journal of Life Cycle Assessment, 18(3): 647-658. DOI:10.1007/s11367-012-0465-0.

Cavalett O., Junqueira T. L., Dias M. O. S., Jesus C. D. F., Mantelatto P. E., Cunha M. P., Franco H. C. J., Cardoso T. F., Maciel Filho R., Rossell C. E. V, Bonomi A., 2012, Environmental and economic assessment of sugarcane first generation biorefineries in Brazil. Clean Technologies and Environmental Policy, 14(3): 399-410. DOI: 10.1007/s10098-011-0424-7.

Colombo G., Ocampo-Duque W., Rinaldi F., 2014, Challenges in Bioenergy Production from Sugarcane Mills in Developing Countries: A Case Study. Energies, 7(9): 58745898. DOI: $10.3390 /$ en7095874.

Cortez L. A. B, Bioetanol de Cana-de-Açúcar: P\&D Para a Produtividade e Sustentabilidade. ${ }^{\text {st }}$. Ed. São Paulo: Blücher, 2010.

Dewulf J., Van Langenhove H., Muys B., Bruers S.; Bakshi B. R., Grubb G. F. M. Paulus D. M., Sciubba E., 2008, Exergy: Its Potential and Limitations in Environmental Science and Technology. Environmental Science \& Technology, 42(7): 2221-2232. DOI: 10.1021/es071719a.

Dias M. O. S.; Cunha M. P., Jesus C. D. F., Rocha G. J. M., Pradella J. G. C., Rossell C. E. V., Maciel Filho R., Bonomi A., 2011a, Second generation ethanol in Brazil: Can it compete with electricity production? Bioresource Technology, 102(19): 8964-8971. DOI: 10.1016/j.biortech.2011.06.098. 
Dias M. O. S., Cunha M. P., Jesus C. D. F., Scandiffio M. I. G., Rossell C. E. V., Maciel Filho R., Bonomi A., 2010, Simulation of ethanol production from sugarcane in Brazil: economic study of an autonomous distillery. Computer Aided Chemical Engineering, 28: 733738. DOI: $10.1016 /$ S1570-7946(10)28123-3.

Dias M. O. S., Ensinas A. V., Nebra S. A., Maciel Filho R., Rossell C. E. V., Maciel M. R. W., 2009, Production of bioethanol and other bio-based materials from sugarcane bagasse: Integration to conventional bioethanol production process. Chemical Engineering Research and Design, 87(9): 1206-1216. DOI: 10.1016/j.cherd.2009.06.020.

Dias M. O. S., Junqueira T. L., Cavalett O., Cunha M. P., Jesus C. D. F., Mantelatto P. E., Rossell C. E. V., Maciel Filho R., Bonomi A., 2013, Cogeneration in integrated first and second generation ethanol from sugarcane. Chemical Engineering Research and Design, 91(8): 1411-1417. DOI: 10.1016/j.cherd.2013.05.009.

Dias M. O. S., Modesto M., Ensinas A. V., Nebra S. A., Maciel Filho R., Rossell C. E. V., 2011b, Improving bioethanol production from sugarcane: evaluation of distillation, thermal integration and cogeneration systems. Energy, 36(6): 3691-3703. DOI: 10.1016/j.energy.2010.09.024.

Dincer I., Rosen M. A. Exergy: Energy, Environment and Sustainable Development. $2^{\text {nd }}$. Ed. Oxford, UK: Elsevier Science, 2013.

Eboh F., Ahlström P., Richards T., 2017, Exergy Analysis of Solid Fuel-Fired Heat and Power Plants: A Review. Energies, 10(2): 165. DOI: 10.3390/en10020165.

Ensinas A. V., Modesto M., Nebra S. A., Serra L., 2009, Reduction of irreversibility generation in sugar and ethanol production from sugarcane. Energy, 34(5): 680-688. DOI: 10.1016/j.energy.2008.06.001.

Ensinas A. V., Nebra S. A., Lozano M. A., Serra L. M., 2007, Analysis of process steam demand reduction and electricity generation in sugar and ethanol production from sugarcane. Energy Conversion and Management, 48(11): 2978-2987. DOI: 10.1016/j.enconman.2007.06.038.

EPE-Energy Research Enterprise. Brazilian Energy Balance 2014 Year 2015 CDU 620.9:553.04. Ministry of Mines and Energy. Brasília-DF. In Portuguese. 2015.

EPE-Energy Research Enterprise. Brazilian Energy Balance 2015. Year 2016 CDU 620.9:553.04. Ministry of Mines and Energy. 2016. Brasilia-DF. In Portuguese.

Fredo C. E., Caser D. V., Sachs R. C., Olivette M. P. A., Filho A. A. V., 2014, Mecanização na Colheita da Cana-de-açúcar paulista supera $80 \%$ da safra 2012/2013. Análise e Indicadores do Agronegócio, 9(7): 1-7.

Gil M. P., Moya A. M. C., Domínguez E. R., 2013, Life cycle assessment of the cogeneration processes in the Cuban sugar industry. Journal of Cleaner Production, 41: 222-231. DOI: 10.1016/j.jclepro.2012.08.006.

Goedkoop M., Heijungs R., Huijbregts M., Schryver A., Struijs J., Van Zelm R. Description of the ReCiPe Methodology for Life Assessment Impact Assessment. 2013.

GREET Greenhouse Gases, Regulated Emissions, and Energy Use in Transportation. Version 1.8d. Technical Report; Argonne National Laboratory Illinois: Lemont US 2000. 
Guerra J. P. M., Coleta J. R., Arruda L. C. M., Silva G. A., Kulay L., 2014, Comparative analysis of electricity cogeneration scenarios in sugarcane production by LCA. International Journal of Life Cycle Assessment, 19(4): 814-825. DOI: 10.1007/s11367-014-0702-9.

Gupta M. K., Kaushik S. C., Ranjan K. R., Panwar N. L., Reddy V. S., Tyagi S. K., 2015, Thermodynamic performance evaluation of solar and other thermal power generation systems: A review. Renewable and Sustainable Energy Reviews, 50: 567-582. DOI: 10.1016/j.rser.2015.05.034.

Hansen A. P., Silva G. A., Kulay L., 2015, Evaluation of the environmental performance of alternatives for polystyrene production in Brazil. Science of the Total Environment, 532: 655-668. DOI: 10.1016/j.scitotenv.2015.06.049.

Hassuani S. J., Leal M. R. L. V., Macedo I. C., 2005, Canavieira., C. de T.; PROGRAMME., U. N. D. Biomass power generation: sugar cane bagasse and trash. Piracicaba; Brasil: CTC; PNUD, 2005.

Kadiyala A., Kommalapati R., Huque Z., 2016, Evaluation of the Life Cycle Greenhouse Gas Emissions from Different Biomass Feedstock Electricity Generation Systems. Sustainability, 8(11): 1181. DOI: 10.3390/su8111181.

Kamate S. C., Gangavati P. B., 2009, Exergy analysis of cogeneration power plants in sugar industries. Applied Thermal Engineering, 29: 1187-1194. DOI: 10.1016/j.applthermaleng.2008.06.016.

Klein, S. A. EES-Engineering Equation Solver. EES® V.10.249. Disponível em: <http://www.fchart.com/assets/downloads/ees_manual.pdf>. Acesso em: 15 mar. 2017.

Kosaric N., Duvnjak Z., Farkas A., Sahm H., Bringer-Meyer S., Goebel O., Mayer D., 2005, Ethanol. In Dithiocarbamic Acid and Derivatives to Ethanol, Volume A9, Ullmann's Encyclopedia of Industrial Chemistry, $5^{\text {th }}$ Edition; Wiley-VCH: Weinheim, Germany, 2005; p. 8762-8817.

INTERGOVERNMENTAL PANEL ON CLIMATE CHANGE (IPCC) Guidelines for National Greenhouse Gas Inventories, Volume 4. Agriculture, Forestry and Other Land Use. 2006. 563p.

ISO (International Organization for Standardization). ISO 14040, 2006, Environmental management - life cycle assessment - principles and framework, $1^{\text {st }}$ Ed. International Organization for Standardization: Genève, Switzerland, 20p

ISO (International Organization for Standardization). ISO 14044, 2006, Environmental Management-Life Cycle Assessment-Requirements and Guidelines, $1^{\text {st }}$ Ed. International Organization for Standardization: Genève, Switzerland, 46p.

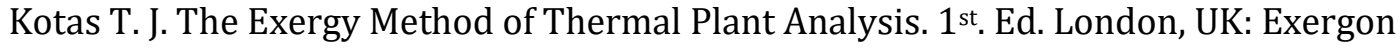
Publishing Company, 2012.

Leal M. R. L. V., Galdos M. V., Scarpare F. V., Seabra J. E. A., Walter A., Oliveira C. O. F., 2013, Sugarcane straw availability, quality, recovery and energy use: A literature review. Biomass and Bioenergy, 53: 11-19. DOI: 10.1016/j.biombioe.2013.03.007. 
Lisboa I. P., Cherubin M. R., Cerri C. C., Cerri D. G. P., Cerri C. E. P., 2017, Guidelines for the recovery of sugarcane straw from the field during harvesting. Biomass and Bioenergy, 96: 69-74. DOI: 10.1016/j.biombioe.2016.11.008.

MAPA (Ministério da Agricultura, Pecuária e Abastecimento) Statistical yearbook of Agrienergy 2014. Secretariat of Production and Agrienergy. CDU 633.61 Brasilia-DF. In Portuguese. 2015.

Menandro L. M. S., Cantarella H., Franco H. C. J., Kölln O. T., Pimenta M. T. B., Sanches G. M., Rabelo S. C., Carvalho J. L. N., 2017, Comprehensive assessment of sugarcane straw: implications for biomass and bioenergy production. Biofuels, Bioproducts and Biorefining, 11(3): 488-504. DOI: 10.1002/bbb.1760.

Modesto M., Aoki A., Lodi A., Pina E., 2016, Assessment of the Potential to Increase Electricity Generation from Sugarcane Straw in Brazilian Sugarcane Cogeneration Plants. Chemical Engineering Transactions, 50: 193-198. DOI: 10.3303/CET1650033.

Moore C. C. S., Nogueira A. R., Kulay L., 2016, Environmental and energy assessment of the substitution of chemical fertilizers for industrial wastes of ethanol production in sugarcane cultivation in Brazil. International Journal of Life Cycle Assessment, 22(4): 628-643. DOI: 10.1007/s11367-016-1074-0.

Moore C. C. S., Rego E. E., Kulay L., 2017, The Brazilian Electricity Supply for 2030: A Projection Based on Economic, Environmental and Technical Criteria. Environment and Natural Resources Research, 7(4): 17. DOI: 10.5539/enrr.v7n4p17.

Moran M. J., Shapiro H. N., Fundamentals of Engineering Thermodynamics, $6^{\text {th }}$. Ed. Wiley India Pvt. Limited, 2010.

Moya C., Domínguez R., Van Langenhove H., Herrero S., Gil P., Ledón C., Dewulf J., 2013, Exergetic analysis in cane sugar production in combination with Life Cycle Assessment. Journal of Cleaner Production, 59: 43-50. DOI: 10.1016/j.jclepro.2013.06.028.

Murphy D., Carbajales-Dale M., Moeller D., 2016, Comparing Apples to Apples: Why the Net Energy Analysis Community Needs to Adopt the Life-Cycle Analysis Framework. Energies, 9(11): 917. DOI: 10.3390/en9110917.

Nemecek T., Kägi T. Life Cycle Inventories of Swiss and European Agricultural Production System Final Report Ecoinvent v2.0 N15a; Technical Report; Agroscope Reckenholz Taenikon Research Station ART, Swiss Centre for Life Cycle Inventories: Zurich, Switzerland, 2007.

Nemecek T., Schnetzer J. Methods of Assessment of Direct Field Emissions for LCIs of Agricultural Production Systems; Technical Report; Agroscope Reckenholz Tänikon Research Station ART: Zurich, Switzerland, 2011.

Nogueira A. R., Donke A. C. G., Matsuura M. I. S. F., Matai P. H. L. S., Kulay L., 2014, Use of Environmental and Thermodynamic Indicators to Assess the Performance of an Integrated Process for Ethanol Production. Environment and Natural Resources Research, 4(4): 59-74. DOI: 10.5539/enrr.v4n4p59.

Oliveira Jr, S. Exergy: Production, Cost and Renewability. 1st. ed. London, UK: SpringerVerlag, 2013. 
Olivério J. L., Ferreira F. M., 2010, COGENERATION - A new source of income for sugar and ethanol mills or bioelectricity-A new business. In: Proc. Int. Soc. Sugar Cane Technol., Anais.

Ometto A. R., Hauschild M. Z., Roma W. N. L., 2009, Lifecycle assessment of fuel ethanol from sugarcane in Brazil. The International Journal of Life Cycle Assessment, 14(3): 236-247. DOI: 10.1007/s11367-009-0065-9.

Ometto A. R., Roma W. N. L., 2010, Atmospheric impacts of the life cycle emissions of fuel ethanol in Brazil: based on chemical exergy. Journal of Cleaner Production, 18(1): 71-76. DOI: 10.1016/j.jclepro.2009.09.003.

Palacios-Bereche R., Mosqueira-Salazar K. J., Modesto M., Ensinas A. V., Nebra S. A., Serra L. M., Lozano M.-A., 2013, Exergetic analysis of the integrated first- and secondgeneration ethanol production from sugarcane. Energy, 62: 46-61. DOI: 10.1016/j.energy.2013.05.010.

Pellegrini L. F., Oliveira Jr S., 2011, Combined production of sugar, ethanol and electricity: Thermoeconomic and environmental analysis and optimization. Energy, 36(6): 3704-3715. DOI: 10.1016/j.energy.2010.08.011.

Pellegrini L. F., Oliveira Jr S., Burbano J. C., 2010, Supercritical steam cycles and biomass integrated gasification combined cycles for sugarcane mills. Energy, 35 (2): 11721180. DOI: $10.1016 /$ j.energy.2009.06.011.

Ramos R. C., Nachiluk K., 2017, Geração de Bioenergia de Biomassa da Cana-de-açúcar nas Usinas Signatárias ao Protocolo Agroambiental Paulista, Safra 2015/2016.

Análises e Indicadores do Agronegócio, 12: 7.

Rodrigues B. N.; Almeida F. S. Guia de Herbicidas. $6^{\text {th }}$. Ed. Londrina: Livroceres, 2011.

Sea Rates Distance and Time [map]. Scale Undetermined, Generated by SeaRates LP Using Google Maps. 2016.

Sartori M. M. P., Florentino H. O., 2007, Energy balance optimization of sugarcane crop residual biomass. Energy, 32(9): 1745-1748. DOI: 10.1016/j.energy.2006.11.013.

Seabra J. E. A., Macedo I. C, 2011, Comparative analysis for power generation and ethanol production from sugarcane residual biomass in Brazil. Energy Policy, 39(1): 421-428. DOI: 10.1016/j.enpol.2010.10.019.

Seabra J. E. A., Macedo I. C., Chum H. L., Faroni C. E., Sarto C. A, 2011, Life cycle assessment of Brazilian sugarcane products: GHG emissions and energy use. Biofuels, Bioproducts and Biorefining, 5(5): 519-532. DOI: 10.1002/bbb.289.

Shen X., Kommalapati R., Huque Z., 2015, The Comparative Life Cycle Assessment of Power Generation from Lignocellulosic Biomass. Sustainability, 7(10): 12974-12987. DOI: $10.3390 /$ su71012974.

Silva D.A.L., Delai I., Montes M.L.D., Ometto A.R., 2013, Life cycle assessment of the sugarcane bagasse electricity generation in Brazil. Renewable and Sustainable Energy Reviews, 32: 532-547. DOI: 10.1016/j.rser.2013.12.056. 
Silva D. A. L., Pavan A. L.R., Oliveira J.A., Ometto A. R., 2015, Life cycle assessment of offset paper production in Brazil: hotspots and cleaner production alternatives. Journal of Cleaner Production, 93: 222-233. DOI: 10.1016/j.jclepro.2015.01.030.

Sugawara, E. T. Comparação dos desempenhos ambientais do B5 etílico de soja e de óleo diesel, por meio da avaliação do ciclo de vida (ACV). Dissertação de Mestrado. São Paulo, Brasil, 2012.242p (em português).

Szargut, J. Exergy Method: Technical and Ecological Applications. 1st. Ed. Southampton, UK: WIT Press, 2005.

Torchio M.F., 2013, Energy-Exergy, Environmental and Economic Criteria in Combined Heat and Power (CHP) Plants: Indexes for the Evaluation of the Cogeneration Potential. Energies, 6(5): 2686-2708. DOI: 10.3390/en6052686 


\section{Projeto de produto baseado em conceitos de Produção mais Limpa e Design for Environment (DfE)}

\section{Resumo}

No relato que segue a ACV se presta a uma de suas aplicações originais: auxiliar no projeto de um novo produto (Design for Environment). 0 caso em análise compreende o desenvolvimento de biofilme estruturado a partir de fécula de mandioca, que além de acondicionar alimentos, pode ainda fornecer informações sobre seu grau de preservação. Os resultados obtidos na fase inicial do estudo apontaram o cultivo de mandioca, o uso de glicerina e etanol de origem fóssil e a fabricação de filmes em si, como etapas daquele ciclo produtivo que mais impactos acarretam em termos energéticos e ambientais. A partir disso, foram planejadas medidas para reduzir esses efeitos. Um arranjo utilizando glicerina renovável e extrusão de amido de mandioca e polietileno para conformação do filme mostrou-se uma opção adequada para reduzir impactos energéticos. Além disso, se por um lado a inclusão de etanol derivado de cana-de-açúcar eleva impactos na maioria das categorias analisadas; por outro, a presença desse reagente na formulação do filme reduz significativamente as contribuições para Mudanças Climáticas, sobretudo quando sequestro carbono e emissão de $\mathrm{CO}_{2}$ biogênico são considerados na estimativa. Por fim, a análise desrecomenda a importação de amido de mandioca desde a Índia, pais em que esse processamento agrícola ocorre com mínimos consumos de recursos e emissões, em função exatamente dos impactos associados ao transporte do reativo até o Brasil.

\subsection{Introdução}

A embalagem desempenha um papel fundamental na redução do desperdício de alimentos, por ser capaz de melhorar a forma como estes são preservados, e otimizar espaços em seus manuseios, remessa e armazenamento. Além disso, inovações no design e nas etiquetas criaram oportunidades para melhorar a eficiência da cadeia de suprimentos desses gêneros de orientar o consumidor final (VERGHESE et al., 2013).

Os plásticos têm sido utilizados com frequência como agentes de embalagem em substituição a metais, vidro e materiais fibrosos. Essa opção se dá muitas vezes por conta de: (i) suas características e propriedades estruturais; (ii) dos baixos custos de produção; e (iii) da grande e variada disponibilidade de resinas (SOUZA et al., 2012). 
Os fatos de serem originários de fontes fósseis, e de seu descarte proporcionar grandes quantidades de rejeitos dadas sua lenta decomposição, e baixa (ou ausente) taxa de biodegrabilidade fizeram com que fontes alternativas de insumos, menos impactantes, fossem investigadas. Nesse contexto, o plástico de base biológica, ou biofilme, se torna uma opção viável (ALVAREZ-CHAVEZ et al., 2012; GARRIDO et al., 2014). A literatura traz vários desenvolvimentos recentes no campo dos biofilme abordando aspectos práticos a ele associados (ALHENDI e CHOUDHARY, 2013; GALI et al., 2011; SORRENTINO et al., 2007), ou suas eficácias em preparações ou funções bem definidas (AVELLA et al., 2005; BANGYEKAN et al., 2006; KECHICHIAN et al., 2010; MBEY et al., 2012; PAGNO et al., 2015). Uma parcela de literatura científica que trata do tema se ocupa em caracterizar suas propriedades mecânicas (FAMÁ et al., 2006, 2007), ou de verificar certos atributos desses materiais, como: hidrofilicidade (GAO et al., 2012; MALI et al., 2005), estabilidade estrutural (CYRAS et al., 2008; VEIGA-SANTOS et al., 2008; XIONG et al., 2008), ou mesmo propriedades de barreira (SOUZA et al., 2012, 2013). De acordo com Leceta et al., (2013) tais esforços tornaram o desempenho funcional do biofilme bastante próximo ao obtido por seus congêneres de fonte fóssil, no âmbito da preservação de alimentos.

Os benefícios ambientais potenciais desses materiais também têm sido avaliados. Em muitas situações, a técnica de ACV é usada para esses diagnósticos, por conta de duas características que lhe são inerentes: (i) uso de escopo sistêmico, e (ii) quantificação do desempenho ambiental (BAYER et al., 2010; HOSPIDO et al., 2010). Alvarez-Chavez et al. (2012) fizeram uma avaliação qualitativa dos riscos ambientais dos plásticos de base biológica, concluindo depois que a decisão de substituir plásticos fósseis por alternativas de renováveis deve necessariamente considerar o ciclo de vida completo dos materiais em análise, a fim de selecionar de maneira inequívoca a opção mais sustentável.

Garrido et al. (2014) analisaram os aspectos funcionais e o impacto ambiental do filme isolado de proteína de soja (SPI-b) comparado com o filme de polipropileno (PP) fóssil. A produção do filme de PP causou os mais sérios danos ambientais. A etapa mais crítica para SPI-b foi o cultivo de soja, dado o uso do diesel no maquinário agrícola, de fertilizantes e pesticidas. Leceta et al. (2013) realizou uma ACV comparativa entre um filme convencional para embalagem de comida à base de PP e um filme à base de quitosana biodegradável (Ch-b) desenvolvido em laboratório. O filme de PP foi mais agressivo quanto a efeitos cancerígenos e esgotamento de recursos energéticos fósseis. Em contraste, Ch-b mostrou impactos ambientais mais elevados em termos de emissão de orgânicos respiratórios, uso de terra e depleção de recursos minerais. 
A embalagem de base biológica está atualmente em uma fase experimental no Brasil, mas o setor mostra potencial para expansão (REIS et al., 2011). Pesquisas recentes tem se concentrado em avaliar propriedades e formulação de filmes de amido de mandioca (ALVES et al., 2012; SOUZA et al., 2012, 2013; VEIGA-SANTOS et al., 2008), pelo fato destes serem muito disponíveis. A extensão dos impactos ambientais da implementação desta tecnologia no país é, no entanto, ainda desconhecida.

Este estudo se propõe a ajudar a preencher em parte essa lacuna, realizando uma avaliação dos desempenhos energético e ambiental da produção do biofilme de acordo com condições de processo praticadas no Brasil. Como o diagnóstico pode identificar os principais focos de impacto nessa cadeia de produção, o estudo também avalia a eficácia de medidas potenciais de redução daqueles efeitos. Os resultados gerados por esta investigação podem ajudar a integrar a dimensão ambiental a formulação de embalagem de base biológica no Brasil.

\subsection{Metodologia}

O método adotado para realização desse estudo se constitui das seguintes etapas: (i) caracterização dos perfis de impacto energético e ambiental associados à produção de biofilme; (ii) identificação dos estágios de sua cadeia produtiva que mais influenciam aqueles desempenhos; (iii) proposição de ações que se convertam na melhoria daqueles resultados; (iv) especificação e modelagem dessas soluções; e, por fim, (v) investigação de suas eficiências em termos energético e ambiental.

O perfil de impactos ambientais para produção de filme foi determinado por ACV atribucional, e segundo escopo de aplicação do tipo 'berço ao portão'. Tendo em conta os avanços realizados por Souza et al. (2012), o produto em análise consiste de um biofilme manufaturado a partir de amido de mandioca.

As ações potenciais de melhoria foram propostas a partir de conceitos definidos pelo programa da Resource Efficiency and Cleaner Production (RECP), estabelecido pela United Nations Industrial Development Organization (UNIDO) em conjunto com o United Nations Environment Program (UNEP) (UNEP-UNIDO, 2010). Nessa pesquisa, os pontos focais identificados pelo RECP foram adaptados para a temática da análise. Assim, ações voltadas ao aumento da eficiência da produção e à gestão ambiental se converteram em propostas para substituição de determinadas substâncias, e vetores de modificação de processo. 
As especificação e modelagem dessas soluções obedeceram a certos requisitos e exigências complementares, como: (a) uso de tecnologias estabelecidas; (b) viabilidade de implementação; (c) potencial para redução simultânea de impactos em diferentes categorias; e, (d) preservação das propriedades originais do filme. Cada solução possível gerou um cenário específico para análise cujo impactos energéticos e ambientais foram verificados novamente a partir da ACV. Esses resultados foram avaliados em dois níveis: (i) comparação direta entre perfis de desempenho individuais de cada cenário, incluindo o cenário base (caracterizado pela cadeia de produção original); e, todas as vezes em que foi possível, (ii) combinação de cenários independentes, a fim de que se pudesse verificar efeitos dessa integração.

\subsection{Processamento de filme de amido de mandioca a partir da técnica de casting}

A mandioca (Manihot esculenta Crantz) é uma cultura perene e espessa. Sua parte mais valiosa é a raiz, composta tipicamente de $70 \% \mathrm{~m} / \mathrm{m}$ de água, $24 \% \mathrm{~m} / \mathrm{m}$ amido, 1,0\% $\mathrm{m} / \mathrm{m}$ proteína, 2,0\% $\mathrm{m} / \mathrm{m}$ fibra e $3,0 \% \mathrm{~m} / \mathrm{m}$ lipídios, minerais e açúcares (Sebrae Bahia, 2009). 0 Brasil produziu algo em torno de 22 milhões de toneladas de mandioca na safra de 2013. As regiões Centro-Sul do país respondem por cerca de $41 \%$ dessa produção, destacandose em escala econômica, com produtividades agrícolas entre $14-24 \mathrm{t} / \mathrm{ha}$ e ciclos de safra de 18 a 24 meses (IBGE, 2015). A preparação do solo requer intervenções mínimas e requer o uso de máquinas agrícolas. 0 cultivo compreende a adição de macronutrientes primários ( $\mathrm{N}, \mathrm{P}, \mathrm{K})$, além de cálcio (Ca) e magnésio (Mg), que são fornecidos sob a forma de calcário. A mandioca é resistente a pragas e doenças, mas sofre com a competição de culturas espontâneas (Fialho e Vieira, 2011).

O amido é extraído lavando-se as raízes, que antes disso devem ser descascadas, trituradas e desintegradas. Durante a operação, cianeto de hidrogênio (HCN) é removido por um processo de lavagem. A suspensão obtida após a lavagem deverá ser submetida a tratamentos sucessivos de filtração, peneiração e centrifugação para separar o amido de outros materiais solúveis. Ao longo do processo adiciona-se dióxido de enxofre $\left(\mathrm{SO}_{2}\right)$ na proporção de $0,05 \%$ p/p para inibir o crescimento microbiano. 0 amido é então seco, por exposição a ar quente ou flasheamento, finalizando assim o processo (Daniel et al., 2007). Para obter $1,0 \mathrm{~kg}$ de amido, serão necessários de 3,0 - 4,0 kg de raízes (Dischsen et al., 2012), além de 0,45 MJ de energia, dos quais 35\% são usados para fragmentar as raízes, e o restante na secagem do produto. As unidades de extração são em geral autossuficientes em termos energéticos, ao fazerem cogeração a partir da queima de biomassa originada da própria mandioca (Salla et al., 2010). 
O processo de casting do filme tem início a partir da preparação de uma solução polimérica contendo os componentes indicados na Tabela 1 (Souza et al., 2012). Neste caso, etanol e glicerina são de origem fóssil.

Tabela 3.1 - Formulação da solução de polímero para produzir 1,0 kg de filme (base seca)

\begin{tabular}{lc}
\hline \multicolumn{1}{c}{ Componente } & Quantidade (\%) \\
\hline amido de mandioca & 68,5 \\
glicerina $\left(\mathrm{C}_{3} \mathrm{H}_{8} \mathrm{O}_{3}\right)$ & 10,3 \\
Argila & 1,40 \\
etanol $\left(\mathrm{C}_{2} \mathrm{H}_{6} \mathrm{O}\right)$ & 19,8 \\
\hline
\end{tabular}

Fonte: adaptado de Souza et al. (2012)

A solução deve ser colocada de maneira contínua e uniforme em um molde liso e plano. A espessura é ajustada de acordo com a quantidade e a rapidez com que o líquido é derramado sobre o molde (Andreuccetti et al., 2012). 0 material é então seco por contato indireto com um elemento elétrico até a água quase totalmente evaporar.

\subsection{ACV da produção do filme pela técnica de casting}

\subsubsection{Requisito gerais para a definição de escopo}

0 estudo ocorreu aplicando a técnica de ACV em conformidade com a norma da ISO 14044 (ISO, 2006). O software SimaPro - versão 8.1.1.16 de PreConsultants® foi utilizado para calcular o inventário do ciclo de vida do processo e realizar a avaliação de impactos. 0 processo de definição do Fluxo de Referência (FR) a ser adotado pelo estudo baseou-se em informações fornecidas por Souza et al. (2012). Concluída essa avaliação, estabeleceu-se como FR 'manufaturar 1,0 t de biofilme à base de amido de mandioca com espessura média de 91,8 $\mu \mathrm{m}$, Resistência à tração de 3,96 MPa, Alongamento à ruptura de $124 \%$, Permeabilidade a vapor de água de 3,81 g. mm/( $\mathrm{m}^{2}$. d. kPa); e Permeabilidade ao $\mathrm{O}_{2}$ de $22,5 \mathrm{~cm}^{3} /($ m. d. Pa)'.

A Figura 3.1 mostra um diagrama da modelagem do ciclo de vida para o sistema. A produção agrícola de mandioca instalada na cidade de Assis (SP), foi considerada como sendo representativa da tecnologia atual praticada na região Centro-Sul para o cultivo. A produtividade agrícola média na região entre as safras 2005/2006 e 2013/2014 foi de 20 t/ha (CONAB, 2013). 
Figura 3.1 - Diagrama do Sistema de Produto em análise

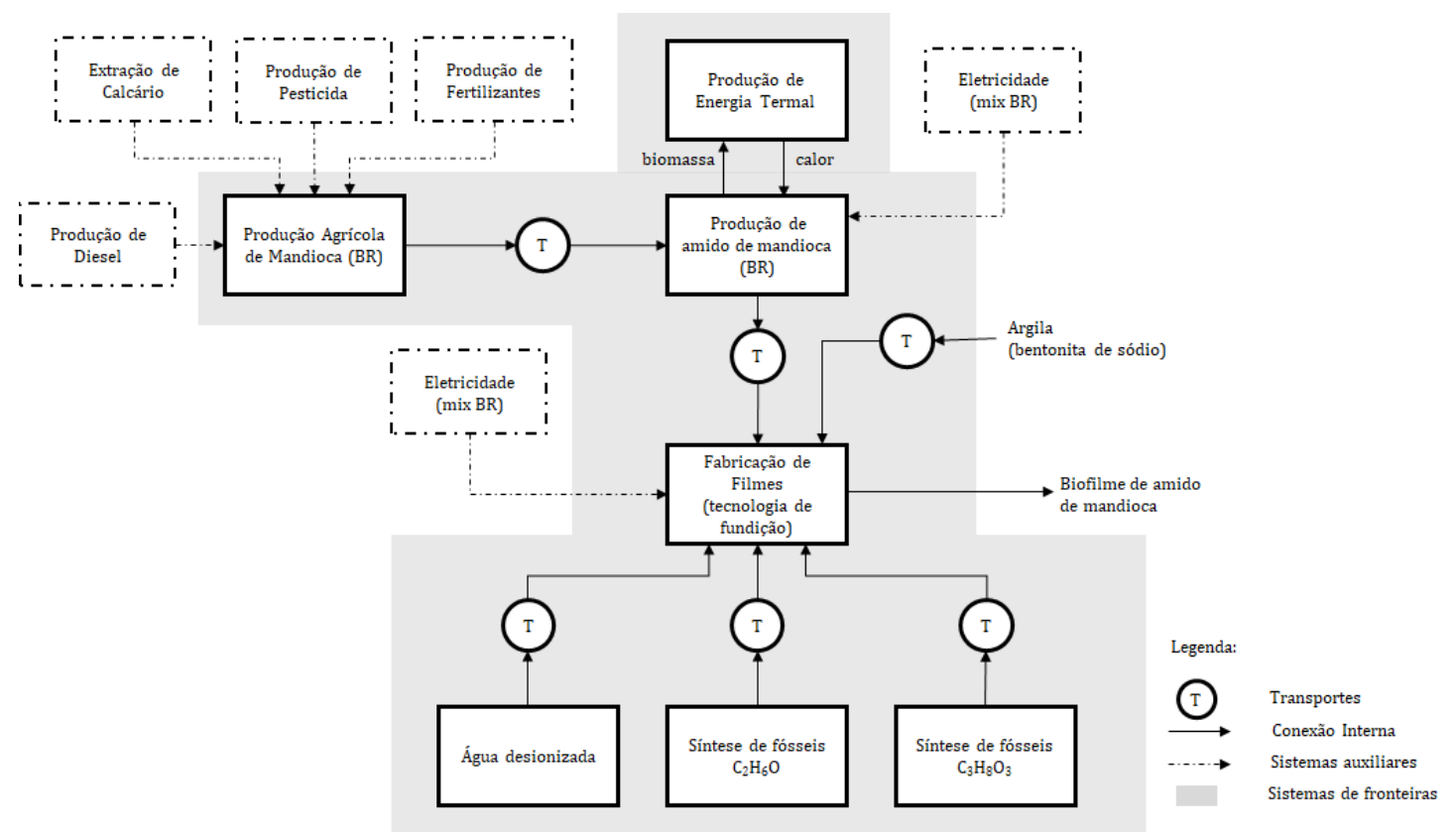

A extração de amido ocorre em uma unidade industrial localizada no município de Palmital (SP), distante $32 \mathrm{~km}$ das áreas de cultivo. Um caminhão com capacidade de carga entre 7,5 - 16 t é usado no transporte da mandioca para o local de processamento. 0 amido é obtido de acordo com a tecnologia descrita na Seção 3.3 e depois transportado para a capital São Paulo (a 404 km), também em veículo de médio porte, para produção de filmes. Quanto ao transporte de outros aditivos usados na formulação do filme, a argila é extraída na cidade de Valcheta (Argentina) e percorre $3300 \mathrm{~km}$ de trem até seu destino final. Etanol e a glicerina são adquiridos junto ao mercado brasileiro e considerou-se um deslocamento médio de $100 \mathrm{~km}$ por estrada em veículos de médio porte desde os locais de suas produções, até a unidade de processamento do filme.

\subsubsection{Premissas Específicas}

Além dos requisitos definidos na seção 3.4.1, foram também fixadas premissas específicas para realização desse estudo. As mais relevantes dentre estas são:

- Como a mandioca é cultivada na área há oito décadas (Normanha e Pereira, 1950), as emissões de $\mathrm{CO}_{2}$ originárias da transformação da terra associadas a essa atividade não foram consideradas. Pelas mesmas razões, os estoques de carbono da mandioca foram também considerados nulos; 
- As emissões de $\mathrm{CO}_{2}$ biogênico, bem como a captura de $\mathrm{CO}_{2}$ do ar, solo e biomassa não foram contabilizadas na quantificação de impactos de Mudanças Climáticas;

- Os agroquímicos usados no controle de pragas agem apenas superficialmente e não são retidos pela mandioca;

- As cargas ambientais associadas ao transporte de matérias-primas usadas no cultivo da mandioca não foram consideradas;

- As perdas líquidas derivadas da extração de amido foram modeladas como se essas fossem efluentes domésticos, dadas sua composição e características;

- O consumo de eletricidade para a produção de filme foi estimado a partir da potência nominal dos equipamentos utilizados, e da duração de cada uma das operações

\subsubsection{Inventário de Ciclo de Vida (ICV) - fontes e qualidade dos dados}

Os principais Inventários de Ciclo de Vida (ICVs) usados na modelagem dessa cadeia produtiva estão representados a seguir na Tabela 3.2. 0 ICV de produção de filmes fez uso de dados agregados da preparação da solução polimérica, casting, e da secagem. Como não existem unidades operando em escala econômica no Brasil, foram coletados dados primários a partir de dezessete experimentos de laboratório agrupados em quatro campanhas e realizados entre 2014 e 2015 no Laboratório de Engenharia de Alimentos do Departamento de Engenharia Química da Universidade de São Paulo.

As sínteses de etanol fóssil e glicerina, bem como a obtenção de água desionizada (Figura 3.1) foram modeladas a partir de dados secundários obtidos da base Ecoinvent v.2.2. Os conjuntos de dados brutos são: 'Ethanol from ethylene, at plant/RER U' (SUTTER, 2007), 'Glycerine, from epichlorohydrin, at plant/RER U' (JUNGBLUTH et al., 2007), and 'Water, deionized, at plant/CH U' (ALTHAUS et al., 2007).

Os dados que representam sistemas auxiliares foram também coletados junto ao Ecoinvent - v 2.2. Para descrever o processamento do calcário utilizou-se 'Limestone, milled, loose, at plant/CH $U^{\prime}$, e para os fertilizantes foram empregados, respectivamente 'Urea, as $N$, at regional storehouse/RER $U$ ', 'Single superphosphate, as $P_{2} O_{5}$, at regional storehouse/RER $U$ ' e 'Potassium chloride, as $K_{2} O$, at regional storehouse/RER $U$ ', os quais estão, todos eles, descritos em Althaus et al., (2007).

Algumas adaptações foram realizadas no caso específico dos agroquímicos: as produções de ametrina, clomazona, fluazifop-P-butil e metribuzina foram representadas, respectivamente, pelos ICVs 'Pyretroid-compounds, at regional storehouse/RER U', 'Cyclic 
$N$-compounds, at regional storehouse/RER U', 'Diphenylether-compounds, at regional storehouse/RER $U$ ' e 'Triazine-compounds, at regional storehouse/RER U'(ALTHAUS et al., 2007). Por outro lado, o conjunto de dados geral 'Herbicides, at regional storehouse/RER U' (ALTHAUS et al., 2007) foi adotado para efeito de descrição das fases de produção de cletodim e isoxaflutol. Além disso, o refino de petróleo bruto para produção de diesel foi modelado a partir de 'Diesel, at refinery/l/ US' (NREL, 2003).

Para a modelagem desses ICVs, assumiu-se que as tecnologias consideradas nos conjuntos de dados Ecoinvent seriam semelhantes às praticadas no Brasil para obter os mesmos bens de produção e consumo. Consequentemente, rendimentos e seletividades dos processos seriam idênticos para ambos os casos, bem como as emissões para o ar, a água e geração de rejeitos sólidos. Portanto, todas as suposições feitas por Ecoinvent na elaboração de seus ICVs permaneceram também aplicáveis no caso do estudo. Talvez a principal adaptação desses ICVs às condições locais ocorreu a partir da substituição das matrizes de energia elétrica originais de cada conjunto por dados do ICV ‘Electricity, from Brazilian grid / $B R U$ ', o qual foi produzido a partir de 'Electricity, production mix $B R / B R$ $U^{\prime}$, que, de sua parte, aglutina parâmetros típicos da matriz energética brasileira de 2012 (HANSEN et al., 2015).

O ICV da produção de amido de mandioca foi baseado em dados primários. Os consumos de matéria e energia foram coletados junto a um fabricante, e representam o desempenho operacional médio do período 2013-2014. Os fluxos de matéria e energia para o ICV do processamento agrícola derivam de dados secundários obtidos a partir de recomendações técnicas e coeficientes de desempenho para o cultivo de mandioca no Brasil (FERREIRA FILHO et al., 2013; ROMANELLI E MILAN, 2010; SALLA et al., 2010). A quantidade de energia associada ao diesel refere-se ao consumo agregado necessário para operar máquinas agrícolas. As emissões para o ar de amônia $\left(\mathrm{NH}_{3}\right)$ e óxido nitroso $\left(\mathrm{N}_{2} \mathrm{O}\right)$, bem como as perdas de nitratos $\left(\mathrm{NO}_{3}{ }^{-}\right)$para a água foram determinadas de acordo com abordagem metodológica descrita em Nemecek et al., (2014). A lixiviação de fósforo (P) em as águas subterrâneas e o escoamento de fosfato $\left(\mathrm{PO}_{4}^{3-}\right)$ para as águas superficiais foram estimados com o modelo sugerido em Nemecek e Schnetzer (2011). A cobertura tecnológica para a produção do biofilme incluiu condições e parâmetros descritos na Seção 3.3. Foram incluídas todas as correntes que superassem em, no mínimo, 5,0\% as contribuições cumulativamente de entrada e saída de matéria e energia do sistema em análise. Conforme arbitra a ISO 14044 (ISO, 2006), exceções a essa diretriz foram abertas para emissões com relevante significado ambiental, e para argila (bentonita de sódio), as quais foram mantidas dada sua importância na fabricação dos filmes (CYRAS et al., 2008; TANG et al., 2008). 
Tabela 3.2 - Cargas ambientais principais referentes à produção de filmes de amido de mandioca pela técnica de casting

\begin{tabular}{|c|c|c|c|c|}
\hline Estágio da cadeia de produção & Unidade & $\begin{array}{c}\text { Produção } \\
\text { Agrícola de } \\
\text { Mandioca }\end{array}$ & $\begin{array}{l}\text { Obtenção de } \\
\text { amido }\end{array}$ & $\begin{array}{l}\text { Fabricação do } \\
\text { Filme }\end{array}$ \\
\hline \multicolumn{5}{|c|}{ Produtos } \\
\hline Mandioca, na fazenda & $\mathrm{t}$ & 1,00 & & \\
\hline Amido, na fábrica & $\mathrm{t}$ & & 1,00 & \\
\hline Filme de mandioca, na fábrica & $\mathrm{t}$ & & & 1,00 \\
\hline \multicolumn{5}{|c|}{ Entradas } \\
\hline \multicolumn{5}{|c|}{ Recursos Naturais } \\
\hline Argila, em minério & $\mathrm{kg}$ & & & 15.9 \\
\hline Ocupação, arável & $m^{2} a$ & 680 & & \\
\hline Transformação, das pastagens & $\mathrm{m}^{2}$ & 255 & & \\
\hline Transformação, do arável & $m^{2}$ & 245 & & \\
\hline Transformação, para o arável & $\mathrm{m}^{2}$ & 250 & & \\
\hline \multicolumn{5}{|c|}{ Recursos de Materiais Antropogênicos } \\
\hline Calcário & $\mathrm{kg}$ & 250 & & \\
\hline Cloreto de potássio $(\mathrm{KCl})$, como $\mathrm{K}_{2} \mathrm{O}$ & $\mathrm{kg}$ & 4,15 & & \\
\hline Superfosfato único (SSP), como $\mathrm{P}_{2} \mathrm{O}_{5}$ & $\mathrm{~kg}$ & 22,2 & & \\
\hline Uréia, como $\mathrm{N}$ & $\mathrm{kg}$ & 3,35 & & \\
\hline $\mathrm{ZnS}$ & $\mathrm{kg}$ & 1,00 & & \\
\hline Ametrina, como compostos piretróides & $\mathrm{kg}$ & $1,00 \mathrm{E}-01$ & & \\
\hline Cletodime, como Herbicidas & $\mathrm{kg}$ & $4,80 \mathrm{E}-03$ & & \\
\hline Clomazona, como compostos $\mathrm{N}$ cíclicos & $\mathrm{kg}$ & $4,05 \mathrm{E}-02$ & & \\
\hline $\begin{array}{l}\text { Fluazifope-P-butilo, como compostos de éter } \\
\text { difenílico }\end{array}$ & $\mathrm{kg}$ & 1,41E-03 & & \\
\hline Isoxaflutol, como Herbicidas & $\mathrm{kg}$ & $4,22 \mathrm{E}-03$ & & \\
\hline Metribuzina, como compostos de triazina & $\mathrm{kg}$ & $2,10 \mathrm{E}-02$ & & \\
\hline Mandioca, na fazenda & $\mathrm{kg}$ & & 3920 & \\
\hline Água da torneira, na fábrica & $\mathrm{m}^{3}$ & & 11.0 & \\
\hline Amido de mandioca, na fábrica & $\mathrm{kg}$ & & & 794 \\
\hline Água deionizada, na fábrica & $\mathrm{L}$ & & & 14944 \\
\hline Etanol $\left(\mathrm{C}_{2} \mathrm{H}_{6} \mathrm{O}\right)$ de etileno, na fábrica & $\mathrm{kg}$ & & & 230 \\
\hline Glicerina $\left(\mathrm{C}_{3} \mathrm{H}_{8} \mathrm{O}_{3}\right)$ de epicloridrina, na fábrica & $\mathrm{kg}$ & & & 119 \\
\hline \multicolumn{5}{|c|}{ Recursos de Energia Atropogênica } \\
\hline Diesel & MJ & 219 & & \\
\hline Eletricidade, da rede brasileira & $\mathrm{kWh}$ & & 10,1 & 11566 \\
\hline Calor, biomassa de mandioca, na fornalha & MJ & & 412 & \\
\hline \multicolumn{5}{|c|}{ Transportes } \\
\hline Transporte, frete, trem & t.km & & & 52,4 \\
\hline Transporte, caminhão (carga: 7,5-16t) & t.km & & 125 & 355 \\
\hline \multicolumn{5}{|c|}{ Saídas } \\
\hline \multicolumn{5}{|c|}{ Emissões no $\mathrm{Ar}$} \\
\hline $\mathrm{CO}_{2}$, fóssil & $\mathrm{kg}$ & 4,52 & & \\
\hline $\mathrm{C}_{2} \mathrm{H}_{6} \mathrm{O}$ & $\mathrm{kg}$ & & & 230 \\
\hline $\mathrm{H}_{2} \mathrm{O}$ & $\mathrm{L}$ & & & 14873 \\
\hline $\mathrm{NH}_{3}$ & $\mathrm{~kg}$ & 1,21 & & \\
\hline $\mathrm{N}_{2} \mathrm{O}$ & $\mathrm{kg}$ & $1,65 \mathrm{E}-01$ & & \\
\hline NOx & $\mathrm{kg}$ & $3,46 \mathrm{E}-02$ & & \\
\hline \multicolumn{5}{|c|}{ Emissões na Água } \\
\hline $\mathrm{NO}_{3}{ }^{-}$(lençóis freáticos) & $\mathrm{kg}$ & 486 & & \\
\hline $\mathrm{P}$ (river) & $\mathrm{kg}$ & $1,94 \mathrm{E}-01$ & & \\
\hline $\mathrm{PO}_{4}^{3-}$ (lençóis freáticos) & $\mathrm{kg}$ & $2,39 \mathrm{E}-01$ & & \\
\hline $\mathrm{PO}_{4}^{3-}$ (rio) & $\mathrm{kg}$ & 1,13 & & \\
\hline \multicolumn{5}{|c|}{ Emissões no Solo } \\
\hline Ametrina & $\mathrm{kg}$ & $1,00 \mathrm{E}-01$ & & \\
\hline Clomazona & $\mathrm{kg}$ & $4,05 \mathrm{E}-02$ & & \\
\hline Cletodime & $\mathrm{kg}$ & $4,80 \mathrm{E}-03$ & & \\
\hline Fluazifope-P-butilo & $\mathrm{kg}$ & $1,41 \mathrm{E}-03$ & & \\
\hline Isoxaflutol & $\mathrm{kg}$ & $4,22 \mathrm{E}-03$ & & \\
\hline Metribuzina & $\mathrm{kg}$ & $2,10 \mathrm{E}-02$ & & \\
\hline \multicolumn{5}{|c|}{ Resíduos para tratamento } \\
\hline Efluente, para tratamento de esgoto & $\mathrm{m}^{3}$ & & 13,9 & \\
\hline
\end{tabular}


Finalmente, para representar as cargas ambientais associadas ao tratamento dos efluentes gerados durante a produção de amido, selecionou-se o ICV 'Treatment, potato starch production effluent, wastewater treatment, class 2 / CH U' também de Ecoinvent. Em relação à tecnologia, o arranjo é composto por um tratamento estruturado em três etapas: mecânico, biológico - incluindo a digestão do sólido dissolvido por lodo ativado - e químico, para remoção de cor, gomas e coloides antes do descarte final (DOKA, 2009). Esse ICV foi selecionado por conta de a tecnologia de lodos ativados ser uma alternativa frequente para o tratamento de esgoto doméstico no Brasil (IBGE, 2010). Os ajustes feitos nesse inventário com o propósito de adaptá-lo para a condição brasileira ficaram restritos mais uma vez a inclusão da matriz energética brasileira de 2012 (HANSEN et al., 2015).

\subsubsection{Avaliação de Impacto do Ciclo de Vida (AICV)}

A fase de Avaliação de Impacto do Ciclo de Vida (AICV) compreende a coleta de resultados de indicadores para diferentes categorias de impacto, que juntos definem o Perfil de Impacto do Sistema do Produto em análise (ISO, 2006). Tal como mencionado antes a AICV foi aplicada em dois níveis. 0 primeira quantificou o consumo de recursos energéticos em termos de Demanda de Energia Primária (DEP) para processar o filme de biopolímero à base de amido de mandioca. 0 resultado dessa estimativa foi denominado Perfil Energético do biofilme de amido de mandioca.

O método Cumulative Energy Demand (CED) - v 1.09 (FRISCHKNECHT et al., 2007a) foi selecionado para expressar contribuições individuais de diferentes fontes não renováveis (fósseis: NRF; nuclear: NRN; e biomassa: NRB) e renováveis (biomassa: RB; eólica: RWD; e hídrica: RWA). O segundo nível da AICV calculou os efeitos ambientais das emissões e ocupação do solo na cadeia produtiva. Nesse caso, o método ReCiPe Midpoint (H) v 1.12 (GOEDKOOP et al., 2013) foi adotado para as categorias de impacto de Mudança Climática (CC), Acidificação Terrestre (AT), Formação de Oxidantes Fotoquímicos (POF), Eutrofização de Água Doce ( FEu), Ocupação de Terras Agrícolas (ALO) e Ecotoxicidade Terrestre (TEc). 0 ReCiPe foi selecionado após um levantamento da literatura existente, uma vez que não existem métodos específicos de AICV para as condições brasileiras (SILVA et al., 2015). Hauschild et al. (2013) destacam que essa abordagem adota modelos de caracterização de nível médio robustos e consistentes para verificar o impacto em termos de CC (FORSTER et al., 2007), POF (VAN ZELM et al., 2008) e FEu (STRUIJS et al., 2009). 


\subsection{Desempenho Ambiental e Energético da manufatura de biofilme}

\subsubsection{Perfil Energético}

A tabela 3.3 traz o perfil energético da produção de filmes de amido de mandioca. Os resultados indicam um consumo total de energia de $152 \mathrm{GJ} / \mathrm{FR}$. As contribuições mais significativas foram em termos de NRF, RB e RWA, que juntas somam 145 GJ/FR. A NRF concentra-se no consumo de petróleo e gás natural. A participação do gás natural se dá em $50 \%$ ( $\left.220 \mathrm{~m}^{3} / \mathrm{FR}\right)$ na forma de fonte integrante do grid elétrica brasileira - 7,9\% em 2012 (EPE, 2013). Além disso, o insumo é usado durante os processamentos de glicerina (21\%) e etanol (23\%). No caso da $\mathrm{C}_{3} \mathrm{H}_{8} \mathrm{O}_{3}$, cerca de $29 \mathrm{~m}^{3} / \mathrm{FR}$ são consumidos durante a síntese do propileno, um dos precursores da epicloridrina. Para obter etanol fóssil, são necessários outros $82 \mathrm{~m}^{3} / \mathrm{FR}$ de gás natural, que servem de insumo na síntese de $\mathrm{C}_{2} \mathrm{H}_{4}$, um produto intermediário dessa cadeia de produção.

0 consumo total de petróleo bruto pelo sistema é de $366 \mathrm{~kg} / \mathrm{FR}$. A geração de eletricidade e as sínteses de $\mathrm{C}_{3} \mathrm{H}_{8} \mathrm{O}_{3}$ e $\mathrm{C}_{2} \mathrm{H}_{6} \mathrm{O}$ representam $25 \%, 18 \%$ e $38 \%$ daquele total. Outros $17 \%$ servem a operação de máquinas agrícolas para processamento de mandioca. Os impactos associados ao consumo de eletricidade recaem em sua maioria parte sobre produção de biofilme por casting, em particular nas operações de agitação, aquecimento e secagem, e representam 11,6 MWh/FR (Tabela 3.2).

Tabela 3.3 - DEP para a produção de 1,0 t de filme de amido de mandioca (valores em MJ)

\begin{tabular}{llllllll}
\hline $\begin{array}{l}\text { Categoria } \\
\text { de Impacto }\end{array}$ & Total & $\begin{array}{l}\text { Produção } \\
\text { Agrícola de } \\
\text { Mandioca }\end{array}$ & $\begin{array}{l}\text { Produção de } \\
\text { Amido de } \\
\text { Mandioca }\end{array}$ & $\begin{array}{l}\text { Fabricação } \\
\text { de Filme }\end{array}$ & $\begin{array}{l}\text { Síntese de } \\
\text { Glicerina }\end{array}$ & $\begin{array}{l}\text { Síntese de } \\
\text { Etanol }\end{array}$ & Transporte \\
\hline NRF & 39127 & 2804 & 37,8 & 16375 & 7990 & 10448 & 1473 \\
NRN & 6711 & 78,8 & 64,0 & 4649 & 1566 & 254 & 98,1 \\
NRB & $1.95 \mathrm{E}-02$ & $1,80 \mathrm{E}-03$ & $1,10 \mathrm{E}-05$ & $8,71 \mathrm{E}-03$ & $3,18 \mathrm{E}-03$ & $5,79 \mathrm{E}-03$ & $3,91 \mathrm{E}-05$ \\
RB & 57014 & 53578 & 533 & 2794 & 85,4 & 19.4 & 2,97 \\
RWD & 40,1 & $6,24 \mathrm{E}-01$ & $1,94 \mathrm{E}-01$ & 10,4 & 26,6 & $5,17 \mathrm{E}-01$ & 1,81 \\
RWA & 49107 & 497 & 48,5 & 47960 & 541 & 49,3 & 11,2 \\
\hline
\end{tabular}

Os impactos da RB estão associados aos Poderes Caloríficos Superiores (PCSs) das biomassas de mandioca e cana-de-açúcar, este último integrando o sistema via grid elétrica brasileiro (6,8\% em 2012), e se manifestando principalmente na fabricação de biofilme. A concentração de impactos da RWA, nesta etapa do ciclo de vida (98\%), devese igualmente à rede brasileira, composta à época do estudo por $77 \%$ de hidreletricidade. 


\subsubsection{Perfil dos Impactos associados a emissões}

A Tabela 3.4 mostra os resultados gerais do Perfil de Impactos que se originam a partir de emissões que ocorreram durante a produção de 1,0 t filme. A Figura 3.2 ilustra as contribuições relativas para cada uma das categorias selecionadas para essa etapa do estudo, estratificadas por estágio da cadeia de produção. 0 cultivo de mandioca, e a natureza energo-intensiva do processo se destacam de outros estágios e transformações do arranjo, com contribuições que variam entre 7,0 - 95\% e 3,4-73\%, respectivamente.

Tabela 3.4 - Perfil de Impactos derivados de emissões da produção de 1,0 t de filme de amido de mandioca

\begin{tabular}{lll}
\hline Categorias de Impacto & Unidades $(/ \mathrm{RF})$ & Quantidade \\
\hline $\mathrm{CC}$ & $\mathrm{kg} \mathrm{CO}_{2 \mathrm{eq}}$ & 4310 \\
$\mathrm{TA}$ & $\mathrm{kg} \mathrm{SO}_{2 \mathrm{eq}}$ & 17,3 \\
Feu & $\mathrm{kg} \mathrm{P}$ eq & 2,56 \\
POF & $\mathrm{kg} \mathrm{NMVOC}$ & 7,76 \\
Tec & $\mathrm{kg} \mathrm{1,4-DB}$ eq & 11,2 \\
ALO & $\mathrm{m}^{2} \mathrm{a}$ & 2232 \\
\hline
\end{tabular}

Os dados apresentados na Figura 3.2 mostram que as contribuições da síntese de glicerina, que variam de 7,0 a $12 \%$ entre as categorias de impacto, superam aquelas relativas aos processamentos de etanol. A exceção fica por conta de POF. Esses produtos químicos não contribuíram para o TEc ou ALO. 0 transporte afeta o CC, TA e POF, no qual aparece sua contribuição mais significante em termos relativos (11\%).

Os impactos causados em termos de CC nascem de emissões atmosféricas de $\mathrm{CO}_{2}$ fóssil $\left(\mathrm{CO}_{2, \mathrm{f}}\right), \mathrm{CO}_{2}$ da transformação da terra $\left(\mathrm{CO}_{2, \mathrm{LT}}\right)$, de metano biogênico $\left(\mathrm{CH}_{4, \mathrm{~b}}\right)$ e $\mathrm{N}_{2} \mathrm{O}$, cujas contribuições representam 45\%, 31\%, 13 \% e 4,1\%, respectivamente. As principais emissões de $\mathrm{CO}_{2, \mathrm{f}}$ procedem da queima de gás natural para geração eletricidade $(1,18 \mathrm{t} /$ FR). A síntese de $\mathrm{C}_{3} \mathrm{H}_{8} \mathrm{O}_{3}$ contribui com $391 \mathrm{~kg} / \mathrm{FR}$ (produção de epicloridrina e energia térmica) e o processamento de $\mathrm{C}_{2} \mathrm{H}_{6} \mathrm{O}$ aporta $237 \mathrm{~kg} / \mathrm{FR}$ (obtenção de $\mathrm{C}_{2} \mathrm{H}_{4} \mathrm{e}$, mais uma vez, geração de calor). Além disso, os transportes acumulam $121 \mathrm{~kg} \mathrm{CO}_{2, \mathrm{f}} / \mathrm{FR}$, e o cultivo de mandioca outros 34 kg/FR (via manufaturas de SSP, ureia e agroquímicos e operações agrícolas). 
As emissões de $\mathrm{CO}_{2, \mathrm{LT}}(1,34$ t/FR) advém da digestão anaeróbica de biomassa que está submersa nos reservatórios hidrelétricos, fenômeno que também produz outros 25 $\mathrm{kg} \mathrm{CH}_{4, \mathrm{~b}} / \mathrm{FR}$. As perdas de $\mathrm{N}_{2} \mathrm{O}$ (588 g/FR) são provenientes do uso da ureia no cultivo da mandioca e do transporte de eletricidade.

Figura 3.2 - Contribuições relativas de cada estágio da produção de biofilme por categoria de impacto

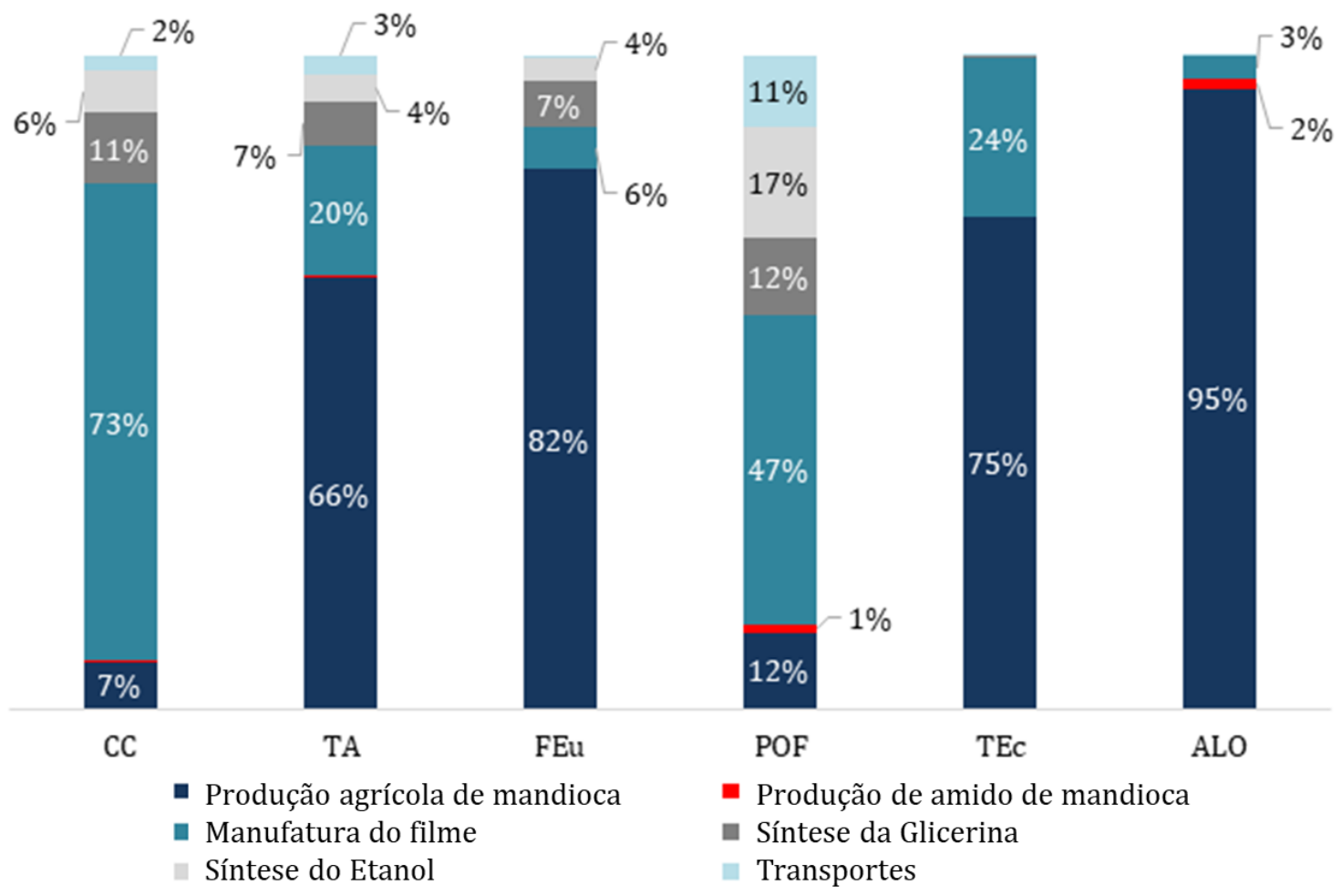

As emissões gasosas de $\mathrm{NH}_{3}$ (53\%), $\mathrm{SO}_{2}(30 \%)$ e $\mathrm{NO}_{\mathrm{x}}(14 \%)$ constituem-se nos principais agentes da AT. As perdas de $\mathrm{NH}_{3}(3,70 \mathrm{~kg} / \mathrm{FR})$ ocorrem desde o uso de ureia em culturas de mandioca. As contribuições termoelétricas à rede brasileira acumulam as maiores emissões de $\mathrm{SO}_{2}(2,42 \mathrm{~kg} / \mathrm{FR})$ devido à queima de petróleo e gás natural. Há também perdas de óxido de enxofre durante o processamento de $\mathrm{C}_{3} \mathrm{H}_{8} \mathrm{O}_{3}(514 \mathrm{~g} / \mathrm{FR}$ : via epicloroidrina), $\mathrm{C}_{2} \mathrm{H}_{6} \mathrm{O}$ (321 g/FR: síntese de $\mathrm{C}_{2} \mathrm{H}_{4}$ ) e culturas de mandioca (produção de 786g/FR: SSP).

As liberações de $\mathrm{NO}_{\mathrm{x}(\mathrm{g})}$ ocorrem nos mesmos estágios do processo que as de $\mathrm{SO}_{2}$ ou seja, na geração de eletricidade (1,82 kg/FR: queima de óleo pesado e gás natural); processamento de $\mathrm{C}_{3} \mathrm{H}_{8} \mathrm{O}_{3}$ (370 g/FR síntese de cloreto de alilo e epicloridrina) e $\mathrm{C}_{2} \mathrm{H}_{6} \mathrm{O}$ (326 g/FR: síntese de $\mathrm{C}_{2} \mathrm{H}_{4}$ ); mandioca (232 g/FR: dosagem de ureia) e operações de transporte $(1,13 \mathrm{~kg} / \mathrm{FR})$. 
Os impactos de $\mathrm{FEu}$ estão relacionados às perdas de $\mathrm{P}$ na água de superfície (24\%) e $\mathrm{PO}_{4}^{3-}$ em água superficiais (52\%) e subterrâneas (24\%). Esses lançamentos ocorreram na produção de SSP ( $305 \mathrm{gPO}_{4}^{3-} / \mathrm{FR}$ ) e em sua aplicação junto aos cultivos de mandioca (3,9 $\mathrm{kgPO}_{4}^{3-} / \mathrm{FR}$ e $605 \mathrm{~g} \mathrm{P} / \mathrm{FR}$ ), e durante a geração de energia (963 $\mathrm{gPO}_{4}^{3-} / \mathrm{FR}$ ). A parcela atribuída à rede brasileira se origina do descarte da ganga da mineração de linhito, que, juntamente com os carvões betuminosos e sub-betuminosos, compreendem a mistura de recurso natural importado pelo país para uso em usinas termelétricas (EPE, 2007). Cerca de 57\% dos impactos da produção de biofilme na forma de POF advém de emissões de $\mathrm{NO}_{\mathrm{x}(\mathrm{g})}$. Outros $10 \%$ resultam de emissões de monóxido de carbono biogênico $\left(\mathrm{CO}_{\mathrm{b}}: 17 \mathrm{~kg} / \mathrm{FR}\right)$, atribuíveis à rede brasileira devido à queima da cana-de-açúcar. As perdas de compostos orgânicos voláteis não metânicos (NMVOC), responsáveis por 14\% dos impactos da categoria, também são derivadas da geração de eletricidade (465 g/FR: queima de petróleo e gás natural) e das fabricações de $\mathrm{C}_{3} \mathrm{H}_{8} \mathrm{O}_{3}$ (108 g/FR: via síntese de cloreto de alilo) e $\mathrm{C}_{2} \mathrm{H}_{6} \mathrm{O}$ (305 g/FR: síntese de $\mathrm{C}_{2} \mathrm{H}_{4}$ ). 0 processamento de etanol emite outros 286 g de $\mathrm{C}_{2} \mathrm{H}_{4} / \mathrm{FR}$, que correspondem a 6,3\% dos impactos para a categoria.

Os impactos da TEc podem ser atribuídos às emissões no solo de ametrina (311 g /FR) e isoxaflutol (13 g/FR). A parcela correspondente à produção de biofilme vem da rede brasileira de 2012, devido à energia derivada da biomassa. Nesse caso, os pesticidas utilizados no controle de pragas da cana-de-açúcar (CAVALETT et al., 2012) representam uma perda acumulada no solo de $20 \mathrm{~g} / \mathrm{FR}$.

O cultivo da mandioca ocupa $2116 \mathrm{~m}^{2} \mathrm{a} / \mathrm{FR}$ de solo agrícola, que representam em termos relativos $95 \%$ dos impactos de ALO. A esse total devem ser adicionados outros $78 \mathrm{~m}^{2} \mathrm{a} / \mathrm{FR}$ de formação de lagos das hidrelétricas. Esse resultado foi determinado para os horizontes temporais de uso da terra estabelecidos para cada projeto antropogênico: 18 meses para o cultivo de mandioca (SALLA et al., 2010) e 100 anos para a operação de sistemas hidrelétricos (SILVA et al., 2013).

\subsection{Discussão}

A Tabela 3.5 resume os principais focos de impacto que foram identificados pela ACV ao analisar os desempenhos ambiental e energético do processamento de biofilme. A produção industrial inclui as sínteses de glicerina fóssil e etanol, bem como a fabricação do filme per se. Esses efeitos são causados em sua maior parte, por eletricidade e energia térmica. A produção agrícola também se reverte em impactos relevantes em termos de TEc e ALO. 
Tabela 3.5 - Focos de impacto associados a produção de filmes de amido de mandioca

\begin{tabular}{|c|c|c|}
\hline $\begin{array}{l}\text { Categoria de } \\
\text { Impacto }\end{array}$ & Foco & Processo \\
\hline \multicolumn{3}{|c|}{ Perfil Energético } \\
\hline $\begin{array}{l}\text { Não renovável, } \\
\text { fóssil }\end{array}$ & $\begin{array}{l}\text { Combustível para máquinas agrícolas e } \\
\text { Consumo de Eletricidade }\end{array}$ & $\begin{array}{l}\text { Produção de Mandioca; Fabricação de } \\
\text { filmes }\end{array}$ \\
\hline Biomassa renovável & Valor Energético Bruto da Mandioca & Produção de Mandioca \\
\hline Água renovável & Consumo de eletricidade & $\begin{array}{l}\text { Produção de Mandioca; Síntese de } \\
\text { Glicerina; Fabricação de filmes }\end{array}$ \\
\hline \multicolumn{3}{|c|}{ Perfil dos Impactos de Emissões } \\
\hline \multirow[t]{5}{*}{$\mathrm{CC}$} & $\begin{array}{l}\text { emissões atmosféricas de } \mathrm{CO}_{2, \mathrm{f}, \text {, da }} \\
\text { produção de calor }\end{array}$ & $\begin{array}{l}\text { Produção de bens agrícolas, Sínteses de } \\
\text { Glicerina e Etanol, e Transportes }\end{array}$ \\
\hline & $\begin{array}{l}\text { emissões atmosféricas de } \mathrm{CO}_{2, \mathrm{lt}} \text {, da } \\
\text { geração de eletricidade }\end{array}$ & $\begin{array}{l}\text { Produção de bens agrícolas e Fabricação } \\
\text { de filmes }\end{array}$ \\
\hline & $\begin{array}{l}\text { emissões atmosféricas de } \mathrm{CO}_{2, \mathrm{f}, \mathrm{d}} \text { da } \\
\text { geração de eletricidade }\end{array}$ & $\begin{array}{l}\text { Produção de bens agrícolas e Fabricação } \\
\text { de filmes }\end{array}$ \\
\hline & $\begin{array}{l}\text { emissões atmosféricas de } \mathrm{CH}_{4, \mathrm{~b}, \text {, da }} \\
\text { geração de eletricidade }\end{array}$ & $\begin{array}{l}\text { Produção de bens agrícolas e Fabricação } \\
\text { de filmes }\end{array}$ \\
\hline & $\begin{array}{l}\text { emissões atmosféricas de } \mathrm{N}_{2} \mathrm{O} \text {, da } \\
\text { nitrificação de ureia }\end{array}$ & Produção de mandioca \\
\hline \multirow[t]{4}{*}{ TA } & $\begin{array}{l}\text { emissões atmosféricas de } \mathrm{NH}_{3} \text {, da } \\
\text { nitrificação de ureia }\end{array}$ & Produção de mandioca \\
\hline & $\begin{array}{l}\text { emissões atmosféricas de } \mathrm{SO}_{2} \text {, de geração } \\
\text { de eletricidade }\end{array}$ & $\begin{array}{l}\text { Produção de bens agrícolas, Sínteses de } \\
\text { Glicerina e Fabricação de filmes }\end{array}$ \\
\hline & $\begin{array}{l}\text { emissões atmosféricas de } \mathrm{SO}_{\mathrm{x}}, \mathrm{da} \\
\text { produção de SSP }\end{array}$ & Produção de mandioca \\
\hline & $\begin{array}{l}\text { emissões atmosféricas de } \mathrm{NO}_{\mathrm{x},} \text { da geração } \\
\text { de eletricidade }\end{array}$ & $\begin{array}{l}\text { Produção de bens agrícolas, Sínteses de } \\
\text { Glicerina e Fabricação de filmes }\end{array}$ \\
\hline \multirow[t]{3}{*}{$\mathrm{FEu}$} & $\begin{array}{l}\text { P, para os lençóis freáticos, da produção e } \\
\text { uso de SSP }\end{array}$ & Produção de mandioca \\
\hline & $\begin{array}{l}\mathrm{PO}_{4}^{3-} \text {, para água da superfície, da } \\
\text { produção e uso de SSP }\end{array}$ & Produção de mandioca \\
\hline & $\begin{array}{l}\mathrm{NO}_{3}-\text {, para água da superfície, do uso de } \\
\text { ureia }\end{array}$ & Produção de mandioca \\
\hline \multirow[t]{7}{*}{ POF } & $\begin{array}{l}\text { emissões atmosféricas de } \mathrm{NO}_{\mathrm{x}} \text { da geração } \\
\text { de eletricidade }\end{array}$ & $\begin{array}{l}\text { Produção de bens agrícolas, Sínteses de } \\
\text { Glicerina e Fabricação de filmes }\end{array}$ \\
\hline & $\begin{array}{l}\text { emissões atmosféricas de } \mathrm{NO}_{\mathrm{x}, \text {, produção }} \\
\text { de calor }\end{array}$ & Sínteses de Glicerina e Etanol \\
\hline & $\begin{array}{l}\text { emissões atmosféricas de NMVOC, da } \\
\text { geração de eletricidade e produção } \\
\text { industrial }\end{array}$ & $\begin{array}{l}\text { Produção de bens agrícolas, Sínteses de } \\
\text { Glicerina e Etanol, e Fabricação de filmes }\end{array}$ \\
\hline & $\begin{array}{l}\text { emissões atmosféricas de CO biogênico, da } \\
\text { geração de eletricidade }\end{array}$ & $\begin{array}{l}\text { Produção de bens agrícolas, Sínteses de } \\
\text { Glicerina e Fabricação de filmes }\end{array}$ \\
\hline & $\begin{array}{l}\text { emissões atmosféricas de } \mathrm{SO}_{\mathrm{x}} \text {, da } \\
\text { produção de SSP }\end{array}$ & Produção de mandioca \\
\hline & $\begin{array}{l}\text { emissões atmosféricas de } \mathrm{SO}_{2} \text {, da geração } \\
\text { de eletricidade }\end{array}$ & $\begin{array}{l}\text { Produção de bens agrícolas, Sínteses de } \\
\text { Glicerina e Fabricação de filmes }\end{array}$ \\
\hline & $\begin{array}{l}\text { emissões atmosféricas de } \mathrm{NH}_{3} \text {, da } \\
\text { nitrificação de ureia }\end{array}$ & Produção de mandioca \\
\hline \multirow[t]{2}{*}{ TEc } & $\begin{array}{l}\text { Perdas de pesticidas, emissões no solo, } \\
\text { preparação do solo }\end{array}$ & Produção de mandioca \\
\hline & $\begin{array}{l}\text { Perdas de pesticidas, emissões no solo, } \\
\text { geração de eletricidade }\end{array}$ & $\begin{array}{l}\text { Produção de bens agrícolas, Sínteses de } \\
\text { Glicerina e Etanol, e Fabricação de filmes }\end{array}$ \\
\hline \multirow[t]{2}{*}{ ALO } & Uso da terra, agricultura & Produção de mandioca \\
\hline & Uso da terra, geração de eletricidade & $\begin{array}{l}\text { Produção de bens agrícolas, Sínteses de } \\
\text { Glicerina e Etanol, e Fabricação de filmes }\end{array}$ \\
\hline
\end{tabular}


Os resultados mostram tendências semelhantes aos da literatura para os casos em que se verificou o desempenho ambiental de outros bioplásticos. Isso ocorreu com Álvarez-Chávez et al. (2012) que avaliaram, via ACV, diferentes materiais - incluindo amido termoplástico puro (PTS) -, elaborados usando ativos agrícolas como milho, arroz, mandioca, batata e trigo. Os autores notaram que a opção por processamentos agrícolas para esse fim poderia estabelecer uma concorrência indesejável pela ocupação do solo com o cultivo de gêneros para alimentação humana, além de poluir a água e o solo.

Garrido et al. (2014) e Leceta et al. (2014) chegaram a conclusões semelhantes em suas avaliações dos impactos ambientais do filme SPI-b flexível no País Basco. Nesses casos, o cultivo de soja trouxe contribuições significativas para as categorias de impacto de Acidificação, Eutrofização e Consumo de Fósseis que poderiam ser atribuídas ao uso de fertilizantes e de diesel em máquinas agrícolas. Leceta et al. (2014) observaram que o uso de glicerina, proveniente de biodiesel, como aditivo na produção de SPI-b intensifica impactos no estágio agrícola. As tendências descritas acima são verificadas para o filme de amido de mandioca, a partir dos desempenhos indicados na Tabela 3.5 em termos de ALO, TEc, FEu e TA. Leceta também relatou impactos ambientais em termos de consumo de combustíveis fósseis associados à demanda de eletricidade da tecnologia de filmes SPI-b. No entanto, a autora admite que o efeito se fez notar apenas em escala laboratorial e, por isso ainda requer avaliações complementares mais profundas.

A mesma cadeia de eventos se estabeleceu para o filme de amido de mandioca; no entanto, dadas as características da rede brasileira, esses impactos se manifestam em termos de consumo de fósseis não renováveis, biomassa renovável e água, além de CC, TA, POF e TEc (Tabela 3.5).

Os resultados dessa análise, somados a questões levantadas antes na Seção 3.2 do estudo, estabeleceram-se como pontos críticos do arranjo de produção em análise as etapas de: (i) cultivo de mandioca; (ii) fabricação de filme; e as (iii) sínteses de ativos de base orgânica utilizados na formulação daquele produto. Uma análise de cenários foi realizada para identificar alternativas de Produção mais Limpas que pudessem substituir essas etapas, a fim de melhorar o desempenho geral do filme de amido de mandioca.

\subsection{Proposição de cenários baseados em Produção mais Limpa (P+L)}

O uso de conceitos de Production Efficiency and Environmental Management (RECP) adaptados às condições específicas deste estudo, conduziu à elaboração quatro cenários alternativos de produção de filmes. 
A Tabela 3.6 mostra características e variações processuais desses arranjos, e que serão analisados nessa etapa do estudo. 0 código (+) indica que o estágio (ou ativo associado) é parte integrante do cenário em questão, ao passo que o código (-) mostra que aquele elemento não foi incorporado ao arranjo.

O cenário I corresponde a cadeia de produção original, fazendo assim o papel de cenário base para as comparações. 0 cenário II substitui glicerina de origem fóssil por congênere (parcialmente) renovável que é subproduto da síntese de biodiesel. No Brasil, a legislação vigente exige que o diesel mineral seja misturado ao biocombustível segundo a proporção [93:7 $]_{\mathrm{v} / \mathrm{v}}$ para assim originar o combustível usado em veículos e maquinário pesado. Essa condição projetava uma produção doméstica de biodiesel de 4,3 milhões de $\mathrm{m}^{3}$ para 2015 (USDA, 2014). 0 cenário III substitui etanol sintético derivado de etileno por etanol equivalente obtido de cana-de-açúcar. A produção autorizada de $\mathrm{C}_{2} \mathrm{H}_{6} \mathrm{O}$ no Brasil é de 314 milhões de L / dia, dos quais 65\% são obtidos na forma hidratada (95\% $\mathrm{v} / \mathrm{v})$ e o restante, como etanol anidro $(99,5 \% \mathrm{v} / \mathrm{v})(\mathrm{ANP}, 2015)$.

Tabela 3.6 - Propostas de cenários alternativos de melhoria

\begin{tabular}{lccccc}
\hline Cenário & I (base) & II & III & IV & V \\
\hline Glicerina fóssil & + & - & + & + & + \\
Glicerina renovável & - & + & - & - & - \\
Etanol fossil & + & + & - & + & + \\
$\begin{array}{l}\text { Etanol renovável } \\
\text { Amido de mandioca do }\end{array}$ & - & - & + & - & - \\
$\begin{array}{l}\text { Brasil } \\
\text { Amido de mandioca da }\end{array}$ & - & + & + & - & + \\
Îndia & - & - & + & - \\
Tecnologia de Fundição & + & + & + & + & - \\
Tecnologia de extrusão & - & - & - & - & + \\
\hline
\end{tabular}

O cenário IV considera uma alternativa para o estágio agrícola: importar amido de mandioca da Índia, um país com os mais altos níveis de produtividade agrícola da mandioca em nível global, com desempenho acima de 38 t/ha (FAO, 2015). Finalmente, o cenário $\mathrm{V}$ examina os efeitos ambientais da produção de filmes por extrusão, nos quais o recobrimento é criado a partir da combinação de amido de mandioca e outro polímero. Devido sua representatividade (36\%) no mercado doméstico de resinas termoplásticas, considerou-se para essa composição o polietileno de origem fóssil (ABIPLAST, 2014). 
Assim como já havia sido indicado antes na seção 3.2, cada cenário alternativo foi estruturado contendo uma única variante do cenário I. A abordagem permitiu identificar possíveis desvios de cada proposta em relação ao cenário de referência. Encerrada essa etapa, partiu-se então para uma análise complementar que investigou os desempenhos energético e ambiental (derivado de emissões, e do uso da terra) de onze combinações possíveis entre os mesmos cenários. 0 interesse nesse caso foi de identificar sinergias (ou incompatibilidade) geradas em decorrência da integração entre alternativas.

\subsubsection{Descrição de cenários alternativos}

O processo de especificação dos cenários alternativos teve em conta requisitos adicionais como robustez tecnológica, potencial de redução de impacto, viabilidades de implementação/operação, e preservação das propriedades técnicas do filme (seção 3.2) para sua condução. São apresentados a seguir mais detalhes sobre cada situação.

Cenário II: modelar a cadeia produtiva da glicerina compreendeu as seguintes etapas: cultivo de soja e extração de óleo; extração e refino de gás natural; produção de metanol; e transesterificação. Todas essas etapas foram modeladas a partir de dados secundários coletados para o período 2008-2011. 0 tratamento de multifuncionalidades se deu por alocação com critérios econômicos e resultou na divisão de cargas ambientais entre óleo e farelo de soja [38:62]; e biodiesel e glicerina [99,8: 0,20]. 0 modelo de cultivo de soja considerou plantio direto, e a adubação se restringiu aos fertilizantes fosfatados e potássicos (Embrapa, 2011). As estimativas de emissões foram baseadas em EPFL (2011), Comissão Europeia (2010) e Nemecek e Kägi (2007). A modelagem para extração de óleo de soja usou dados de Cavalett e Ortega (2010) e Sugawara (2012).

A produção brasileira de metanol $\left(\mathrm{CH}_{3} \mathrm{OH}\right)$ se dá por reforma a vapor a partir do gás natural. Para atender a 77\% da demanda interna para o período 2009-2010, o gás natural foi importado do Chile e da Venezuela (MDICE, 2013). Os modelos de extração e refino de gás natural, bem como a produção de $\mathrm{CH}_{3} \mathrm{OH}$, foram gerados a partir dos ICVs 'Natural gas, production at onshore/RU U' (FAIST et al., 2007) e 'Methanol, at plant / GLO U' de Ecoinvent v 2.2 (ALTHAUS et al., 2007), e adaptados para as condições dos países produtores. 0 modelo que descreve o processamento de glicerina por transesterificação também consistiu de uma adaptação do ICV 'Glycerine, from soybean oil, at esterification plant / BR U' de Ecoinvent v 2.2 (JUNGBLUTH et al., 2007) para as condições brasileiras. 
Cenário III: a produção de $\mathrm{C}_{2} \mathrm{H}_{6} \mathrm{O}$ compreende as etapas de cultivo da cana-deaçúcar, moagem, fermentação do caldo, produção de etanol hidratado, além daquelas que perfazem o ciclo de cogeração de energia (caldeira, turbina, condensador, desaerador e bomba). A modelagem desse processo foi baseada nos seguintes ICVs de Ecoinvent (v 2.2): 'Sugarcane, at farm/BR U' e "Ethanol, $95 \%$ in $\mathrm{H}_{2} \mathrm{O}$, from sugar cane, at fermentation plant/BR U' (JUNGBLUTH et al., 2007), bem como em dados secundários obtidos para o período 2007-2011 em Cavalett et al., (2013), CGEE, (2008), Dias et al., (2013), EPFL, (2011), GREFL (2010), IPCC (2006), Nemecek e Kägi (2007), Seabra et al., (2011), CONAB (2011), IDEA (2012), e Guerra et al., (2014).

Cenário IV: o suprimento de amido de mandioca originário da Índia compreende os seguintes estágios: produção de mandioca, extração de amido e transporte para o Brasil. 0 processo foi baseado em dados secundários coletados para o período 20042013 (BAMGBOYE e KOSEMANI, 2015; EDISON et al., 2006; RAMANATHAN et al., 2013). O modelo agrícola adotado nessa situação parte da composição entre tecnologias distintas. $O$ balanceamento levou em conta os totais de produção gerados pelos sistemas durante o período 2011-2012 (RAMANATHAN et al., 2013). Esses dados apontaram para proporções [60:40] estabelecidas entre sistemas agrícolas de alta (38 t/ha) e média (2025 t/ha). Em qualquer dos casos, o uso de máquinas agrícolas está restrito ao preparo do solo. As diferenças mais significativas entre essas abordagens dizem respeito a irrigação e controle de pragas. 0 método usado para obtenção de amido era bastante próximo das práticas exercitadas no Brasil prevalecendo assim, o modelo usado no caso base. No entanto, a geração de eletricidade que atende à demanda dessa etapa foi ajustada para o grid indiano (IEA, 2013). 0 modelo rodoviário de transporte é usado para movimentação do produto desde a planta de extração de amido até o porto de Chennai, na Índia (321 $\mathrm{km}$ ) e, mais adiante, desde o porto de Santos, Brasil, até a planta de produção de filmes (83 km). A conexão de porto-a-porto é transoceânica (14967 km) (SeaRates, 2013) e foi descrita como se ocorresse em navio cargueiro com porte de $40000 \mathrm{dwt}$ (deadweight tonnage) e velocidade de 14 nós (SPIELMANN et al., 2007).

Cenário V: a extrusão de filme é um método usual para preparação de embalagens à base de polímeros sintéticos. Nesse caso assumiu-se uma formulação com proporções [80:20 $]_{\mathrm{m} / \mathrm{m}}$ entre o filme de amido de mandioca e outro, obtido de polietileno (OLIVATO et al., 2015). A manufatura do filme de biopolímero segue o arranjo tecnológico descrito no cenário I. Os dados usados para simular a produção de polietileno foram obtidos de Hansen et al. (2015). A rede brasileira fornece eletricidade para a extrusão e a demanda de energia térmica é atendida pela queima de gás natural. 
As adaptações realizadas nos LCIs coletados no banco de dados Ecoinvent, que permitiram a estruturação dos cenários de melhoria em potencial, foram baseadas em critérios semelhantes àqueles aplicados para modelar o cenário base. Essa conduta foi adotada com o objetivo de harmonizar os padrões de modelagem aplicados para as duas fases do estudo e, assim, possibilitar a comparação entre as alternativas.

\subsection{Comparação de Perfis Energéticos e de Impactos de Emissões entre Cenários}

\subsubsection{Análise de Cenário Individual}

As comparações entre os cenários de I (base) - V foram realizadas para o mesmo fluxo de referência estabelecido na fase inicial do estudo, ou seja, 1,0 t de filme à base de amido de mandioca biopolimérico. A Avaliação de Impactos continuou a ocorrer quanto aos perfis de energia - expressos como PED e pelo método CED -, e de impacto devido a emissões -gerados pela aplicação do método ReCiPe Midpoint $(\mathrm{H})$ para as categorias $\mathrm{CC}$, TA, FEu, POF, TEC e ALO. A Tabela 3.7 mostra os perfis de energia para os cinco cenários analisados, enquanto a Figura 3.3 descreve as variações relativas de PED dos cenários de II - V em relação ao cenário I.

Tabela 3.7 - Perfis Energéticos para os cenários I - V

\begin{tabular}{llllll}
\hline & \multicolumn{5}{c}{ Cenários (MJ/FR) } \\
\cline { 2 - 6 } $\begin{array}{l}\text { Categoria } \\
\text { de Impacto }\end{array}$ & I & II & III & IV & V \\
\cline { 2 - 6 } & Base & $\begin{array}{l}\text { Glicerina } \\
\text { renovável }\end{array}$ & $\begin{array}{l}\text { Etanol } \\
\text { renovável }\end{array}$ & $\begin{array}{l}\text { Amido de } \\
\text { mandioca da } \\
\text { Índia }\end{array}$ & Extrusão \\
\hline NRF & 39127 & 32630 & 29241 & 40111 & 49222 \\
NRN & 6711 & 5397 & 6495 & 6831 & 5772 \\
NRB & 0,019 & 0,043 & 0,060 & 0,16 & 0,017 \\
RB & 57014 & 60860 & 73963 & 71210 & 46856 \\
RWD & 40,1 & 14,6 & 40,3 & 42,5 & 34,4 \\
RWA & 49107 & 48644 & 49064 & 48600 & 42679 \\
Total & 151999 & 147546 & 158803 & 166794 & 144563 \\
\hline
\end{tabular}

Os totais de NRB foram de duas a três ordens de grandeza menores que os geradas para a RWD, categoria a ele se segue. Tal como ocorre com I, prevalecem contribuições para PED de RB, RWA e NRF. Os resultados de RB são ainda influenciados pelo cultivo da mandioca; no entanto, para II e III, estes derivam de processos agrícolas de soja e cana. 
Figura 3.3 - Variação relativa de PED para cenários II - V comparado com a cenário base

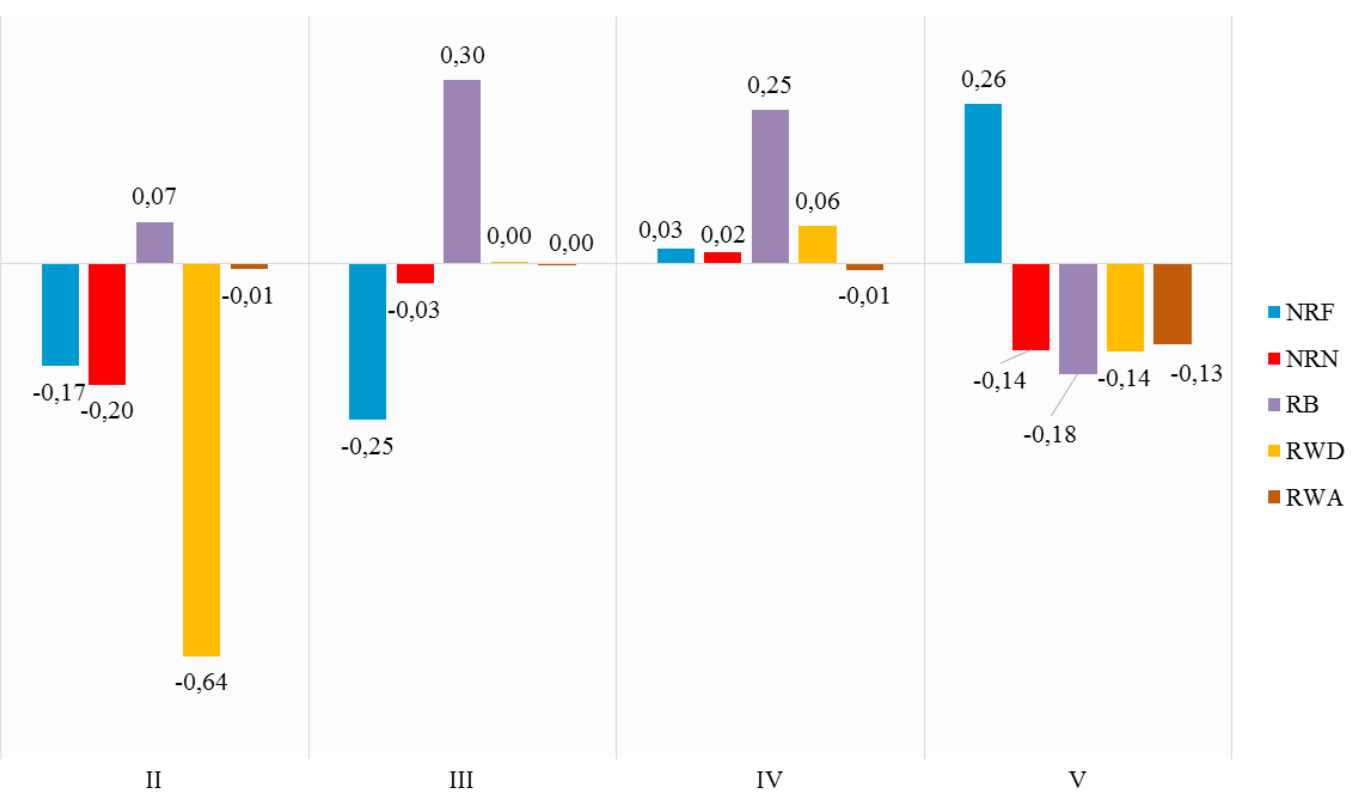

Para todos os casos os efeitos da RWA estão ligados à quantidade de eletricidade consumida na fabricação de filmes, enquanto que os impactos na forma de NRF ainda se vinculam aos processamentos de glicerina fóssil e etanol, geração de energia e operações de transporte.

Cabe ressaltar que a RWA influenciou significativamente apenas o PED total do cenário $\mathrm{V}$, em que a substituição parcial do biopolímero por polietileno trouxe redução de impacto para essa categoria, entre 12 e 13\% em comparação com outros cenários. Assim, as variações de PED para os cenários II - IV (inclusive quanto ao cenário I) foram determinadas pelo equilíbrio entre impactos a forma NRF e RB.

Os resultados dos cenários II e III mostram que a substituição de ativos fósseis como glicerina e etanol, por fontes renováveis melhora de fato o desempenho da cadeia produtiva em termos de NRF. No entanto, a ação é prejudicial para RB. Para o cenário II, os benefícios da redução do consumo de recursos fósseis superaram a carga de PCS associada à biomassa e assim, o saldo de PED acaba sendo positivo em 2,9\% com relação ao cenário I. Por outro lado, embora a energia absorvida durante o cultivo da soja seja maior do que no caso da cana-de-açúcar, o consumo de etanol para a produção de filmes é em duas vezes mais elevada do que o da glicerina. Logo, os ganhos da NRF acabam sendo subjugados pelos efeitos adversos de RB, gerando um aumento global de 4,5\% de PED no cenário III em relação ao cenário base. 
O PED do cenário IV foi de 167 GJ/FR, aproximadamente 9,7\% superior ao de I. Embora as práticas agrícolas na Índia sejam menos intensivas em termos de consumo de recursos fósseis, houve um aumento na NRF, atribuível à matriz energética indiana, que era composta por $69 \%$ de carvão e em 14\% de outras fontes fósseis à época da realização do estudo (IEA, 2013). As longas distâncias de deslocamento, particularmente os trechos rodoviários, também contribuíram para a elevação de NRF. No entanto, essa alternativa foi de fato desqualificada devido à baixa eficiência do processamento de amido na região, de 5,0 t mandioca/t amido, em comparação ao desempenho brasileiro: 3,9 t/t. Como resultado direto dessa (menor) conversão, os valores obtidos para RB foram em 25\% superiores aos do cenário base.

A incorporação do PE à formulação do filme trouxe benefícios em termos de PED. O valor acumulado do cenário $V$ para esse impacto - 144 GJ/FR -, é cerca de 4,9\% menor do que o obtido no cenário I. Por outro lado, o consumo de gás natural ao longo da cadeia de produção de eteno ( $57 \mathrm{MJ} / \mathrm{kg} \mathrm{C}_{2} \mathrm{H}_{4}$ ), bem como a demanda de eletricidade do processo de extrusão (676 kWh/t produto extrudido), elevaram a participação individual NRF no resultado. Já a redução do consumo de biopolímero diminuiu em 13\% e 18\% os impactos originais da RB e RWA. Essa ação não foi suficiente para se contrapor aos aportes descritos antes e assim, o cenário $\mathrm{V}$ apresentou o maior valor de PED de toda a série.

A Tabela 3.8 descreve os resultados do Perfil de impactos de emissões para o cenário I e suas variações. Seguindo a mesma abordagem usada para os perfis de energia, a Figura 3.4 mostra as variações relativas dos cenários II-V em comparação com aquele padrão. 0 uso de glicerina renovável para não alterar os desempenhos da maior parte das categorias, tanto que, as reduções constatadas $(3,0 \%$ em AT, 1,5\% para FEu e POF, e menos de $0,25 \%$ em relação a TEc e ALO) podem ser consideradas pouco significantes. Vale ressaltar uma melhora no CC (8,5\%), em virtude de as contribuições associadas a glicerina derivadas de transesterificação do óleo de soja, resultarem em $98 \mathrm{~kg} \mathrm{CO}_{2}$ eq $/ \mathrm{FR}$, correspondendo a $21 \%$ da contribuição da glicerina fóssil no cenário I.

O uso de etanol de cana-de-açúcar (cenário III) trouxe impactos ambientais mais significativos do que os registrados pelo cenário I em termos de AT, POF, TEc e ALO. 0 aumento em relação a AT se deve a emissões de $\mathrm{NH}_{3}$ no cultivo da cana (814 $\mathrm{g} \mathrm{SO}_{2}$ eq/FR) e $\mathrm{NO}_{\mathrm{x}}\left(431 \mathrm{~kg} \mathrm{SO} \mathrm{z}_{2} / \mathrm{FR}\right)$ na produção de etanol. As maiores contribuições em termos de POF são causadas pelas emissões atmosféricas de $\mathrm{CO}$ e $\mathrm{NO}_{\mathrm{x}}$ (4,69 kg e 772 g NMVOC/FR) através da operação de máquinas agrícolas no cultivo de cana e por conta do transporte de etanol para a fábrica de filmes. 
Tabela 3.8 - Perfil de Impactos de emissões para os cenários I - V

\begin{tabular}{lllllll}
\hline & & \multicolumn{5}{c}{ Cenários (/FR) } \\
\cline { 3 - 6 } $\begin{array}{l}\text { Categoria } \\
\text { de impacto }\end{array}$ & Unidade & $\mathrm{I}$ & $\mathrm{II}$ & $\mathrm{III}$ & $\mathrm{IV}$ & $\mathrm{V}$ \\
\cline { 3 - 6 } & & Base & $\begin{array}{l}\text { Glicerina } \\
\text { Renovável }\end{array}$ & $\begin{array}{l}\text { Etanol } \\
\text { Renovável }\end{array}$ & $\begin{array}{l}\text { Amido de } \\
\text { mandioca da } \\
\text { Índia }\end{array}$ & Extrusão \\
\hline $\mathrm{CC}$ & $\mathrm{kg} \mathrm{CO}$ eq & 4310 & 3942 & 4114 & 4376 & 4007 \\
$\mathrm{TA}$ & $\mathrm{kg} \mathrm{SO}$ eq & 17,3 & 16,9 & 18,0 & 9,49 & 19,9 \\
FEu & $\mathrm{kg} \mathrm{P}$ eq & 2,56 & 2,53 & 2,50 & 0,48 & 2,11 \\
POF & $\mathrm{kg} \mathrm{NMVOC}$ & 7,76 & 7,65 & 12,0 & 10,2 & 7,52 \\
TEc & $\mathrm{kg} \mathrm{1,4-DB}$ eq & 11,2 & 11,2 & 27,5 & 3,72 & 9,29 \\
ALO & $\mathrm{m}^{2} \mathrm{a}$ & 2232 & 2228 & 2698 & 1502 & 1833 \\
\hline
\end{tabular}

Em relação à TEc, o aumento de impacto no cenário III foi de 146\% em relação ao cenário I. 0 ciclo produtivo do etanol de cana respondeu por $59 \%$ do valor apontado na Tabela 3.8, por conta das emissões para o solo por pesticidas e outros metais pesados introduzidos por fertilizantes (CAVALETT et al. 2013). 0 aumento do impacto de ALO pode ser atribuído ao cultivo da cana-de-açúcar. Embora a produtividade agrícola no estado de São Paulo seja superior à média brasileira, a inclusão de um ativo de fontes agrícolas no arranjo ocasionou um aumento de $466 \mathrm{~m}^{2}$ a sobre o valor do cenário base.

Figura 3.4 - Relative variations of emission impacts and land use for scenarios II-V in relation to baseline

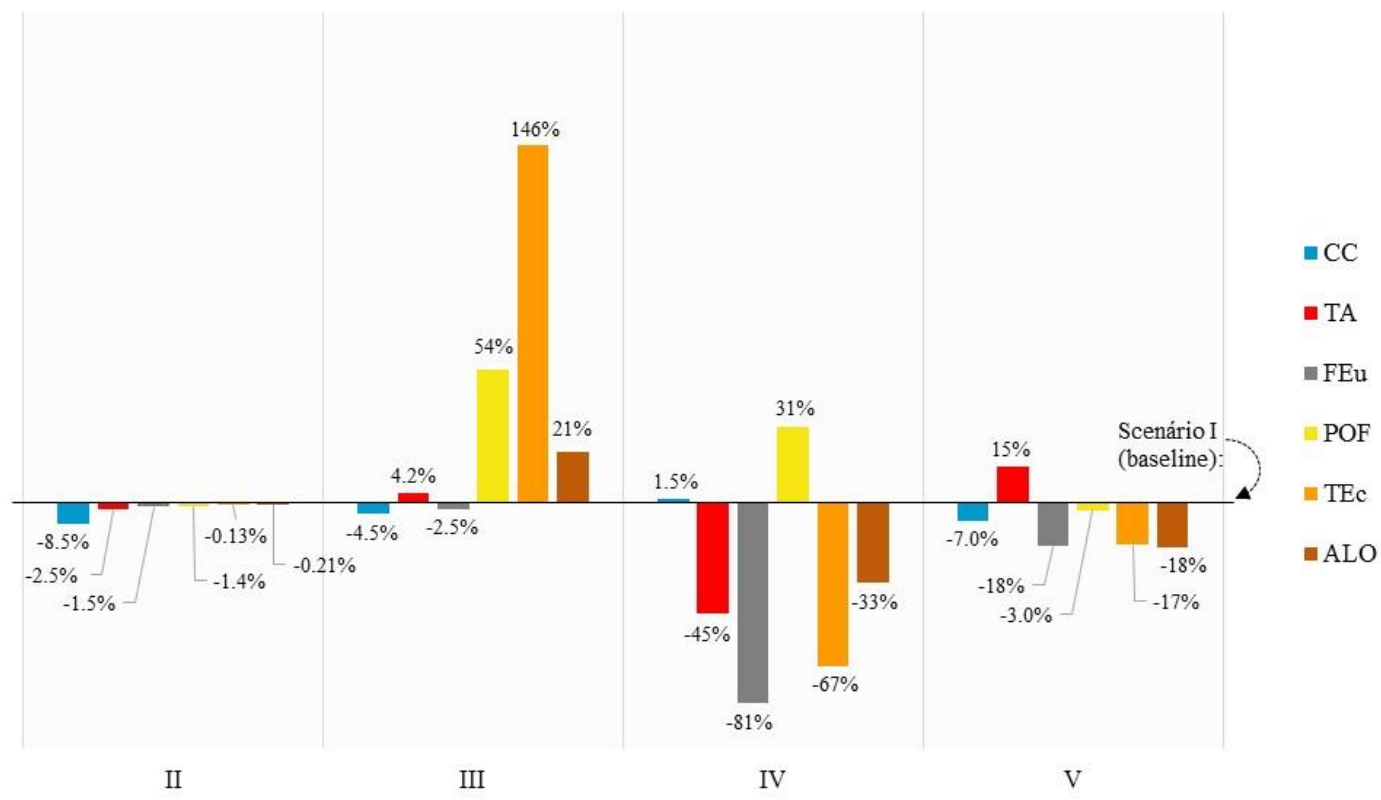


Se comparada ao cenário I, a importação de amido de mandioca da Índia resultou em oscilações positivas e negativas. Houve benefícios notáveis em termos de AT (de 45\%, como mostra a Figura 3.4), FEu (81\%), TEc (67\%) e ALO (33\%), devido a dois fatores relacionados ao cultivo da mandioca. 0 primeiro deles refere-se a maior produtividade da mandioca na Índia: muito embora ponderados, os valores considerados no modelo para esse parâmetro (32 t/ha) são típicos para o país e superam o desempenho brasileiro em mais de $60 \%$. 0 segundo fator está relacionado às práticas de cultivo da mandioca: na Índia, uma carga de esterco é adicionada aos fertilizantes químicos como método de complementação de nutrientes. Além disso, pequenos e médios produtores geralmente não empregam pesticidas para o controle de pragas e ervas daninhas (EDISON et al., 2006; RAMANATHAN et al., 2015). O resultado adverso do cenário IV está no aumento, em 31\%, das emissões que contribuem para POF, causadas principalmente em função dos transportes rodoviário e transoceânico de amido de mandioca. Essas atividades contribuíram com 2,95 kg NMVOC /FR para a categoria de impacto, o que representa $29 \%$ do resultado para o cenário IV (Tabela 3.8). Em termos de CC, houve uma redução nas contribuições decorrentes de práticas agrícolas, que são menos intensas na Índia. Por outro lado, os transportes voltam a ser um problema nesse caso. A distribuição do amido indiano no Brasil produz um impacto acumulado de $212 \mathrm{~kg} \mathrm{CO}_{2}$ eq/FR. Ponderando prós e contras, o cenário IV causa cerca de 2,0\% mais de impacto para a categoria do que o arranjo original de produção de filmes.

Os efeitos positivos em termos de Fel, Tec. e ALO, motivados pela substituição parcial do biopolímero pelo polietileno (cenário V) podem ser atribuídos à influência do cultivo da mandioca no desempenho global da cadeia produtiva do biofilme. Há também benefícios gerados em termos de CC por conta dessa ação, que, no entanto, acabam sendo atenuados por emissões de $\mathrm{CO}_{2 \mathrm{f}}$ e $\mathrm{CH}_{4 \mathrm{f}} \mathrm{O}$ mesmo ocorre com a POF, em função das perdas de $\mathrm{SO}_{2}$ e $\mathrm{NO}_{\mathrm{x}}$ para o ar. Todos esses efeitos se originam de causa única: o processamento de gás natural para produção de $\mathrm{C}_{2} \mathrm{H}_{4}$. As mesmas emissões de $\mathrm{SO}_{2}$ e $\mathrm{NO}_{\mathrm{x}}$ aportam outros $5,5 \mathrm{~kg} \mathrm{SO}_{2}$ eq/FR para AT, que são suficientes para piorar o desempenho do cenário $\mathrm{V}$ em relação ao cenário I também em termos dessa categoria de impacto.

\subsubsection{Cenário combinado}

A Figura 3.5 descreve os comportamentos de onze combinações entre os cenários II - V em comparação ao demonstrado pelo cenário base em termos de Demanda de Energia Primária. As possibilidades (III e V), (II, III, V) e (II e V) apresentam PED menor do que o do cenário I, respectivamente em 1,2\%, 3,6\% e 7,3\%. 
Essas melhorias confirmam duas observações feitas anteriormente durante as análises individuais: (i) a extrusão tem melhor desempenho energético do que o casting quando o filme de amido de mandioca e o filme de polietileno são combinados; (si) a troca de $\mathrm{C}_{3} \mathrm{H}_{8} \mathrm{O}$ sintético por renovável é mais vantajosa do que a aplicação de $\mathrm{C}_{2} \mathrm{H}_{6} \mathrm{O}$ da cana-de-açúcar em substituição àquele de origem fóssil uma vez que o álcool renovável traz consigo altos níveis de RB devido à energia intrínseca associada a cana. Ambos os fatores justificam a escolha da combinação (II e V) em detrimento de outras opções, incluindo o cenário base.

Figura 3.5 - Comparação entre valores de PED de combinações entre II - V e o do cenário I

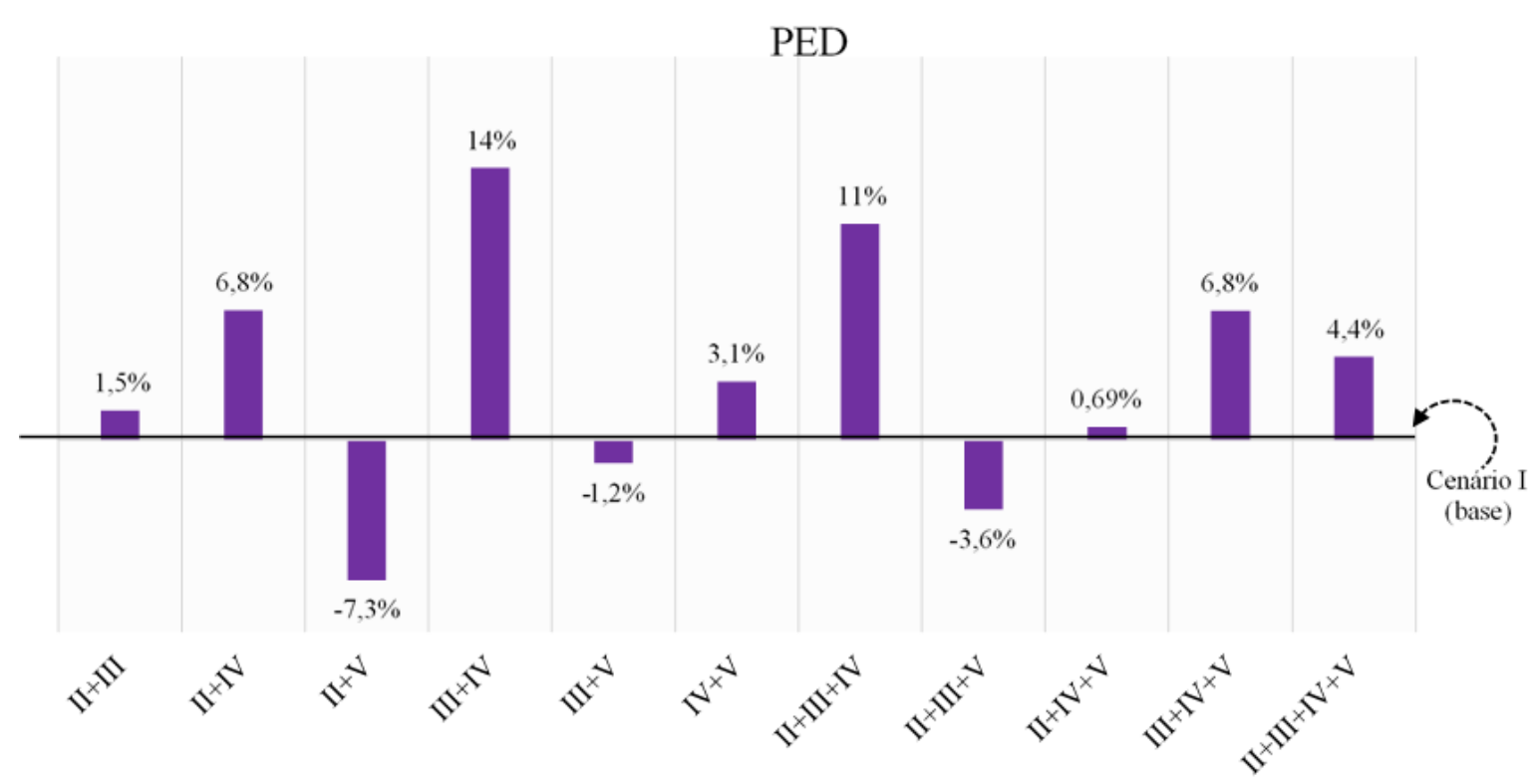

Por outro lado, em todas as alternativas que envolveram o cenário IV, percebeuse aumento no consumo de PED em relação ao cenário I. Isso se deve à carga de energia primária associada a importação de fécula de mandioca da Índia. Devido aos efeitos que causa, essa prática não é, portanto, recomendável, mesmo que coordenada com outras medidas que comprovadamente tragam menores impactos do que as exercitada no arranjo vigente.

A combinação envolvendo (II, IV e V) detém o melhor desempenho energético dentre as alternativas que têm em conta o cenário IV como uma das ações potenciais de melhoria. No entanto, o resultado obtido pelo arranjo - 153 GJ/FR - é apenas equivalente ao alcançado originalmente pelo cenário I. 
Figura 3.6 - Comportamento de impactos derivados de emissões e uso de terra para combinações de cenários II - V em relação ao cenário base: (a) Mudança de Clima (CC); (b) Eutrofização de água doce (FEu); (c) Ecotoxicidade terrestre (TEc); (d) Formação de oxidantes Fotoquímicos (POF); (e) Acidificação Terrestre (AT); e (f) Ocupação de Terras Agrícolas (ALO).
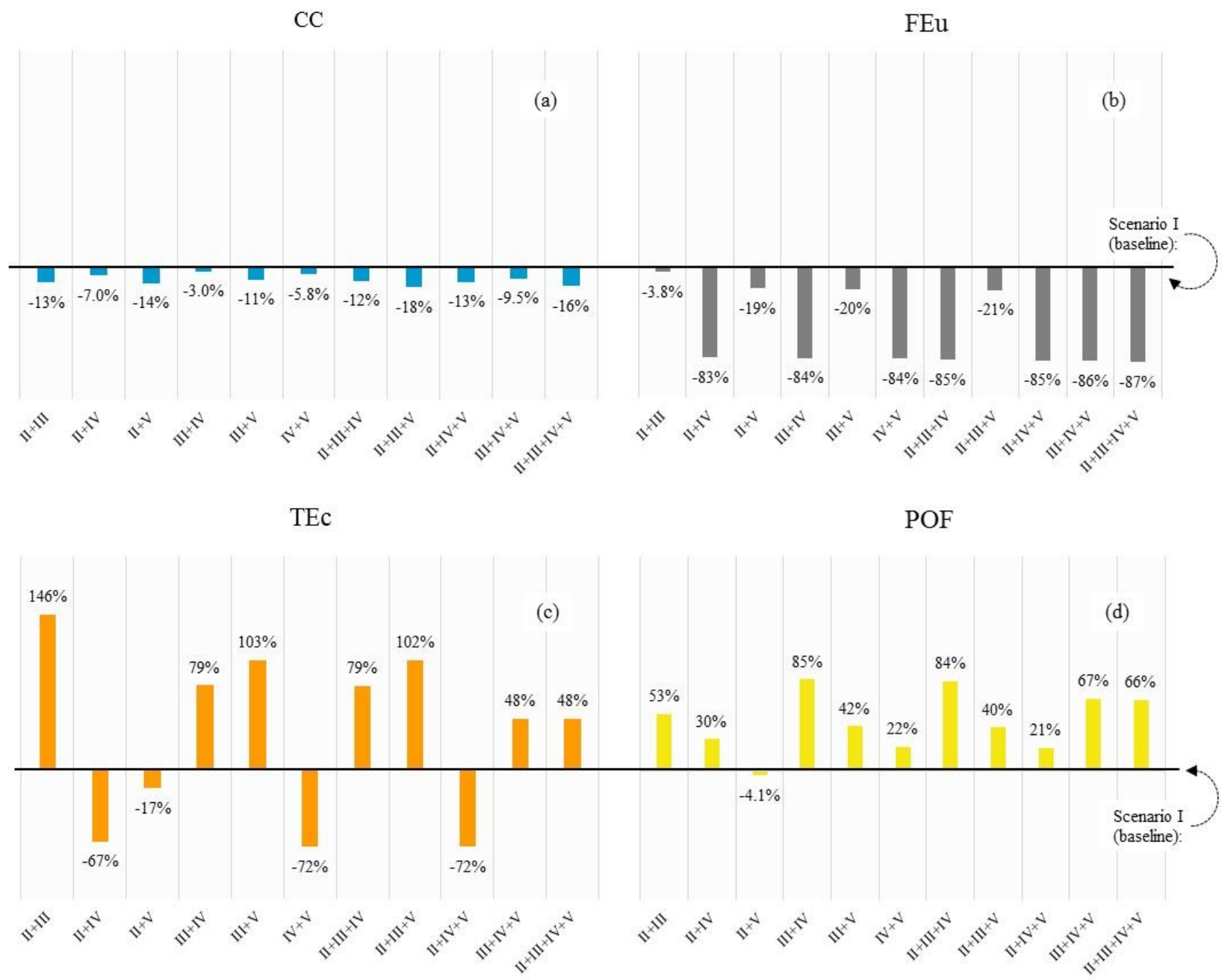

TA

ALO

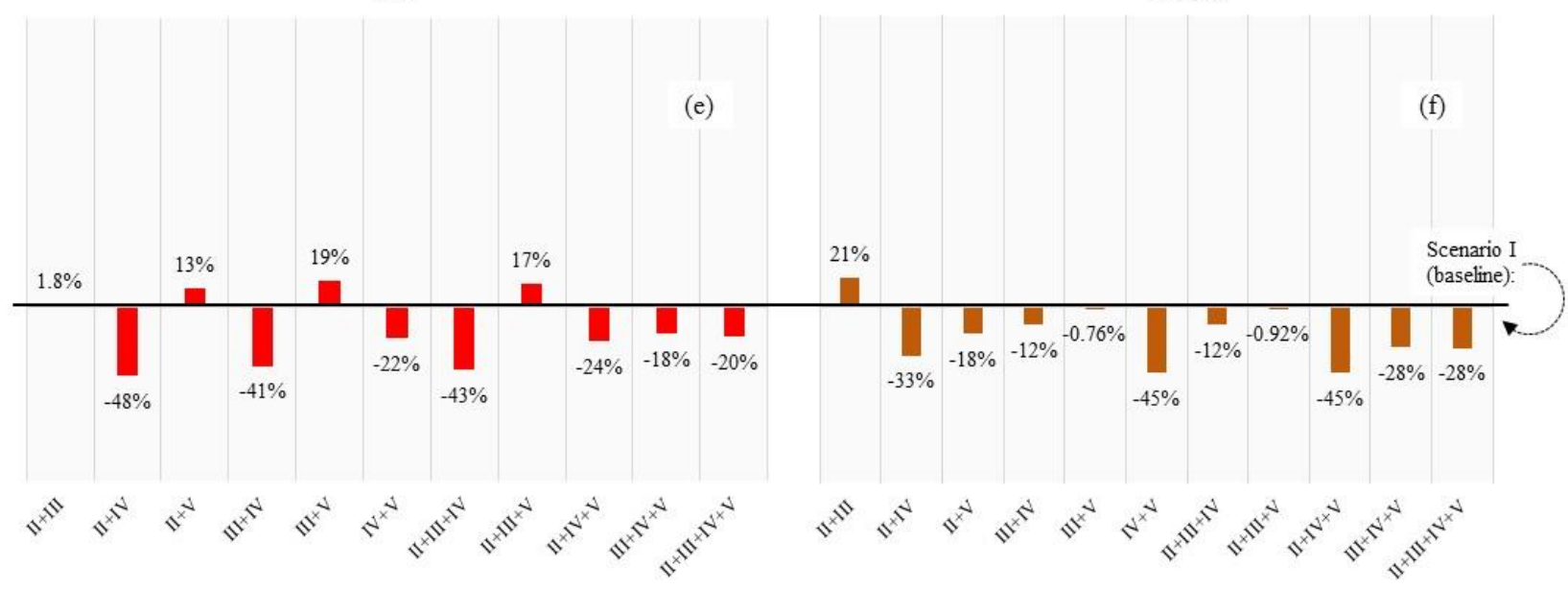


Para aos impactos derivados de emissões e do uso da terra, todas as combinações testadas superaram o cenário I em termos de CC e FEu (Figuras 3.5a e 3.5b). Para CC, as combinações que adotaram $\mathrm{C}_{3} \mathrm{H}_{8} \mathrm{O}$ e $\mathrm{C}_{2} \mathrm{H}_{6} \mathrm{O}$ de fontes renováveis, bem como o processo de extrusão, confirmam a baixa eficiência da importação de amido de mandioca da Índia como forma de reduzir os impactos nessa categoria. 0 melhor desempenho para essa categoria $\left(3,54 \mathrm{t} \mathrm{CO}_{2}\right.$ eq/FR) foi alcançado precisamente pela combinação entre (II, III, V), ao que se seguiram (II, III, IV e V: 3,60 t $\mathrm{CO}_{2 \text { eq }}$ FR) e (II e V: 3,71 t $\mathrm{CO}_{2}$ eq/FR).

A associação de medidas também melhorou o desempenho do sistema em termos de FEu. Contudo, diferentemente do que ocorreu com CC, quaisquer composições com o cenário IV foram muito vantajosas, ao reduzir os impactos para $321 \mathrm{~g}$ P eq/FR (II, III, IV, V) e $442 \mathrm{~g} \mathrm{P}$ eq/FR (II, IV). A opção pelo uso esterco como fonte de fósforo para o cultivo da mandioca indiana foi decisivo para que fossem alcançados tais desempenhos.

Quase todas as combinações entre cenários foram positivas quanto a ALO (Figura 3.5f). A exceção ocorreu com (II e III), que projetava maior necessidade de terras aráveis do que as do cenário I. Esse aumento já era esperado, dado o acréscimo de área por conta do cultivo da cana-de-açúcar da qual se origina o $\mathrm{C}_{2} \mathrm{H}_{6} \mathrm{O}$ pleiteado pelo cenário III. Como (II) teve desempenho semelhante do cenário base nesta categoria, os efeitos adversos de (III) que se somaram aos anteriores explicam o aumento de contribuições. A integração entre as opções (IV) e (V) e (II) mostrou-se muito favoráveis, ao trazer reduções de aporte para ALO que variavam de 18\% (II e V) a 45\% (IV e V; e II, IV, V).

Além disso, uma associação entre extrusão e casting neutraliza as consequências de (III) para ocupação do solo. A elevada produtividade da mandioca na Índia compensa a contribuição adicionada pelo rendimento da cana-de-açúcar e assim, a combinação (III e V) proporciona impacto inferior ao do cenário I para o ALO.

Ao contrário do que ocorreu com CC, FEu e ALO, as contribuições para POF se elevaram por conta da coordenação dos cenários (Figura 3.5d). A exceção ocorreu com o arranjo (II e V). Quaisquer combinações envolvendo (IV) - dado o transporte de amido de mandioca desde a Índia -, e/ou (III) - graças ao uso de máquinas agrícolas nos cultivo e colheita da cana - introduziram emissões significantes de $\mathrm{NO}_{\mathrm{x}}$ e NMVOC que até então não existiam em (I).

A inclusão de (V) em qualquer arranjo ajuda a reduzir os efeitos globais, mas não em intensidade suficiente para equilibrar os aumentos descritos acima. Por outro lado, (II) teve efeito inócuo. Logo, a união hipotética entre (II e V) geraria 7,44 kg NMVOC/FR, ao passo que (III e IV) e (II, III, IV) trariam $\sim 14,4 \mathrm{~kg} \mathrm{NMVOC/FR} \mathrm{de} \mathrm{impacto} \mathrm{para} \mathrm{POF.}$ 
Quanto à AT, os ganhos e perdas do desempenho em relação a (I) dependeram dos componentes do arranjo. Combinações com (IV) diminuem impactos, em quanto que as que ocorrem com (V) os elevam. As presenças de (II) e (III) têm pouca significância para os valores totais. $\mathrm{O}$ uso de amido de mandioca importado traz aportes que variam de 9,05 (II e IV) a 14,1 kg SO 2 eq/FR (III, IV, V). Para combinações considerando extrusão, esses resultados vão de 13,5 $\mathrm{kg} \mathrm{SO}_{2}$ eq/FR (IV e V), até $20,5 \mathrm{~kg} \mathrm{SO}_{2 \text { eq }} / \mathrm{FR}$ (III e V).

O efeito das combinações sobre TEc foi semelhante ao percebido em AT, porém com sinais de maior reverberação. 0 etanol de cana-de-açúcar intensifica esses impactos em 146\% (II e III) em relação a (I), dadas às perdas de agroquímicas para o solo. Por outro lado, o uso de amido estrangeiro acumula vantagens para a categoria, uma vez que seu processamento agrícola não usa defensivos no controle de pragas.

Dado todo esse quadro, uma análise sistêmica aponta (II e IV) e (II, IV, V) como combinações mais equilibradas da série em termos de impactos causados pelas emissões e uso da terra, e desaconselha a formulação de propostas envolvendo (II e III) e (III e V) também pelos motivos ali expostos.

\section{9 - Considerações acerca do Balanço de Carbono}

Os resultados de CC para todos os cenários foram parcialmente condicionados por uma decisão metodológica adotada para os presentes propósitos de desconsiderar fluxos relacionados à fixação de $\mathrm{CO}_{2}$ do ar $\left(\mathrm{CO}_{2}\right.$, fix $)$, e emissões biogênicas de $\mathrm{CO}_{2}$ derivadas de ativos renováveis $\left(\mathrm{CO}_{2}, \mathrm{~b}\right)$. Para examinar com mais detalhes os efeitos causados por esse ajuste, decidiu-se realizar uma quantificação complementar dos impactos para CC em que tais parcelas fossem contabilizadas (Tabela 3.9).

A estimativas predispuseram a formulação dos seguintes fatores de impacto $\mathrm{IF}_{\text {fix }}$ $=(-) 1,0 \mathrm{~kg} \mathrm{CO}{ }_{2}$ eq $/ \mathrm{kgCO}_{2, \text { fix }}$ e $\mathrm{IF}_{\mathrm{b}}=1,0 \mathrm{~kg} \mathrm{CO} \mathrm{Cq}_{2} / \mathrm{kgCO}_{2}$, b. Essa decisão está baseada em três premissas: (i) o $\mathrm{CO}_{2}$ foi adotado como substância padrão para o CC pela abordagem do IPCC (IPCC, 2006), que integra o modelo ReCiPe. Assim, seu valor de IF é unitário por convenção; (ii) como ambas as parcelas $\left(\mathrm{CO}_{2, \mathrm{fix}}\right.$ e $\left.\mathrm{CO}_{2, \mathrm{~b}}\right)$ se associam à mesma substância química, e os fluxos de fixação e emissão têm sentidos oposto, seria razoável admitir que $\mathrm{IF}_{\mathrm{fix}}=(-) \mathrm{IF}_{\mathrm{b}}$; e, (iii) a referência para quantificar as emissões de $\mathrm{CO}_{2}$ foi o meio ambiente, ou seja, a vizinhança do sistema antrópico em análise. Dada a convenção, o processo de fixação compreende a retirada do gás de seu ambiente de origem, provocando um déficit daquele patrimônio, que foi totalizado com sinal negativo (-). 
Tabela 3.9 - Balanço de CC para produção de biofilme soba perspectiva do 'berço-ao-portão'

\begin{tabular}{llllll}
\hline & \multicolumn{5}{c}{ Cenários $(\mathrm{kg} \mathrm{CO}$ 2 eq FR) } \\
\cline { 2 - 6 } $\begin{array}{l}\text { Contribuições } \\
\text { para Impactos CC }\end{array}$ & $\mathrm{I}$ & $\mathrm{II}$ & $\mathrm{III}$ & $\mathrm{IV}$ & $\mathrm{V}$ \\
\cline { 2 - 6 } & Base & $\begin{array}{l}\text { Glicerina } \\
\text { Renovável }\end{array}$ & $\begin{array}{l}\text { Etanol } \\
\text { Renovável }\end{array}$ & $\begin{array}{l}\text { Amido de } \\
\text { mandioca } \\
\text { Índia }\end{array}$ & Extrusão \\
\hline $\begin{array}{l}\text { Valor acumulado } \\
\text { (IPCC, 2006) }\end{array}$ & 4310 & 3942 & 4114 & 4376 & 4007 \\
$\begin{array}{l}\text { CO2,fix } \\
\text { CO }\end{array}$ & $(-)$ 338 & $(-) 330$ & $(-) 2014$ & $(-) 60,1$ & $(-) 289$ \\
Saldo ajustado CC & 4315 & 459 & 1421 & 65,3 & 293 \\
\hline
\end{tabular}

Diferentemente do que havia ocorrido quando as estimativas feitas com base no modelo proposto pelo IPCC (2006) apontaram o cenário II como sendo de menor impacto para CC, as considerações de $\mathrm{CO}_{2, \mathrm{fix}}$ e $\mathrm{CO}_{2, \mathrm{~b}}$ - que originaram o "Saldo ajustado CC" - agora indicam o cenário III como opção menos impactante para a categoria. Esse desempenho se atribuí à taxa de fixação de $\mathrm{CO}_{2}$ da cana-de-açúcar, $653 \mathrm{~kg} / \mathrm{t}$ (CGEE, 2008), que supera em $42 \%$ as emissões de $\mathrm{CO}_{2, \mathrm{~b}}$, mesmo com as expressivas queimas de biomassa ocorridas em 2011 para colheita do ativo agrícola.

Figura 3.7 - Efeito da consideração de $\mathrm{CO}_{2, \mathrm{fix}}$ e $\mathrm{CO}_{2, \mathrm{~b}}$ sobre os impactos de $\mathrm{CC}$ dos diferentes arranjos de melhorias

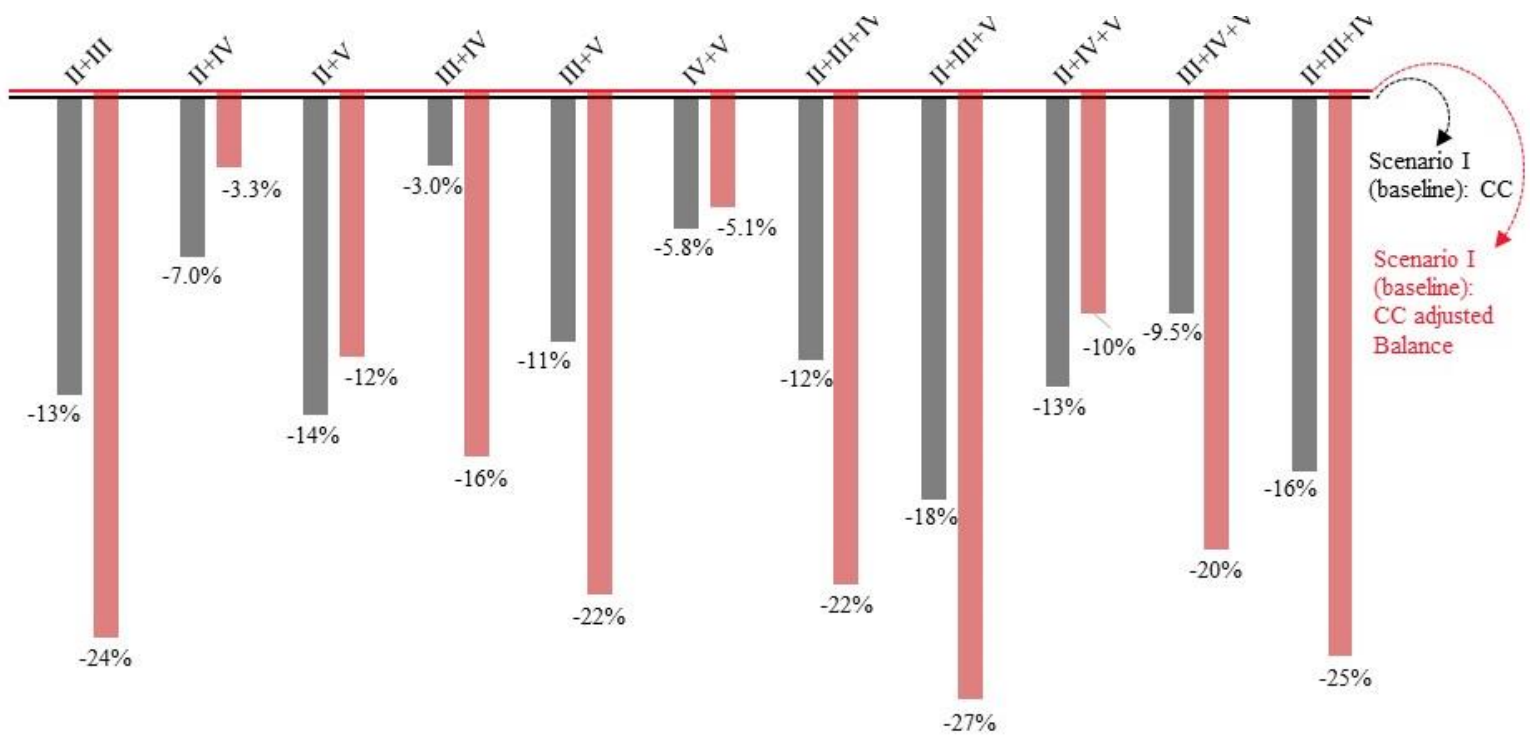

$\mathrm{CC}$

CC adjusted Balance 
Os ganhos potenciais envolvendo o cultivo da soja seguem o mesmo diapasão, chegando a 1,54 $\mathrm{kg} \mathrm{CO}_{2} / \mathrm{kg}$ grão (SUGAWARA, 2012). O fato de o cenário III deter um desempenho superior inclusive ao do cenário de referência, pode ser visto como um sinal positivo na direção de os filmes de base biológica se firmarem no mercado nacional de embalagens.

Com os ajustes descritos acima, o valor acumulado de CC para o cenário I passou de 4310 para $4315 \mathrm{~kg} \mathrm{CO}_{2 \text { eq }} / \mathrm{FR}$ (Tabela 3.9). Isso ocorreu devido à ligeira superioridade

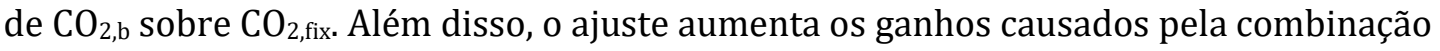
de cenários para a maioria das situações analisadas. As exceções ocorrem apenas quando $\left[\sum\left(\mathrm{CO}_{2, \mathrm{~b}}\right)-\sum\left(\mathrm{CO}_{2, \mathrm{fix}}\right)>0\right]$, como para as opções (II e IV), (II e V), (IV e V) e (II, IV, V). A inclusão de (III) melhora esse quadro, uma vez que cultivo da cana-de-açúcar resulta em expressiva retirada de $\mathrm{CO}_{2}$ da atmosfera, projetando um impacto de (-) $593 \mathrm{~kg} \mathrm{CO}_{2}$ eq/FR.

A análise revela por fim que os resultados globais do CC sofrem influência do 'Valor acumulado IPCC' do que pelas contribuições de $\mathrm{CO}_{2, \mathrm{~b}}$ e $\mathrm{CO}_{2, \mathrm{fix}}$. Dessa forma, podese concluir que a combinação (II, III, V) registra os melhores resultados de Saldo ajustado

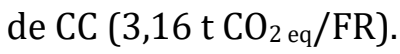

\subsection{0 - Conclusões}

Este estudo teve por objetivo analisar os desempenhos energético e ambiental da fabricação de filmes à base de amido de mandioca, considerando condições possíveis de processo existentes no Brasil. A ACV foi usada nessa determinação, e seus resultados mostraram que as principais contribuições para aquelas dimensões ocorrem no cultivo da mandioca, consumo de eletricidade para fabricação do filme, e produção dos aditivos utilizados no processamento.

O estudo discutiu também a validade ambiental de ações, concebidas com base em conceitos de Eficiência de Recursos e Produção mais Limpa, para reduzir esses efeitos adversos. Para isso, foram então estabelecidos cenários alternativos: (II): substituição da glicerina fóssil por contrapartida parcialmente renovável; (III): troca de etanol sintético por etanol de cana; (IV): importação de amido de mandioca da Índia; e, (V): produção de um biofilme combinando filme de amido de mandioca e polietileno. 0 sistema existente, que foi explorado na etapa anterior do estudo tornou-se o cenário (I) de referência para essa verificação. 
Em termos de Demanda de Energia Primária o uso de glicerina renovável (II) foi benéfico ao processo, enquanto a substituição de etanol fóssil por bioetanol (III) levou a aumento de impactos. Da mesma forma, não seria adequado importar amido, devido ao elevado consumo de combustível de seu transporte até o Brasil, e porque a mandioca da Índia tem menor rendimento de extração do que a nacional. 0 uso de extrusão (V) foi o cenário menos impactante dentre as medidas analisadas, uma vez que a substituição de parte do biopolímero à base de amido de mandioca por polietileno contrabalançaram a demanda de energia primária associada a obtenção de polietileno. Uma análise coletiva mostrou que combinação (II e V) resulta em maiores reduções de PED (7,3\%) em relação a (I) pois a extrusão tem desempenho superior ao da tecnologia casting, e por conta dos ganhos associados ao uso de $\mathrm{C}_{3} \mathrm{H}_{8} \mathrm{O}$ parcialmente renovável em comparação aos do $\mathrm{C}_{2} \mathrm{H}_{6} \mathrm{O}$ de cana-de-açúcar.

Quanto aos impactos ambientais, (II) trouxe pouca variação em relação (I), com benefícios moderados em termos de CC, AT, FEu, POF e ALO. Por outro lado, (III) teve impactos expressivos para AT, POF, TEc e ALO, principalmente devido ao cultivo de cana para produção de álcool. Já (IV) apresentou menores contribuições para AT, FEu, TEc e ALO devido à maior produtividade do cultivo de mandioca. 0 mesmo não ocorreu para a CC e POF, dado que o transporte de amido teve influência marcante sobre o desempenho nessas categorias. Por fim, (V) apresentou o pior desempenho ambiental para AT de todo a série por conta do processamento de polietileno.

As combinações (II e IV) e (II, IV, V) mostraram-se as mais equilibradas de todo o acervo de opções no tocante a impactos de emissões e uso da terra. Ao analisar o balanço de carbono para todos os cenários segundo uma perspectiva ampla, que acrescenta aos índices estimados pelo IPCC (2006), também as emissões de $\mathrm{CO}_{2}$ fixado do ar $\left(\mathrm{CO}_{2, \mathrm{fix}}\right)$ e de $\mathrm{CO}_{2}$ biogênico $\left(\mathrm{CO}_{2, \mathrm{~b}}\right)$, o cenário (III) registrou o melhor desempenho para a categoria, devido à fixação de $\mathrm{CO}_{2}$ que durante o cultivo da cana-de-açúcar. A partir disso, o arranjo que combina (II, III, V) tornou-se a melhor opção em termos de não agredir o entorno em termos de CC. Este estudo mostrou que, além das vantagens técnicas, o processamento do biofilme de amido de mandioca pode levar a ganhos ambientais consistentes.

Um movimento natural no sentido de seguir explorando a interface delimitada entre (bio)embalagens para alimentos e desempenho energético/ambiental seria o de realizar uma análise comparativa entre materiais de base biológica e não-biológica. Os resultados deste estudo apoiam tal desenvolvimento, embora a produção de biofilme de amido de mandioca no Brasil seja ainda incipiente. 
Os avanços nesse campo, passam também pelo (necessário) estabelecimento de perfis consistentes de consumo de recursos e de emissões, dos materiais não- biológicos para as condições brasileiras de processamento. Uma maneira de atingir esse propósito passa por criar junto a indústria nacional de embalagens de alimentos o valor de que ações e desenvolvimentos dessa natureza podem avançar para a instauração de uma cultura de Design for Environment (DfE) no segmento. Esse quadro seria positivo em diversos sentidos, melhorando a eficiência e a qualidade das embalagens, reduzindo custos e, a partir disso, aumentando a competitividade dessa classe de produtos em escala global, e mitigando impactos sobre o entorno e, talvez mais importante do que qualquer desses dividendos, ajudando a definir princípios proativos quanto a importância da preservação ambiental no consumidor.

\subsection{Referências}

ABIPLAST - Brazilian Plastic Processed Industry. Profile 2014. 37p. Disponível em: $<$ www.abiplast.org.br>.

Alhendi A., Choudhary R., 2013, Current Practices in Bread Packaging and Possibility of Improving Bread Shelf Life by Nanotechnology. Int. J. Food Sci. Nutr. Eng. 3 (4): 55-60. DOI: 10.5923/j.food.20130304.02.

Althaus H.J., Chudacoff M., Hischier R., Jungbluth N., Osses M., Primas A., 2007, Life Cycle Inventories of Chemicals. Ecoinvent report n.8, v2.0 EMPA, Dübendorf, Swiss Centre for Life Cycle Inventories, Dübendorf, CH. Disponível em: <www.ecoinvent.org>.

Álvarez-Chávez CR, Edwards S, Moure-Eraso R, Geiser K., 2012, Sustainability of biobased plastics: general comparative analysis and recommendations for improvement. J. Clean. Prod. 23: 47-56. DOI:10.1016/j.jclepro.2011.10.003

Alves G.S., Sampaio A.P.L., Zavolski C.A., Careda M.P., Neves E., 2012, Material a base de amido de mandioca para confecção de embalagem de alimentos. Revista Citino. 2 (1): $15-24$.

ANP - National Agency of Petroleum, Natural Gas and Biofuels. 2015. Boletim do Etanol no. 4, junho - 2015. 25p. Disponível em: www.anp.gov.br

Avella M., De Vlieger J.J., Errico M.E., Fischer S., Vacca P., Volpe M.G., 2005, Biodegradable starch/clay nanocomposite films for food packaging applications. Food Chem. 93: 467-474. DOI: 10.1016/j.foodchem.2004.10.024.

Bamgboye A.I., Kosemani B.S., 2015, Energy Input in the Production of Cassava. Energy and Environ. Res. 5 (1): 42-48. DOI:10.5539/eer.v5n1p42.

Bangyekan C., Aht-Ong D., Srikulkit K., 2006, Preparation and properties evaluation of chitosan-coated cassava starch films. Carbohydr. Polym. 63: 61-71. DOI: 10.1016/j.carbpol.2005.07.032. 
Bayer C., Gamble M., Gentry R., 2010, AIA Guide to Building Life Cycle Assessment in Practice. The American Institute of Architects, Washington DC.

Cavalett O., Chagas M.F., Seabra J.A.E., Bonomi A., 2013, Comparative LCA of ethanol versus gasoline in Brazil using different LCIA methods. Int. J. Life Cycle Assess.18: 647-658. DOI: 10.1007/s11367-012-0465-0.

Cavalett O., Junqueira T.L., Dias M.O.S., Jesus C.D.F., Mantelatto P.E., Cunha M.P., Franco H.C.J., Cardoso T.F., Maciel Filho R., Rossel C.E.V., Bonomi A., 2012, Environmental and economic assessment of sugarcane first generation biorefineries in Brazil. Clean.

TEchn. Environ. Policy. 14 (3): 399-410. DOI: 10.1007/s10098-011-0424-7.

Cavalett O., Ortega E., 2010, Integrated environmental assessment of biodiesel production from soybean in Brazil. J. Clean. Prod. 18: 55-70.

DOI:10.1016/j.jclepro.2009.09.008.

CGEE - Centro de Gestão e Estudos Estratégicos., 2008, Bioetanol de cana-de-açúcar: energia para o desenvolvimento sustentável. BNDES, Rio de Janeiro. 316 p.

CONAB - Brazilian Supply Company., 2011, Acompanhamento de safra brasileira: canade-açúcar, terceiro levantamento, dezembro 2011. 633.61C212. Disponível em: $<$ http://www.conab.gov.br/grãos>.

CONAB - Brazilian Supply Company. 2013, Agricultural Outlook. Volume 1 - Crop 2013/14. Disponível em: <http://www.conab.gov.br (accessed on June, 2015)>.

Cyras V.P., Manfredi L.P., Ton-that M.T., Vásquez A., 2008, Physical and mechanical properties of thermoplastic starch/montmorillonite nanocomposite films. Carbohydr. Polym. 73: 55-63. DOI: 10.1016/j.carbpol.2007.11.014.

Daniel J.R., Whistler R.L., Röper E.B., 2007, Starch and Other Polysaccharides to Surfactants, in: Arpe, H.J. (Ed.), Ullmann's encyclopedia of industrial chemistry. 5th ed. Vol. A25. Wiley-VCH, Weinheim, p. 23779-23804.

Dias M.O.S., Junqueira T.L., Cavalett O., Cunha M.P., Jesus C.D.F., Mantelatto P.E., Rossell C.E.V., Maciel Filho R., Bonomi A., 2013, Cogeneration in integrated first and second generation ethanol from sugarcane. Chem. Eng. Res. Des. 91 (8): 1411-1417. DOI: 10.1016/j.cherd.2013.05.009.

Dischsen A.E., Monteiro A.R.G., Fukuda G.T., Marques D.R., 2012, Development of a breakfast cereal using waste from cassava processing industry. Acta Scientiarum TEchnol. 35 (1): 157-161. DOI: 10.4025/actasciTEchnol.v35i1.12012.

Djomo S.N., Blumberga D., 2011, Comparative life cycle assessment of three biohydrogen pathways. Bioresour. TEchnol. 102: 2684-2694.

DOI:10.1016/j.biorTEch.2010.10.139.

Doka G., 2009, Life Cycle Inventories of Waste Treatment Services. Ecoinvent report $n$. 13. Swiss Centre for Life Cycle Inventories, Dübendorf, CH. Disponível em: $<$ www.ecoinvent.org>. 
Edison S., Anantharaman M., Srinivas T., 2006, Status of Cassava in India an overall view. Central Tuber Crops Research Institute. Indian Council of Agricultural Research. TEchnical Bulletin Series: 46: 173p. Disponível em: <http://www.ctcri.org>.

EMBRAPA - Empresa Brasileira de Pesquisa Agropecuária., 2011, TEcnologias de Produção de Soja - Região Central do Brasil 2012 e 2013. Embrapa Soja, Londrina, 21st ed. CDD: 633.340981. 261p. ISSN 2176-2902. Disponível em:

<https://www.embrapa.br/soja>.

EPE - Ministério de Minas e Energia, Empresa de Pesquisas Energéticas., 2007, Plano Nacional de Energia 2030 - Vol. 6 Geração Termelétrica (CDU 621.3(81)"2030":338.28). Ministério de Minas e Energia, Brasilia.

EPE - Ministério de Minas e Energia, Empresa de Pesquisas Energéticas., 2013, Brazilian energy balance 2013 year 2012 (CDU 620.9:553.04(81)). Ministério de Minas e Energia, Brasilia.

EPFL. Roundtable on Sustainable Biomaterials., 2011. RSB GHG Calculation Methodology. Switzerland. Disponível em: <http://rsb.org>.

European Commission, 2010, Guidelines for the calculation of land carbon stocks for the purpose of Annex V to Directive 2009/28/EC. Official Journal of the European Union, L151/19 de 17.6.2010. Disponível em: <http://lct.jrc.ec.europa.eu>.

European Commission - Joint Research Centre - Institute for Environment and Sustainability, 2010, International Reference Life Cycle Data System (ILCD) Handbook General guide for Life Cycle Assessment - Detailed guidance. 1st Ed. EUR 24708 EN. Publications Office of the European Union, Luxembourg. Disponível em: $<$ http://lct.jrc.ec.europa.eu>.

Faist E.M., Heck T., Jungbluth N., Tuchschmid M., 2007, Erdgas. In: Dones, R., ed. Sachbilanzen von Energiesystemen: Grundlagen für den ökologischen Vergleich von Energiesystemen und den Einbezug von Energiesystemen in Ökobilanzen für die Schweiz. Final ecoinvent report n. 6-V. Dübendorf: Paul Scherrer Institut. Swiss Centre for Life Cycle Inventories, Villigen. CH. Disponível em: <www.ecoinvent.org>.

Famá L., Flores S.K., Gerchenson L., Goyanes S., 2006, Physical characterization of cassava starch biofilms with special reference to dynamic mechanical properties at low temperatures. Carbohydr. Polym. 66: 8-15. DOI: 10.1016/j.carbpol.2006.02.016.

Famá L., Goyanes S., Gerchenson L., 2007, Influence of storage time at room temperature on the physicochemical properties of cassava starch films. Carbohydr. Polym. 70: 265-273. DOI: 10.1016/j.carbpol.2007.04.003.

FAO - Food and Agriculture Organization of the United Nations., 2015, FAOSTAT database 2015. Disponível em: <http://faostat3.fao.org/home/E>.

Ferreira Filho J.R., Silveira H.F., Macedo J.J.G., Lima M.B., Cardoso C.E.L., 2013, Cultivo, processamento e uso de mandioca - Instruções práticas. Embrapa Bahia. 34p. Disponível em: <http://www.cnpmf.embrapa.br>.

Fialho J.F., Vieira E.A., 2011, Mandioca no Cerrado: orientações técnicas. Embrapa Cerrados, Planaltina, 208 p. 
Forster P., Ramaswamy V., Artaxo P., Berntsen T., Betts R., Fahey D.W., Haywood J., Lean J., Lowe D.C., Myhre G., Nganga J., Prinn R., Raga G., Schulz M., Van Dorland R., 2007, Changes in atmospheric constituents and in radiative forcing. Chapter 2, in: Solomon S., Qin D., Manning M., Chen Z., Marquis M., Averyt K.B., Tignor M., Miller H.L. (Eds.), Climate change 2007: the physical science basis. Contribution of Working Group I to the Fourth Assessment Report of the Intergovernmental Panel on Climate Change. Cambridge University Press, Cambridge.

Frischknecht R., Jungbluth N., Althaus H.J., Doka G., Dones R., Hischier R., Hellweg S., Humbert S., Margni M., Nemecek T., Spielmann M., 2007a, Implementation of Life Cycle Impact Assessment Methods: Data v2.0. ecoinvent report n. 3, Swiss centre for Life Cycle Inventories, Dübendorf. CH. Disponível em: <www.ecoinvent.ch>.

Galić K., Ščetar M., Kurek M., 2011, The benefits of processing and packaging. Trends in Food Sci. \& TEchnol. 22: 127-137. DOI: 10.1016/j.tifs.2010.04.001

Gao W., Dong H., Hou H., Zhang H., 2012, Effects of clays with various hydrophilicities on properties of starch-clay nanocomposites by film blowing. Carbohydr. Polym. 88: 321-328. DOI: 10.1016/j.carbpol.2011.12.011.

Garrido T., Etxabide A., Leceta I., Cabezudo S., de la Caba K., Guerrero P., 2014, Valorization of soya by-products for sustainable packaging. J. Clean. Prod. 64: 228-233. DOI: 10.1016/j.jclepro.2013.07.027.

Goedkoop M., Heijungs R., Huijbregts M., De Schryver A., Struijs J., 2013, Description of the ReCiPe methodology for life assessment impact assessment. ReCiPe Main Report Revised July 13th, 2012. Disponível em: <http://www.lcia-recipe.net>. Acessado em junho, 2015.

GREET - Greenhouse gases, regulated emissions, and energy use in transportation, 2010, Version 1.8d. Argonne National Laboratory, Argonne.

Guerra J.P., Coleta Jr J.R., Arruda L.C.M., Silva G.A., Kulay L., 2014, Comparative analysis of electricity cogeneration scenarios in sugarcane production by LCA. Int. J. Life Cycle Assess. 19: 814-825. DOI: 10.1007/s11367-014-0702-9.

Hansen A.P., Silva G.A., Kulay L., 2015, Evaluation of the environmental performance of alternatives for polystyrene production in Brazil. Sci. Total Environ. 532: 655-668. DOI: $10.1016 /$ j.scitotenv.2015.06.049.

Hauschild M.Z., Goedkoop M., Guinée J., Heijungs R., Huijbregts M., Jolliet O., Margni M., De Schryver A., Humbert S., Laurent A., Sala S., Pant R., 2013, Identifying best existing practice for characterization modeling in life cycle impact assessment. Int. J. Life Cycle Assess. 18: 683-697. DOI: 10.1007/s11367-012-0489-5.

Hospido A., Davis J., Berlin J., Sonesson U., 2010, A review of methodological issues affecting LCA of novel food products. Int. J. Life Cycle Assess. 15: 44-52. DOI: 10.1007/s11367-009-01304.

IBGE - Instituto Brasileiro de Geografia e Estatística., 2015, Levantamento Sistemático da Produção Agrícola. 29(4): 1-81. IBGE, Rio de Janeiro. ISSN 0103-443X.

IBGE - Instituto Brasileiro de Geografia e Estatística., 2010, Pesquisa Nacional de Saneamento Básico. IBGE, Rio de Janeiro. 219p. ISBN 978-85-240-4135-8. 
IDEA - Instituto Desenvolvimento Agroindustrial., 2012, Indicadores de desempenho da agroindústria canavieira - safras 2010/11 e 2011/12. Grupo IDEA, Ribeirão Preto. 98p.

IEA - International Energy Agency. 2013. Energy Balances of Non-OECD Countries. Paris. 554p. ISBN 978.92.64.20306.8

IPCC - Intergovernmental Panel on Climate Change. 2006. IPCC guidelines for national greenhouse gas inventories. Vol. 2. Energy - fugitive emissions. IGES, Kanagawa.

ISO - International Organization for Standardization. 2006. ISO 14044. Environmental management - life cycle assessment - requirements and guidelines. International Organization for Standardization. Geneva.

Jungbluth N., Chudacoff M., Dauriat A., Dinkel F., Doka G., Faist E.M., Gnausounou E., Kljun N., Schleiss K., Spielmann M., Stettler, C., Sutter J., 2007, Life Cycle Inventories of Bioenergy. Ecoinvent report n. 17. Swiss Centre for Life Cycle Inventories, Dübendorf. CH.Disponível em: <www.ecoinvent.org $>$.

Kechichian V., Ditchfield C., Veiga-Santos P., Tadini C.C., 2010, Natural antimicrobial ingredients incorporated in biodegradable films based on cassava starch. LWT - Food Sci. and Technol. 43> 1088-1094. DOI: 10.1016/j.lwt.2010.02.014.

Kimming M., Sundberg C., Nordberg A., Baky A., Bernesson S., Norén O., Hansson P.A., 2011, Life cycle assessment of energy self-sufficiency systems based on agricultural residues for organic arable farms. Bioresour. Technol. 102: 1425-1432. DOI: 10.1016/j.biorTech.2010.09.068

Leceta I., Etxabide A., Cabezudo S., de la Caba K., Guerrero P., 2014, Bio-based films prepared with by-products and wastes: environmental assessment. J. Clean. Prod. 64: 218-227. DOI: 10.1016/j.jclepro.2013.07.054.

Leceta I., Guerrero P., Cabezudo S., de la Caba K., 2013, Environmental assessment of chitosan-based films. J. Clean. Prod. 41: 312-318. DOI: 10.1016/j.jclepro.2013.07.054.

Mali S., Sakanaka L.S., Yamashita F. Grossmann M.V.E., 2005, Water sorption and mechanical properties of cassava starch filmsand their relation to plasticizing effect. Carbohydr. Polym. 60: 283-289. DOI: 10.1016/j.carbpol.2005.01.003.

Mbey J.A., Hoppe S., Thomas F., 2012, Cassava starch-kaolinite composite film. Effect of clay content and clay modification on film properties. Carbohydr. Polym. 88: 213-222. DOI: 10.1016/j.carbpol.2011.11.091.

MDICE - Ministry of Development, Industry and Foreign Trade, 2013, Aliceweb System. Disponível em: <aliceweb2.mdic.gov.br>.

Nemecek T., Kägi T., 2007, Life Cycle Inventories of Swiss and European Agricultural Production System Final report Ecoinvent v.2.0 n. 15a. Agroscope Reckenholz-Taenikon Research Station ART, Swiss Centre for Life Cycle Inventories, Zurich and Dübendorf. CH. Disponível em: <www.ecoinvent.org >.

Nemecek T., Schnetzer J., 2011, Methods of assessment of direct field emissions for LCIs of agricultural production systems. Agroscope Reckenholz-Tänikon Research Station ART, Zurich, 34p. 
Nemecek T., Schnetzer J., Reinhard J., 2014, Updated and harmonised greenhouse gas emissions for crop inventories. Int. J. Life Cycle Assess. 1-18. DOI: 10.1007/s11367014-0712-7.

Normanha E.S., Pereira A.S., 1950, Aspectos agronômicos da cultura da mandioca (Manihot utilissima, Pohl). Bragantia, 10: 179-202. Disponível em:

<www.scielo.br/pdf/brag/v10n7/01.pdf>

NREL - National Renewable Energy Laboratory, 2003, U.S. LCI Database ProjectPhase I Final Report. NREL/SR-550-33807. Golden. Disponível em:

$<$ http://www.nrel.gov/lci/>

Olivato J.B., Marini J., Pollet E., Yamashita F., Grossmann M.V.E., Avérous L., 2015, Elaboration, morphology and properties of starch/polyesternano-biocomposites based on sepiolite clay. Carbohydr. Polym. 118: 250-256. DOI:

10.1016/j.carbpol.2014.11.014.

Pagno C.H., Costa T.M.H., Menezes E.W.,Benvenutti E.V., Hertz P.F., Matte C.R., Tosati J.V., Monteiro A.R., Rios A.O., Flôres S.H., 2015, Development of active biofilms of quinoa (Chenopodium quinoa W.) starch containing gold nanoparticles and evaluation of antimicrobial activity. Food Chem. 173:755-762. DOI: 0.1016/j.foodchem.2014.10.068.

Ramanathan S., Anantharaman M., Sheriff J.T., 2013, Status of Cassava in Maharashtra. J. Root Crop. 39 (2): 211-214.

Reis L.C.B., Barcellos A.D., Machado B.A.S., Druzian J.I., 2011, Filme Biodegradável Incorporado com Glicerol e Aditivos Naturais. Cad. de Prospecção. 4 (4): 23-32. DOI: 10.9771/S.CPROSP.2011.004.003.

Romanelli T.L., Milan M., 2010, Material flow determination through agricultural machinery management. Sci. Agric. (Piracicaba, Braz.). 67 (4): 375-383. DOI: 10.1590/S0103-9016201000040000.

Salla D.A., Furlaneto F.P.B., Cabello C., Kanthack R.A.D., 2010, Análise energética de sistemas de produção de etanol de mandioca (Manihot esculenta Crantz). Rev. Bras.

Eng. Agríc. Ambient. 14 (4): 444-448. DOI: 10.1590/S1415-43662010000400015.

Seabra J.E.A., Macedo I.C., Chum H.L., Faroni C.E., Sarto C.A., 2011, Life cycle assessment of Brazilian sugarcane products: GHG emissions and energy use. Biofuels, Bioprod.

Biorefin. 5: 519-532. DOI: 10.1002/bbb.289.

SeaRates., 2013, Distance and Time [map]. Scale undetermined; generated by SeaRates LP. Disponível em: <http://www.searates.com/reference/portdistance >. Acessado em maio, 2015.

Sebrae Bahia., 2009, Mandiocultura: derivados da mandioca. Integra Consultoria e Representação e Comercio, Sebrae Bahia, Salvador, 40p.

Silva D.A.L., Pavan A.L.R., Oliveira J.A., Ometto A.R., 2015, Life cycle assessment of offset paper production in Brazil: hotspots and cleaner production alternatives. J. Clean.

Prod. 93: 222-233. DOI: 10.1016/j.jclepro.2015.01.030. 
Silva G.A., Ribeiro F.M., Kulay L., 2013, Hydropower Life-Cycle Inventories:

Methodological Considerations and Results Based on a Brazilian Experience, in: Sing A., Pant D., Olsen S.I. (Eds.), Life Cycle Assessment of Renewable Energy Sources, $1^{\text {st. Ed. }}$ Springer, London. pp. 241-267. DOI: 10.1007/978-1-4471-5364-1.

Sorrentino A., Gorrasi G., Vittoria V., 2007, Potential perspectives of bionanocomposites for food packaging applications. Trends in Food Sci. \& Technol. 18: 84-95. DOI: 10.1016/j.tifs.2006.09.004.

Souza A.C., Benze R., Ferrão E.S., Ditchfield C., Coelho A.C.V., Tadini C.C., 2012, Cassava starch biodegradable films: Influence of glycerol and clay nanoparticles content on tensile and barrier properties and glass transition temperature. LWT - Food Sci. and Technol. 46: 110-117. DOI: 10.1016/j.lwt.2011.10.018.

Souza A.C., Goto G.E.O., Mainardi J.A., Coelho A.C.V., Tadini C.C., 2013, Cassava starch composite films incorporated with cinnamon essential oil: Antimicrobial activity, microstructure, mechanical and barrier properties. LWT - Food Sci. and Technol. 54: 346-352. DOI: 10.1016/j.lwt.2013.06.017.

Spielmann A., Bauer C., Dones R., Tuchschmid M., 2007, Transport Service, Ecoinvent reort n. 14. Swiss Centre for Life Cycle Inventories. Dübendorf. CH. Disponível em: $<$ www.ecoinvent.org>.

Struijs J., Beusen A., van Jaarsveld H., Huijbregts M.A.J., 2009, Aquatic eutrophication. Chapter 6, in: Goedkoop M., Heijungs R., Huijbregts M.A.J., De Schryver A., Struijs J., Van Zelm R. (Eds.), ReCiPe 2008 A life cycle impact assessment method which comprises harmonized category indicators at the midpoint and the endpoint level. Report I: Characterization, first edition, January 6th, 2009. Disponível em: <http://www.lciarecipe.net>. Acessado em janeiro, 2015.

Sugawara E.T., 2012, Comparação dos desempenhos ambientais do B5 etílico de soja e do óleo diesel, por meio da Avaliação do Ciclo de Vida (ACV). Master in Chemical Engineering. Escola Politénica, University of Sao Paulo. Sao Paulo. 240p.

Sutter J., 2007, Life Cycle Inventories of Petrochemical Solvents. Ecoinvent report n. 22 Swiss Centre for Life Cycle Inventories, Dübendorf. CH. Disponível em: $<$ www.ecoinvent.org $>$.

Tang X., Alavi S., Herald T.J., 2008 Effects of plasticizers on the structure and properties of starch-clay nanocomposite films. Carbohydr. Polym. 74: 552- 558. DOI: 10.1016/j.carbpol.2008.04.022

UNEP-UNIDO - United Nations Environment Programme \& United Nations Industrial Organization. 2010. Taking Stock and Moving Forward. The UNIDO-UNEP National Cleaner Production Centre. Sustainable Production in Practice in Developing and Transition Countries. Joint UNIDO-UNEP Programme on Resource Efficient and Cleaner Production. Disponível em: <http://www.unep.org/resourceefficiency/Business/CleanerSaferProduction/Resourc eEfficientCleanerProduction>. Acessado em janeiro 2015.

USDA - United States Department of Agriculture., 2014, Global Agricultural Information Nework: Brazil - Biofuels Annual. Report number: BR14004. 27p. Disponível em: $<$ http://gain.fas.usda.gov . 
Van Zelm R., Huijbregts M.A.J., Den Hollander H.A., Van Jaarsveld H.A., Sauter F.J., Struijs J., VanWijnen H.J., Van de Meent D., 2008, European characterization factors for human health damage of PM10 and ozone in life cycle impact assessment. Atmos. Environ. 42: 441-453. DOI: 10.1016/j.atmosenv.2007.09.072.

Veiga J.P.S., 2012, Caracterização de resíduos de colheita da mandioca (Manihot esculenta CRANTZ) e avaliação do potencial de co-geração de energia no processo de produção de etanol. Master in Mechanical Engineering. University of Campinas (UNICAMP). Campinas, Brazil. 90p.

Veiga-Santos P., Cereda M.P., Scamparini A.R.P., 2008, Cassava starch-gelatin bio-based films structural stability and color during storage. Bol. Centro Pesqui. Process. Aliment. 26 (1): 123-134.

Verghese K., Lewis H., Lockrey S., Williams H., 2013, The role of packaging in minimizing food waste in the supply chain of the future. Royal Melbourne Institute of Technology (RMIT). School of Architecture and Design. Melbourne 50p. Disponível em: $<$ http://www.chep.com/foodwaste/ .

Xiong H., Tang S, Tang H., Zou P., 2008, The structure and properties of a starch-based biodegradable film. Carbohydr. Polym. 79, 263-268. DOI:

10.1016/j.carbpol.2007.05.035 


\section{Uso de ACV na seleção de rotas para reúso de água em refinaria de petróleo}

\section{Resumo}

Este capítulo apresenta um caso em que a técnica de ACV foi aplicada para avaliar efeitos ambientais e energéticos do reúso de efluentes de processo como fluído de troca térmica em torre de resfriamento. Para que o efluente atingisse os padrões requeridos por aquela função, um arranjo composto por osmose inversa (OI), evaporação (EV) e cristalização (CR) foi projetado para realizar sua dessalinização. Seis variantes possíveis desse tratamento foram então estabelecidas e avaliadas: S1: pré-tratamento por ácido etilenodiaminotetracético (EDTA) ao que se seguem RO, EV (destilação multi-efeito) e $\mathrm{CR}$; S2: S1 tendo como agente de pré-tratamento o $\mathrm{BaSO}_{4}$; S3: S1 com pré-tratamento via $\mathrm{Ca}(\mathrm{OH})_{2} / \mathrm{CaCO}_{3} / \mathrm{HCl}$; S4: S3 tendo calor residual como meio para suprir a demanda térmica de EV; S5: S3 com recompressão de vapor em EV; e S6: S3 com substituição de $\mathrm{HCl}$ por $\mathrm{HNO}_{3}$. A análise foi realizada para os impactos da Demanda de Energia Primária (DEP) e Aquecimento Global (AG). A experiência demonstrou que a técnica ACV é capaz de atuar como critério de especificação no âmbito do projeto de processos, pelo fato de poder estabelecer correlações intrínseca entre a eficiência da recuperação de água na OI e os impactos ambientais que a ela são inerentes.

\subsection{Introdução}

O setor de petróleo é a principal fonte de energia primária, correspondendo a aproximadamente 35\% do consumo global de combustível em 2017 (IEA, 2018). Para suprir a demanda por derivados de petróleo, principalmente no setor de combustíveis, faz-se necessário um consumo expressivo de água, principalmente para trocas térmicas. Este cenário é observado principalmente em países com grandes produções de derivados de petróleo, como o Brasil, que ocupa a nona posição no ranking mundial (IEA, 2018). No entanto, dada a realidade local do Brasil, de irregular disponibilidade de água, e escassez do recurso natural em grandes centros urbanos em certos períodos do ano, as agências reguladoras aumentaram suas restrições no que se refere à coleta de água e disposição de efluentes, a fim de equacionar a depleção da malha hídrica nacional. Tal cenário tem estimulado pesquisas visando o aumento da eficiência do tratamento de efluentes e, consequentemente, a mitigação dos prejuízos relacionados às captações e disposição final deste recurso. 
0 reúso de água é uma técnica que vem ganhando espaço na área, por viabilizar o tratamento de parte, ou até mesmo, de todo efluente, e quando possível, destiná-lo para suprimento de necessidades domésticas e industriais. Esta prática tem grande potencial para resolver problemas de demanda de água. Contudo, o reúso de água traz associados impactos ambientais como o consumo de recursos energéticos (aquecimento de fluidos e bombeamento), resultantes de ações de condicionamento da água, aplicadas desde sua entrada do processo, até a geração de efluente.

Trabalhos publicados recentemente na literatura trazem contribuições variadas para as práticas de reúso de água. Quando as pesquisas ocorreram no domínio ambiental, os enfoques foram também diversificados. Chang et al. (2017) avaliaram o consumo de energia e as emissões de gases de efeito estufa (GEE) para sistemas de reúso de água em ambiente urbano da Coréia do Sul. Hendrickson et al. (2015), por sua vez, estudaram os mesmos parâmetros para um sistema de tratamento do tipo Living Machine (LM), que se atem a promover o reciclo de efluente em edifícios comerciais. 0 estudo também avaliou o desempenho da planta centralizada de tratamento de efluentes do complexo, que aliás, se mostrou mais eficiente do que o LM. 0 enfoque de ciclo de vida foi utilizado para os casos em que a especificação da variável ambiental requeria uma abordagem sistêmica.

Morera et al. (2016) aplicaram o conceito de Pegada Hídrica com o intuito de verificar o consumo de recursos hídricos em unidades de tratamento de efluentes. Os autores concluíram que os tratamentos de efluentes trazem significativa diminuição de 'água cinza' mas também, podem gerar uma pequena pegada em termos de 'água azul' se comparados a cenários sem tratamento. Cornejo et al. (2014) realizaram uma extensa revisão de literatura focada em trabalhos de Pegada de Carbono (PC) para sistemas de reúso de água e dessalinização. 0 estudo identificou haver tendências de elevação de PC conforme as tecnologias de tratamento se tornam mais sofisticadas e seletivas. Por conta disso, Cornejo et al recomendaram que a dimensão ambiental fosse considerada para efeito de concepção, especificação e dimensionamento dessas técnicas.

Nesse contexto, a ACV foi utilizada para aplicações diversas, dentre os quais se encontram identificados impactos resultantes de estratégias de controle em unidades de tratamento de efluentes (MENESES et al., 2015), investigar o desempenho ambiental associado a plantas de pequena (GARFí et al., 2017) e larga escala (McNAMARA et al., 2016), ou até, comparar alternativas descentralizadas de depuração de vertidos domésticos para reúso não-potável em ambiente urbano (OPHER e FRIEDLER, 2016). 
A ACV serviu também de meio de geração de subsídios em avaliações ambientais e econômicas desenvolvidas para determinar o ponto ótimo de reúso em um complexo residencial (GARCÍA-MONTOYA et al., 2016), ou ainda, em análises de Ecoeficiência de sistemas de purificação destinados ao reciclo de 'água cinza' em construções domésticas para usos não-potáveis (LAM et al., 2017).

Baresel et al. (2016) quantificaram efeitos ambientais derivados da utilização de matrizes energéticas de diferentes países (EUA, Espanha e Suécia), e da aplicação de lodo originado em sistemas de tratamento de efluentes como fertilizante dentro de sistemas de reuso de água para fins industriais e de agricultura. Os achados de pesquisa indicaram que alterações no grid elétrico podem ser determinantes para o desempenho ambiental do processo e que podem condicionar o tipo de tecnologia de depuração a ser usada em certa situação.

O'Connor et al. (2014) avaliaram 14 diferentes arranjos para o tratamento de efluentes de indústrias de papel e celulose, estruturados a partir da comutação de seis operações: flotação, clarificação, lodo ativado, reator UASB, ultrafiltração e osmose inversa (OI). Foram avaliados impactos na forma de Mudanças Climáticas, Eutrofização, Ecotoxicidade de Água Doce e Depleção de Água. Os resultados mostraram a influência significativa dos resíduos sólidos originado no tratamento, e do uso de eletricidade, sobre os impactos de Mudanças Climáticas, bem como uma maior eficiência da OI em termos de qualidade da água de reúso, se comparada a tecnologia de ultrafiltração. Por outro lado, nenhum dos cenários analisados obteve as menores contribuições para todas as categorias avaliadas.

Pintilie et al. (2016) testaram a viabilidade de práticas de reúso de água no setor industrial a partir de efluentes recuperados por uma unidade de tratamento na Espanha. Os autores concluíram que o consumo de eletricidade se configurava como a principal fonte de impactos ambientais naquela situação, e que o reúso poderia ser uma alternativa adequada para usos não-potáveis, como ocorre com muitas aplicações industriais.

No entanto, até onde se pôde verificar, não foram encontrados registros de estudos de ACV voltados para a avaliação de tecnologias de reúso de água em processos de circuito fechado. Esse estudo se propõe a dar uma contribuir ao tema, investigando o desempenho ambiental de diferentes cenários de condicionamento do efluente gerado em uma refinaria de petróleo localizada no Brasil, de forma a poder reutilizá-lo em etapas de processo da própria unidade. Para atingir este objetivo, uma ACV atribucional com enfoque 'berço-ao-portão' foi realizada. 
Além de identificar que limitações associados ao tratamento e ao reúso devem ser analisadas com maior nível de detalhe para reduzir impactos ambientais, essa análise pode também gerar informações para a gestão de recursos hídricos em situações nas quais a captação de água seja limitada (ou mesmo, proibida) por dispositivos legais.

Nesse contexto desempenho ambiental tem potencial para ser um dos critérios de tomada de decisão para práticas de reúso. Além da correlação (próxima) com aspectos econômicos, a adoção desta metodologia pode apoiar ações de otimização em arranjos processuais e na seleção de tecnologias.

\subsection{Metodologia}

O método aplicado neste estudo se constituiu de seis passos: (i) especificação das características do efluente à jusante da estação de tratamento de despejos industriais (ETDI) da refinaria, e a escolha de um processo para ser suprido com a água recuperada; (ii) definição das estratégias de recuperação e água e estabelecimento dos cenários de análise; (iii) descrição dos sistemas de recuperação de água em termos das tecnologias abordadas e condições de operação, bem como os consumos de recursos e emissões; (iv) elaboração de modelos matemáticos para representar cada sistema a partir dos dados e informações obtidos na etapa anterior; (v) aplicação da técnica de ACV para estabelecer um diagnóstico ambiental para cada cenário em termos de Demanda de Energia Primária e Aquecimento Global; e (vi) análise dos resultados obtidos.

\subsubsection{Caracterização do efluente e destinação da água recuperada}

O efluente da refinaria é submetido a um tratamento convencional na Estação de Tratamento de Despejos Industriais (ETDI). Os passos iniciais do processo consistiram na separação entre água e óleo, realizada por separador API, bem como na remoção de sólidos suspensos, óleos e graxas, efetuada por filtro flotador. 0 princípio de operação do separador API é baseado na diferença de peso específico entre o óleo e o efluente, o qual é menor do que a existente entre os sólidos suspensos e a água. Dessa forma, os sólidos se depositam no fundo do separador, o óleo segue para o topo, e o efluente passa a ocupar a camada intermediária, sendo recuperado separadamente de outros componentes (API, 1990). Sólidos dissolvidos que atribuem carga orgânica ao efluente são tratados na etapa secundária, composta de lagoas de aeração (completa e facultativa) e biodiscos. 
Por fim, na etapa terciária, os contaminantes que conferem cor e condutividade ao efluente, bem como sais e nutrientes, metais, compostos não biodegradáveis e sólidos suspensos voláteis, são removidos da corrente líquida por sua passagem através de um clarificador e um filtro de carvão ativado. A Tabela 4.1 apresenta as características de um efluente típico de ETDI.

O efluente de saída da ETDI pode sofrer variações significativas dependendo do tipo de óleo processado, da configuração da refinaria e dos procedimentos adotados para o tratamento (DIYA'UDDEEN et al., 2011). Essa informação não é, no entanto, facilmente acessível. Assim, a Tabela 4.1 apresenta as faixas de concentração dos contaminantes presentes na corrente de entrada da ETDI. Os limites que definem cada intervalo foram estabelecidos com base nos dados de Gripp (2013), Moreira (2017) e Pantoja (2015) para refinarias com mesmas características tecnológicas, mas em períodos diferentes. Outra característica do efluente de refinaria destacada na Tabela 4.1 refere-se à elevada diversidade de sais inorgânicos em sua composição à saída da ETDI. De qualquer forma, tendo em conta que o escopo de aplicação da técnica de ACV definido para esse estudo parte do efluente tratado, o desempenho ambiental da ETDI não foi analisado. De qualquer forma, as operações acima descritas são fundamentais na especificação da qualidade dos vertidos à entrada dos arranjos analisados.

O processo adotado para definição do destino da água recuperada levou em conta dois critérios: (i) volume consumido pelos setores produtivos ou atividades da refinaria; e, (ii) restrições de qualidade da água para cada uso. A referência mundial para consumo específico de água em processos de refino de petróleo estabelece uma faixa entre 0,7 e 1,2 m³ água/m³ óleo processado (DIEPOLDER, 1992; ANZE et al., 2010). Tomando-se por referência o perfil médio estratificado de consumo de água das refinarias brasileiras é possível concluir : 46\% desse montante se presta a para reposição de perdas em torres de resfriamento; $26 \%$ serve a produção de vapor em caldeiras; 9,0\% são utilizados em sistemas de combate a incêndios; e o restante ( 19\%) será absorvido na preparação de compostos químicos (diluição), na limpeza da unidade e para consumo humano (POMBO, 2011). A água alimentada nas caleiras requer o padrão de qualidade mais restritivo em termos de concentração de sais, matéria orgânica e gás dissolvido. A reposição da água de torres de resfriamento predispõe níveis intermediários de qualidade; nesses casos, os limites de contaminação são estabelecidos para controlar (ou prevenir) incrustações, corrosões formação de algas e lodo. 
De modo geral, a água usada em combate de incêndio não requer qualquer tratamento (IPIECA, 2010). Considerando esses argumentos, além do desempenho do sistema de recuperação de água em relação à qualidade do produto final e a eficácia com que tais limites podem ser atingidos, definiu-se a alimentação de uma das torres de resfriamento da refinaria como o uso final da água tratada.

Tabela 4.1 - Concentrações de sais no efluente de refinaria

\begin{tabular}{|c|c|c|}
\hline \multirow{2}{*}{ Analitos } & $\begin{array}{l}\text { Efluente ETDI } \\
\text { (Faixas de concentração) }\end{array}$ & $\begin{array}{l}\text { Efluente ETDI } \\
\text { (Valores definidos para o estudo) }\end{array}$ \\
\hline & $(\mathrm{ppm})$ & $(\mathrm{ppm})$ \\
\hline $\mathrm{Ba}^{2+}$ & $0,20-0,50$ & 0,30 \\
\hline $\mathrm{Ca}^{2+}$ & $38,0-63,0$ & 53,1 \\
\hline $\mathrm{Al}^{3+}$ & $0,00-0,01$ & $<0,01$ \\
\hline $\mathrm{Sr}^{2+}$ & $1,10-1,83$ & 1,32 \\
\hline $\mathrm{SiO}_{2}$ & $0,80-19,4$ & 7,33 \\
\hline $\mathrm{Fe}$ (total) & $0,00-0,01$ & $<0,01$ \\
\hline $\mathrm{Mg}^{2+}$ & $4,00-7,52$ & 6,56 \\
\hline $\mathrm{Na}^{+}$ & $179-283$ & 255 \\
\hline $\mathrm{Cl}^{-}$ & $311-425$ & 385 \\
\hline $\mathrm{HCO}_{3}^{-}$ & $55,9-308$ & 216 \\
\hline $\mathrm{K}^{+}$ & $6,00-11,5$ & 7,76 \\
\hline $\mathrm{NH}_{4}^{+}$ & $0,50-7,60$ & 4,56 \\
\hline $\mathrm{PO}_{4}^{3-}$ & $0,00-3,74$ & 2,12 \\
\hline $\mathrm{NO}_{3}^{-}$ & $22,4-207$ & 101 \\
\hline $\mathrm{SO}_{4}^{2-}$ & $85,6-163$ & 110 \\
\hline $\mathrm{F}^{-}$ & $0,10-0,69$ & 0,20 \\
\hline TDS (como, $\mathrm{NaCl})^{1}$ & $359-1103$ & 762 \\
\hline $\mathrm{pH}$ & $6,74-8,81$ & 6,74 \\
\hline
\end{tabular}

Fontes: Gripp (2013), Moreira (2017) e Pantoja (2015).

(1) TDS: sólidos dissolvidos totais. 


\subsubsection{Definição de cenários de análise e descrição dos sistemas de recuperação}

A qualidade do efluente na saída da etapa terciária da ETDI (Tabela 4.1) torna necessária uma remoção complementar de metais $\left(\mathrm{Ca}^{2+}, \mathrm{Ba}^{2+}\right.$ e $\left.\mathrm{Na}^{+}\right)$, cloretos $\left(\mathrm{Cl}^{-}\right)$e carbonatos $\left(\mathrm{CO}_{3}{ }^{2-}\right)$ para recondicionamento desse fluxo como água de reposição na torre de resfriamento. Desta forma, seis arranjos de recuperação de água foram definidos. As operações de OI, evaporação (EV) e cristalização (CR) são comuns a todas as estratégias. Por outro lado, essas estratégias variam com relação ao pré-tratamento do efluente antes da entrada na OI e à tecnologia usada na EV.

Baseando-se em princípios de precipitação, o pré-tratamento se ocupa da remoção de íons que podem reduzir, ou até comprometer, o desempenho da OI. A definição dos agentes químicos aplicados neste estágio levou em conta seus potenciais de remoção, por meio de mecanismos que afetam a solubilidade iônica em soluções aquosas. Em relação à tecnologia EV, duas alternativas foram estudadas: (i) a destilação multi-efeito, e (ii) a recompressão de vapor. Cada estratégia de recuperação resultou na formulação de um cenário de análise (S1 a S6). A Tabela 4.2 traz algumas especificidades de cada cenário quanto às condições tecnológicas e à proveniência da energia utilizada.

S1 foi definido como o cenário-base e, dessa forma, nenhum pré-tratamento foi alocado para esta situação. Por conta da alta concentração iônica no efluente, foi constatado o risco de incrustações na membrana de osmose, tornando necessária a adição de reagentes anti-incrustantes no efluente líquido na entrada do módulo de OI. Em S1, esta situação foi contornada pela adição de EDTA, frequentemente utilizado em tais casos. No entanto, o excesso deste componente pode causar efeitos colaterais, como bio-incrustação, fenômeno nocivo para situações de fechamento de circuito como regime de Descarga Zero de Líquidos (RAHARDIANTO et al., 2007).

Em S2, o pré-tratamento ocorreu pela dessupersaturação por meio da adição de sementes de $\mathrm{BaSO}_{4}(\mathrm{BaDs})$. Esta estratégia visa a remoção do próprio sulfato de bário através de seu acúmulo na presença de cristais formados por este sal (BREMERE et al., 1998). $\mathrm{BaSO}_{4}$ é em geral encontrado em concentrações de supersaturação em efluentes industriais (particularmente em refinarias de petróleo), sendo um dos principais agentes de incrustação em plantas de OI (BREMERE et al., 1999). 
0 método de coprecipitação (CPT) em ambiente alcalino $(\mathrm{pH}=11)$ aplicando $\mathrm{Ca}(\mathrm{OH})_{2}$ e sementes de $\mathrm{CaCO}_{3}$ (RAHARDIANTO et al., 2007) foi adotado em S3 como prétratamento. Além de precipitar a maior parte do carbonato de cálcio em solução, essa medida auxiliou também na remoção $\mathrm{SiO}_{2}$, outro componente limitante em OI, ao ter sua solubilidade reduzida com o aumento do $\mathrm{pH}$. A CPT também conduziu à remoção de íons metálicos - $\mathrm{Ba}^{2+}, \mathrm{Sr}^{2+}, \mathrm{Fe}^{2+}, \mathrm{Mn}^{2+}$ e $\mathrm{Cd}^{2+}$ - pela incorporação ao $\mathrm{CaCO}_{3}$ precipitante via adsorção isomórfica, absorção ou substituição (ASTILLEROS, 2006). 0 sobrenadante que resulta do processo de CPT é posteriormente acidificado até $\mathrm{pH}=8,0$ para a prevenção de incrustações principalmente no sistema de OI. Em S3 e S5, isto ocorre pela adição de $\mathrm{HCl}$ (1,0 M) e, em S6, via $\mathrm{HNO}_{3}(1,0 \mathrm{M})$.

Tabela 4.2 - Características técnicas e fontes de energia de cada cenário

\begin{tabular}{|c|c|c|c|c|c|c|c|}
\hline Parâmetro & Condições tecnológicas & $\mathrm{S} 1$ & $\mathrm{~S} 2$ & S3 & S4 & S5 & S6 \\
\hline \multirow{2}{*}{$\begin{array}{l}\text { Arranjo } \\
\text { tecnológico }\end{array}$} & Osmose inversa (OI) & + & + & + & - & + & + \\
\hline & $\begin{array}{l}\text { Cristalização evaporativa } \\
\text { (EV + CR) }\end{array}$ & + & + & + & + & + & + \\
\hline \multirow{2}{*}{$\begin{array}{l}\text { Método de } \\
\text { pré- } \\
\text { tratamento }\end{array}$} & $\begin{array}{l}\text { Dessupersaturação de } \\
\text { bário (BaDs) }\end{array}$ & - & + & - & - & - & - \\
\hline & Coprecipitação (CPT) & - & - & + & - & + & + \\
\hline \multirow{2}{*}{$\begin{array}{l}\text { Fonte } \\
\text { energética }\end{array}$} & Eletricidade & $\begin{array}{l}\text { Matriz } \\
\text { BR }^{1}\end{array}$ & $\begin{array}{l}\text { Matriz } \\
\text { BR }\end{array}$ & $\begin{array}{l}\text { Matriz } \\
\text { BR }\end{array}$ & $\begin{array}{l}\text { Matriz } \\
\mathrm{BR}+\mathrm{VR}\end{array}$ & $\begin{array}{l}\text { Matriz } \\
\text { BR }\end{array}$ & $\begin{array}{l}\text { Matriz } \\
\text { BR }\end{array}$ \\
\hline & Calor & $\mathrm{GN}^{2}$ & GN & GN & $\mathrm{VR}^{3}$ & $\mathrm{~N} / \mathrm{A}^{4}$ & GN \\
\hline $\begin{array}{l}\text { Rendimento } \\
\left(\boldsymbol{\eta}_{\boldsymbol{S} i}\right)\end{array}$ & $\begin{array}{l}\text { Recuperação de água na OI } \\
(\%)\end{array}$ & 84,6 & 87,0 & 95,8 & - & 95,8 & 95,8 \\
\hline
\end{tabular}

Legenda: (1)Matriz BR: Matriz elétrica brasileira; (2)GN: gás natural; (3)VR: vapor residual (calor);

(4) N/A: não aplicável

S4 avaliou a situação na qual a energia térmica consumida pelo EV e CR é originada de vapor residual. Neste caso, parte do calor liberado para a atmosfera nas chaminés das caldeiras segue para a planta de dessalinização. Esta opção é economicamente atrativa dada a redução dos custos de geração de calor, além da eliminação da OI - e por conseguinte, de qualquer pré-tratamento - do sistema (HEINS e SCHOOLEY, 2004). 
S5 examinou um arranjo substitutivo de S3, no qual a demanda energética de EV é suprida exclusivamente por eletricidade. Este cenário assume uma mudança tecnológica na etapa de evaporação, na qual a destilação multi-efeito, adotada pelos cenários S1-S4 e S6, dá lugar a recompressão de vapor (MICKLEY, 2008). Esta tecnologia aplica o vapor produzido no próprio equipamento para realizar a evaporação. Para tal, um compressor alimentado por motor elétrico eleva as funções de estado (temperatura e pressão) do vapor. Além de evaporar água presente na solução salina, a corrente de vapor também é usada para ajustar a temperatura do efluente à entrada do evaporador (Al-KARAGHOULI e KAZMERSKI, 2013).

Dado que a eletrólise, tecnologia comumente usada para a obtenção de $\mathrm{HCl}$, detém elevadas necessidades de eletricidade (ALTHAUS et al., 2007), uma variante de S3 - denominada S6 - foi também analisada. Nesse caso, a acidificação do sobrenadante obtido na CPT é realizada por adição de $\mathrm{HNO}_{3}$, tal como descrito anteriormente.

O uso de ácido nítrico torna-se viável porque o íon NO3- é, com poucas exceções, bastante solúvel em água. Portanto, sua presença no efluente não resulta em riscos de incrustação nos estágios subsequentes de tratamento.

Finalmente, deve-se ressaltar que o pré-tratamento de efluente por BaDs aumenta a taxa de recuperação de água em $2,8 \%$ no estágio de OI $\left(\eta_{\mathrm{S} 2}\right)$ se comparada àquela que foi observada em S1. Nos casos em que essa ação ocorre pela CPT (S3, S5 e S6) o ganho na eficiência é ainda mais expressivo, ultrapassando $\eta_{S 1}$ em cerca de $13 \%$.

\subsection{Modelagem do sistema}

A ferramenta computacional Hydranautics ${ }^{\circledR}$ 'IMS Design' foi usada para modelar a unidade de RO. O projeto deste estágio considerou um fluxo médio de $\mathrm{Q}=20 \mathrm{Lmh}$, concentração limitante de polarização máxima $\left(\beta_{\max }=1,18\right)$ e uma membrana padrão de alta rejeição de solução salina CPA7 MAX. Assumiu-se também que as bombas da OI atingiriam rendimentos médios $\eta=87 \%$. Com exceção de $S 5$, todos os cenários avaliados adotaram a tecnologia de destilação multi-efeitos para o estágio EV. Nesses casos, foram necessários fluxos de calor de $230 \mathrm{MJ} / \mathrm{m}^{3}$ efluente -para colocar o vapor em condições de processo -, e eletricidade, a razão de $9,00 \mathrm{MJ} / \mathrm{m}^{3}$ - empregado na maior parte em operações de bombeamento (ALTHAUS et al., 2007). Em S5, a evaporação se dá por meio de recompressão do vapor, demandando apenas eletricidade. Uma unidade que opera com essa tecnologia atinge um consumo de $115 \mathrm{MJ} / \mathrm{m}^{3}$ (HEINS e SCHOOLEY, 2004). 
No estágio CR, o fluxo de efluente alimentado ao sistema de dessalinização (250 $\mathrm{m}^{3} / \mathrm{h}$ ) também justifica o uso de recompressão de vapor (VEZA, 1995). Além disso a demanda de energia relacionada à tecnologia de cristalização é de 238 MJ/m³ (MICKLEY, 2008). Esse desempenho foi considerado para modelagem de todos os cenários.

$\mathrm{O}$ calor residual que atende à demanda térmica de $\mathrm{S} 4$ foi descrito como um fluxo elementar. Em termos metodológicos, essa decisão representa a eliminação de todas as cargas ambientais associadas a esse fluxo (e assim, também os impactos decorrentes) que tenham sido geradas por intervenções antrópicas antes de seu uso pelo sistema de dessalinização. A decisão é sustentada pela hipótese de que o calor, um dos resíduos de refino de petróleo bruto, é revalorizado em S4, quando se torna fluido de processo. Para $\mathrm{EV}$, a redução de energia assumida em outros cenários $\left(9,00 \mathrm{MJ} / \mathrm{m}^{3}\right)$ também foi adotada para S4. Por outro lado, a modelagem do estágio CR admitiu que o bombeamento de fluido consumiria cerca de $576 \mathrm{MJ} / \mathrm{t}$ sal obtido. Esse valor foi estimado por Jongema (1983) a partir de abordagem termodinâmica baseada em uma análise de exergia.

As estimativas de taxa de precipitação foram realizadas com auxílio do simulador OLI Systems Inc. ®, que fornece as composições aproximadas dos sais formados. Para S1, esse cálculo incluiu uma taxa adicional de 4,0 ppm de EDTA. Em S2, assumiu-se que a troca de sementes de $\mathrm{BaSO}_{4}$ é realizada uma vez por ano (C $\left.\sim 10 \mathrm{~g} / \mathrm{L}\right)$. Além disso, foram considerados um consumo de 79,2 kJ/m³ para agitação no estágio de precipitação, e uma limpeza mensal dos equipamentos com solução de $\mathrm{HCl}(\mathrm{pH}=3,0)$.

S3 inclui um consumo elétrico de $317 \mathrm{~kJ} / \mathrm{m}^{3}$ para agitação no coprecipitador, além da inserção de 12,5 g/L de sementes de $\mathrm{CaCO}_{3}$ (renovação anual), e da acidificação do sobrenadante obtido no estágio de precipitação (adição de $\mathrm{HCl}$ 1,0 M) para atingimento de $\mathrm{pH}=8,0$ condição que evitam a formação de incrustações alcalinas.

Os transportes considerados nos modelos foram a tubulação que distribui a água recuperada desde a unidade de dessalinização, até a torre de resfriamento ( $\mathrm{L} \sim 200 \mathrm{~m}$ ) e o transporte do sal dos estágios de precipitação e cristalização a um aterro sanitário localizado a $20 \mathrm{~km}$ da refinaria. Por fim, a matriz energética brasileira (matriz BR) foi a fonte exclusiva de suprimento de eletricidade do sistema de dessalinização em todos os cenários analisados. 


\subsection{Modelagem do ciclo de vida}

\subsubsection{Definição de escopo}

Os diagnósticos ambientais foram realizados por meio de uma ACV atribucional, sob uma abordagem "berço-ao-portão" e de acordo com as diretrizes fornecidas pela norma ISO 14044 (2006). Um fluxo de referência (FR) de 'adicionar 1,0 m3 de água reutilizada a uma torre de resfriamento dentro dos requisitos de qualidade que permitem o bom funcionamento deste equipamento' foi definido para realizar as análises.

A Figura 4.1 mostra uma visão geral do conjunto de elementos, destacando todas as interconexões entre o processo de refino, a ETDI e o sistema de recuperação de água. O sistema de produto que representa os cenários S1 - S4 e S6 está contido no retângulo cinza escuro. A Figura 4.2 detalha o mesmo arranjo para S5. A modelagem do sistema de produto foi baseada em dados primários e secundários, que expressam condições locais. Nenhuma situação de multifuncionalidade foi encontrada

Figura 4.1 - Sistemas de recuperação de efluentes (S1-S4 e S6) para reúso em torre de resfriamento

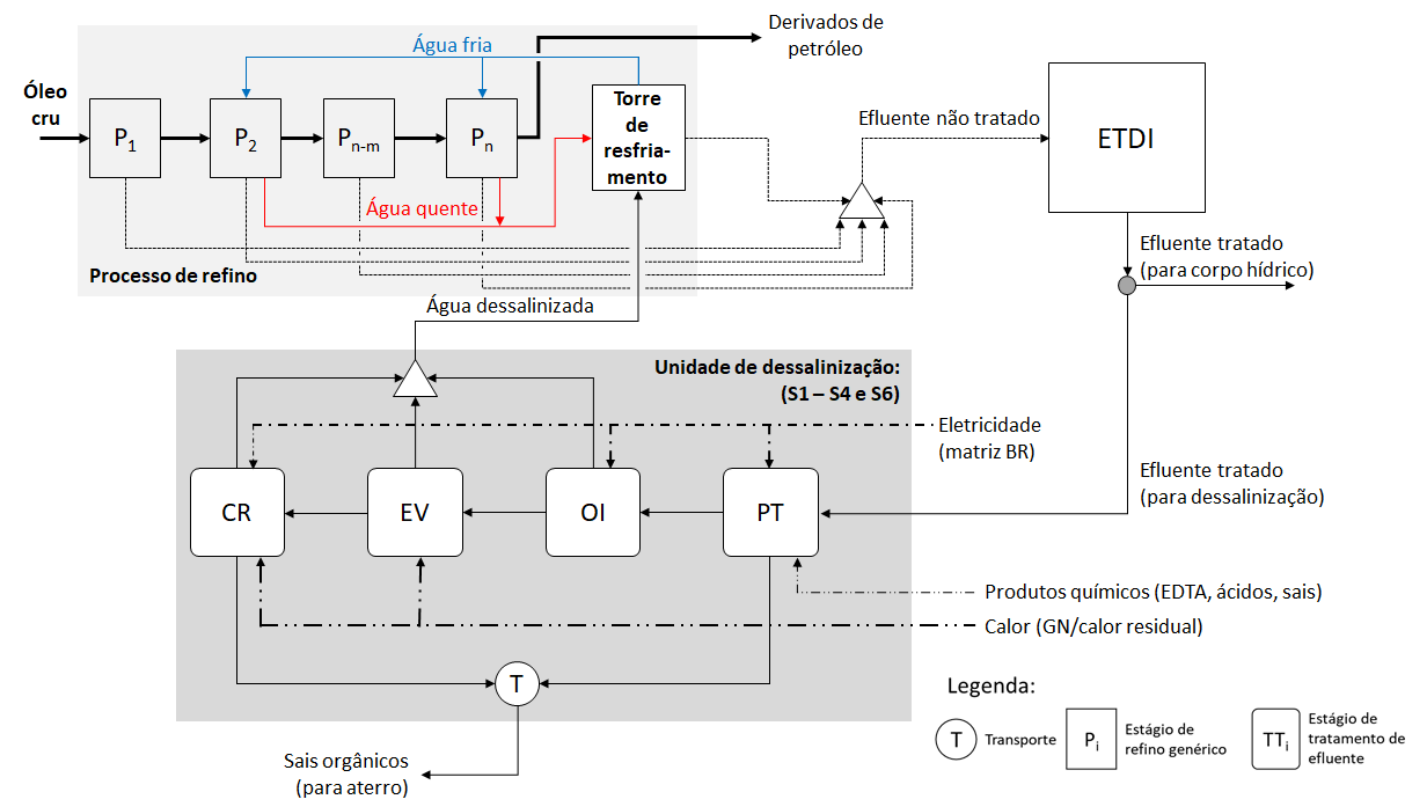


Figura 4.2 - Detalhe do sistema de dessalinização para o cenário S5

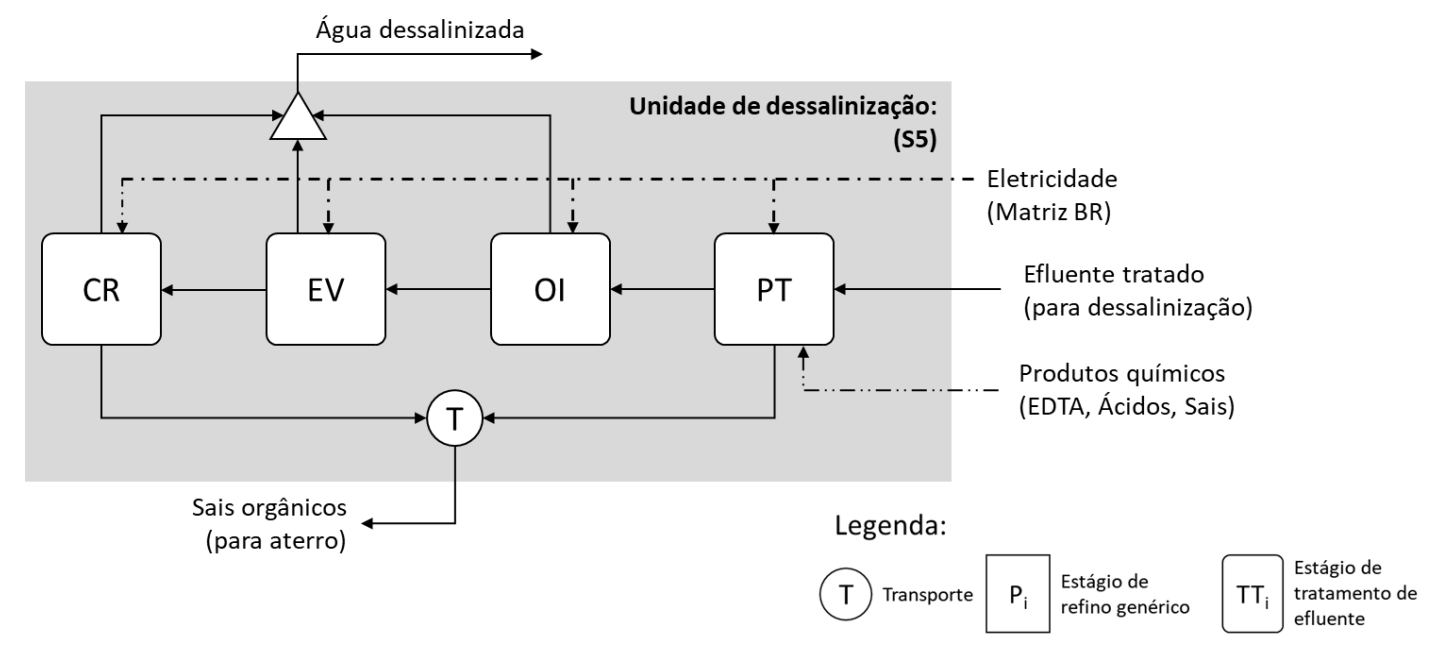

A avaliação de impacto de ciclo de vida foi realizada em dois níveis. No primeiro, o consumo de energia do processo em termos de Demanda de Energia Primária (DEP) foi quantificado pelo método da Demanda Cumulativa de Energia (CED) - v1.10 (HISCHIER et al., 2010), que aborda as contribuições das diferentes fontes de energia , renováveis (biomassa: RB; eólica: RE; água: RA) e não renováveis (fósseis: NRF; nuclear: NRN; biomassa: NRB). No segundo nível, o efeito ambiental do Aquecimento Global (AG) foi estimado pelo método ReCiPe 2016 Midpoint (H) - v1.13 (HUIJBREGTS et al., 2016).

\subsubsection{Inventário de Ciclo de Vida (ICV)}

As concentrações de efluentes à entrada do arranjo processual (Tabela 4.1) são dados primários obtidos de uma refinaria. Por outro lado, os suprimentos de energia elétrica e gás natural (GN) foram modelados a partir de dados secundários. A geração de eletricidade via matriz BR foi editada para as condições brasileiras de 2015 (EPE, 2016a). A energia hidrelétrica continua sendo a fonte mais expressiva de suprimento de energia (64\% da matriz BR) e a biomassa (8,0\%) é representada por bagaço de cana-de-açúcar. Para o carvão $(4,0 \%)$, foi criado um modelo de oferta mista (nacional e colombiano) considerando a operação de mineração e as distâncias das minas brasileiras às principais usinas termelétricas (EPE, 2016b). Quanto ao gás natural usado da matriz BR (13\%) e no fornecimento de calor, um modelo obtido no banco de dados Ecoinvent foi adaptado às condições brasileiras, considerando a extração offshore local, as atividades envolvidas no refino de gás natural bruto e o transporte do produto final. 
No Brasil, o transporte terrestre ocorre principalmente por via rodoviária. 0 diesel consumido nessas ações foi adaptado a partir do ICV 'Crude oil, in refinery/US' disponível no banco de dados USLCI (FRANKLIN ASSOCIATES, 2003), mais uma vez considerando os requisitos processuais e tecnológicos praticados no país. As entradas e materiais auxiliares, como EDTA, barita e hidróxido de cálcio, foram editados a partir dos conjuntos de dados Ecoinvent intitulados ' EDTA, ethylenediaminetetraacetic acid, at plant/RER U' (HISCHIER et al., 2007), ' barite, at plant/RER' (JUNGBLUTH etl al., 2007) e 'lime, hydrate, loose weight at plant/RER' (KELLENBERGER et al., 2007) para efeito de reprodução da realidade nacional de modo confiável.

Abordagem semelhante foi aplicada ao processo de produção de $\mathrm{HCl}$ (ajustado a partir do Ecoinvent: 'Hydrochloric acid, 30\% in $\mathrm{H}_{2} \mathrm{O}$, at plant/RER $U$ '), $\mathrm{HNO}_{3}$ (desde o ICV 'nitric acid, 50\% in $\mathrm{H}_{2} \mathrm{O}$, at plant/RER $U$ ' também da base Ecoinvent) e água (adaptada do Ecoinvent: 'Tap water, at user/U') (ALTHAUS et al., 2007) usada para diluição de ácidos concentrados até 1,0 M. Como no caso do diesel, os insumos originais de energia - eletricidade, GN, o próprio diesel e outros derivados de petróleo - foram substituídos por inventários criados especificamente para este estudo.

\subsection{Resultados}

A Tabela 4.3 descreve os impactos ambientais de DEP e AG dos sistemas incluídos nos cenários $\mathrm{S} 1$ - $\mathrm{S} 6$, associados ao fornecimento de 1,0 $\mathrm{m}^{3}$ de água recuperada para uma torre de resfriamento na refinaria.

O S4 apresentou os menores impactos de toda a série para ambas as categorias, principalmente devido ao uso de calor residual como fonte de energia térmica para o sistema. Por outro lado, S1 (cenário-base) registrou os piores índices de desempenho nas mesmas dimensões, devido à ausência de pré-tratamento do efluente destinado para OI. Essa condição sobrecarrega o sistema de osmose, que então apresenta taxas reduzidas de recuperação de água (Tabela 4.1) e faz com que todos os elementos do arranjo exijam maiores quantidades de calor e eletricidade, a fim de gerar água dentro dos padrões de qualidade exigidos pela torre de resfriamento. A adoção de métodos de pré-tratamento melhorou o desempenho da DEP em todos os cenários. 0 uso de BaDs (S2) levou a uma redução de $13 \%$ no impacto em relação ao $\mathrm{S} 1$, enquanto que os ganhos foram ainda mais expressivos com o CPT, atingindo 55\%, 66\% e 54\% de atenuação, respectivamente para S3, S5 e S6. 
Tabela 4.3 - Impactos relacionados à Demanda de Energia Primária (DEP) (descritos por subcategoria e impacto total) e ao Aquecimento Global (AG) para os cenários S1-S6

\begin{tabular}{|c|c|c|c|c|c|c|c|}
\hline \multicolumn{2}{|c|}{ Categoria de impacto } & S1 & S2 & S3 & S4 & S5 & S6 \\
\hline \multirow{6}{*}{$\begin{array}{l}\text { DEP } \\
(\mathrm{MJ} / \mathrm{FR})\end{array}$} & Não-renovável, fóssil & 44,4 & 37,6 & 15,7 & 3,49 & 5,97 & 16,8 \\
\hline & $\begin{array}{l}\text { Não-renovável, } \\
\text { nuclear }\end{array}$ & 0,51 & 0,51 & 0,57 & 0,57 & 0,88 & 0,57 \\
\hline & Renovável, biomassa & 0,78 & 0,78 & 0,78 & 0,99 & 1,32 & 0,69 \\
\hline & Renovável, eólica & 0,32 & 0,32 & 0,32 & 0,42 & 0,50 & 0,32 \\
\hline & Renovável, água & 4,79 & 4,79 & 5,33 & 6,43 & 8,53 & 4,62 \\
\hline & Total & 50,8 & 44,0 & 22,7 & 11,9 & 17,2 & 23,0 \\
\hline \multicolumn{2}{|c|}{$\mathrm{AG}\left(\mathrm{kgCO}_{2, \mathrm{eq}}\right)$} & 2,93 & 2,56 & 1,52 & 0,72 & 1,24 & 1,93 \\
\hline
\end{tabular}

A mudança tecnológica aplicada a EV também trouxe ganhos para a categoria, pois a DEP acumulada para S5 foi 24\% menor que a do S3. Por outro lado, o uso de $\mathrm{HNO}_{3}$ (S6) ao invés de $\mathrm{HCl}$ (S3) não aportou qualquer variação significante ao comportamento energético. Essa troca de posições se dá pois S1 - S3 e S6 apresentam demandas finitas de energia térmica na EV (Tabela 4.4), que são supridas por gás natural, enquanto S4 utiliza mais calor durante o processo EV que os demais cenários (230 MJ/FR). No entanto, devido ao fato de o calor ser residual, essa utilidade não traz impactos para DEP. O S5 não utiliza fluxos térmicos durante esta etapa do processo. Por outro lado, S4 e S5 apresentam as maiores taxas de consumo elétrico entre os cenários avaliados (13,1 e 10,4 MJ/FR). A matriz BR, predominantemente de energia hidrelétrica, atende a essas demandas (EPE, 2016a), tendo a Renovável, água como principal agente de impacto.

Conforme mostra a Tabela 4.4, o consumo de gás natural para geração de calor em S1/EV se constitui na principal fonte de contribuição em Não-renovável, fóssil e, portanto, de DEP para o cenário. 0 pré-tratamento do efluente eleva o consumo elétrico de S2/RO em 19\% em relação a S1. Por outro lado, o uso de BaDs faz com que $\eta_{\mathrm{S} 2}>\eta_{\mathrm{S} 1}$ (Tabela 4.2), levando a uma diminuição de 16\% nas demandas térmica (aquecimento) e elétrica (bombeamento) do EV, em relação à evaporação em S1. A combinação desses efeitos é favorável a S2, uma vez que, ao consumir quantidades menores de gás natural, as contribuições de Não-renovável, fóssil chegam a ser em 15\% inferior às observadas em S1. Como as contribuições para as outras subcategorias são equivalentes para os dois cenários (Tabela 4.3), $\mathrm{DEP}_{\mathrm{S} 2}$ superou $\mathrm{DEP}_{\mathrm{S} 1}$ em pouco mais de $13 \%$. 
Tabela 4.4 - Consumo total de energia por estágio do sistema em cada cenário (MJ/FR)

\begin{tabular}{|c|c|c|c|c|c|c|c|}
\hline Estágio & Fonte de energia & S1 & $\mathrm{S} 2$ & S3 & S4 & S5 & S6 \\
\hline \multirow[t]{2}{*}{ OI } & Eletricidade & 1,12 & 1,33 & 2,12 & - & 2,12 & 2,12 \\
\hline & Calor & 35,9 & 30,3 & 9,74 & - & - & 9,76 \\
\hline \multirow[t]{3}{*}{ EV } & Eletricidade & 1,40 & 1,19 & 0,40 & 9,00 & 4,86 & 0,40 \\
\hline & Calor residual & - & - & - & 230 & - & - \\
\hline & Eletricidade & 4,07 & 4,07 & 3,38 & 0,11 & 3,38 & 3,53 \\
\hline & Calor residual & - & - & - & 3,96 & - & - \\
\hline
\end{tabular}

Legenda: OI: osmose inversa; EV: evaporação; CR: cristalização

S3 segue tendências semelhantes às observadas para S2. Nesse caso porém, o fato de $\eta_{\mathrm{S} 3}$ ser maior que $\eta_{\mathrm{S} 1}$ se deve à CPT ter maior consumo elétrico na OI do que $\mathrm{S} 1$, além de reduzir ainda mais a demanda de energia em EV. Com isso, o consumo de gás natural acaba sendo atenuado de forma tal que (Não-renovável, fóssil)s3 é menor do que (Nãorenovável, fóssil) $)_{S 1}$ em 64\%, o que imediatamente resultou em diminuição de 55\% no $\mathrm{DEP}_{\mathrm{S} 3}$ em comparação ao cenário-base. No entanto, uma análise mais detalhada dos resultados em termos de RA para S2 e S3 indicou um aumento de 11\% nessa fonte de impacto devido à substituição de BaDs por CPT. Essa disparidade pode ser explicada pelas cargas ambientais associadas à fabricação de $\mathrm{HCl}$.

A eletrólise, uma tecnologia energo-intensiva, é uma das tecnologias mais difundidas para a síntese de $\mathrm{Cl}_{2}$. A obtenção de $\mathrm{Cl}_{2}$ a partir da água do mar consome de 414 a $500 \mathrm{~kJ} / \mathrm{kg} \mathrm{Cl}_{2}$ de eletricidade (ALTHAUS et al., 2007). Portanto, o ciclo de fabricação de $\mathrm{HCl}$ exibe uma contribuição de $757 \mathrm{~kJ} / \mathrm{RF}$, correspondente a $14 \%$ de todo o valor de RA para S3.

$\mathrm{O}$ uso de calor residual reduziu o $\mathrm{DEP}_{\mathrm{S} 4}$ em relação aos impactos gerados por conta da demanda elétrica do sistema pela matriz BR. Portanto, já era esperado que os impactos em RA representassem a maior parcela (54\%) do total. No processo, destacamse gastos individuais com eletricidade para bombear o efluente até EV (6,23 MJ/RF). 
A mudança na tecnologia de evaporação implementada em S5 - de múltiplo efeito para recompressão de vapor - desobrigou do uso de gás natural nesta etapa do sistema, mas aumentou o consumo de eletricidade. Muito embora $22 \%$ da matriz BR se componha por fontes não renováveis (EPE, 2016a), o efeito da interrupção do uso de gás natural em EV no desempenho de (Não-renovável, fóssil) S5 $_{5}$ prevaleceu sobre as entradas que a subcategoria recebeu devido ao aumento do uso de eletricidade. Além disso, a recompressão de vapor fez com que RA se tornasse o precursor dominante de $\mathrm{DEP}_{\mathrm{s5}} \mathrm{com}$ $49 \%$ de contribuição.

A substituição do $\mathrm{HCl}$ por $\mathrm{HNO}_{3}$ introduzido em $\mathrm{S} 6$ causou um efeito positivo. Por conta da eletrólise no processo de produção de $\mathrm{HCl}$, o consumo acumulado de eletricidade do sistema foi reduzido (Renovável, água) $)_{\mathrm{s} 6}<(\text { Renovável, água) })_{\mathrm{s} 3}$. Por outro lado, a síntese de $\mathrm{HNO}_{3}$ tem como matéria-prima essencial a amônia obtida através da reforma a vapor de gás natural $\left(0,63 \mathrm{~m}^{3} \mathrm{GN} / \mathrm{kg} \mathrm{NH}_{3}\right)$. Além disso, como os processos de produção de $\mathrm{NH}_{3}$ e $\mathrm{HNO}_{3}$ são endotérmicos, outra porção de gás natural necessita ser adicionada ao sistema para atender a essas necessidades. A combinação entre esses elementos explica o fato de que (Não-renovável, fóssil)s6 superou (Não-renovável, fóssil) $)_{\mathrm{S} 3}$ em 1,08 MJ/RF, apesar da diminuição do consumo elétrico global observado em S6.

Finalmente, uma análise coletiva das constatações descritas acima indica uma correlação intrínseca entre as ações realizadas para o processo e seu desempenho em termos de DEP. Com relação aos cenários S1 - S3 e S6, que diferem apenas na tecnologia de pré-tratamento aplicada, o aumento de $\eta_{\mathrm{Si}}$ (Tabela 4.2) se reverte na mitigação dos impactos globais de DEP (Tabela 4.3). A substituição de EDTA (S1) por BaDs (S2) e de BaDs (S2) pela CPT (S3 e S6) elevou a eficiência de recuperação de água em RO a níveis acentuados. Esta tendência é baseada na (alta) eficácia alcançada pela CPT na remoção de sal dissolvido no efluente em comparação com outras alternativas.

0 aumento de $\eta_{\mathrm{Si}}$ conduziu a melhoria do consumo de energia na OI (Tabela 4.4), devido à resistência adicional que o soluto formado pelo pré-tratamento impõe ao fluxo de solvente (água em uso pela torre de resfriamento) através da membrana. No entanto, os fluxos de concentrado transferidos para EV foram reduzidos. Tal efeito levou a maiores benefícios em DEP do que os aqueles, prejudiciais, causados pelo aumento da temperatura de ebulição das soluções, resultando em consumos de calor mais discretos na destilação multi-efeito (Tabela 4.4). Fenômeno semelhante foi observado para as correntes de concentrado encaminhados para CR que, devido aos seus baixos fluxos, proporcionaram diminuição da demanda elétrica para esse estágio. 
A produção de calor pela queima de gás natural resultou em contribuições mais significativas em DEP do que a geração de eletricidade da matriz BR. Desta maneira, o ganho em $\eta_{\mathrm{Si}}$ proporcionado pela maior eficácia do pré-tratamento, é revertido em redução do indicador em todos os arranjos que dependem dessas utilidades para operar. O sucesso de S5 pode ser explicado pelo mesmo raciocínio. Embora apresente maior consumo elétrico se comparado aos de outros cenários (4,90 MJ/RF), a sinergia que se estabelece entre a taxa de recuperação de água em $S 5\left(\eta_{S 5}=98,5 \%\right)$, e a isenção do uso de calor no EV compensa essa desvantagem.

A situação descrita em S4 é bastante peculiar. Devido ao calor residual, o processo de dessalinização é limitado ao conjunto EV-CR e, mesmo assim, esse cenário alcançou o melhor resultado de DEP entre as outras opções. Deve-se notar, no entanto, que, além de depender de outros setores da refinaria, a operação desse arranjo exige cuidados especiais para atender aos fins a que se destina (funcionamento das caldeiras em nível de produção suficiente para geração do calor residual). Esta restrição torna S4 uma opção não recomendada para situações regulares da planta de dessalinização. Esse cenário pode, por outro lado, ser caracterizado como o menor nível de impacto de DEP a ser alcançado pelo sistema em relação às suas tecnologias-base. S4 também apresentou o menor índice de desempenho em AG entre as opções avaliadas, novamente devido ao uso de calor residual. Nessas circunstâncias, a geração de eletricidade da matriz BR se torna a principal fonte de impacto para a categoria, ao responder por cerca de $98 \%$ das contribuições para o cenário.

S3 prevalece sobre outros cenários que utilizam gás natural para geração de calor, seguido pelo S6 e S2, e tornando S1 como alternativa de maior impacto de toda a série analisada. Além disso, nenhuma dessas opções superou o desempenho de S5, que aplicou eletricidade apenas na operação de recompressão de vapor. Essa constatação corrobora aquela feita por Pintilie et al. (2016), que afirmam que os impactos em AG são mais sensíveis à oscilação da intensidade das demandas térmicas do que aos requisitos elétricos dos sistemas de tratamento. Nos cenários com as menores taxas de recuperação de água na OI ( $\mathrm{S} 1$ e S2), as emissões de $\mathrm{CO}_{2}$ de origem fóssil $\left(\mathrm{CO}_{2, \mathrm{f}}\right)$ derivadas da combustão de gás natural para produção de calor em EV foram a principal fonte de impacto. De acordo com Cornejo et al. (2014), isso não se deve apenas ao uso de fontes fósseis para o suprimento de energia térmica do estágio, mas também ao fato de que EV demanda, naturalmente, mais energia do que OI. Em S1 e S2, as perdas de $\mathrm{CO}_{2, \mathrm{f}}$ para o ar representaram 78\% e 75\% de seus impactos totais em AG. A disparidade entre os resultados para esses cenários deve-se às flutuações da demanda térmica causadas pelo uso de BaDs, que diminuíram de 1,03 m3/RF em S1 para 0,87 m³/RF em S2. 
A redução do consumo de gás natural causada pela CPT se reverteu em ganhos significativos para S3 em relação ao AG. Porém, mesmo que amortecidas em comparação com os desempenhos $\mathrm{S} 1$ e $\mathrm{S} 2$, as emissões de $\mathrm{CO}_{2, \mathrm{f}}$ originadas pela geração de calor ainda representaram $41 \%$ de $(\mathrm{AG})_{\mathrm{S} 3}$. Outro foco relevante do impacto desse cenário está nas emissões de GEE da geração de eletricidade. Responsáveis por $38 \%$ de $(\mathrm{AG})_{\mathrm{S} 3}$, essas contribuições são originárias (mais uma vez) de $\mathrm{CO}_{2, \mathrm{f}}$ ao que se somam perdas de $\mathrm{CH}_{4}$, que ocorrem durante o ciclo de vida do gás natural que alimenta as plantas termelétricas. Os precursores desse impacto compreendem liberações de óxido de dinitrogênio $\left(\mathrm{N}_{2} \mathrm{O}\right)$ e $\mathrm{CO}_{2}$ da transformação da terra $\left(\mathrm{CO}_{2, \mathrm{LT}}\right)$ para geração de bioeletricidade, uma fonte que representa 8,0\% da matriz BR (EPE, 2016a). Além de intervir em S3 para atender aos requisitos de energia de $\mathrm{OI}, \mathrm{EV}$ e $\mathrm{CR}$, a matriz $\mathrm{BR}$ atua indiretamente sobre o sistema participando dos estágios de fabricação da membrana de osmose $\left(147 \mathrm{~kJ} / \mathrm{m}^{2}\right)$ e $\mathrm{Ca}(\mathrm{OH})_{2}$ $(22,9 \mathrm{~kJ} / \mathrm{kg})$, bem como, e principalmente, na cadeia de manufatura do $\mathrm{HCl}$. Assim como já fora mencionado anteriormente, essa ação se concentra na eletrólise do cloreto de sódio, que, devido ao caráter energo-intensivo, contribui com $11 \%$ do impacto total da categoria. Finalmente, o uso de $\mathrm{Ca}(\mathrm{OH})_{2}$ na CPT trouxe contribuição significativa para $(\mathrm{AG})_{\mathrm{S} 3}$, devido à tecnologia usada regularmente para efeitos de obtenção de cal $(\mathrm{CaO})$ decomposição térmica do calcário, um material que contém carbonato de cálcio $\left(\mathrm{CaCO}_{3}\right)$ - em forno. A calcinação do $\mathrm{CaCO}_{3}$ libera $909 \mathrm{gCO}_{2} / \mathrm{kg} \mathrm{CaO}$ (KELLENBERGER et al., 2007), correspondendo um impacto de $146 \mathrm{gCO}_{2 \mathrm{eq}} / \mathrm{FR}$.

A opção pelo uso da compressão de vapor na etapa de evaporação da água foi promissora para AG, pois os efeitos do aumento da demanda elétrica de EV também sobre essa categoria, foram compensados pela supressão da queima de gás natural e, portanto, das emissões de GEE que esta operação geraria. Assim, o impacto observado em S5 foi cerca de 18\% inferior ao alcançado por S3. De qualquer forma, o aumento do consumo de eletricidade na fase de evaporação transformou a matriz BR na principal fonte de impacto em (AG) $)_{S 5}$, acumulando $74 \%$ do impacto total.

Diferentemente do que fora observado na DEP, a troca de $\mathrm{HCl}$ por $\mathrm{HNO}_{3}$ levou a uma piora no desempenho de S6 em AG em comparação ao alcançado por S3. Isso ocorre devido as emissões de $\mathrm{N}_{2} \mathrm{O}$ durante a síntese ácida (Processo de Ostwald), em que o $\mathrm{NH}_{3}$ anidro é oxidado até $\mathrm{HNO}_{3}$ pela ação de catalisadores metálicos e sob condições rigorosas de temperatura e pressão. $\mathrm{O} \mathrm{N}_{2} \mathrm{O}$ acaba sendo formado porque uma pequena porção do $\mathrm{NH}_{3}$ é parcialmente oxidada (ALTHAUS et al., 2007). $\mathrm{O}$ alto fator de impacto de $\mathrm{N}_{2} \mathrm{O}$ para $\mathrm{AG}\left(298 \mathrm{kgCO}_{2}\right.$ eq $/ \mathrm{kg}$, IPCC (2013)) motivou essas perdas $\left(8,40 \mathrm{~g} / \mathrm{kg} \mathrm{HNO}_{3}\right)$, que representam $22 \%$ do impacto de $\mathrm{AG}_{\mathrm{S} 6}$. 
Devido às semelhanças entre a demanda de energia primária e os precursores do Aquecimento Global, a correspondência diagnosticada para DEP entre o tipo de prétratamento, $\eta_{\mathrm{Si}}$, e o desempenho cumulativo de cada sistema também permanece válida em relação aos impactos de AG.

\subsection{Conclusões}

Este estudo avaliou o reúso de um efluente salino de refinaria de petróleo como fonte de suprimento de uma torre de resfriamento dentro da própria unidade, em regime de fechamento de circuito. Um arranjo consistindo em osmose inversa (OI), evaporação (EV) e cristalização (CR) foi projetado para recuperação da água. Seis cenários foram avaliados, observando-se principalmente opções de pré-tratamento (dessupersaturação ou coprecipitação) e diferentes abordagens para o fornecimento de energia durante na EV. Quais sejam: (i) o uso de calor residual para substituir gases da queima de gás natural para atender à demanda térmica do sistema e (ii) a aplicação de recompressão de vapor em substituição à destilação multi-efeito.

As estimativas dos impactos ambientais dos tratamentos foram realizadas por meio de ACV atribucional, para um escopo de aplicação 'berço-ao-portão', para as categorias de impacto de Demanda de Energia Primária (DEP) e Aquecimento Global (AG).

O cenário que utiliza calor residual como fonte de energia térmica para EV (S4) apresentou os menores impactos dentre as possibilidades analisadas (DEP:

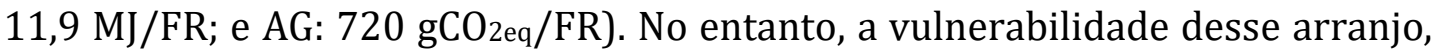
em função do sucesso de sua operação estar subordinada às de outros setores da refinaria, torna a alternativa não recomendada. Portanto, o cenário S5, que aplica a coprecipitação como técnica de pré-tratamento para o efluente alimentado na OI e adota a recompressão de vapor para atender às demandas de energia do EV, aparece como a alternativa de menor impacto da série (DEP: 17,2 MJ/FR; e AG: $1,24 \mathrm{kgCO}_{2}$ eq/FR). Isso ocorre porque a matriz BR fornece menores contribuições em termos de DEP e AG do que o ciclo de vida do gás natural para fins de geração de calor.

Uma análise abrangente dos resultados da pesquisa identificou uma correlação intrínseca entre as taxas de recuperação de água na OI e os impactos gerais de DEP e AG nos arranjos que usam calor e eletricidade para sua operação. 
Apesar da variabilidade de desempenho observada entre os cenários, os ganhos identificados pela análise sugerem que a dessalinização da água é uma alternativa ambientalmente eficiente para efeito de redução do consumo de água, e de descarte de efluentes. Esses resultados ainda podem ser aprimorados com a aplicação de compostos menos agressivos no ambiente para remover sais durante a fase de pré-tratamento, e uma exploração mais detida sobre a reutilização de fontes residuais de energia.

\subsection{Referências}

Al-Karaghouli A., Kazmerski L., 2013, Energy consumption and water production cost of conventional and renewable-energy-powered desalination processes. Renew. Sustain. Energy Rev. 24: 343-356, doi:10.1016/j.rser.2012.12.064.

Althaus H.J., Chudacoff M., Hischier R., Jungbluth N., Osses M., Primas, A., 2007, Life Cycle Inventories of Chemicals; Ecoinvent Report n. 8, v2.0; EMPA Dübendorf, Swiss Centre for Life Cycle Inventories: Dübendorf, Switzerland, 957p.

API (American Petroleum Institute), 1990, Design and Operation of Oil-Water Separators; Monographs on Refinery Environmental Control-Management of Water Discharges: Washington, DC, USA, 54p.

Anze, M.; Alves, R.M.B.; Nascimento, C.A.O., 2010, Optimization of Water Use in Oil Refinery. In Proceedings of the 2010 Annual AIChE Meeting, Salt Lake City, USA, 7-12 November 2010.

Astilleros J.M., Pina C.M., Fernández-Díaz L., Prieto M, Putnis, A, 2006, Nanoscale phenomena during the growth of solid solutions on calcite $\{101-4\}$ surfaces. Chem. Geol. 225: 322-335, doi:10.1016/j.chemgeo.2005.08.025.

Baresel C., Dalgren L., Almemark M, Lazic A, 2016, Environmental performance of wastewater reuse systems: Impact of system boundaries and external conditions. Water Sci. Technol. 73: 1387-1394, doi:10.2166/wst.2015.624.

Bremere I., Kennedy M.D., Johnson, A., van Emmerick, R., Witkamp G.-J, Schippers J.C., 1998, Increasing conversion in membrane filtration systems using a desupersaturation unit to prevent scaling. Desalination. 119: 199-204, doi:10.1016/S00119164(98)00152-0.

Bremere I., Kennedy M., Michel P., van Emmerick R., Witkamp G.J., Schippers, J., 1999, Controlling scaling in membrane filtration systems using a desupersaturation unit. Desalination. 124: 51-62, doi:10.1016/S0011-9164(99)00088-0.

Chang J., Lee W., Yoon S., 2017, Energy consumptions and associated greenhouse gas emissions in operation phases of urban water reuse systems in Korea. J. Clean. Prod. 141: 728-736, doi:10.1016/j.jclepro.2016.09.131. 
Cornejo P.K., Santana M.V.E., Hokanson D.R., Mihelcic J.R., Zhang, Q., 2014, Carbon footprint of water reuse and desalination: A review of greenhouse gas emissions and estimation tools. J. Water Reuse Desal. 4: 238-252, doi:10.2166/wrd.2014.058.

Diepolder, P., 1992, Is zero discharge realistic? Hydrocarb. Process. 71: 129-160.

Diya'uddeen B.H., Daud W.M.A.W., Aziz A.R.A., 2011, Treatment technologies for petroleum refinery effluents: A review. Process Saf. Environ. Prot. 89: 95-105, doi:10.1016/j.psep.2010.11.003.

Empresa de Pesquisa Energética. Balanço Energético Nacional 2016-Ano 2015. Rio de Janeiro, Brasil, 2016a; 294p. (em português)

Empresa de Pesquisa Energética. Energia Termelétrica: Gás Natural, Biomassa, Carvão, Nuclear; Empresa de Pesquisa Energética: Rio de Janeiro, Brasil, 2016b; 417p. (em português)

Franklin Associates. Data Details for Petroleum Refining; Franklin Associates, A Division of ERG (Eastern Research Group, Inc.) Prairie Village, Kansas, 2003.

García-Montoya M., Sengupta D., Nápoles-Rivera, F., Ponce-Ortega, J.M., El-Halwagi, M.M., 2016, Environmental and economic analysis for the optimal reuse of water in a residential complex. J. Clean. Prod. 130: 82-91, doi:10.1016/j.jclepro.2015.06.109.

Garfí M., Flores L., Ferrer I., 2017, Life Cycle Assessment of wastewater treatment systems for small communities: Activated sludge, constructed wetlands and high rate algal ponds. J. Clean. Prod. 161: 211-219, doi:10.1016/j.jclepro.2017.05.116.

Gripp V.S. Análise ambiental, energética e econômica de arranjo processual para reúso de água em refinaria de petróleo. Dissertação de Mestrado, Universidade de São Paulo, São Paulo, Brasil, 2013; 166p. (em português)

Heins W., Schooley K., 2004, Achieving Zero Liquid Discharge in SAGD heavy oil recovery. J. Can. Petrol. Technol. 43: 37-42, doi:10.2118/04-08-01.

Hendrickson T.P., Nguyen M.T., Sukardi M., Miot A., Horvath A., Nelson K.L., 2015 LifeCycle Energy Use and Greenhouse Gas Emissions of a Building-Scale Wastewater Treatment and Nonportable Reuse System, Environ. Sci. Technol. 49: 10303-10311, doi:10.1021/acs.est.5b01677.

Hischier, R., 2007, Life Cycle Inventories of Packaging and Graphical Papers; Ecoinvent report n. 11, v2.0; Swiss Centre for Life Cycle Inventories: Dübendorf, Switzerland, 17p.

Hischier R., Weidema B.P., Althaus H.-J., Bauer C., Doka G., Dones R., Frischknecht R., Hellweg S., Humbert S., Jungbluth N., 2010. Implementation of Life Cycle Assessment Methods; Ecoinvent report n. 3, v. 2.2; Swiss Centre for Life Cycle Inventories:

Dübendorf, Switzerland, 176p. 
Huijbregts M.A.J., Steinmann Z.J.N., Elshout P.M.F., Stam G., Verones F., Vieira, M.D.M., Hollander A., Zijp M., van Zelm, R., 2016, ReCiPe 2016: A Harmonized Life Cycle Impact Assessment Method at Midpoint and Endpoint Level Report I: Characterization; Department of Environmental Science, Radbound University: Nijmegen, The Netherlands, 194p.

Intergovernmental Panel on Climate Change. Climate Change 2013: The Physical Science Basis. Contribution of Working Group I to the Fifth Assessment Report of the Intergovernmental Panel on Climate Change; Stocker, T.F., Qin, D., Plattner, G.-K., Tignor, M., Allen, S.K., Boschung, J., Nauels, A., Xia, Y., Bex, V., Midgley, P.M., Eds.; Cambridge University Press: Cambridge, UK; New York, NY, USA, 1535p.

IEA (International Energy Agency), 2018, Key World Energy Statistics 2018; IEA: Paris, France, 51p.

IPIECA (International Petroleum Industry Environmental Conservation Association), 2010, Petroleum Refining Water/Wastewater Use and Management; IPIECA Operations Best Practice Series: London, UK, 60p.

ISO (International Organization for Standardization). ISO 14044, 2006, Environmental Management_Life Cycle Assessment-Requirements and Guidelines, $1^{\text {st }}$ Ed. International Organization for Standardization: Genève, Switzerland, 46p.

Jongema P., 1983, Optimization of the Fuel Consumption of an Evaporation Salt Plat with the Aid of the Exergy Concept Sixth International Symposium on Salt,, Salt Institute, Alexandria, Virginia, USA. pp. 463-469.

Jungbluth N., 2007, Erdöl. In Sachbilanzen von Energiesystemen: Grundlagen fùr den ergleich von Energiesystemen und den Einbezug von Energiesystemen in Ökobilanzen für die Schweiz; Ecoinvent report n. 6-IV, v 2.0; Dones, R., Ed.; Swiss Centre for Life Cycle Inventories: Dübendorf, Switzerland, 327p. (em alemão)

Kellenberger D, Althaus,H.-J., Jungbluth N., Künniger T., Lehmann M., Thalmann, P., 2007, Life Cycle Inventories of Building Products; Final Report Ecoinvent n. 7, v2.0; EMPA Dübendorf, Swiss Centre for Life Cycle Inventories: Dübendorf, Switzerland, $914 \mathrm{p}$.

Lam C.-M., Leng L., Chen P.-C., Lee P.-H., Hsu S.-C., 2017, Eco-efficiency analysis of nonpotable water systems in domestic buildings. Appl. Energy. 202: 293-307, doi:10.1016/j.apenergy.2017.05.095.

McNamara G., Horrigan M., Phelan T., Fitzsimons L., Delaure Y., Corcoran B., Doherty E., Clifford E., 2016, Life Cycle Assessment of Wastewater Treatment Plants in Ireland.

JSDEWES, 4: 216-233, doi:10.13044/j.sdewes.2016.04.0018.

Meneses M., Concepción H., Vrecko D., Vilanova R., 2015, Life Cycle Assessment as an environmental evaluation tool for control strategies in wastewater treatment plants, J.

Clean. Prod. 107: 653-661, doi:10.1016/j.jclepro.2015.05.057. 
Mickley M., 2008, Survey of High-Recovery and Zero Liquid Discharge Technologies for Water Utilities; WateReuse Foundation: Alexandria, VA, USA, 180p.

Moreira R.H. Desenvolvimento de um processo de reúso do efluente de refinaria baseado em um sistema de osmose reversa combinado com precipitação. Dissertação de Mestrado, Universidade de São Paulo, São Paulo, Brasil, 2017; 112p. (em português)

Morera S., Corominas L., Poch M., Aldaya M.M., Comas J., 2016, Water footprint assessment in wastewater treatment plants. J. Clean. Prod. 112: 4741-4748, doi:10.1016/j.jclepro.2015.05.102.

O'Connor M., Garnier G., Batchelor W., 2014, Life cycle assessment comparison of industrial effluent management strategies. J. Clean. Prod. 79: 168-181, doi:10.1016/j.jclepro.2014.05.066.

Opher T., Friedler E., 2016, Comparative LCA of decentralized wastewater treatment alternatives for non-potable urban reuse. J. Environ. Manag. 182: 464-476, doi:10.1016/j.jenvman.2016.07.080.

Pantoja C.E. Cristalização assistida por destilação por membranas aplicada ao reuso de água: Comparação com outros métodos de reuso, análise do processo e projeto hierárquico de processo. Tese de Doutorado, Universidade de São Paulo, São Paulo, Brasil, 2015; 162p. (em português)

Pintilie L., Torres C.M., Teodosiu, C., Castells, F. 2016, Urban wastewater reclamation for industrial reuse: An LCA case study. J. Clean. Prod. 139: 1-14, doi:10.1016/j.jclepro.2016.07.209.

Pombo F.R. Gestão da demanda de água na indústria de refino de petróleo: desafios e oportunidades de racionalização. Tese de Doutorado, Universidade Federal do Rio de Janeiro, Rio de Janeiro, Brasil, 2011; 169p. (em português)

Rahardianto A., Gao J., Gabelich C.J., Williams M.D., Cohen, Y. 2007, High recovery membrane desalting of low-salinity brackish water: Integration of accelerated precipitation softening with membrane RO. J. Memb. Sci. 289: 123-137, doi:10.1016/j.memsci.2006.11.043.

Veza J.M., 1995, Mechanical vapour compression desalination plants-A case study. Desalination 101: 1-10, doi:10.1016/0011-9164(95)00002-J. 


\section{Avaliação da efetividade de tecnologias de abatimento de impactos ambientais}

\section{Resumo}

Nesse capítulo a ACV foi aplicada para verificar a efetividade ambiental de Carbon Looping (CaL) uma das técnicas de Carbon Capture and Storage (CCS), concebida para reduzir emissões de $\mathrm{CO}_{2}$ e, por conseguinte, impactos na forma de Aquecimento Global. Quatro cenários foram analisados: S1: cenário base, por descrever o atual grid brasileiro; S2: CaL é aplicado a termelétricas operadas a carvão; S3: usa CaL em usinas movidas a gás natural; e S4: acopla CaL às as duas classes de usinas. Foram então determinados os desempenhos ambiental (via Aquecimento Global), Energético (Demanda de Energia Primária) e Econômico (Custo Nivelado de Energia: LCOE) de cada caso para geração de 1,0 MWh. Os resultados obtidos indicaram que nenhum dos cenários avaliados acumulou os melhores índices em todas as dimensões. $\mathrm{CO}_{2}$ e $\mathrm{CH}_{4}$ são os principais precursores do impacto para Aquecimento Global e S4 acumula os efeitos positivos da implantação de CaL. As Demanda de Energia Primária de S3 e S4 foram semelhantes e mais elevadas do que as alcançadas por S1 e S2 devido a consumos adicionais de petróleo cru e gás natural bruto para operação de CaL. 0 fato de o preço do gás ser em duas vezes superior ao do carvão no mercado internacional à época da realização do estudo, fez com que a operação de S3 fosse também mais custosa do que a de S2. Uma análise complementar determinou ser S2 a alternativa mais harmônica dentre a opções avaliadas tendo em conta todas as dimensões de análise.

\subsection{Introdução}

De acordo com a informação publicada pelo Intergovernmental Panel on Climate Change (IPCC), as emissões mundiais de gases de efeito estufa (GEE) em 2010 excederam a marca de $49 \mathrm{Gt} \mathrm{CO}_{2 \text { eq. }}$. A porção mais significante deste total se origina da geração de energias elétrica e térmica decorrente da queima de combustíveis fósseis. Diagnósticos feitos pela mesma instituição indicam que, em 2030, as concentrações atmosféricas de $\mathrm{CO}_{2}$ alcançarão entre 600 e 1550 ppm, tornando insustentável o balanço dinâmico entre os sistemas antrópicos e a biosfera (IPCC, 2014; THEO et al., 2016).

A matriz brasileira difere levemente deste perfil, dado que $43 \%$ da energia consumida no país em 2017 se originou de fontes renováveis. Esse comportamento é em muito influenciado pelo abastecimento doméstico de energia, cuja parcela de renováveis 
tem nas hidrelétricas sua principal contribuinte com 65\% do total gerado (KILEBER et al., 2015). Esse modelo é, contudo, bastante vulnerável a situações extremas, como as vividas entre 2012 e 2015, quando efeitos como as mudanças nos regimes de chuvas, em associação ao aumento na demanda, expuseram o Brasil a sucessivas crises de energia (ALAM et al., 2016).

Fenômenos tais como crescimento populacional, urbanização, desenvolvimento industrial e aumento da disponibilidade de sistemas computacionais e digitais que vêm ocorrendo nas últimas décadas, tendem a aumentar a demanda de eletricidade do país (KILEBER et al., 2015). Este cenário levou o operador nacional do sistema elétrico a buscar maneiras de melhorar, a curto prazo, a capacidade da rede elétrica brasileira (grid BR). A estratégia fez aumentar a participação de recursos fósseis, como carvão, derivados de petróleo e gás natural no grid BR e, por isso mesmo, suas emissões de Gases de Efeito Estufa (GEE) (TURCONI et al., 2013; GELLER et al., 2016).

Diante dessa situação, ações voltadas para o aumento da eficiência da conversão de eletricidade e/ou sua taxa de utilização, bem como a intensificação de uso de fontes renováveis, foram estabelecidas para melhorar os níveis de desempenho ambiental do sistema (MME, 2017). No entanto, a descoberta de bacias de gás e petróleo nos litorais dos estados do Rio de Janeiro e de São Paulo, aumentaram a potencial geração de energia destas fontes, projetando um cenário em que ativos fósseis continuarão representando uma porção significante da grid BR.

Uma oportunidade de conciliar a política doméstica de expansão de suprimento de energia elétrica com propostas definidas para redução de emissões de GEE é adotar práticas de Captura e Armazenamento de Carbono (Carbon Capture and Storage: CCS). Tais sistemas fazem isso possível ao separar o $\mathrm{CO}_{2}$ gerado em transformações antrópicas que usam a combustão fóssil como forma de gerar energia para depois armazená-la em locais onde $\mathrm{o}_{\mathrm{CO}_{2}}$ não entre em contato com a atmosfera (KOOMNEEF et al., 2010; CUÉLLAR-FRANCA et al., 2015; ANWAR et al., 2018).

Projetos recentes dão ao CCS o status de alternativa técnica e economicamente viável em termos de mitigação do Aquecimento Global. Neste contexto se encontra, o estudo realizado por Cormos e Petrescu (2013), que avaliou a adequação do processo de 'Calcium Looping' (CaL) como opção de captura de carbono em sistemas de geração de eletricidade operado por carvão e gás natural. 
Os autores observaram uma redução significante das emissões de $\mathrm{CO}_{2}(66$ - $82 \mathrm{~kg} / \mathrm{MWh})$ para atmosfera comparada, a de plantas em que o CCS não havia sido implantado (760 $930 \mathrm{~kg} / \mathrm{MWh}$ ). Seguindo a mesma tendência, Cormos (2015) compara o desempenho de sistemas de absorções reativas baseados em metildietanolamina (MDEA) com aquele obtido por sistemas de CaL para captura de $\mathrm{CO}_{2}$ emanado de usinas movidas a gás. $\mathrm{O}$ autor observou que o uso de CCS fornece melhores indicadores ambientais e econômicos do que os proporcionados pela tecnologia com MDEA para as condições do estudo.

Outras pesquisas mostram-se mais céticas quanto a eficácia do CCS na repressão do Aquecimento Global. Para esses autores as técnicas de CCS são inócuas, pelo fato de apenas atrasam a liberação de $\mathrm{CO}_{2}$ para o ar, uma vez que o gás não pode ser armazenado indefinidamente (BLAMEY et al., 2010; ADANEZ et al., 2012; BILIYOK et al., 2013; DIETER et al., 2014; SREEDHAR et al., 2017; MICCIO et al., 2018). Além disso, na opinião desses cientistas, as operações unitárias típicas de CCS - absorção, adsorção e separação por membrana - não são rentáveis. Assim, suas implementações aumentariam o custo unitário da eletricidade em situações em que não há regulamentação ou subsídios.

Por vias distintas, Adanez et al. (2012) e Rochedo et al. (2016) identificaram o caráter energo-intensivo das tecnologias do CCS que, dada essa característica, é capaz de reduzir a eficiência energética e a flexibilidade operacional das unidades nas quais forem acopladas. Existe, contudo, uma ala da comunidade científica que prefere examinar esses arranjos com mais rigor. Realizando estudos independentes, Singh et al. (2011), Korre et al. (2010) e Branco et al. (2013) notaram que mesmo nos casos que a aplicação de CCS resulta em alta remoção de $\mathrm{CO}_{2}$ dos gases de combustão de usinas termoelétricas operadas a gás natural e carvão, tal efeito será atenuado pelas emissões de GEE surgidas em outros estágios que compõem essa tecnologia. Para que pudessem chegar a essa conclusão, os autores determinaram as liberações de GEE por todo arranjo produtivo estabelecido para que o CCS pudesse atender as aplicações para as quais foram projetados. Tal estimativa foi possível somente por intermédio da ACV. Os pesquisadores perceberam que a partir de uma abordagem como a de ACV a eficiência dos sistemas de sequestro de carbono pode ser drasticamente reduzida a limites entre $14 \%$ a $23 \%$.

A literatura registra um conjunto vasto de estudos no qual sistemas de CCS são acoplados a usinas termoelétricas operadas com combustível fóssil. No entanto, não foi possível identificar registros de investigações em que múltiplas dimensões de análises fossem verificadas a partir de uma abordagem sistêmica. Esse busca preencher ainda que em parte essa lacuna analisando sob uma perspectiva ampla os efeitos da instalação dos sistemas CCS no desempenho ambiental, energético e econômico do grid BR. 
Espera-se que os achados dessa iniciativa possam de alguma forma auxiliar em ações futuras, tomadas no âmbito do planejamento energético brasileiro com o propósito de enfrentar o antagonismo de tendências entre a (esperada) expansão do suprimento doméstico de eletricidade, e a redução (desejável) de aportes para o Aquecimento Global que dela ser originam.

\subsection{Metodologia}

O método estabelecido para o desenvolvimento deste estudo inclui as etapas de: (i) caracterização tecnológica, operacional, e de consumo de recursos e emissões da atual rede brasileira; (ii) definição de cenários de geração de eletricidade, considerando a implementação de CCS em usinas termoelétricas a carvão e a gás natural; (iii) estimativa do consumo de matérias-primas, insumos e aditivos, e utilidades requeridas por sistema de CCS para cumprir as funções a que se destina nessa situação; (iv) investigação do desempenho ambiental do grid, a fim de quantificar impactos na forma de Aquecimento Global e Demanda de Energia Primária; (v) verificação dos custos associados ao arranjo; e, (vi) análise do efeito da combinação das dimensões ambiental e econômica, na busca por sinergias (ou discrepâncias) que sejam proporcionadas por essa integração.

\subsubsection{Visão Geral da Matriz Energética Brasileira}

O complexo de geração elétrica do Brasil era caracterizado em 2017 - período usado como referência para essa pesquisa, pelo agrupamento de projetos hidrelétricos de grande porte e que representam $96 \mathrm{GW}$ de sua capacidade instalada (ANEEL, 2018; BARROS et al., 2018). A maior fração de geração de hidreletricidade ocorria em usinas que operam com ciclos combinados de capacidade instalada de 4,0 GW, e com rendimento médio de $\eta_{c c, H} \approx 55 \%$. As unidades se concentravam na região Sudeste, que também representava a maior demanda de energia elétrica (EPE, 2016). 0 grid brasileiro compreendia também uma parcela da geração termoelétrica derivada de gás natural, óleo combustível e carvão, que representava $27 \mathrm{GW}$ do montante total. Na maioria dos casos, as usinas a carvão operavam segundo ciclos subcríticos usando sistemas de Combustão de Carvão Pulverizado (PCC), $\eta_{P C C} \leq 40 \%$ (ANEEL, 2018). Por fim, a geração proveniente de derivados de petróleo (óleo combustível e diesel) ocorria em caldeiras ou sistemas de combustão (ANEEL, 2018). 
Outros $14 \mathrm{GW}$ da rede instalada provinham de plantas operadas com biomassa. A rota tecnológica adotada tipicamente por esta fonte compreendia ciclos de geração de vapor com turbinas de contrapressão e de extração-condensação, ou, ciclos combinados que eram acoplados a gaseificadores de biomassa. Apesar de ser capaz de usar diferentes tipos de combustíveis no processo (p.ex., madeira, resíduos de colheita de arroz, soja e milho, ou até resíduos urbanos e industriais), cerca de $80 \%$ da biomassa consumida no Brasil para fins energéticos era derivada do bagaço e palha de cana-de-açúcar (UNICA, 2019). Conjuntos de caldeira-turbina que operavam segundo ciclos Rankine ou Brayton e produziam vapor a 65 bar e $550{ }^{\circ} \mathrm{C}$ eram aplicados com frequência para exportação de eletricidade (ANEEL, 2018; EPE, 2016; UNICA, 2019; GUERRA et al., 2018).

A geração nuclear brasileira se restringia a duas usinas: Angra I, abrangendo 640 MW da capacidade de instalação, e Angra II, com capacidade para 1350 MW. Localizadas no estado do Rio de Janeiro, as plantas são do tipo Reator Pressurizado de Água (PWR) (EPE, 2016). O Brasil dispunha de 534 fazendas eólicas concentradas em sua maioria nos estados do Rio Grande do Norte, Bahia, Ceará, Rio Grande do Sul e Piauí. Essa fonte de geração tem experimentado significante expansão desde 2013, e já representava 13 GW da capacidade de instalação em 2017. Energia eólica é vista como uma opção promissora para o futuro por gerar impactos ambientais inferiores aos de muitos de seus congêneres (BARROS et al., 2018).

Figura 5.1 - Distribuição por fonte da capacidade instalada de geração de eletricidade no Brasil: ano base - 2017

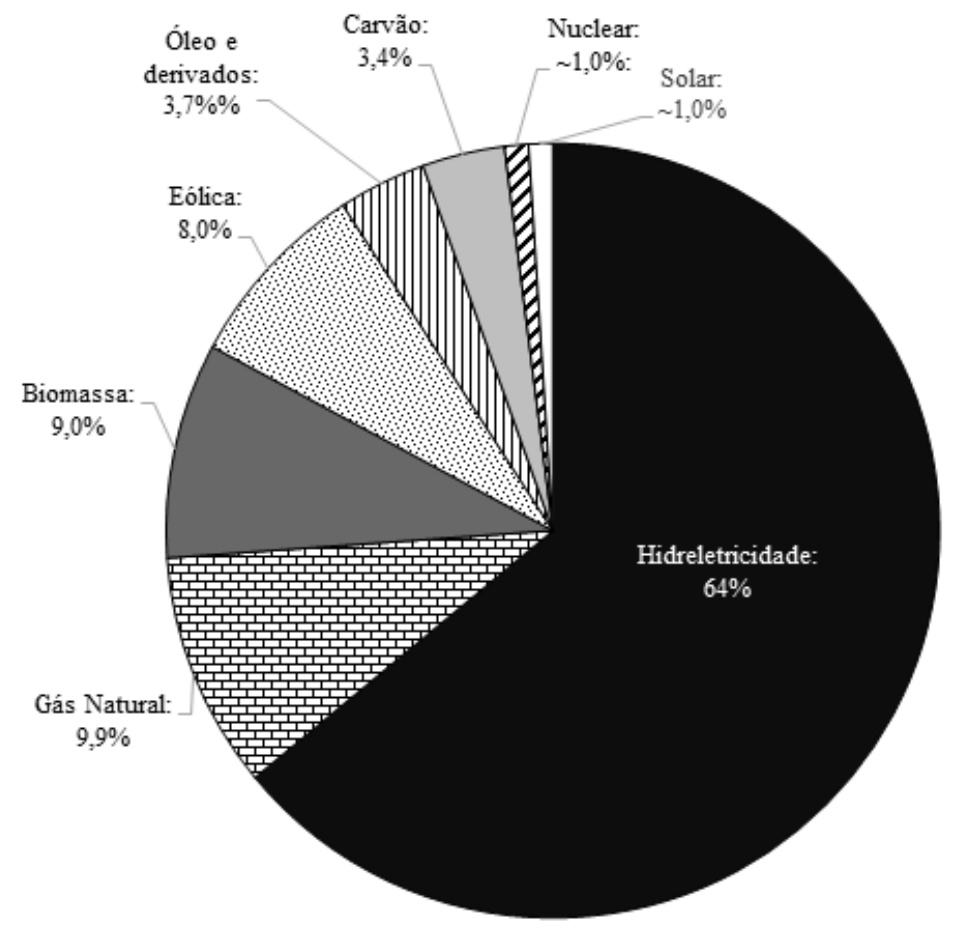


Finalmente, até meados de 2018 o país registrava cerca de 30.000 instalações de geração solar fotovoltaica cuja soma das capacidades alcançava 2,4 GW (MME, 2018). Mesmo que os índices de potência sejam menos significativos do que os de outras fontes renováveis, o número de microgeradores solares cresceu 407\% entre 2015 e 2017. Esse comportamento pode ser atribuído a fatores tais como maturação tecnológica, baixos custos de investimento, conscientização ambiental por parte da população, e aplicação de incentivos fiscais por parte do governo (ANEEL, 2018; EPE, 2016). A Figura 1 descreve a capacidade instalada de geração de eletricidade no Brasil em 2017 (MME, 2018).

\subsubsection{Carbon Capture and Storage: tecnologia Calcium Looping (CaL)}

Dados seus volumes de geração de $\mathrm{CO}_{2}$, os sistemas CCS se difundem com mais frequência pelos setores de energia, petroquímica, cimento e metalurgia (KOOMNEEF et al., 2010; CUÉLLAR-FRANCA et al., 2015; CORSTEN et al., 2013). No segmento energético essas tecnologias são vistas como meios para permitir o uso contínuo de recursos fósseis - evitando assim a substituição por fontes renováveis - apesar dos níveis de emissão de GEE (ZHANG et al., 2017; FRANSSON et al., 2014).

Neste estudo, os sistemas CCS foram representados pelo processo de CaL. Esta decisão foi baseada nos seguintes fatores: (i) compatibilidade dos conceitos tecnológicos praticados pelo processo CaL e pelas usinas termoelétricas ativas no país, que permite sua associação ao sistema sem ajustes significativos; (ii) redução dos consumos de energia; e, (iii) custos acessíveis de implementação e operação se comparados aos de tecnologias de mesma natureza (RUIZ, 2015; JAYARATHNA et al., 2015).

No processo CaL, o $\mathrm{CO}_{2}$ presente nos gases de combustão emanados da usina reage com óxido de cálcio ( $\mathrm{CaO}$ ) dentro de um vaso (carbonatador) para formar $\mathrm{CaCO}_{3}$. Essa transformação aparece representada na Equação (1). 0 fato dela ser endotérmico faz com as temperaturas no interior do carbonatador sejam mantidas entre $500-650^{\circ} \mathrm{C}$. A corrente de produto desse estágio alimenta outro reator (calcinador) no qual ocorre a regeneração de $\mathrm{CaO}$, novamente por efeito térmico (Equação (2)). 0 calor aplicado no sistema para decomposição do carbonato $\left(800-950^{\circ} \mathrm{C}\right)$ é produzido em um forno onde combustíveis fósseis são queimados na presença de $\mathrm{O}_{2}$ puro. A Equação (3) representa a reação de combustão global (em termos estequiométricos) que ocorre em termoelétricas operadas a carvão. Já a Equação (4) traz a mesma transformação para uma planta movida com gás natural (CORMOS, 2015; JAYARATHNA et al., 2015; SHIMIZU et al., 1999): 


$$
\begin{aligned}
& \mathrm{CaO}+\mathrm{CO}_{2} \rightarrow \mathrm{CaCO}_{3} \\
& \mathrm{CaCO}_{3} \rightarrow \mathrm{CO}_{2}+\mathrm{CaO} \\
& \mathrm{C}+\mathrm{O}_{2} \rightarrow \mathrm{CO}_{2}+\text { Calor } \\
& \mathrm{CH}_{4}+2 \mathrm{O}_{2} \rightarrow \mathrm{CO}_{2}+2 \mathrm{H}_{2} \mathrm{O}+\text { Calor }
\end{aligned}
$$

$\mathrm{O} \mathrm{CO}_{2}$ obtido será então seco e comprimido antes do armazenamento definitivo. Já oCaO, contudo, retorna ao primeiro reator por meio de um reciclo fechado do processo a fim de ser reutilizado (VALVERDE et al., 2014).

\subsubsection{Definição de cenários}

A Tabela 5.1 apresenta e descreve os cenários estabelecidos para a análise. Este processo de especificação foi baseado em quatro critérios. 0 primeiro deles determinou a criação de um cenário referência (S1) que representa o arranjo atual do grid brasileiro. 0 segundo critério instituiu que a aplicação da tecnologia CaL se restringiria às usinas termoelétricas operadas a carvão e a gás natural. Essa decisão foi tomada tendo em conta o (elevado) potencial de expansão de fornecimento doméstico de eletricidade associados a essas fontes (EPE, 2016).

Tabela 5.1 - Especificação de cenários por tipo de fonte geradora de eletricidade

\begin{tabular}{llllll}
\hline \multirow{2}{*}{ Fonte } & $\begin{array}{l}\text { Contribuição } \\
(\%)\end{array}$ & \multicolumn{4}{c}{ Cenário } \\
\cline { 3 - 6 } & S1 (base) & S2 & S3 & S4 \\
\hline Energia hidrelétrica & 65,2 & $\mathrm{C}$ & $\mathrm{C}$ & $\mathrm{C}$ & $\mathrm{C}$ \\
Combustível & 2,51 & $\mathrm{C}$ & $\mathrm{C}$ & $\mathrm{C}$ & $\mathrm{C}$ \\
Carvão & 4,09 & $\mathrm{C}$ & $\mathrm{CaL}$ & $\mathrm{C}$ & $\mathrm{CaL}$ \\
Gás Natural & 10,5 & $\mathrm{C}$ & $\mathrm{C}$ & $\mathrm{CaL}$ & $\mathrm{CaL}$ \\
Biomassa & 8,23 & $\mathrm{C}$ & $\mathrm{C}$ & $\mathrm{C}$ & $\mathrm{C}$ \\
Nuclear & 2,52 & $\mathrm{C}$ & $\mathrm{C}$ & $\mathrm{C}$ & $\mathrm{C}$ \\
Eólica & 6,82 & $\mathrm{C}$ & $\mathrm{C}$ & $\mathrm{C}$ & $\mathrm{C}$ \\
Solar & 0,13 & $\mathrm{C}$ & $\mathrm{C}$ & $\mathrm{C}$ & $\mathrm{C}$ \\
\hline
\end{tabular}

Legenda: (C): Tecnologia atualmente praticada pela geração de fonte respectiva; (CaL): indica acoplamento com o processo $\mathrm{CaL}$ 
0 terceiro critério designou que os efeitos ambientais, energéticos e econômicos do acoplamento CaL seriam verificados individual - por fonte de geração (S2 e S3) -, e associativamente em usinas movidas a gás e a carvão (S4). 0 último critério decidiu que as demais fontes de geração que constituem a rede brasileira seriam representadas por tecnologias consistentes com as que são atualmente praticadas no país (Seção 5.2.1). Essa medida procurou evitar a influência de parâmetros externos ao campo de análise sobre os achados da pesquisa. Os dados de fornecimento doméstico de eletricidade por fonte elétrica foram coletados junto ao Balanço Nacional de Energia de 2018, para uma produção total de 588 TWh (EPE, 2018).

\subsubsection{Simulação do Processo de CaL: condições de processo e premissas}

O comportamento do CaL foi simulado com ajuda do software Aspen Plus v.8.8 de Aspentech®. Tal como os demais envolvidos na simulação, este processo opera em estado estacionário. Os padrões de produção e parâmetros técnicos adotados para essas estimativas estão de acordo com o perfil tecnológico médio praticado no Brasil para as usinas correspondentes.

Tabela 5.2 - Composições do carvão betuminoso usado na simulação

\begin{tabular}{ccc}
\hline \multicolumn{3}{c}{ Ultanal $(\% \mathrm{~m} / \mathrm{m})$} \\
\hline $\mathrm{C}$ & 72,3 \\
$\mathrm{O}$ & 4,09 \\
$\mathrm{~S}$ & 5,93 \\
$\mathrm{~N}$ & 0,58 \\
$\mathrm{Cl}$ & 1,70 \\
Cinza & 0,00 \\
PCI (MJ/kg) & 15,4 \\
& & 22,2 \\
\hline Umidade & Proxanal $(\% \mathrm{~m} / \mathrm{m})$ & \\
Voláteis & 8,00 \\
Carbono fixo & 24,9 \\
Cinza & 59,7 \\
\hline Sulfato & 15,4 \\
\hline Pirítico & \\
Orgânico & 0,26 \\
\hline
\end{tabular}

Legenda: Ultanal: Análise final; Proxanal: Análise aproximada; Sulfanal: Análise de fonts de enxofre; PCI: Poder Calorífico Inferior. 
No caso de termoelétricas a carvão, o CaL foi acoplado a plantas com capacidade de geração de $500 \mathrm{MW}$, equipadas com sistema para remoção de compostos de enxofre dos gases de combustão (dessulfuração) com eficiência média $\eta_{S}=90 \%$. Assumiu-se por condição de contorno que o gás de combustão seria alimentado no carbonatador depois apenas de ter sido resfriado e dessulfurizado. 0 carvão betuminoso foi considerado como um fluxo 'não convencional', devido ao perfil médio de composição que apresenta, (Tabela 5.2) (RUIZ, 2015).

Para as termoelétricas que operam com gás natural, definiu-se uma capacidade instalada de 300 MW. A composição média molar do combustível utilizado na simulação foi coleta em Vaz et al. (2008) e está apresentada a seguir na Tabela 5.3.

Tabela 5.3 - Composição média aproximada do gás natural

\begin{tabular}{llllllll}
\hline Componente & $\mathrm{CH}_{4}$ & $\mathrm{C}_{2} \mathrm{H}_{6}$ & $\mathrm{C}_{3} \mathrm{H}_{8}$ & $\mathrm{C}_{4} \mathrm{H}_{10}$ & $\mathrm{CO}_{2}$ & $\mathrm{~N}_{2}$ & Outros \\
\hline$X_{i}(\%)$ & 86,1 & 8,15 & 2,14 & 0,52 & 0,72 & 1,34 & 1,03 \\
\hline
\end{tabular}

Fonte: Vaz et al., (2008)

Os diagramas de processo que remetem respectivamente as usinas termoelétricas movidas a carvão e gás natural, são descritos pelas Figuras 5.2 (a) e (b). Os carbonatador e calcinador tiveram seus comportamentos simulados por reatores do tipo RStoic, cujo modelo disponível em Aspen Plus® é usado para descrever transformações cujo perfil de progressão é estequiométrico ou suficientemente perto deste. A taxa de conversão de $\mathrm{CO}_{2}$ em $\mathrm{CaCO}_{3}$ no carbonatador foi determinada pela Equação (5)

$$
E_{\mathrm{CO} 2}=\left(\frac{F_{R}}{F_{\mathrm{CO} 2}}\right) \times X_{c a r b}
$$

Sendo:

$\left(E_{C O 2}\right)$ : eficiência de remoção de $\mathrm{CO}_{2}$ do gás alimentado ao carbonatador;

$\left(X_{\text {carb }}\right)$ : taxa de conversão de $\mathrm{CO}_{2}$ em $\mathrm{CaCO}_{3}$ no carbonatador;

$\left(\frac{F_{R}}{F_{\mathrm{CO} 2}}\right)$ : razão molar entre o $\mathrm{CaO}$ gerado $\left(F_{R}\right)$ e o $\mathrm{CO}_{2}$ introduzido no carbonatador $\left(F_{\mathrm{CO} 2}\right)$

A taxa de conversão $\left(\eta_{\mathrm{r}}\right)$ de reagentes em produtos do calcinador, a qual também expressa o grau de regeneração de $\mathrm{CaO}$, foi fixada em $\eta_{r}=100 \%$. 
Figura 5.2 - Sistema CaL acoplado a termoelétrica movida a: (a) carvão; e (b) gás natural
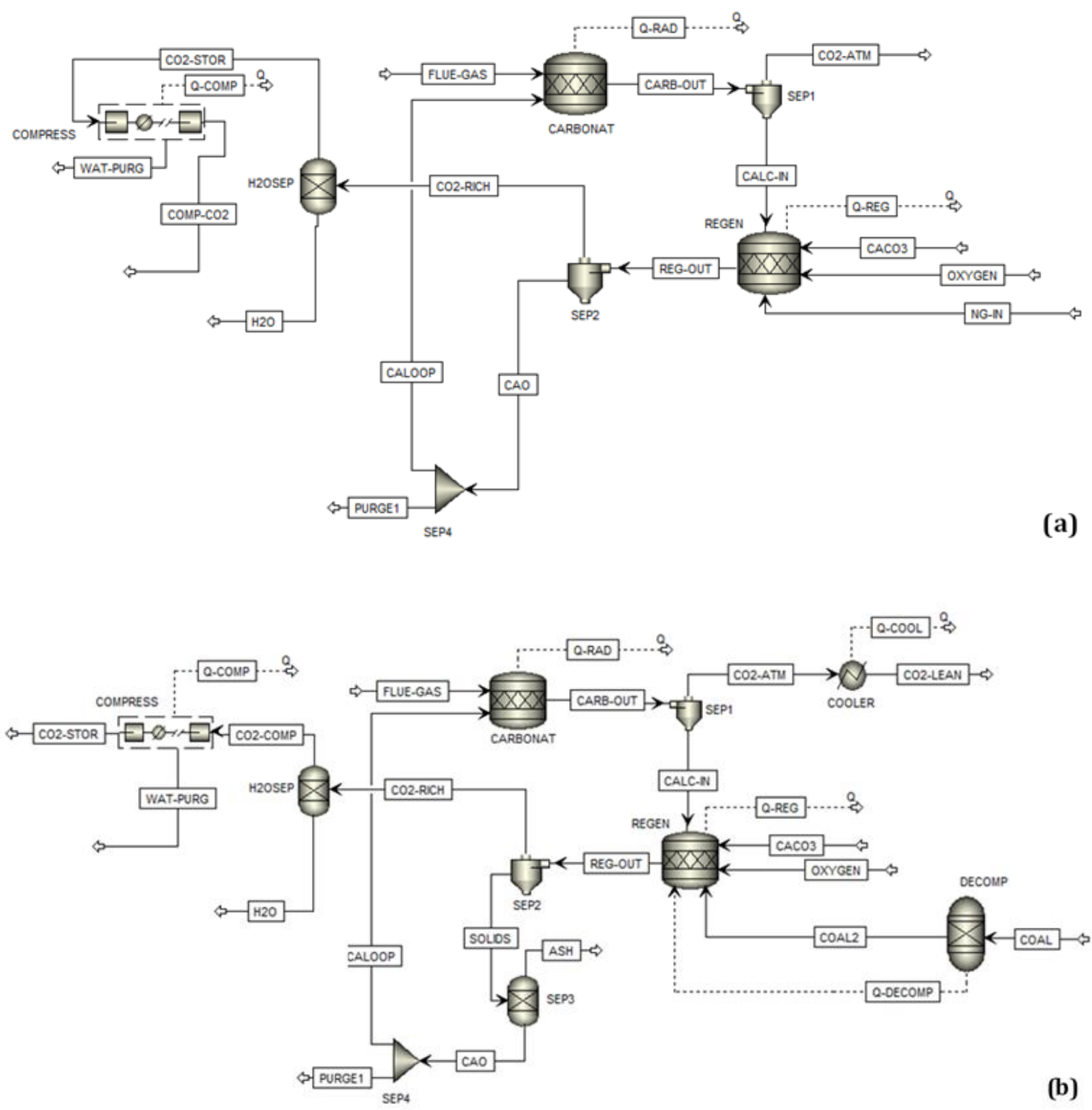

O oxigênio queimado para geração de calor no calcinador é obtido a partir de uma Unidade de Separação do Ar (ASU). Os fluxos de oxigênio e combustível consumidos no calcinador (carvão ou gás natural) foram determinados usando-se a ferramenta Design Spec disponível em Aspen Plus®. A pressão do $\mathrm{CO}_{2}$ puro é elevada até 80 bar, após este ser submetido a três estágios de compressão intercalados por chillers. 0 gás é resfriado até $28^{\circ} \mathrm{C}$ a cada etapa (VORRIAS et al., 2013). Os parâmetros básicos de processo usados nas simulações do sistema CaL junto a termoelétricas operadas a carvão é gás natural estão indicados na Tabela 5.4 
Tabela 5.4 - Parâmetros do processo que especificam o sistema CaL para cada tipo de termoelétrica

\begin{tabular}{|c|c|c|c|}
\hline Parâmetro (Unidade) & Unidade & Termoelétrica CA & Termoelétrica GN \\
\hline Combustível usado no calcinador & & Carvão & Gás Natural \\
\hline Temperatura do Carbonatador & $\left({ }^{\circ} \mathrm{C}\right)$ & 650 & 600 \\
\hline Pressão do Carbonatador & (bar) & 1,00 & 1,00 \\
\hline Temperatura do Calcinador & $\left({ }^{\circ} \mathrm{C}\right)$ & 900 & 900 \\
\hline Pressão do Calcinador & (bar) & 1,00 & 1,00 \\
\hline$E_{\mathrm{CO} 2}$ & $(\%)$ & 90,0 & 90,0 \\
\hline$\left(F_{R} / F_{C O 2}\right)$ & & 7,00 & 14,0 \\
\hline$\left(F_{\mathrm{CaCO} 3} / F_{\mathrm{CO} 2}\right)$ & & 0,10 & 0,10 \\
\hline Purga de $\mathrm{CaO}$ & $(\%)$ & 10,0 & 10,0 \\
\hline Temperatura de $\mathrm{CaCO}_{3}$ Fresco & $\left({ }^{\circ} \mathrm{C}\right)$ & 25,0 & 25,0 \\
\hline Grau de pureza de $\mathrm{O}_{2}$ & $(\% v / v)$ & 95,0 & 95,0 \\
\hline Temperatura da corrente de $\mathrm{O}_{2}$ & $\left({ }^{\circ} \mathrm{C}\right)$ & 15,0 & 15,0 \\
\hline Temperatura do combustível & $\left({ }^{\circ} \mathrm{C}\right)$ & 25,0 & 25,0 \\
\hline
\end{tabular}

\subsubsection{Avaliação Ambiental}

Este estudo seguiu orientações conceituais e requerimentos descritos na norma ISO 14040 (ISO, 2006), para ACV atribucional e escopo de aplicação "do berço ao portão". Os impactos ambientais que se originam em cada cenário foram mensurados tendo por Fluxo de Referência (FR): 'gerar 1,0 MWh de eletricidade, a partir dos elementos, e suas proporções, que compõem o grid elétrico brasileiro de 2018' (Tabela 5.1). A Figura 5.3 traz os componentes de cada modelo (Sistema de Produto), criados para reproduzir as situações de estudo.

Os Inventários de Ciclo de Vida (ICV) foram elaborados com auxílio do software SimaPro - Pre-Consultants ${ }^{\circledR}$ a partir dos dados secundários obtidos pela base de dados Ecoinvent (DONES et al., 2007). Esses bancos de dados fornecem ICVs de tecnologias médias de geração de eletricidade cujas características são representativas dos sistemas instalados no Brasil. Quando houve dissintonia entre a condição real e o conteúdo de um banco de dado, esse último foi tratado de maneira a ficar em harmonia com os demais. 
Para a geração hidrelétrica, a eficiência de conversão considerada pelo estudo foi de $\eta_{H Y}=95 \%$, ao passo que para termoelétricas operadas com carvão e óleo combustível, os desempenhos foram respectivamente de $\eta_{\text {Coal }}=40 \%$ e $\eta_{F O}=37 \%$. Para as situações das termonucleares e termoelétricas que usam gás natural, esses índices foram fixados em $\eta_{N U}=33 \%$ e $\eta_{N G}=38 \%$.

Figura 5.3 - Sistema de Produto para a produção de 1,0 MWh: (a) estrutura original grid BR; (b) sistema com CCS acoplado
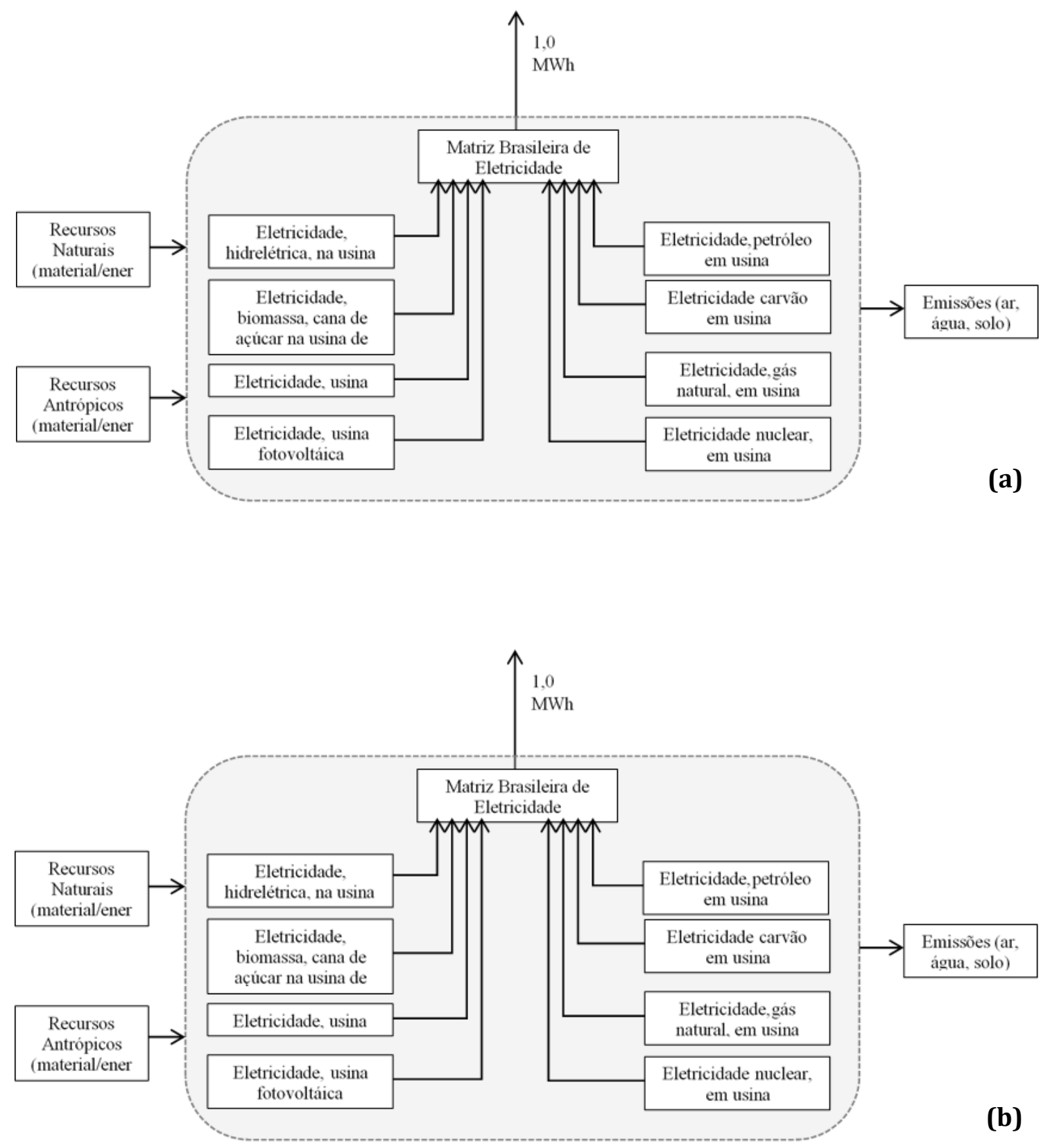
Os ICVs consolidados para geração de eletricidade no Brasil foram elaborados a partir dos seguintes bancos de dados originais: (i) Hidrelétrica: 'Electricity, hydropower, at reservoir power plant/BR U'; (ii) Óleo e derivados: 'Electricity, oil, at power plant/CH U'; (iii) Carvão: 'Electricity, hard coal, power plant/UCTE U'; (iv) Gás Natural: 'Electricity, natural gas, at power plant/UCTE $U^{\prime}$ que foi adaptado para as condições brasileiras de extração, refino e logísticas de distribuição do recurso natural e do produto acabado; (v) Nuclear: 'Electricity, nuclear, at power plant/CH U' admitindo nesse caso que a geração ocorra apenas em sistemas do tipo PWR; (vi) Solar: 'Electricity, photovoltaic production mix, at plant/CH U', e (vii) Eólica: 'Electricity at wind power plant/RER U'.

Todos esses conjuntos foram modificados para representar as condições de operação locais das respectivas fontes. Para a geração termoelétrica com biomassa, o ICV 'Electricity, bagasse, sugarcane, at fermentation plant/BR $U$ ' sofreu ajustes e revisões a partir de premissas estabelecidas por Guerra et al. (2018). Nos cenários que consideram usinas termoelétricas operadas com carvão e gás natural tendo CaL acoplado, respectivamente S2, S3 e S4, os ICVs da base Ecoinvent foram complementados com dados sobre o consumo de matérias-primas, insumos e emissões, que ocorrem no CCS. Esses valores foram obtidos a partir das simulações realizadas em Aspen Plus® (seção 5.2.4). As interações com o ambiente da produção de $\mathrm{CaCO}_{3}$ foram representadas por uma versão adaptada para as condições nacionais do ICV 'Limestone, milled, loose, at plant/CH U'. Os consumos elétricos da unidade ASU $\left(200 \mathrm{kWh} / \mathrm{t}_{2}\right)$ e dos compressores de $\mathrm{CO}_{2}$ purificado $\left(100 \mathrm{kWh} / \mathrm{t} \mathrm{CO}_{2}\right)$ foram revistos tendo em conta desempenhos indicados em Martinez et al., (2011) e Vassudevan et al., (2007). Na preparação do ICV de transporte de $\mathrm{CaCO}_{3}$ assumiu-se que: (i) os deslocamentos ocorrem por via rodoviária em caminhões com capacidade de carga entre 16 - 32 t (CNT, 2018); (ii) a distância média percorrida entre a mina de extração, e a termoelétrica a carvão (Região Sul) foi de $4408 \mathrm{~km}$. Para as termoelétricas a gás natural, o trajeto compreenderia $3000 \mathrm{~km}$.

O método ReCiPe Midpoint (H) v 1.12 (GOEDKOOP et al., 2013) foi aplicado para quantificar contribuições para a categoria de impacto de Aquecimento Global. Em termos gerais, essa quantificação ocorre multiplicando-se a quantidade totalizada de cada GEE por seu respectivo fator de impacto (FI). Os FIs que descrevem a magnitude dos efeitos de GEE em termos de Aquecimento Global adotados por ReCiPe Midpoint (H) se originam de pesquisas e desenvolvimentos científicos realizados pelo Intergovernmental Panel on Cimate Change (IPCC). Essa abordagem definiu o $\mathrm{CO}_{2}$ como substância de referência para a categoria, atribuindo-lhe $\mathrm{FI}=1,0 \mathrm{~kg}$ de $\mathrm{CO}_{2} \mathrm{eq} / \mathrm{kg} \mathrm{CO}_{2}$ emitido. Os coeficientes para $\mathrm{CH}_{4}$ e $\mathrm{N}_{2} \mathrm{O}$, outros dos GEE mais frequentes foram estimados com base nesse padrão e, para o ReCiPe v1.12, estes correspondem a $25 \mathrm{~kg} \mathrm{CO}_{2 \text { eq }} / \mathrm{kg} \mathrm{CH}_{4}$ e $298 \mathrm{~kg} \mathrm{CO}$ 2eq $/ \mathrm{kg} \mathrm{N}_{2} \mathrm{O}$. 
Os impactos energéticos de cada cenário foram medidos em função de Demanda de Energia Primária (DEP) pelo método Cumulative Energy Demand (CED) v1.10. o CED descreve os impactos relacionados ao esgotamento da energia primária do planeta para recursos energéticos não-renováveis (p.ex. fósseis, nucleares, biomassa) e renováveis (biomassa, eólica, solar, geotérmica e hídrico) (FRISCHKNECHT et al., 2007). Para isso, o método aplica a lógica conceitual similar à utilizada por ReCiPe para Aquecimento Global, de multiplicar os consumos e emissões acumulados de precursores de impactos por seus respectivos IFs.

Para o CED, o conteúdo energético intrínseco de um recurso natural é usado para estimar a demanda de energia primária a ele associada ao longo de todo o ciclo de vida de um bem (processo ou serviço). Essa energia intrínseca refere-se, portanto, ao fator de impacto do recurso. Para combustíveis fósseis e biomassa, esse FI corresponde ao Poder Calorífico Superior. Em relação à energia nuclear, o índice é baseado na cadeia de urânio, considerando as características do PWR. Para energia hidrelétrica, o método assume que $\mathrm{FI}=1,0 \mathrm{MJ} / \mathrm{MJ}$, a despeio do precursor de impacto (energia potencial ou hidrelétrica). Por outro lado, se a DEP vier de água armazenada em um lago de barragem, o fator passa a ser IF = $10 \mathrm{~kJ} / \mathrm{kg}$ água. Finalmente, para outras fontes renováveis - casos de eólica, solar, geotérmica -, o CED admite ser a entrada de energia igual à quantidade de energia convertida, ou seja, e novamente, FI = 1,0 MJ/MJ (FRISCHKNECHT et al., 2007).

\subsubsection{Análise Econômica}

A análise econômica está baseada no método de Custos Atualizados de Energia (Levelised Cost of Energy: LCOE) (ROMEIRO et al., 2015). Essa abordagem consiste em uma das maneiras de instrumentalizar as variáveis envolvidas na dimensão econômica, comparando diferentes fontes de geração de eletricidade.

O LCOE corresponde ao custo real específico (por kWh) relativo à construção e operação da planta, em um horizonte de tempo - o período $(\mathrm{t})$ - para o qual esta foi projetada, incluindo ações de manutenção. Esse indicador também pode ser definido como a receita média específica necessária - medida por unidade de energia produzida -, para que se possa recuperar investimentos e despesas de operação e manutenção que afetam o projeto (ROMEIRO et al., 2015). A expressão que permite determinar o LCOE está indicada na equação (6): 


$$
C O E=\frac{\sum\left(\text { Capital }_{t}+O \& M_{t}+\text { Combustível }_{t}+\text { Carbono }_{t}+D_{t}\right) \times(1+r)^{-t}}{\sum M W h(1+r)^{-t}}
$$

Sendo:

$\left(\right.$ Capital $\left._{t}\right)$ : custos totais de construção no ano $(\mathrm{t})$;

$\left(O \& M_{t}\right):$ despesas de operação e manutenção;

(Combustível $)_{t}$ : custo do combustível;

$\left(\right.$ Carbono $\left._{t}\right)$ : custo do carbono;

$\left(D_{t}\right)$ : custos de desativação e gerenciamento de resíduos;

$\left((1+r)^{-t}\right):$ fator de desconto

Os componentes usados para determinar o LCOE incluem capital, combustível, operação e manutenção e custos de financiamento. Além disso, aspectos técnicos dos processos em análise (ou seja, eficiência da planta e fator de capacidade) também são considerados pela estimativa (ROMEIRO et al., 2015). Para tecnologias solares e eólicas que dispensam o consumo de combustíveis e apresentam despesas discretas de operação e manutenção, o valor do LCOE está bastante condicionado ao custo estimado de capital para capacidade de geração.

Quando os custos de combustível mostram-se elevados, como ocorre nas usinas termoelétricas que operam com óleo e gás natural, o valor do LCOE tende a variar. Como em qualquer projeção, são observadas incertezas associadas aos componentes da estimativa, as quais são geralmente introduzidas devido a aspectos geográficos, grau de consolidação da tecnologia de geração elétrica e, principalmente, cotações de preços de combustíveis (IEA, 2015). Neste estudo, os valores de LCOE para cada cenário ( $\left.L C O E_{i}\right)$ foram determinados a partir de dados e informações disponíveis em documentos da Agência Internacional de Energia (IEA) e da Empresa de Pesquisas Energéticas (EPE), e tendo em conta uma taxa de desconto anual $r=10 \%$. 0 valor é típico para investimentos de mercado de alto risco como ocorre com esses empreendimentos, e foi considerado constante ao longo do ciclo de vida das plantas (IEA, 2015; EPE, 2017). Os parâmetros de entrada para o cálculo dos $\left(L C O E_{i}\right)$ s são apresentados na Tabela 5.5. 
Tabela 5.5 - Parâmetros para estimativas de LCOE de cada fonte de energia: $r=10 \%$

\begin{tabular}{llllll}
\hline Fonte & $\begin{array}{l}\text { Custo de } \\
\text { Capital }\end{array}$ & $\begin{array}{l}\text { Custo de } \\
\text { O\&M }\end{array}$ & $\begin{array}{l}\text { Custo de } \\
\text { Combustível }\end{array}$ & $\begin{array}{l}\text { Custo de } \\
\text { Carbono }\end{array}$ & CDS \\
\hline \multicolumn{5}{c}{ (USD/MWh) } \\
\hline $\begin{array}{l}\text { Hidrelétrica } \\
\text { Óleo e }\end{array}$ & 50,9 & 9,00 & 0,00 & 0,00 & 0,04 \\
derivados & 40,5 & 7,56 & 149 & 23,3 & 0,03 \\
Carvão & 40,5 & 7,56 & 30,8 & 23,3 & 0,03 \\
Gás Natural & 15,9 & 5,72 & 74,6 & 10,3 & 0,03 \\
Biomassa & 86,6 & 17,6 & 93,2 & 0,00 & 0,08 \\
Nuclear & 74,4 & 13,1 & 10,0 & 0,00 & 0,12 \\
Eólica & 94,0 & 23,0 & 0,00 & 0,00 & 0,62 \\
Solar & 140 & 27,9 & 0,00 & 0,00 & 0,00 \\
\hline
\end{tabular}

Para energia solar, os custos de $(O \& M)$ incluem o descomissionamento. Para as usinas termoelétricas a óleo, decidiu-se que custos associados a Capital, (O\&M), Carbono e Descomissionamento ( $C D S$ ) seriam semelhantes aos usados para usinas termoelétricas a gás. Além disso, admitiu-se também que para derivados de petróleo, as mesmas parcelas corresponderiam ao dobro de suas equivalentes para o gás natural.

\subsubsection{Combinação de indicadores ambientais, energéticos e econômicos}

A pesquisa também tratou de estimar o efeito da associação das dimensões analisadas sobre as tendências de geração de eletricidade, a partir das diferentes fontes de energia que constituem a rede brasileira, com e sem acoplamento do sistema CCS. Para isso, os índices de desempenho ambiental, energético e econômico foram calculados e normalizando a partir do valor máximo dos resultados obtidos nas etapas anteriores do estudo. 0 procedimento aparece descrito a seguir pelas Equações (7) - (9):

$$
\begin{gathered}
E I_{i}=\left(\frac{I_{G W P, i}}{I_{G W P, S 1}}\right) \\
E n I_{i}=\left(\frac{I_{P E D, i}}{I_{P E D, S 1}}\right)
\end{gathered}
$$




$$
E c I_{i}=\left(\frac{I_{L C O E, i}}{I_{L C O E, S 1}}\right)
$$

Sendo:

$\left(E I_{i}\right)$ : indicador ambiental para o cenário (i);

$\left(I_{G W P, i}\right)$ : impacto em termos de Aquecimento Global para cenário (i);

$\left(I_{G W P, S 1}\right)$ : impacto de S1 em termos de Aquecimento Global;

$\left(E n I_{i}\right):$ indicador de energia para o cenário (i);

$\left(I_{P E D, i}\right)$ : impacto em termos de Demanda de Energia Primária para cenário (i);

$\left(I_{P E D, S 1}\right):$ impacto de S1 em termos de Demanda de Energia Primária;

$\left(E c I_{i}\right)$ : indicador econômico para o cenário (i);

$\left(I_{L C O E, i}\right)$ : valor do Custo Atualizado de Energia para cenário (i);

$\left(I_{L C O E, S 1}\right)$ : valor do Custo Atualizado de Energia para S1.

Um Indicador Combinado $\left(C I_{i}\right)$ foi estabelecido para cada cenário. Isso ocorreu a partir da multiplicação dos valores normalizados dos indicadores que descrevem cada dimensão de análise. A Equação (10) ilustra esse procedimento:

$$
C I_{i}=\left(E I_{i} \times E n I_{i} \times E c I_{i}\right)
$$

\subsection{Resultados e Discussão}

De acordo com os resultados obtidos, para alcançar uma eficiência $\eta=90 \%$ de captura do $\mathrm{CO}_{2}$ presente no fluxo de exaustão de uma termoelétrica a carvão à qual está acoplado um sistema CCS do tipo CaL, será necessário dispor de um fluxo de carvão de $f_{C}=48,6 \mathrm{~kg} / \mathrm{s}$ para fornecer energia necessária ao calcinador. No caso da termoelétrica a gás natural, a taxa de adição de combustível é $f_{G N}=23,0 \mathrm{~m}^{3} / \mathrm{s}$. Além disso, o consumo de $\mathrm{CaCO}_{3}$ para operar o CaL na termoelétrica a carvão foi $Q_{\mathrm{CaCO} 3}=34,9 \mathrm{~kg} / \mathrm{s}$, ao passo que para o sistema gerador com gás natural este foi de apenas $Q_{\mathrm{CaCO} 3}^{*}=10,0 \mathrm{~kg} / \mathrm{s}$. 
A energia térmica recuperada do carbonatador devido à reação exotérmica e os fluxos de gás que deixaram o arranjo do compressor e o calcinador totalizaram $1370 \mathrm{MW}$ para a unidade termoelétrica a carvão, e 600 MW para a usina de gás natural. 0 uso dessa energia permitiu aumentar a potência bruta em ambos os empreendimentos para níveis, respectivamente de 3000 MW e 1400 MW. Desses totais, no entanto, 175 MW e 62 MW ainda devem ser descontados, pois correspondem às demandas específicas de CaL para cada situação. As eficiências líquidas obtidas pelas modelagens realizadas nos processos atingiram valores de $\eta_{\text {coal }}=38 \%$ e $\eta_{N G}=34 \%$.

Tais valores são considerados aceitáveis devido à sua baixa variabilidade quando comparados a índices de plantas equivalentes sem CCS de, respectivamente, 40\% e 38\% (DONES et al., 2007). Esses desempenhos demonstram as vantagens técnicas do uso de CaL, apesar da usina termoelétrica operar com carvão ou gás natural. Os resultados com esta tecnologia foram ainda maiores do que os obtidos por outros sistemas CCS em situações semelhantes, como ocorreu com solventes monoetanolamina, quando $\eta_{\text {coal }} \approx$ $\eta_{N G} \approx 28 \%$ (CASTELO BRANCO et al., 2013; MANTRIPRAGADA et al., 2014).

\subsubsection{Avaliação Ambiental}

A Tabela 6 mostra valores acumulados de impacto ambiental para Aquecimento Global e Demanda de Energia Primária, bem como seus principais precursores em cada cenário. Os resultados obtidos indicaram não haver uma opção que reuna os melhores desempenhos em ambas dimensões analisadas. Quanto ao Aquecimento Global o cenário S4 se destaca dos demais ao atingir $233 \mathrm{~kg} \mathrm{CO}_{2}$ eq $/ \mathrm{MWh}$ de desempenho, ao passo que a supremacia no que se refere a Demanda de Energia Primária cabe a S1, por proporcionar 4,57 GJ/MWh de impacto.

Observando com mais cuidado cada situação, é possível notar que as principais contribuições para o Aquecimento Global, são aportadas por $\mathrm{CO}_{2}, \mathrm{CO}_{2, \mathrm{LT}}, \mathrm{CH}_{4} \mathrm{e} \mathrm{CH}$,b. No entanto, apesar de sua expressividade, as parcelas de $\mathrm{CO}_{2, \mathrm{LT}}$ e $\mathrm{CH}_{4, \mathrm{~b}}$ são constantes para todos os cenários. Isso ocorre, pois, as emissões que geram esses impactos são emanadas por hidrelétricas e termelétrica a biomassa, cujas operações não sofrem ascendência do sistema CCS. 0 mesmo se dá com emanações de $\mathrm{N}_{2} \mathrm{O}$, ainda que em escala mais reduzida. As mesmas tendências podem ser também observadas na Figura 5.4 que descreve perfis de impactos para Aquecimento Global, em termos absolutos e relativos, distribuídos por fonte da rede elétrica brasileira. 
Tabela 5.6 - Desempenho Ambiental e Energético e principais precursores de impacto para geração de 1,0 MWh de eletricidade pela matriz brasileira - 2017

\begin{tabular}{llllll}
\hline \multirow{2}{*}{ Categoria de Impacto } & Precursor & \multicolumn{4}{c}{ Cenário } \\
\cline { 3 - 6 } & & $\mathrm{S} 1$ (base) & $\mathrm{S} 2$ & $\mathrm{~S} 3$ & $\mathrm{~S} 4$ \\
\hline \multirow{2}{*}{ Potencial Aquecimento } & 123 & 92,7 & 76,8 & 46,7 \\
Global (kg CO 2 2eq) & $\mathrm{CO}_{2, \mathrm{LT}}$ & 73,2 & 73,2 & 73,2 & 73,3 \\
& $\mathrm{CH}_{4}$ & 55,1 & 55,2 & 81,0 & 81,1 \\
& $\mathrm{CH}_{4, \mathrm{~b}}$ & 28,7 & 28,7 & 28,8 & 28,8 \\
& $\mathrm{~N}_{2} \mathrm{O}$ & 3,16 & 3,02 & 3,13 & 3,01 \\
& Total & 283 & 253 & 263 & 233 \\
\hline \multirow{2}{*}{$\begin{array}{l}\text { Demanda de Energia } \\
\text { Primária (MJ) }\end{array}$} & Petróleo Cru & 344 & 392 & 406 & 454 \\
& Gás Natural & 1280 & 1290 & 1930 & 1940 \\
& Carvão & 464 & 465 & 467 & 469 \\
& Energia Cinética & 2484 & 2485 & 2488 & 2489 \\
& (água) & 4572 & 4632 & 5291 & 5352 \\
\hline
\end{tabular}

Legenda: $\mathrm{CO}_{2}$, LT: Dióxido de Carbono da transformação da terra; $\mathrm{CH}_{4, \mathrm{~b} \text { : Metano, biogênico }}$

O fato de S4 ter alcançado o melhor resultado para Aquecimento Global da série não é surpreendente, dado que S2 e S3 obtiveram desempenhos superiores aos de S1 nessa categoria. 0 comportamento se explica em virtude de S4 acumular efeitos positivos para Aquecimento Global devido a implantação da tecnologia CaL nas usinas a carvão e gás natural. Diante dos resultados obtidos é possível afirmar que a instalação de CaL nesses empreendimentos gerou uma redução de 17\% nos impactos para a categoria com relação ao que ocorre com $\mathrm{S} 1$, cenário de referência para a análise. Uma explicação fundamentada para esse fenômeno se apoia na redução, em $62 \%$, das emissões de $\mathrm{CO}_{2}$ ocorridas devido a combustão de carvão e gás natural nos respectivos geradores de calor das termelétricas.

Se em conjunto essas etapas contribuem com $32 \%$ dos impactos de $\mathrm{S} 1$, a presença de CaL no sistema diminui essa participação para 3,0\% dos aportes para Aquecimento Global em S4. Por outro lado, o atendimento das demandas térmicas de CaL se dá através da queima de gás natural, cujas extração, refino e uso (exatamente para gerar calor para o CCS) resultam em emissões de $\mathrm{CH}_{4}$ e $\mathrm{CO}_{2}$ que elevaram em $47 \%$ as contribuições para a mesma categoria em S4. 
Figura 5.4 - Distribuição dos aportes para o Potencial Aquecimento Global por fonte integrante da rede brasileira: valores relativos (\%) e absoluto $\left(\mathrm{kg} \mathrm{CO}_{2 \mathrm{eq}} / \mathrm{MWh}\right)$

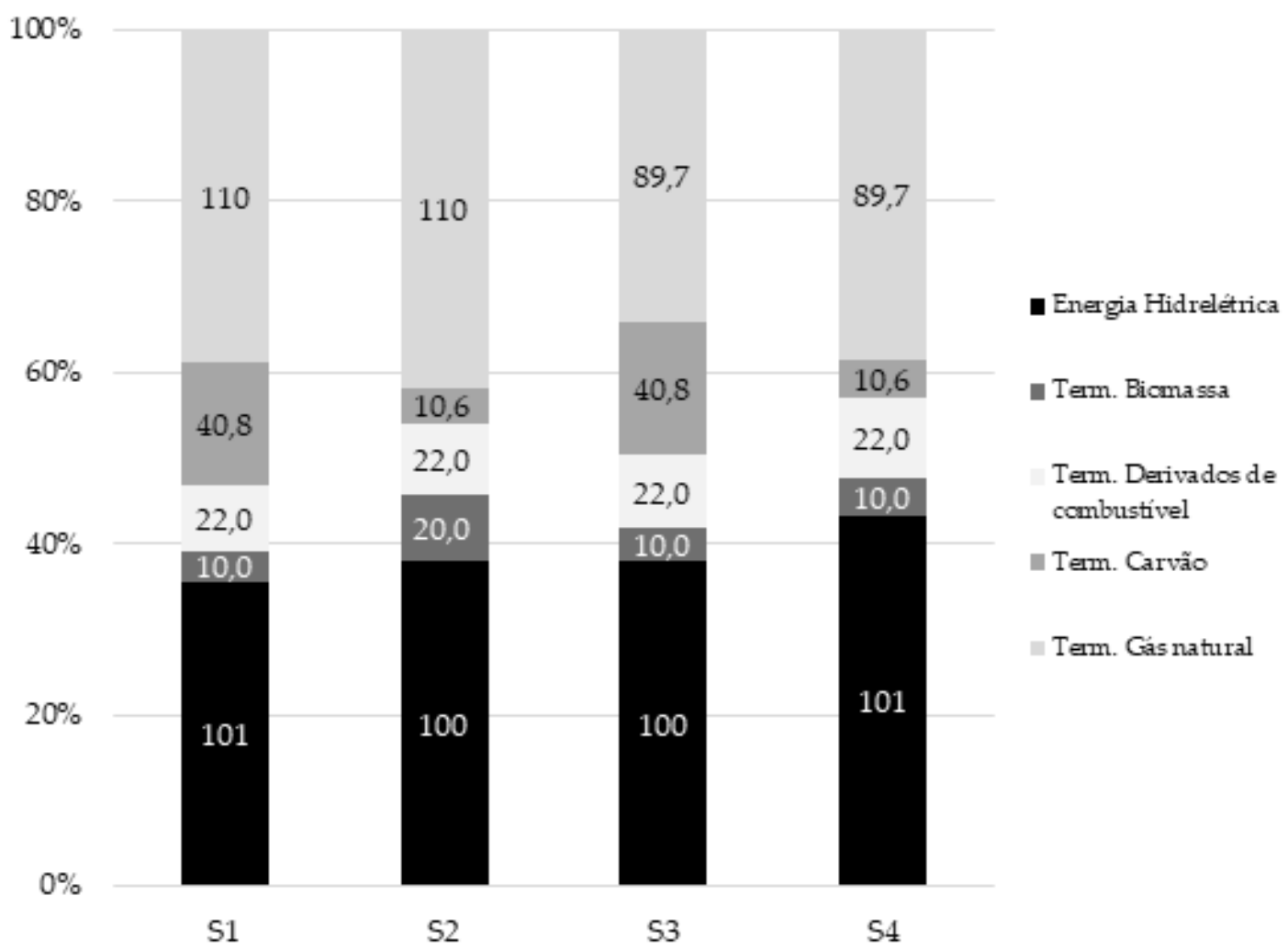

A instalação de CaL nas usinas a carvão (S2) evitou que fossem emitidos cerca de $30 \mathrm{~kg} \mathrm{CO} / \mathrm{MWh}$, correspondentes a $11 \%$ menos de impactos em relação ao desempenho de S1. Além disso, os lançamentos de $\mathrm{CH}_{4}$ associados a essa fonte não se alteraram uma vez que, nesse cenário, o calor necessário para manter o CaL ativo advém da queima do próprio carvão. Dessa forma o acoplamento de CaL a termelétricas operadas com carvão alcançou o segundo melhor desempenho quanto ao Aquecimento Global, ficando atrás, apenas, do arranjo S4.

Em S3 a implementação do CaL para mitigar as emissões de $\mathrm{CO}_{2}$ da combustão de gás natural reduziu os impactos de Aquecimento Global em 7,1\% com relação aos de S1. Nesse contexto, a extração e o refino do combustível tiveram influência decisiva sobre o impacto acumulado pelo cenário, respondendo por 33\% desse efeito. A queima de gás natural na termelétrica trouxe mais $13 \%$ de contribuição para o Aquecimento Global. 0 uso de CaL em termelétricas a gás natural é promissor em virtude da redução expressiva de emissões de $\mathrm{CO}_{2}$ que acarreta. No entanto, o fato de o suprimento da demanda térmica dessa alternativa de CCS ocorrer via queima de gás natural acaba comprometendo aquele desempenho dadas as liberações de $\mathrm{CH}_{4}$ e mesmo, do próprio gás carbônico, associadas ao ciclo produtivo do combustível. 
Com isso conclui-se que para efeito de Aquecimento Global, a aplicação de CaL a termelétricas operadas com gás natural é pouco recomendável, ao menos nas condições pleiteadas por essa análise. Duas possibilidades não mutuamente excludentes poderiam ser exploradas para o aprimoramento dessa abordagem visando seu (re)aproveitamento para mitigação de emissões de $\mathrm{CO}_{2}$ naquele contexto; a saber: (i) revisão dessa tecnologia de CCS, buscando reduzir suas demandas térmicas; e (ii) verificação de alternativas de provimento daquela forma energia necessária a partir de combustíveis, ou tecnologias cujo ciclo de vida acumulassem menos emissões de GEE do que o gás natural.

Afora os efeitos adversos já mencionados, certos aspectos inerentes ao ciclo de vida da tecnologia CaL acabaram também amortecendo seus benefícios para os cenários das termelétricas movidas a carvão e a gás natural. Isso ocorreu com os transportes do $\mathrm{CaCO}_{3}$ dosado no regenerador para fins de reposição desse ativo. A operação contribuiu com 2,57 kg CO $\mathrm{keq}_{2} / \mathrm{MWh}$ para S2 e 3,03 $\mathrm{kg} \mathrm{CO}_{2 \text { eq }} / \mathrm{MWh}$ para S3. Em S4, caso em que o CaL opera simultaneamente em ambas as fontes, o serviço ocasionou pouco mais de $12 \%$ de toda a contribuição associada a $\mathrm{CO}_{2}$ (ou seja, 5,09 $\mathrm{kg} \mathrm{CO} \mathrm{CO}_{2 \mathrm{eq}} / \mathrm{MWh}$ ). A impossibilidade de realizar transporte compartilhado com outros ativos, a prevalência do modal rodoviário para distribuição de cargas pesadas no Brasil e, assim como as longas distâncias entre as minas de extração de $\mathrm{CaCO}_{3}$ e plantas termelétricas (que variam desde 660 até $1100 \mathrm{~km}$ ) justificam esses desempenhos.

Os resultados obtidos para Demanda de Energia Primária sugerem uma pequena vantagem de S1 sobre S2. No cenário base, a produção de hidreletricidade responde por $54 \%$ do impacto total para a categoria, seguida por termeletricidade proveniente de gás natural (28\%). S2 mostra tendências semelhantes, e assim, as diferenças de contribuição entre os dois esquemas de processo são tênues no tocante as depleções de gás natural e carvão brutos, e energia cinética (hidrelétrica). Por outro lado, observou-se um aumento de 14\% no consumo de petróleo cru de S2 com relação a S1, dado o uso de diesel para transporte $\mathrm{CaCO}_{3}$. A propagação desse efeito elevou em 1,3\% o impacto global de S2 em termos de Demanda de Energia Primária, mais uma vez com relação ao alcançado por S1.

Os desempenhos de S3 e S4 foram bastante destoantes do atingido por S1 para a dimensão energética. A baixa performance de S3 na categoria se apoia em dois motivos já discutido nesta análise: (i) consumo adicional de petróleo bruto (18\%) para produção do diesel a ser usado no transporte de $\mathrm{CaCO}_{3}$; e, (ii) o aumento de demanda de gás natural (51\%) para suprimento de calor para o CCS. Assim como já ocorrera com Aquecimento Global, esse desfecho também desrecomenda adotar CaL como técnica de contenção de $\mathrm{CO}_{2}$ em termelétricas a gás natural nos termos em que a técnica foi aplicada neste estudo. 
Por associar as modificações implementadas nos outros cenários alternativos, o desempenho obtido por S4 já era esperado. Tal como ocorrera com Aquecimento Global, os desempenhos de S2 e S3 foram determinantes para esses resultados; porém, o desfecho ocorreu às avessas daquela situação. Os consumo excedentes de recursos energéticos primários, superior em $52 \%$ para petróleo cru, e em $32 \%$ no caso de gás natural bruto, medidos sempre com relação a referência, tornaram S4 mais agressivo do que S1 em 17\%, e colocando-o com última opção da série no que diz respeito a Demanda de Energia Primária.

\subsubsection{Análise Econômica}

A Tabela 5.7 apresenta valores de LCOE discretizados por fonte componente do grid brasileiro para as circunstâncias descritas em S1. Os resultados apontam a queima de óleo combustível como fonte principal de custos unitários de geração de eletricidade no país. A contrapartida desse efeito está exatamente na hidroeletricidade, que devido a sua expressiva participação no grid, coloca no Brasil no grupo dos países industrializados com os menores custos agregados de eletricidade (IEA, 2015).

Tabela 5.7 - LCOE para cada fonte que compõe a matriz elétrica do Brasil em 2017

\begin{tabular}{lcccccccc}
\hline Fonte & HD & O\&D & CV & GN & BMS & NU & EoL & SoL \\
\hline $\begin{array}{l}\text { LCOE } \\
\text { (USD/MWh) }\end{array}$ & 59,9 & 221 & 95,7 & 107 & 154 & 98.0 & 112 & 168 \\
\hline
\end{tabular}

Legenda: HD: hidreletricidade; O\&D: óleo e derivados; CV: carvão; GN: gás natural; BMS: biomassa; NU: nuclear; Eol: eólica; SoL: solar

O valor do LCOE para os demais casos quando CaL foi acoplado às usinas a carvão e a gás natural está baseado em estimativas feitas por Mantripragada et al. (2014). Esses autores determinaram que a implantação dessa tecnologia CCS em usinas a carvão eleva em 137\% o LCOE em relação a plantas que não dispõem do sistema. 0 ajuste foi aplicado aos valores de LCOE apresentados na Tabela 5.5 exatamente para termelétricas operadas a carvão e gás. 0 resultado dessa intervenção foi registrado Tabela 5.8 para cada cenário.

O uso de sistema de captura de carbono do tipo CaL em usinas termelétricas a gás natural (S3) resulta em custos mais elevados do que se o mesmo arranjo fosse acoplado a uma planta operada a carvão (S2). Isto se deve principalmente ao preço do gás natural (74,60 USD/MWh), que superava em cerca de duas vezes a cotação do carvão no mercado internacional à época em que essas cotações foram realizadas (IEA, 2015). 
Tabela 5.8 - Desempenho econômico de cada cenário de geração elétrica expresso por fonte

\begin{tabular}{lllllll}
\hline \multirow{2}{*}{ Fonte de Energia } & \multirow{2}{*}{$\begin{array}{l}\text { Geração } \\
\text { (TWh/y) }\end{array}$} & \multirow{2}{*}{$\begin{array}{l}\text { LCOE } \\
\text { (USD/MWh) }\end{array}$} & \multicolumn{4}{c}{ Custo de Geração de Eletricidade (Bi USD/y) } \\
\cline { 5 - 7 } Hidrelétrica & 383 & 59,9 & 22,9 & 22,9 & 22,9 & 22,9 \\
Petróleo & 14,7 & 221 & 3,25 & 3,25 & 3,25 & 3,25 \\
Carvão & 24,1 & 95,7 & 2,31 & - & 2,31 & - \\
Carvão com CaL & 24,1 & 227 & - & 5,48 & - & 5,48 \\
Gás Natural & 61,7 & 107 & 6,60 & 6,60 & - & - \\
Gás Natural com CaL & 61,7 & 254 & - & - & 15,7 & 15,7 \\
Biomassa & 48,2 & 154 & 7,42 & 7,42 & 7.42 & 7,42 \\
Nuclear & 14,7 & 98,0 & 1,44 & 1,44 & 1,44 & 1,44 \\
Eólica & 40,0 & 112 & 4,48 & 4,48 & 4,48 & 4,48 \\
Solar & 7,64 & 168 & 0,13 & 0,13 & 0,13 & 0,13 \\
Total & 588 & - & 48,5 & 51,7 & 57,6 & 60,8 \\
\hline
\end{tabular}

O preço do carvão praticado no mercado mais uma vez justifica a suavização no aumento dos custos de S2 (6,6\%) em relação a S1. As razões acima expostas, servem de alegação para que as despesas associadas a S3 e S4 fossem em aproximadamente 19\% e 25\% mais elevadas do que as acumuladas pelo cenário base.

\subsubsection{Análises Combinadas: Ambiental, Energética e Econômica}

O fato de não se ter identificado um cenário prevalente para todas as dimensões, enfatiza a importância da análise combinada. Os resultados dessa verificação aparecem representados na Tabela 5.9. De acordo com a métrica utilizada, S2 se destaca das demais opções ao atingir o menor indicador combinado $\left(C_{S 2}\right)$. Esse achado indica que o uso do processo de CaL em termelétricas operadas com carvão é uma possibilidade auspiciosa por coordenar equilibradamente as dimensões ambiental, energética e econômica.

Mesmo com desempenho ambiental inferior ao obtido por S4 $(7,8 \%)$ e de ordens de grandeza semelhantes aos de S1 em termos energéticos e econômicos (1,3\% e 6,5\%), S2 domina seus concorrentes devido à homogeneidade dos índices. No outro extremo, S3 detém o pior desempenho combinado, sem ter acumulado o pior resultado individual em qualquer das dimensões verificadas. 
Portanto, a aplicação da tecnologia CaL na remoção de $\mathrm{CO}_{2}$ das emissões de termelétricas a gás natural seria desaconselhável pelo conjunto de resultados, mas não, por apresentar performances individuais custosa, energo-demandantes, ou agressiva ao ambiente.

Tabela 5.9 - Indicadores individuais e Indicador Combinado para os cenários S1 - S4

\begin{tabular}{cllll}
\hline \multirow{2}{*}{ Indicador } & \multicolumn{5}{c}{ Cenário } \\
\cline { 2 - 5 } & $\mathrm{S} 1$ & $\mathrm{~S} 2$ & $\mathrm{~S} 3$ & $\mathrm{~S} 4$ \\
\hline $\boldsymbol{E I}_{\boldsymbol{i}}$ & 1,000 & 0,894 & 0,929 & 0,823 \\
$\boldsymbol{E n I}_{\boldsymbol{i}}$ & 1,000 & 1,011 & 1,139 & 1,151 \\
$\boldsymbol{E C I}_{\boldsymbol{i}}$ & 1,000 & 1,066 & 1,188 & 1,254 \\
$\boldsymbol{C I}_{\boldsymbol{i}}$ & 1,000 & 0,963 & 1,257 & 1,188 \\
\hline
\end{tabular}

0 resultado geral alcançado por S4 também é destacável. Nesse caso, os reveses nas dimensões energética e econômica, quando $E n I_{S 4}$ e $E c I_{S 4}$ ocupam as últimas posições em suas respectivas séries, foram neutralizados por seu desempenho ambiental $\left(E I_{S 4}\right)$. Tal constatação sugere que a instalação simultânea de CaL em usinas movidas a carvão e a gás natural é uma alternativa dispendiosa e energo-intensiva. Por outro lado, a eficácia com que tecnologia de CCS cumpre seus objetivos é elevada o suficiente para recolocá-la no conjunto de possibilidades consideradas por um processo de tomada de decisão que se desenvolva no âmbito do planejamento energético brasileiro.

\subsection{Conclusões}

Esse estudo avaliou o efeito de uma eventual implantação de sistemas de CCS sobre os desempenhos ambiental, energético e econômico da matriz elétrica brasileira. Foram projetados quatro cenários de análise, sendo três deles modelados tendo em conta o acoplamento da tecnologia de Carbon Looping (CaL) de CCS para captura de $\mathrm{CO}_{2}$. O cenário S1 que descreve a condição atual do grid brasileira, serviu como cenário base. Foram selecionadas para receber o CaL as termelétricas operadas a carvão (cenário S2) e a gás natural (S3), enquanto em S4 o CaL foi aplicado simultaneamente as duas classes de usinas. $O$ desempenho ambiental foi expresso pelo potencial de Aquecimento Global dos sistemas, enquanto a Demanda Primária de Energia serviu de indicador energético, e o Custo Nivelado de Energia (LCOE), de parâmetro para análise econômica. Aquecimento Global e Demanda de Energia Primária foram os impactos estimados pela ACV tendo por base de cálculo a geração elétrica de 1,0 MWh. 
Os resultados obtidos indicaram que nenhum dos cenários avaliados acumulou os melhores índices em todas as dimensões. $\mathrm{CO}_{2}$ e $\mathrm{CH}_{4}$ são os principais precursores do impacto para Aquecimento Global e S4 acumula os efeitos positivos da implantação de CaL. Isso se deve a diminuição (62\%) nas emissões totais de $\mathrm{CO}_{2}$ derivadas da combustão de carvão e gás. Por outro lado, os aportes de impacto feitos pelos lançamentos de $\mathrm{CH}_{4}$ aumentaram significativamente nos casos em que CaL foi implantado em virtude dos operação predispõe. Além de reduziu parte das vantagens proporcionadas por CaL em S4, esse efeito praticamente inviabilizou a qualquer opção por S3. As emissões de $\mathrm{CO}_{2}$ do transporte de $\mathrm{CaCO}_{3}$ usado no processo de CaL também ajudaram a neutralizar os ganhos ambientais que a tecnologia proporcionou.

As Demanda de Energia Primária de S1 e S2 foram semelhantes e melhores do que as alcançadas por S3 e S4. Os reveses associados a S3 e S4 se devem a consumos de petróleo cru, para produção do diesel usado no transporte de $\mathrm{CaCO}_{3}$, e gás natural bruto, para operação de CaL. Essa constatação também desrecomenda o uso de CaL em usinas termelétricas operadas com gás natural. 0 fato de o preço do gás ser em duas vezes superior ao do carvão no mercado internacional à época da realização do estudo faz com que S3 seja também mais dispendioso em termos de operação do que S2.

Uma verificação combinada das três dimensões comprovou ser S2 a melhor opção de toda a série avaliada, devido à homogeneidade de seus índices. Esse resultado referenda a aplicação de Carbn Looping como técnica de mitigação de emissões de $\mathrm{CO}_{2}$ em termelétricas operadas com carvão. Por outro lado, o índice combinado obtido para S4 foi inesperado. Muito embora seus desempenhos energético e econômico fossem os piores do conjunto de opções, a instalação simultânea de CaL em usinas a carvão e gás foi ambientalmente favorável a ponto de compensar aquelas limitações recolocando essa opção no conjunto a ser considerado para efeito de planejamento energético futuro.

O estudo atendeu às suas expectativas originais de buscar equiparar a dicotomia existente entre a necessidade de expansão do suprimento de eletricidade doméstica e a redução de impactos ambientais decorrentes da geração de eletricidade no Brasil. Para isso, porém, a investigação não deixou de observar outros aspectos inerentes a essa classe de empreendimentos com eficiência energética do sistema, e custos associados.

\subsection{Referências}

Adanez J., Abad A., Garcia-Labiano F., Gayan P., De Diego L.F., 2012, Progress in chemical-looping combustion and reforming technologies. Prog. Energy Combust. Sci. 38: 215-282. DOI: 10.1016/j.pecs.2011.09.001. 
Alam M.M., Murad M.W., Noman A.H.M., Ozturk I., 2016, Relationships among carbon emissions, economic growth, energy consumption and population growth: Testing Environmental Kuznets Curve hypothesis for Brazil, China, India and Indonesia. Ecol. Indic. 70: 466-479. DOI: 10.1016/j.ecolind.2016.06.043.

Anwar M.N., Fayyaz A., Sohail N.F., Khokhar M.F., Baqar M., Khan W.D., Rasool K., Rehan M., Nizami A.S., 2018, $\mathrm{CO}_{2}$ capture and storage: A way forward for sustainable environment. J. Environ. Manag. 226: 131-144. DOI: 10.1016/j.jenvman.2018.08.009.

Barros M.V., Piekarski C.M., De Francisco A.C., 2018, Carbon footprint of electricity generation in Brazil: An analysis of the 2016-2026 period. Energies. 11: 1412, DOI: 10.3390/en11061412.

Biliyok C., Yeung H., 2013, Evaluation of natural gas combined cycle power plant for post-combustion $\mathrm{CO}_{2}$ capture integration. Int. J. Greenh. Gas Control. 19: 396-405. DOI: $10.1016 / J . I J G G C .2013 .10 .003$.

Blamey J., Anthony E.J., Wang J., Fennell P.S., 2010, The calcium looping cycle for largescale $\mathrm{CO}_{2}$ capture. Prog. Energy Combust. Sci. 36: 260-279. DOI:

10.1016/j.pecs.2009.10.001.

Castelo Branco D.A., Moura M.C.P., Szklo A., Schaeffer R., 2013, Emissions reduction potential from $\mathrm{CO}_{2}$ capture: A life-cycle assessment of a Brazilian coal-fired power plant. Energy Policy. 61: 1221-1235, DOI: 10.1016/j.enpol.2013.06.043.

Cormos C.C., 2015, Assessment of chemical absorption/adsorption for post-combustion $\mathrm{CO}_{2}$ capture from Natural Gas Combined Cycle (NGCC) power plants. Appl. Therm. Eng. 82: 120-128. DOI: 10.1016/J.APPLTHERMALENG.2015.02.054.

Cormos C.C., Petrescu L., 2013, Evaluation of calcium looping as carbon capture option for combustion and gasification power plants. Energy Procedia. 51: 154-160. DOI: 10.1016/j.egypro.2014.07.017.

Corsten M., Ramírez A., Shen L., Koornneef J., Faaij A., 2013, Environmental impact assessment of CCS chains-Lessons learned and limitations from LCA literature. Int. J. Greenh. Gas Control. 13: 59-71, DOI: 10.1016/J.IJGGC.2012.12.003.

Cuéllar-Franca R.M., Azapagic A., 2015, Carbon Capture, storage and utilization technologies: A critical analysis and comparison of their life cycle environmental impacts. J. CO 2 Util. 9: 82-102. DOI: 10.1016/j.jcou.2014.12.001.

Dieter H., Bidwe A.R., Varela-Duelli G., Charitos A., Hawthorne C., Scheffknecht G., 2014, Development of the calcium looping $\mathrm{CO}_{2}$ capture technology from lab to pilot scale at IFK, University of Stuttgart. Fuel. 127: 23-37. DOI: 10.1016/j.fuel.2014.01.063.

Dones R., Bauer C., Röder A. Coal Energy Chain in USA. Final Report Ecoinvent N. 6-VI; Swiss Centre for Life Cycle Inventories: Dübendorf, Switzerland, 2007.

EPE (Energy Research Company). Brazilian Energy Balance 2018: Year 2017; EPE: Rio de Janeiro, Brazil, 2018; 292p.

EPE (Energy Research Company). Renewable Energy: Hydraulics, Biomass, Wind, Solar, Ocean; EPE: Rio de Janeiro, Brazil, 2016; 452p, ISBN 978-85-60025-06-0. 
EPE (Energy Research Company). Ten Year Energy Expansion Plan 2026; MME/EPE: Brasília, Brazil, 2017; 271p.

EPE (Energy Research Company). Thermoelectric Power: Natural Gas, Biomass, Coal, Nuclear; EPE: Rio de Janeiro, Brazil, 2016; 417p, ISBN 978-85-60025-05-3.

Fransson E., Detert M. Process Integration of $\mathrm{CO}_{2}$ Capture by Means of Calcium Looping Technology. Master's Thesis, Chalmers University of Technology, Gothenburg, Sweden, 2014.

Frischknecht R., Jungbluth N., Althaus H.-J., Bauer C., Doka G., Dones R., Hischier R., Hellweg S., Humbert S., Köllner T., et al. Implementation of Life Cycle Impact Assessment Methods: Data v2.0. Ecoinvent report No. 3; Swiss Centre for Life Cycle Inventories: Dübendorf, Switzerland.

Geller M.T.B., Meneses A.A.D.M., 2016, Life Cycle Assessment of a Small Hydropower Plant in the Brazilian Amazon. J. Sustain. Dev. Energy. 4: 379-391. DOI: 10.13044/j.sdewes.2016.04.0029.

Goedkoop M., Heijungs R., Huijbregts M., De Schryver A., Struijs J., van Zelm R., 2013, Description of the ReCiPe Methodology for Life Assessment Impact Assessment. 2013. Disponível em: <http://www.lciarecipe.net>

Guerra J.P., Cardoso F.H., Nogueira A., Kulay L., 2018, Thermodynamic and environmental Analysis of Scaling up Cogeneration Units Driven by Sugarcane Biomass to Enhance Power Exports. Energies. 11: 73. DOI: 10.3390/en11010073.

Hu Y., Ahn H., 2017, Process integration of a Calcium-looping process with a natural gas combined cycle power plant for $\mathrm{CO}_{2}$ capture and its improvement by exhaust gas recirculation. Appl. Energy. 187: 480-488. DOI: 10.1016/j.apenergy.2016.11.014.

IEA (International Energy Agency). Projected Costs of Generating Electricity; OECD Publishing: Paris, Italy, 2015; 213p.

ISO (International Organization for Standardization). ISO 14040, 2006, Environmental management - life cycle assessment - principles and framework, $1^{\text {st }} \mathrm{Ed}$. International Organization for Standardization: Genève, Switzerland, 20p

ISO (International Organization for Standardization). ISO 14044, 2006, Environmental Management-Life Cycle Assessment-Requirements and Guidelines, $1^{\text {st }}$ Ed. International Organization for Standardization: Genève, Switzerland, 46p.

IPCC (International Panel on Climate Change). Climate Change 2014: Mitigation of Climate Change. Contribution of Working Group III to the Fifth Assessment Report of the Intergovernmental Panel on Climate Change; Cambridge University Press: Cambridge, UK, 2014; 1435p, ISBN 978-1-107-05821-7.

Jayarathna C.K., Mathisen A., Øi L.E., Tokheim L.A. Process Simulation of Calcium Looping with Indirect Calciner Heat Transfer. In Proceedings of the 56th SIMS, Linköping, Sweden, 7-9 October 2015.

Kileber S., Parente V., 2015, Diversifying the Brazilian electricity mix: Income level, the endowment effect, and governance capacity. Renew. Sustain. Energy Rev. 49: 11801189. DOI: $10.1016 /$ j.rser.2015.04.109. 
Koornneef J., Ramirez A., Van Harmelen T., Van Horssen A., Turkenburg W., Faaij A., 2010, The impact of $\mathrm{CO}_{2}$ capture in the power and heat sector on the emission of $\mathrm{SO}_{2}$, $\mathrm{NO}_{\mathrm{x}}$, particulate matter, volatile organic compounds and $\mathrm{NH} 3$ in the European Union. Atmos. Environ. 44: 1369-1385. DOI: 10.1016/j.atmosenv.2010.01.022.

Korre A., Nie Z., Durucan S., 2010, Life cycle modelling of fossil fuel power generation with post-combustion $\mathrm{CO}_{2}$ capture. Int. J. Greenh. Gas Control. 4: 289-300. DOI: 10.1016/j.ijggc.2009.08.005.

Mantripragada H.C., Rubin E.S., 2014, Calcium Looping Cycle for $\mathrm{CO}_{2}$ Capture: Performance, Cost and Feasibility Analysis. Energy Procedia. 63: 2199-2206. DOI: 10.1016/J.EGYPRO.2014.11.239.

Martinez I., Murillo R., Grasa G., Abanades J.C., 2011, Integration of a Ca-looping system for $\mathrm{CO}_{2}$ capture in an existing power plant. Energy Procedia. 4: 1699-1706. DOI: 10.1016/i.egypro.2011.02.043.

Miccio F., Bendoni R., Piancastelli A., Medri V., Landi E., 2018, Geopolymer composites for chemical looping combustion. Fuel. 225: 436-442. DOI: 10.1016/j.fuel.2018.03.153.

MME (Ministério de Minas e Energia). 2018. Monthly Bulletin of Electrical Energy. Disponível em: http://www.mme.gov.br/web/guest/publicacoes-eindicadores/boletins-de-energia

CNT (National Confederation of Transport). Atlas do Transporte. Disponível em: $<$ http://www.cnt.org.br/Paginas/atlas-do-transporte>. (in Portuguese)

ANEEL (National Electric Energy Agency). Generation Information Database (BIG). 2018. Disponível em:

<http://www2.aneel.gov.br/aplicacoes/capacidadebrasil/capacidadebrasil.cfm>.

Rochedo P.R.R., Costa I.V.L., Império M., Hoffmann B.S., Merschmann P.R.D.C., Oliveira C.C.N., Szklo A., Schaeffer R., 2016, Carbon capture potential and costs in Brazil. J. Clean. Prod. 131: 280-295. DOI: 10.1016/j.jclepro.2016.05.033.

Romeiro D.L., Almeida E., Losekann L. The choice of dispatchable versus intermittent electricity generating technologies and the Brazilian case. In Proceedings of the 5th Latin American Energy Economics Meeting, Medellín, Colombia, 15-18 March 2015.

Ruiz M. Assessment of Calcium Looping as a Solution for $\mathrm{CO}_{2}$ Capture in the Steel Production Process. Master's Thesis, University of Stuttgart, Stuttgart, Germany, 2015.

Shimizu T., Hirama T., Hosoda H., Kitano K., Inagaki M., Tejima K., 1999, A twin fluid-bed reactor for removal of $\mathrm{CO}_{2}$ from combustion processes. Chem. Eng. Res. Des. 77: 6268. DOI: $10.1205 / 026387699525882$.

Singh B., Strømman A.H., Hertwich E., 2011, Life cycle assessment of natural gas combined cycle power plant with post-combustion carbon capture, transport and storage. Int. J. Greenh. Gas Control. 5: 457-466. DOI: 10.1016/j.ijggc.2010.03.006.

Sreedhar I., Vaidhiswaran R., Kamani B.M., Venugopal A., 2017, Process and engineering trends in membrane based carbon capture. Renew. Sustain. Energy Rev. 68: 659-684. DOI: 10.1016/j.rser.2016.10.025. 
Theo W.L., Lim J.S., Hashim H., Mustaffa A.A., Ho W.S., 2016, Review of pre-combustion capture and ionic liquid in carbon capture and storage. Appl. Energy. 183: 1633-1663. DOI: 10.1016/j.apenergy.2016.09.103.

Turconi R., Boldrin A., Astrup T., 2013, Life cycle assessment (LCA) of electricity generation technologies: Overview, comparability and limitations. Renew. Sustain. Energy Rev. 28: 555-565. D0I: 10.1016/j.rser.2013.08.013.

UNICA (Union of Sugarcane Industry). 2019. A Bioeletricidade da Cana e o Mercado Livre de Energia Elétrica no Brasil. (In Portuguese) Disponível em:

$<$ http://www.unica.com.br.

Valverde J.M., Sanchez-Jimenez P.E., Perez-Maqueda L.A., 2014, Calcium-looping for post-combustion $\mathrm{CO}_{2}$ capture. On the adverse effect of sorbent regeneration under $\mathrm{CO}_{2}$. Appl. Energy. 126: 161-171. DOI: 10.1016/J.APENERGY.2014.03.081.

Vasudevan S., Farooq S., Karimi I.A., Saeys M., Quah M.C.G., Agrawal R., 2016, Energy penalty estimates for $\mathrm{CO}_{2}$ capture: Comparison between fuel types and capturecombustion modes. Energy. 103: 709-714. DOI: 10.1016/j.energy.2016.02.154.

Vaz C.E.M., Maia J.L.P., Santos W.G. Tecnologia da Indústria do Gás Natur al, 1st. Ed., Petrobras: Rio de Janeiro, Brazil, 2008; 440p, ISBN 9788521204213.

Vorrias I., Atsonios K., Nikolopoulos A., Nikolopoulos N., Grammelis P., Kakaras E., 2013, Calcium looping for $\mathrm{CO}_{2}$ capture from a lignite fired power plant. Fuel. 113: 826-836. DOI: 10.1016/j.fuel.2012.12.087.

Zbicinski I., Stavenuiter J., Kozlowska B., van de Coevering H. Product Design and Life Cycle Assessment; The Baltic University Press: Uppsala, Sweden, 2006; pp. 88-89.

Zhang Z., Huisingh D., 2017, Carbon dioxide storage schemes: Technology, assessment and deployment. J. Clean. Prod. 142: 1055-1064. DOI: 10.1016/j.jclepro.2016.06.199. 


\section{Especificação de unidade de produção de gás de síntese derivado de biomassa de cana-de-açúcar a partir de critério ambiental}

\section{Resumo}

Este capítulo descreve uma aplicação da ACV como critério de especificação de sistema de processamento de gás de síntese a partir de bagaço de cana-de-açúcar. Para tanto, foram avaliados dois tipos de gaseificadores: Leito Fluidizado Borbulhante (GLFB) e Fluxo Arrastado (GFA). Concluída essa etapa, que serviu de critério para seleção do arranjo mais adequado de processo, verificou-se também, e mais uma vez a partir da ACV, o comportamento da cogaseificação do bagaço e palha de cana-de-açúcar no GLFB também quanto ao desempenho ambiental. 0 software Comprehensive Simulator of Fluidized and Moving Bed Equipment - CSFMB $®$ foi empregada para simular o processo de gaseificação em todos os cenários observados pelo estudo.

\subsection{Introdução}

A biomassa já está consolidada como uma alternativa aos combustíveis fósseis, no processo de busca por energias mais limpas provenientes de fontes renováveis. Essa necessidade se dá principalmente em virtude do aumento de emissões para o ar de $\mathrm{CO}_{2}$ proveniente da queima daqueles ativos não renováveis, que pode ser considerado como um dos maiores problemas da sociedade moderna (COUTO et al., 2017). Dentre as possibilidades de conversão de biomassa em combustíveis, a gaseificação é vista como das mais promissoras, por ser capaz de converter a energia intrínseca de diferentes tipos de biomassa em intermediários de valor agregado que encontram uso em processos industriais como agentes provedores de calor e eletricidade (RUOPPOLO et al., 2013).

A gaseificação transforma combustíveis sólidos em uma mistura gasosa, para a qual certas características e propriedades tais como razão $\left(\mathrm{H}_{2} / \mathrm{CO}\right)_{\text {mol, }}$ grau de umidade, Poder Calorífico Inferior (PCS) e temperatura de saída do fluído ( $\mathrm{T}_{\text {out }}$ ) são condicionadas a aspectos inerentes a síntese, como fonte de biomassa, agente gaseificante, temperatura de processo, e tipo de gaseificador (HOSSAIN e CHARPENTIER, 2015; AL-ZAREER et al., 2016; PÉREZ et al., 2012). Dentre suas especificidades o tipo de gaseificador é visto como dos aspectos determinantes para o sucesso das transformações que realiza. 
O Gaseificador de Leito Fluidizado (GLF) é uma opção recorrente para produção de gás de síntese, devido a sua flexibilidade quanto a diversidade de biomassa alimentada, por proporcionar uniformidade em termos de transferência de calor e massa, provoca uma mistura adequada entre a biomassa e o agente gaseificante, além de apresentar alta eficiência na conversão do material carbonáceo (JAIMES FIGUEROA et al., 2014). Outro tipo de gaseificador bastante empregado é o Fluxo Arrastado (GFA), uma tecnologia promissora que opera com partículas pequenas e altas temperaturas (1200$1500{ }^{\circ} \mathrm{C}$ ), podendo por isso atingir taxas de conversão superiores a $90 \%$, com baixo tempo de residência, além de produzir gás de síntese livre de tar (Alcatrão) (QIN et al., 2012).

O Brasil é conhecido por seu potencial de produção de energia a partir de fontes renováveis. A oferta interna de energia do país em 2016 foi de 288 milhões de toe. Desse total, $44 \%$ foram provenientes de fontes renováveis, sendo os derivados de cana-deaçúcar responsável por 18\% do mesmo montante (EPE, 2017). Esse potencial produtivo pode ser ainda aumentado com o uso de rejeitos lignocelulósicos da cana, pelo fato desses conterem cerca de 60\% de materiais carbonáceos. Para Moutta et al. (2014), as formas mais adequada e eficiente de realizar essa expansão se dá a partir da aplicação de tecnologias de gaseificação.

Muito embora a origem das matérias-primas utilizadas para produção de gás de síntese via gaseificação sugira geração de impactos ambientais pouco significantes, o tema poderia ter sido explorado mais a fundo pela literatura técnica, ainda que as pesquisas mais recentes realizadas nesse segmento remetam ao uso de Avaliação de Ciclo de Vida (ACV) para avaliação do desempenho ambiental da síntese de gás de síntese via rotas de gaseificação. Burmistrz et al. (2016) usaram ACV para investigar efeitos ambientais da gaseificação de dois combustíveis fósseis (carvão sub betuminoso e linito) pelas tecnologias de Gaseificador de Fluxo Arrastado GE Energy Texaco e Shell.

Seguindo uma vertente paralela, Muresan et al. (2014) verificaram um potencial menor de aquecimento global da gaseificação de biomassa (madeira) com vapor em um Gaseificador de Leito Fluidizado Duplo comparado com a gaseificação da mistura de carvão and biomassa usando o Gaseificador de Fluxo Arrastado. 0 estudo sugere, porém, que a ACV foi aplicada dentro de um enfoque restrito, do tipo 'portão-ao-portão', que condicionaria os resultados obtidos. Já Kalinci et al. (2012) avaliaram por meio da ACV a gaseificação de madeira de pinos com uso do Gaseificador de Leito Fixo Co-corrente e o de Leito Fluidizado Circulante. 
No entanto, no nosso entendimento, não existem registros de investigações que buscaram relacionar especificidades do processo de gaseificação de rejeitos de biomassa com efeitos sobre o entorno que delas possam decorrer. Este estudo se propõe a contribuir para o tema ao comparar o desempenho ambiental da obtenção de gás de síntese via duas rotas distintas de gaseificação: os sistemas de leito fluidizado e fluxo arrastado. Além disso, são discutidos também pelo estudo os efeitos ambientais gerados da cogaseificação de dois tipos de biomassa - bagaço e palha de cana - em reator de leito fluidizado. A parte de não haver referência de análise desse gênero na literatura, a decisão de avaliar o comportamento ambiental do uso de palha como insumo para síntese de gás de síntese sustenta-se no fato dessa iniciativa ser considerada como prática de revalorização à ótica da Produção mais Limpa $(\mathrm{P}+\mathrm{L})$, uma vez que a biomassa é rejeito do processamento agrícola de cana.

Os diagnósticos foram mais uma vez elaborados via ACV, pelo fato da técnica abordar as cargas ambientais (consumo de recursos naturais e emissões de rejeitos de material e energia) e seus possíveis impactos (consequências dessas extrações e liberações no ambiente) ao longo de um ciclo de vida do produto (transformações antrópicas relacionadas à aquisição de matéria-prima, cadeia de manufatura, uso, tratamento do fim de vida, reciclagem e disposição final) (ISO, 2006a). A ACV é baseada na análise de sistemas, tratando o ciclo de vida de um produto como uma sequência de subsistemas que trocam fluxos de material e energia. Um estudo dessa natureza leva em consideração quatro fases: (i) definição de metas e escopo; (ii) análise de inventário (ICV); (iii) avaliação de impacto (AICV); e (iv) Interpretação (ISO, 2006b).

\subsection{Metodologia}

O método adotado para realização do estudo abrange cinco etapas: (i) descrição da produção de gás de síntese a partir das tecnologias de gaseificação em leito fluidizado e de fluxo arrastado em termos de: condições operacionais, consumo de recursos e emissões; (ii) projeto de modelos matemáticos capazes de representar a rota de processos, a partir dos dados e informações coletados na etapa anterior; (iii) aplicação da técnica de ACV para estabelecer os diagnósticos de desempenho ambiental dos dois processos quanto a Mudanças Climáticas (MC) e Demanda de Energia Primária (DEP); (iv) a ACV foi também aplicada para verificar impactos relacionados à substituições sucessivas de bagaço por palha, na alimentação do Gaseificador de Leito Fluidizado Borbulhante (GLFB); realizou-se, por fim (v) uma análise crítica dos resultados obtidos. 


\subsubsection{Descrição das tecnologias em análise}

A cana-de-açúcar chega à planta industrial por via rodoviária. De sua moagem se originam dois produtos: bagaço e caldo de cana-de-açúcar. 0 caldo será transformado em etanol na destilaria, enquanto a corrente de bagaço se divide em outras duas: (i) de uso no processo, para cogeração e produção de gás de síntese; e (ii) para comercialização. A cogeração fornece eletricidade e calor para a destilaria, além de acionar os moedores da gaseificação.

O modelo que descreve a tecnologia de Gaseificação de Fluxo Arrastado (GFA) parte da secagem de $130 \mathrm{t} / \mathrm{h}$ de bagaço, a fim de reduzir a umidade dessa matéria-prima de $50 \%$ para $10 \% \mathrm{~m} / \mathrm{m}$. A seguir o bagaço foi torrefado (para eliminar completamente a umidade), moído, e aquecido até $800 \mathrm{~K}$, estando em condições de ser dosado no gaseificador. 0 software comercial Comprehensive Simulator of Fluidized and Moving Bed Equipment - CSFMB $®$ foi empregado na simulação do GFA. Nesse caso uma vazão de 64,8 t/h de bagaço seco (Tabela 6.1) é adicionada ao gaseificador juntamente com ar (108 t/h; $929 \mathrm{~K})$, que atua como agente gaseificante, e uma mistura $\mathrm{N}_{2}+\mathrm{CO}_{2}[60: 40](36,0 \mathrm{t} / \mathrm{h})$. A temperatura ideal de processo $(2000 \mathrm{~K})$ será alcançada via combustão de $2198 \mathrm{~m}^{3} / \mathrm{h}$ gás natural (GN). Emanam do sistema as correntes de gás de síntese bruto (202 t/h; $1792 \mathrm{~K}$ ), e cinzas $(7,77 \mathrm{t} / \mathrm{h})$.

Tabela 6.1 - Caracterização de bagaço e palha da cana-de-açúcar

\begin{tabular}{llllll}
\hline \multicolumn{2}{l}{ Análise imediata $(\% \mathrm{~m} / \mathrm{m})$} & \multicolumn{4}{l}{ Análise elementar $(\% \mathrm{~m} / \mathrm{m})$} \\
\hline Componente & Bagaço $^{1}$ & Palha $^{2}$ & Elemento & Bagaço $^{1}$ & Palha $^{2}$ \\
\hline $\begin{array}{l}\text { Umidade } \\
\text { Carbono }\end{array}$ & 0,000 & 0,000 & $\mathrm{C}$ & 49,66 & 42,94 \\
$\begin{array}{l}\text { Fixo } \\
\text { Compostos } \\
\text { voláteis }\end{array}$ & 15,14 & 9,410 & $\mathrm{H}$ & 5,710 & 6,26 \\
$\begin{array}{l}\text { Cinzas } \\
\text { 81,55 }\end{array}$ & 86,64 & $\mathrm{~N}$ & 0,210 & 0,310 \\
& 310 & 3,850 & $\mathrm{O}$ & 41,08 & 46,65 \\
& & & $\mathrm{~S}$ & 0,030 & 0,000 \\
& & & Cinzas & 3,310 & 3,840 \\
\hline
\end{tabular}

Fontes: (1) CSFMB (2017); (2) Rueda-Ordóñez e Tannous (2015); (3) Complemento da composição elementar 
Antes do acabamento o gás de síntese será resfriado por contato indireto com ar atmosférico, que além de ser usado no gaseificador alimentará também o secador e o torrefador. 0 gás de síntese circula por ciclones para retirada de particulados, e segue para um reator $\mathrm{ZnO}$, a fim de remover $\mathrm{H}_{2} \mathrm{~S}$, que envenena os catalisadores da etapa seguinte. Por fim, o gás de síntese chega ao Reator Shift, no qual, o CO ali presente, bem como vapor de água (alimentado ao sistema a $673 \mathrm{~K}$ ), são transformados em $\mathrm{H}_{2}$ e CO, até que seja atingida uma razão $\left(\mathrm{H}_{2} / \mathrm{CO}\right)_{\mathrm{mol}}=2,00$.

A produção de gás de síntese em sistema do tipo Gaseificador de Leito Fluidizado Borbulhante (GLFB) é semelhante à do homólogo já descrito até a moagem da biomassa. Nesse caso, porém, a temperatura do bagaço é reduzida até $290 \mathrm{~K} \mathrm{em}$ um cooler a fim de atender as especificações do gaseificador. 0 gaseificador é alimentado com $64,8 \mathrm{t} / \mathrm{h}$ bagaço, tendo por agente gaseificante, ar (43,2 t/h; 766 K). A gaseificação no GLFB foi também simulada no CSFMB®. As demais operações que ocorrem no sistema GLFB são idênticas àquelas já descritas para o sistema GFA. No entanto, como neste caso o calor cedido ao ar pelo gás de síntese não é capaz de atender por completo as necessidades térmicas das operações de secagem e torrefação, mais $5436 \mathrm{~m}^{3} \mathrm{GN} / \mathrm{h}$ são transformados em calor com o intuito de suprir em definitivo aquelas demandas.

A simulação dos processos de gaseificação baseou-se nas seguintes premissas: (i) todos os fenômenos de processo se desenvolvem em regime permanente; (ii) assumiuse que o leito do gaseificador estivesse dividido em duas fases. A fase emulsão se constituí exclusivamente por partículas sólidas percoladas por gás ascendente, enquanto a fase de bolhas está completamente livres de sólidos, (iii) considerou-se que o modelo de perfil de velocidade seria do tipo plug flow e unidirecional; e, por fim, (iv) a composição de todos os sólidos é homogênea em todo o leito.

\subsubsection{Modelagem do Ciclo de Vida}

Os diagnósticos foram elaborados com a abordagem Atribucional da técnica de ACV, com enfoque do 'berço-ao-portão', e de acordo com a metodologia da ISO 14044 (ISO, 2006b). Definiu-se como Fluxo de Referência (FR) para as análises dessa etapa do estudo como sendo: 'gerar 42,8 $\mathrm{m}^{3}$ etanol em uma destilaria autônoma a qual estivesse acoplada uma unidade produtora de gás de síntese'. Essa decisão elimina a influência de distorções decorrentes da geração de dois produtos no sistema (gás de síntese e etanol). 
A Figura 6.1a descreve o Sistema de Produto usado no estudo, e as Figuras 6.1b e 6.1c detalham as rotas de processamento de gás de síntese analisadas. 0 modelo agrícola foi baseado nos procedimentos e condições técnicas praticados no Estado de São Paulo, principal produtor do país. Fertilizantes químicos - uréia, superfosfato simples e cloreto de potássio - são usados para suprir as necessidades primárias de macronutrientes (N, P e K). A aplicação de agroquímicos, no controle de pragas e na calagem do solo também são ações necessárias. A dosagem de subprodutos industriais (vinhaça e cinzas) é frequente para complementar o conteúdo nutricional da cana. Presume-se o uso de máquinas agrícolas, com consequente consumo de óleo diesel, na preparação do solo, semeadura, tratamento e colheita (MOORE et al 2016).

O desempenho ambiental foi determinado a partir dos efeitos em termos de Mudanças Climáticas (MC) e Demanda de Energia Primária (DEP). As contribuições para MC foram estimadas pelo método proposto pelo Painel Intergovernamental de Mudanças Climáticas (IPCC, 2006), enquanto os consumos de DEP da produção de gás de síntese foram descritos com auxílio do método Cumulative Energy Demand (CED) - v 1,09. 0 método CED expressa contribuições DEP de diferentes fontes de energia não renováveis (fósseis: NRF; nuclear: NRN; biomassa: NRB) e renováveis (biomassa: RB; eólica + solar + geotérmica: RWSG; água: RW) (FRISCHKNECHT et al 2007).

\subsection{Resultados}

\subsubsection{Desempenho Ambiental: GFA vs GLFB}

A Tabela 6.2 apresenta valores de desempenho ambiental da produção de gás de síntese pelas tecnologias GFA e GLFB. Uma comparação baseada em valores absolutos e que considere apenas o fluxo de referência estabelecido para o estudo $\left(42,8 \mathrm{~m}^{3} \mathrm{C}_{2} \mathrm{H}_{6} \mathrm{O}\right.$ hidratado) indica ligeira supremacia $(\sim 2,1 \%)$ de GFA sobre GLFB em termos de MC. No entanto, quando a comparação das tecnologias ocorre relação à DEP é possível notar que GLFB consome $12 \%$ menos de energia primária do que sua homóloga. Por outro lado, quando a mesma análise é realizada em valores relativos, por tonelada de gás de síntese produzido (tsy), o desempenho de GFA supera aquele apresentado por GLFB nas duas dimensões analisadas. No caso de DEP, a vantagem chega a ser de $27 \%$, enquanto para MC a diferença alcança 38\%. 


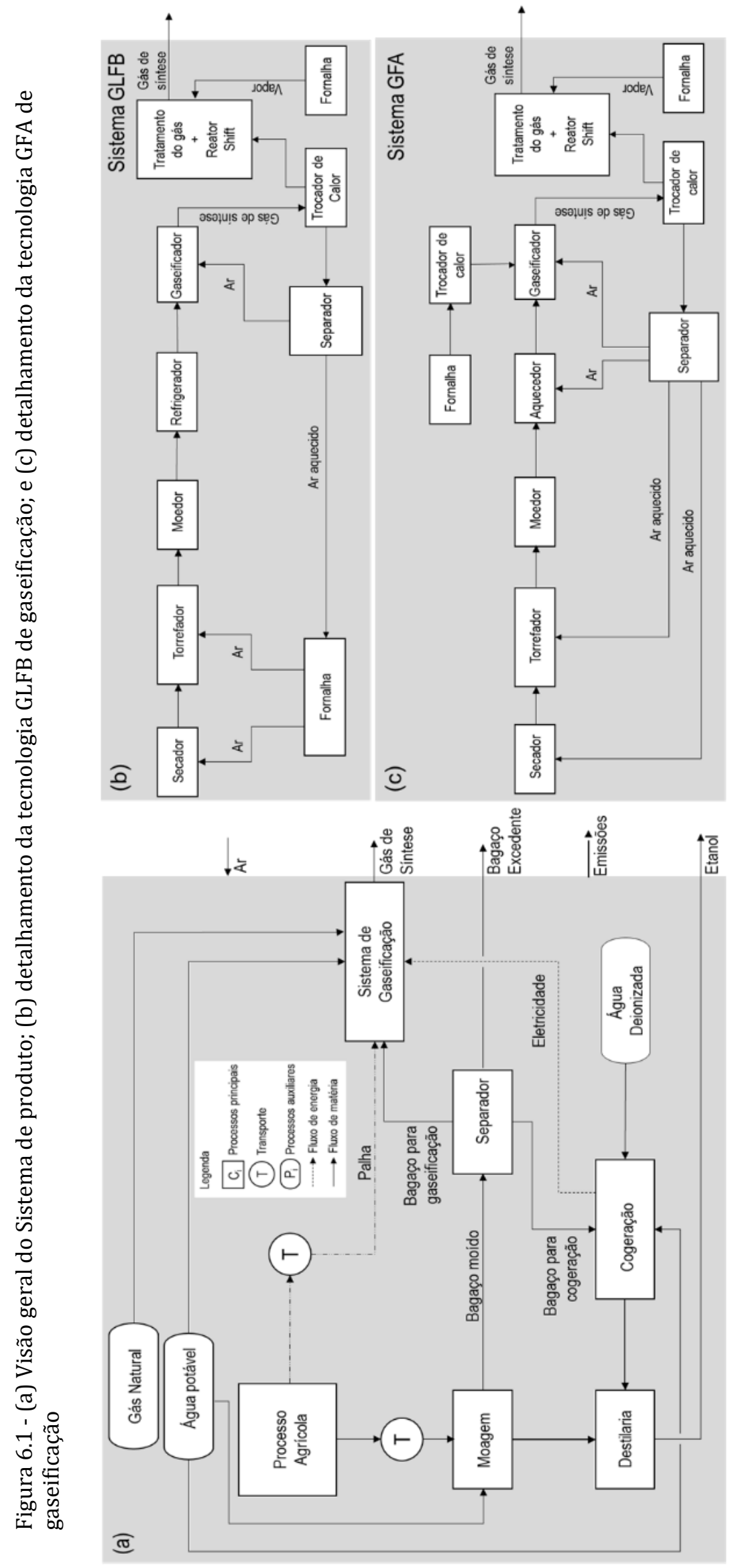


As principais fontes de MC associadas a GFA são emissões de metano e dióxido de carbono fóssil $\left(\mathrm{CH}_{4, \mathrm{f}}\right.$ e $\left.\mathrm{CO}_{2, \mathrm{f}}\right)$, que representam respectivamente $52 \%$ e $35 \%$ dos impactos para a categoria. $\mathrm{O} \mathrm{CH}_{4, \mathrm{f}}$ é emitido ao longo do ciclo de vida do gás natural (GN) usado pelo sistema para geração de energia, nas operações de extração ocorridas no litoral de São Paulo (312 kg/FR) e nos campos onshore instalados em Sabalo, Margarita e San Alberto, na Bolívia (76,9 kg/FR). 0 refino do gás natural é outro foco de geração de $\mathrm{CH}_{4, \mathrm{f}}$ (São Paulo: 181 kg/FR; Bolívia: 243 kg/FR). A extração offshore resulta em mais liberação de $\mathrm{CH}_{4, \mathrm{f}}$ do que os processos onshore devido as condições de operação de cada sistema. Por outro lado, as unidades de refino brasileiras são mais eficientes do que bolivianas.

Tabela 6.2 - Comparação entre desempenhos de GLFB e GFA em termos de MC e DEP

\begin{tabular}{llll}
\hline \multirow{2}{*}{ Impacto } & Unidade & Tecnologia & \\
\cline { 3 - 4 } & & $\mathrm{GLFB}$ & $\mathrm{GFA}$ \\
\hline $\mathrm{MC}$ & $\mathrm{kg} \mathrm{CO}_{2 \text { eq }} / \mathrm{FR}$ & 62903 & 61581 \\
$\mathrm{MC}$ & $\mathrm{kg} \mathrm{CO} \mathrm{eq}_{\mathrm{eq}} / \mathrm{t}_{\mathrm{sy}}$ & 406 & 253 \\
$\mathrm{DEP}$ & $\mathrm{GJ} / \mathrm{FR}$ & 593 & 676 \\
$\mathrm{DEP}$ & $\mathrm{GJ} / \mathrm{t}_{\mathrm{sy}}$ & 3,83 & 2,77 \\
Produção de gás de síntese & $\mathrm{t}_{\text {sy }}$ & 155 & 244 \\
\hline
\end{tabular}

As emissões de $\mathrm{CO}_{2, \mathrm{f}}$ totalizam 21,5 t/FR e são decorrentes da queima de GN para: (i) produção de $\mathrm{CO}_{2 \text { (I) }}$ que compõe a corrente $\left(\mathrm{N}_{2}: \mathrm{CO}_{2}\right)$ e no aquecimento deste fluxo até $2000 \mathrm{~K}$ antes de introduzi-lo no gasifier (58\%); (ii) fornecimento de energia térmica aos estágios de secagem e torrefação do bagaço (16\%); e (iii) geração termelétrica desde o grid $\mathrm{BR}$, a ser consumida na manufatura de aditivo de processo $(5,6 \%)$.

Tais precursores respondem também por contribuições para GLFB, sendo que para aquela tecnologia o $\mathrm{CH}_{4, \mathrm{f}}$ acumula $54 \%$ dos impactos para $\mathrm{MC}$, e o $\mathrm{CO}_{2, \mathrm{f}}$ outros $33 \%$. Mesmo que operando em condições menos restritivas em termos de temperatura, o processo baseado no GLFB é também dependente de GN. Assim, como já havia ocorrido com GFA, as extrações de GN em São Paulo e na Bolívia resultam em perdas expressivas de $\mathrm{CH} 4, \mathrm{f}$ (358 e $136 \mathrm{~kg} / \mathrm{FR}$ ), da mesma forma que os respectivos processos de refino (227 e $304 \mathrm{~kg} / \mathrm{FR})$. 
As emissões de $\mathrm{CO}_{2, \mathrm{f}}$ se concentram mais uma vez, na geração de calor para produção de gás de síntese, por conta da produção de vapor (673 K) a ser injetado no shift (10,4 t/FR), e do aquecimento de ar, usado nos secador e torrefador $(6,75$ e 1,65 t/FR). 0 processamento de gás de síntese consome 64,8 t/FR de bagaço a despeito da rota empregada para a síntese. A produção desse ativo agrícola traz associada a emissão de 6,67 t/FR de $\mathrm{CO}_{2}$ devido a mudanças de uso do solo agrícola $\left(\mathrm{CO}_{2, \mathrm{LT}}\right)$. No caso do estado de São Paulo, os lançamentos de $\mathrm{CO}_{2, \mathrm{LT}}$ derivam da expansão da cana sobre áreas ocupadas originalmente por cultivo de soja e pela pecuária (MOORE et al, 2016).

No que se refere a DEP, as fontes de impacto para o GFA referem-se a consumos na forma de NRF (25\%), RB (64\%) e RW (10\%). Os aportes para NRF originam-se principalmente dos consumos de energia térmica e elétrica impostos pelo sistema. Como não poderia deixar de ser, a participação mais expressiva se dá via extração de gas natural bruto para suprir a demanda de GN do processo (7107 m³/RF). A tecnologia GFA predispõe também o consumo de eletricidade para compressão $\mathrm{N}_{2}$ e $\mathrm{CO}_{2}$ com o intuito de viabilizar operações de transporte e armazenamento. Essa atividade se desdobra em efeitos de NRF devido as participações de óleo cru $(2,4 \%)$, carvão $(4,2 \%)$ e GN $(9,1 \%)$ na matriz elétrica brasileira. Os aportes para RW originam-se também do grid BR, por conta de participação de hidroeletricidade (68\%) no mesmo arranjo (EPE, 2017). A parcela referente a RB se traduz integralmente na energia primária contida na cana-de-açúcar, cujo Poder Calorífico Superior (PCS) varia de 8396 - $8894 \mathrm{~kJ} / \mathrm{kg}$ (u =50\%m/m) (Alena e Sahu, 2013). O perfil de DEP para GLFB não registra contribuições advindas do grid BR, dada a pouca significância dos consumos de eletricidade nesta situação. A participação de NRF totaliza $28 \%$ do impacto total e está associada integralmente à extração de gas natural bruto que atende à demanda de GN do sistema $\left(10732 \mathrm{~m}^{3}\right)$. 0 restante dos impactos ocorrem na forma de RB, mais uma vez em função do VBE da cana-de-açúcar.

\subsubsection{Efeito ambiental da cogaseificação de bagaço e palha no sistema GLFB}

Essa etapa do estudo verificou o desempenho ambiental do sistema GLFB admitindo-se que o gaseificador fosse alimentado com quantidades variáveis de bagaço e palha de cana $(\mathrm{u}=15 \% \mathrm{~m} / \mathrm{m})$. A carga do sistema permaneceu constante $(64,8 \mathrm{t} / \mathrm{h}$ de biomassa, base seca). As simulações projetaram tendências inversas de variação entre as produções de etanol e gás de síntese, e as taxas de admissão de palha ao sistema, condição que poderia ser prevista de antemão em virtude da forma de acoplamento da unidade de gaseificação a destilaria (Figura 6.1a), e das características das biomassas envolvidas no processo (Tabela 6.1). 
A Tabela 6.3 descreve esses resultados, assim como os valores totalizados e específicos $\left(\mathrm{MC}_{\mathrm{s}}\right.$ e $\left.\mathrm{DEP}_{\mathrm{s}}\right)$ de impacto para as diferentes situações analisadas.

Tabela 6.3 - Contribuições de bagaço e palha de cana-de-açúcar para alimentação do gaseificador

\begin{tabular}{lllllll}
\hline $\begin{array}{l}\text { Taxa de Palha } \\
\text { adicionada }\end{array}$ & $\begin{array}{l}\text { Produção de } \\
\text { gás síntese }\end{array}$ & $\begin{array}{l}\text { Produção } \\
\text { de etanol }\end{array}$ & $\mathrm{MC}$ & $\mathrm{MC}_{\mathrm{s}}$ & $\mathrm{DEP}$ & $\mathrm{DEP}_{\mathrm{s}}$ \\
\hline$(\% \mathrm{~m} / \mathrm{m})$ & $\left(\mathrm{t}_{\mathrm{sy}}\right)$ & $(\mathrm{L})$ & $(\mathrm{kg} \mathrm{CO} 2$ eq $)$ & $\left(\mathrm{kg} \mathrm{CO}\right.$ eq $\left./ \mathrm{t}_{\mathrm{sy}}\right)$ & $(\mathrm{G})$ & $\left(\mathrm{kg} \mathrm{CO}_{2 \text { eq }} / \mathrm{t}_{\mathrm{sy}}\right)$ \\
\hline 0 & 155 & 42,8 & 62903 & 406 & 593 & 3,83 \\
20 & 157 & 30,2 & 56162 & 358 & 543 & 3,46 \\
40 & 154 & 20,2 & 49858 & 323 & 501 & 3,24 \\
50 & 153 & 15,9 & 48502 & 317 & 487 & 3,18 \\
60 & 152 & 12,1 & 44177 & 291 & 465 & 3,06 \\
80 & 149 & 5,44 & 40010 & 269 & 437 & 2,94 \\
100 & 147 & 0,015 & 35083 & 239 & 409 & 2,78 \\
\hline
\end{tabular}

0 fato de a palha ser mais seca que o bagaço reduz as necessidades térmicas das unidades de secagem e torrefação da biomassa que alimenta o gaseificador; por conta disso, a demanda de GN no queimador também é menor. A dosagem da mistura bagaço-palha em proporção [80:20] \% $\mathrm{m} / \mathrm{m}$ predispôs um consumo de $25,5 \mathrm{~m}^{3} \mathrm{GN} /$ tsy no queimador, ao passo que quando a biomassa foi administrada em proporções inversas [20:80] \% $\mathrm{m} / \mathrm{m}$ esta necessidade foi de apenas $9,11 \mathrm{~m}^{3} \mathrm{GN} /$ tsy. Com isso, as emissões de $\mathrm{CH}_{4, \mathrm{f}}$ e $\mathrm{CO}_{2, \mathrm{f}}$ que ocorrem ao longo do ciclo de vida sofreram decréscimos significantes, acumulando valores de $\mathrm{MC}_{\mathrm{s}}$ cada vez menores, conforme o teor de palha na alimentação se elevava $\mathrm{MC}_{\mathrm{s}}=\mathrm{f}($ taxa de palha adicionada) (Figura 6.2a).

Perfil semelhante de comportamento foi observado para Deps. $=\mathrm{f}\left(\mathrm{Pa}_{\mathrm{hha}}\right)$ (Figura 6.2b). Nesse caso, porém, destaque-se que as reduções em termos de NRF foram significativas o suficiente para gerar valores decrescentes de DEP a despeito do aumento das contribuições para RB que os incrementos de palha proporcionaram. Os resultados obtidos sugerem que a incorporação de palha ao processo aparece como uma alternativa auspiciosa em termos ambientais. 
Figure 6.2 - Efeitos da taxa de substituição de bagaço por palha em termos de $\mathrm{MC}_{\mathrm{s}}(2 \mathrm{a})$ e $\operatorname{DEP}_{s}(2 b)$
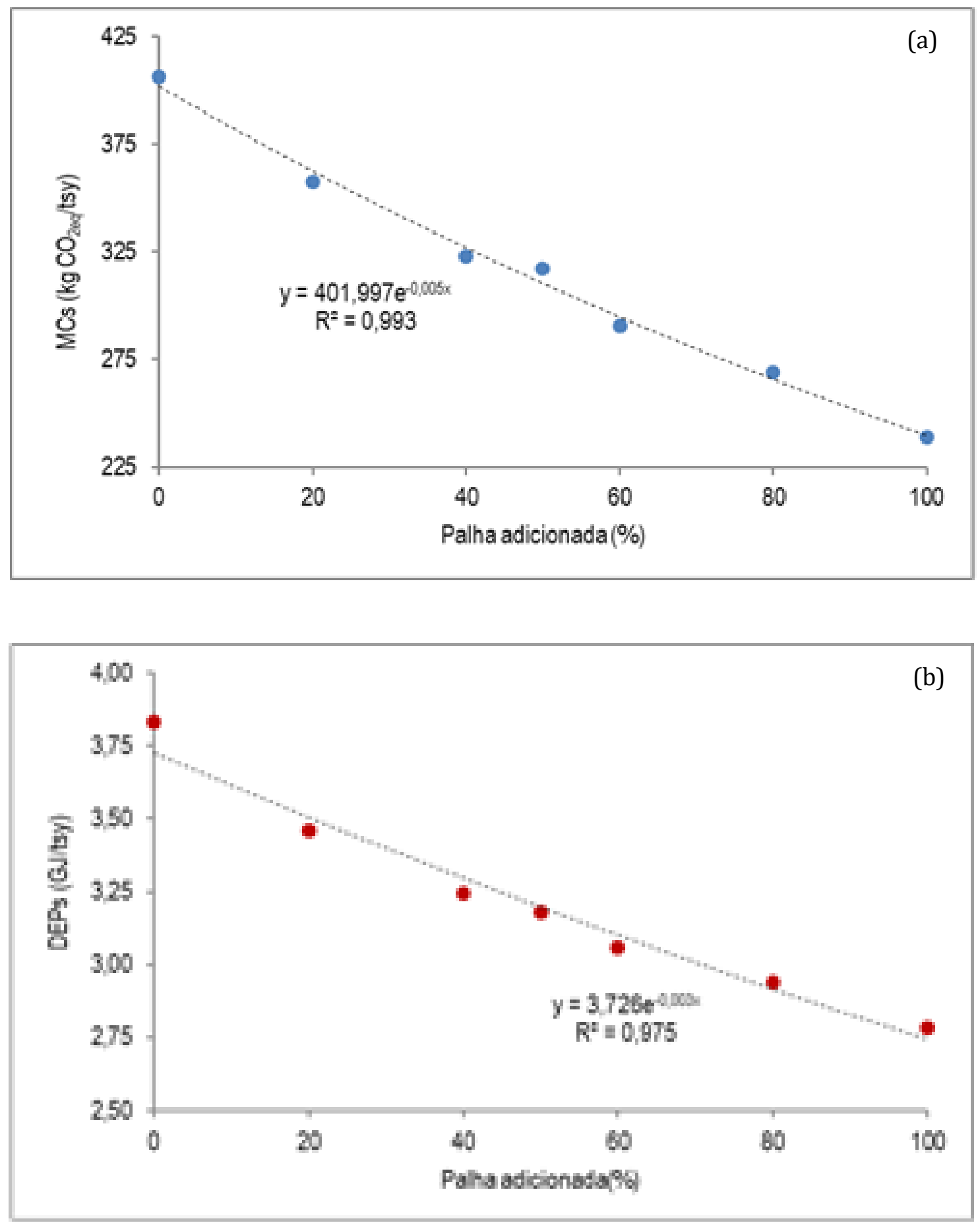

\subsection{Conclusões}

Este estudo tratou de investigar os efeitos ambientais de variantes tecnológicas e processuais, descritas neste caso pelas matérias-primas, na produção de gás de síntese a partir de insumos renováveis. Para tanto fez-se uso da técnica de Avaliação de Ciclo de Vida com enfoque do "berço-ao-portão" para as categorias de impacto de MC e DEP. 
A análise das variantes tecnológicas se materializou por meio da comparação entre as tecnologias GFA e GLFB. Para as condições analisadas o desempenho do sistema GFA supera o de seu homólogo em 38\% com relação a MC, e 27\% em termos de DEP. 0 motivo principal dessa discrepância está nas exigências térmicas de GLFB, que para serem atendidas fazem uso de quantidades expressivas de gás natural, e do que resultam emissões atmosféricas de $\mathrm{CH}_{4, \mathrm{f}}$ e $\mathrm{CO}_{2, \mathrm{f}}$ além do consumo de natural gas.

A verificação do efeito ambiental das matérias-primas se deu pela substituição sucessiva de bagaço por palha na alimentação do sistema GLFB. Por ser mais seca que o bagaço, a palha faz com que o sistema passe a ser menos restritivo em termos de energia térmica do que quando opera apenas com bagaço. A circunstância proporciona reduções de impactos para MC e DEP que podem chegar, respectivamente, a $41 \%$ e $27 \%$ caso a produção de gás de síntese deixe de ocorrer exclusivamente a partir de bagaço para ser realizada apenas com palha. Os resultados obtidos sugerem que a revalorização da palha - desde um rejeito cultivo de cana, para matéria-prima do processamento de gás de síntese - mostra ser uma alternativa promissora em termos de desempenho ambiental e, a partir disso, em condições de ser verificada segundo outros enfoques como o econômico, ou de estratégia de gestão.

\subsection{Referências}

Alena A., Sahu O., 2013, Cogenerations of energy from sugar factory bagasse, American Journal of Energy Engineering, 1 (2): 22-29, DOI: 10.11648/j.ajee.20130102.11.

Al-Zareer M., Dincer I., Rosen, M. A., 2016, Effects of various gasification parameters and operating conditions on syngas and hydrogen production, Chemical Engineering Research and Design, 115: 1-18, DOI: 10.1016/j.cherd.2016.09.009.

Burmistrz P., Chmielniak T., Czepirski L., Gazda-Grzywacz M., 2016, Carbon footprint of the hydrogen production process utilizing subbituminous coal and lignite gasification, Journal of Cleaner Production, 139: 858-865, DOI: 10.1016/j.jclepro.2016.08.112.

Couto N. D., Silva V. B., Monteiro E., Rouboa A., Brito P., 2017. An experimental and numerical study on the Miscanthus gasification by using a pilot scale gasifier.

Renewable Energy 109: 248-261, DOI: 10.1016/j.renene.2017.03.028.

EPE (Empresa de Pesquisa Energética), 2017, Brazilian Energy Balance, Rio de Janeiro, Brazil. 296 p.

Frischknecht R., Jungbluth N., Althaus H.J, Hischier R., Doka G., Bauer Ch., Dones R., Nemecek T., Hellweg S., Humbert S., Margni M., Koellner T., Loerincik Y., 2007. Implementation of Life Cycle Impact Assessment Methods, Ecoinvent report n. 3, Data v2.0; Swiss Centre for Life Cycle Inventories: Dübendorf, Switzerland. 151p. 
Hossain M. Z., Charpentier, P. A., 2015. Hydrogen production by gasification of biomass sepiand opportunity fuels. Compendium of Hydrogen Energy, 137-175. DOI: 10.1016/B978-1-78242-361-4.00006-6.

ISO (International Organization for Standardization). ISO 14040, 2006, Environmental management - life cycle assessment - principles and framework, $1^{\text {st }} \mathrm{Ed}$. International Organization for Standardization: Genève, Switzerland, 20p

ISO (International Organization for Standardization). ISO 14044, 2006, Environmental Management-Life Cycle Assessment-Requirements and Guidelines, $1^{\text {st }} \mathrm{Ed}$. International Organization for Standardization: Genève, Switzerland, 46p.

IPCC (Intergovernmental Panel on Climate Change), 2006, IPCC guidelines for national greenhouse gas inventories. Vol. 2. Energy - fugitive emissions. IGES, Kanagawa.

Figueroa J.E., Ardila Y.C., Peres A.P.G., Maciel Filho R., Maciel M.R.W., 2014, Fluidized bed reactor for gasification of sugarcane bagasse: distribution of syngas, bio-tar and char, Chemical Engineering Transactions, 37: 229-234, DOI: 10.3303/CET1437039.

Kalinci Y., Hepbasli A., Dincer I., 2012, Life cycle assessment of hydrogen production from biomass gasification systems, International Journal of Hydrogen Energy, 37: 14026-14039, DOI: 10.1016/j.ijhydene.2012.06.015.

Moore C.C.S.M., Nogueira A.R., Kulay L., 2016, Environmental and energy assessment of the substitution of chemical fertilizers for industrial wastes of ethanol production in sugarcane cultivation in Brazil, International Journal of Life Cycle Assessment, 22: 6248-643, DOI: 10.1007/s11367-016-1074-0

Moutta R. O., Ferreira-Leitão V. S., Bon E. P. S., 2014, Enzimatic hydrolysis of sugarcane bagasse and straw mixtures pretreated with diluted acid, Biocatalysis and Biotransformation, 32(1): 93-100, DOI: 10.3109/10242422.2013.873795.

Muresan M., Cormos C. C., Agachi P. S., 2014, Comparative life cycle analysis for gasification-based hydrogen production systems, Journal of Renewable and Sustainable Energy, 6: 013131, DOI: 10.1063/1.4864658.

Pérez J. F., Melgar A., Benjumea P. N., 2012, Effect of operating and design parameters on the gasification/combustion process of waste biomass in fixed bed downdraft reactors: An experimental study, Fuel, 96: 487-496, DOI: 10.1016/j.fuel.2012.01.064.

Qin K., Jensen P. A., Lin W., Jensen A. D., 2012, Biomass Gasification Behavior in an Entrained Flow Reactor: Gas Product Distribution and Soot Formation, Energy Fuels, 26 (9): 5992-6002, DOI: 10.1021/ef300960x.

Rueda-Ordóñes Y. J., Tannous K., 2015, Isoconversional kinetic study of the thermal decomposition of sugarcane straw for thermal conversion processes, Bioresource Technology, 196: 136-144, DOI: 10.1016/j.biortech.2015.07.062.

Ruoppolo G., Miccio F., Brachi P., Picarelli A., Chirone R., 2013, Fluidized bed gasification of biomass and biomass/coal pellets in oxygen and steam atmosphere, Chemical Engineering Transactions, 32: 595-600, DOI: 10.3303/CET1332100. 


\section{Otimização de processos tendo em conta parâmetros ambientais}

\section{Resumo}

No último dos capítulos com caráter descritivo que compõem esse documento, o resultado obtido a partir da aplicação da ACV foi associado a congêneres que descrevem os desempenhos técnico e econômico da matriz elétrica brasileira. A iniciativa teve por intuito projetar um cenário otimizado em relação a essas três dimensões, de oferta futura de energia elétrica para o país. Para tanto, modelos de Programação Linear foram usados para compor um grid elétrico que atendesse a demanda nacional em 2030, com o menor custo possível de geração, e restrições de emissão de Gases de Efeito Estufa. A ACV foi também aplicada para aferir o desempenho ambiental do cenário projetado com relação àqueles obtidos nos anos de 2005 e 2015. A análise apontou que para satisfazer tantos requisitos e atributos, as fontes renováveis deveriam responder por $88 \%$ do provimento futuro de eletricidade, com destaque para a hidreletricidade, cuja participação se daria em torno de $66 \%$ de toda a geração. A comparação desse arranjo com o exercitado em 2005 indicou que o grid futuro seria em 12\% menos impactante em termos de Mudanças Climáticas do que seu antecessor. Por outro lado, os impactos registrados em 2005 foram em $50 \%$ e 77\% mais baixos do que aqueles gerados pela proposta, respectivamente para Radiação Ionizante e Ecotoxicidade Terrestre. Esse achado traz associado um alerta: para se tornar efetivo também com relação ao meio ambiente, o planejamento energético do Brasil não deve apenas restringir a amplitude dessa dimensão aos limites que demarcam as Mudanças Climáticas.

\subsection{Introdução}

O consumo mundial de energia elétrica tem variado historicamente, em função do crescimento populacional, adensamento urbano, e em conjunto com os processos de industrialização. Segundo a Empresa de Pesquisa Energética (EPE, 2015) registrou-se entre 2006 e 2015 um aumento de 34\% na demanda doméstica de eletricidade. 0 setor industrial apareceu como o principal consumidor da utilidade no período, ao dispor de $38 \%$ da oferta interna de 2015 , seguido pelo setor residencial, com $25 \%$.

Essa situação deriva em parte de medidas governamentais, como a redução de impostos para aquisição de eletrodomésticos e eletroeletrônicos, e de programas sociais que favorecessem o desenvolvimento do sistema energético brasileiro (CHEN et al., 2017; GUERRA et al., 2015; LIMA e CARVALHO, 2016; SÁEZ-MATINEZ et al., 2016). 
A geração elétrica no Brasil baseia-se majoritariamente em sistemas hidrelétricos devido à disponibilidade de recursos hídricos no país. A maioria dessas fontes já foi, no entanto, explorada e a oferta ainda remanescente está invariavelmente localizada em locais protegidos por restrições sociais e ambientais. Isso ocorre na região Norte, que abrange a Amazônia brasileira, e cujo potencial hidrelétrico supera 100 GW (DANTAS et al., 2017; PEREIRA et al., 2012). Uma limitação desse modelo é a sazonalidade climática, cada vez mais extrema e marcante no Brasil, caracterizada pelo declínio dos níveis de chuvas que impacta negativamente o suprimento de recursos hídricos para a geração de eletricidade. Esse fenômeno torna a oferta elétrica nacional muito sensível, gerando efeitos econômicos e sociais indesejáveis (JACOBI et al., 2015; MOREIRA et al., 2015).

A Tabela 1 descreve o perfil de oferta de eletricidade no Brasil em dois momentos distintos: em 2005, período em que a hidreletricidade alcançou uma participação de $91 \%$ na geração total devido ao alto nível de chuvas; e nos últimos quatro anos, quando suas contribuições não superaram o limite de 68\% daquele montante (2016). Além disso, a fonte hidrelétrica diminuiu 9,4\% entre 2013 e 2014 como resultado de uma crise hídrica em vários municípios brasileiros.

Tabela 7.1 -Oferta Elétrica Brasileira por fonte em 2005 e no período 2013-2016 (\%)

\begin{tabular}{llllll}
\hline Fonte & 2005 & 2013 & 2014 & 2015 & 2016 \\
\hline Hidreletricidade & 91,2 & 70,6 & 65,2 & 64,0 & 68,1 \\
Biomassa (= bagaço) & 0,00 & 7,60 & 7,31 & 8,00 & 8,20 \\
Eólica & 0,16 & 1,10 & 2,01 & 3,44 & 5,41 \\
Gás Natural & 3,14 & 11,3 & 13,0 & 12,9 & 9,12 \\
Derivados do petróleo & 1,88 & 4,40 & 6,89 & 4,75 & 3,68 \\
Nuclear & 2,24 & 2,40 & 2,49 & 2,40 & 2,60 \\
Solar & $\mathrm{NR} 1$ & $\mathrm{NR}$ & $\mathrm{NR}$ & 0,01 & $\mathrm{NR}$ \\
Carvão e derivados & 1,38 & 2,60 & 3,10 & 4,50 & 2,89 \\
\hline Total (TWh) & 442 & 611 & 624 & 616 & 620 \\
\hline
\end{tabular}

Legenda: NR: não representativa, aplicada para contribuições inferiores a 0.01\% Fonte: Empresa de Pesquisa Energética - EPE (2014 - 2017)

Para aumentar as capacidade e segurança energética no país, introduziram-se fontes alternativas, derivadas principalmente de recursos fósseis como óleo combustível, gás natural e carvão, que em 2015 ultrapassavam 22\% da oferta (EPE, 2015; KILEBER e PARENTE, 2015). 
O baixo preço do carvão no mercado internacional e a exploração de reservas de petróleo na camada pré-sal, favoreceram a disseminação de fontes fósseis em detrimento de outras no setor elétrico (SANTOS et al., 2017). Por outro lado, a expansão da oferta de energia a partir desses recursos gerou preocupações ambientais, originando discussões sobre a participação do setor energético nas emissões de Gases de Efeito Estufa (GEE) registradas no país. Muitos autores apontam que a geração de eletricidade responde por cerca de $40 \%$ dos liberações $\mathrm{CO}_{2}, \mathrm{CH}_{4}$ e $\mathrm{N}_{2} \mathrm{O}$ que resultam em Aquecimento Global e nas Mudanças Climáticas (ABBASPOUR et al., 2011; ALAM et al., 2016; CHEN et al., 2017; ELUM e MOMODU, 2017; GUELLER e MENESES, 2016; HARDISTY et al., 2012; PATEL et al., 2016; SHAFIEPOURMOTLAGH et al., 2016; TURCONI et al., 2013; von SPERLING, 2012). Somem-se a essas, outras preocupações também prementes como o esgotamento de recursos naturais, fatores econômicos associados às mudanças nos preços do petróleo e fatores sociais (GUERRA et al., 2015; PATEL et al., 2016).

Acordos políticos globais como o Protocolo de Kyoto, estabelecido pelas Nações Unidas (ONU) em 1997, ou o Acordo de Paris sobre Mudanças Climáticas, de 2015, que visavam reduzir emissões de GEE a fim de conter o Aquecimento Global, incentivavam a implementação de sistemas de energia renováveis e sustentáveis. Essa abordagem busca descarbonizar as atividades humanas para preservar os recursos naturais que são vitais para o crescimento e desenvolvimento econômico e social, caso específico de recursos fósseis como óleo cru, gás natural e carvão não refinados (ALMER e WINKLER, 2017; FOLEY et al., 2017; LAU et al., 2012; MOSSALANEJAD, 2012).

O Brasil se destaca nesse contexto ao apoiar investimentos em sistemas baseados em fontes renováveis (eólica, solar e biomassa) para suplementar a geração hidrelétrica. 0 estímulo ocorre na forma de programas como o PROINFA (Programa de Incentivo às Fontes Alternativas de Energia, e de planos como o PDE (Plano Decenal de Expansão de Energia (PDE) (PAO e FU, 2013; SANTOS et al., 2017). As análises que projetam a Matriz Energética Brasileira para 2030, levam em conta metas de mitigação de emissões de GEE estabelecidas usando como linha de base o desempenho de 2005. A diretriz geral usada nessa estratégia consiste em priorizar os usos de biomassa, energia eólica, e até resíduos urbanos, como alternativas para postergar, quando não for possível evitar, a exaustão do potencial hidrelétrico nacional (GUERRA, 2015). No entanto, alguns desses sistemas são considerados como economicamente não competitivos, se comparados às alternativas convencionais de geração fóssil de energia. Além disso, o aumento das ofertas de óleo e gás, devido as descobertas recentes de jazidas no litoral do país, naturalmente favorecem a carbonização da matriz brasileira, gerando novos conflito entre políticas energéticas e os acordos ambientais (ROCHA et al., 2015; VAHL e CASAROTTO, 2015). 
Situações de impasse como essas, podem ser equacionadas a partir da aplicação de técnicas como as Análises Multicritério. No caso em questão, essa abordagem - de uso frequente em questões como o crescimento econômico, segurança energética e mitigação de alterações climáticas - poderia oferecer um melhor entendimento da sustentabilidade (CHEN et al., 2017; GRILLI et al., 2016, 2017).

Santoyo-Castelazo e Azapagic (2014) e Santos et al. (2015) são enfáticos quando afirmam que o desenvolvimento de sistemas energéticos deve, além da dimensão técnica, considerar também as vertentes ambiental, econômica e social da sustentabilidade, a fim de apoiar de maneira adequada e efetiva, processos de tomada de decisão que ocorrem nesse setor. Seguindo na mesma direção, Blok et al. (2015) apontam como necessário o uso de novas e aprimoradas técnicas de gerenciamento da produção, para criar sistemas de geração energética mais limpos e sustentáveis. Fatores como custos, capacidade e localização devem ser considerados ao projetar e planejar esses arranjos. Moreira et al. (2015) compartilham do discurso, ao destacarem que o planejamento energético requer a realização de estudos de sustentabilidade como parte de sua gestão. Costa et al. (2017) afirmam que um dos principais desafios para formuladores de políticas energéticas e investidores no setor consiste em definir sistemas equilibrados em termos de segurança energética, custos e preocupações ambientais.

Para superar situações como essa, em que variáveis técnicas, econômicas, sociais e ambientais entram em conflito, a aplicação de técnicas de otimização multiobjectivo se mostra uma estratégia útil, confiável e oportuna. Vidal-Amaro et al. (2015) apresentaram um estudo que se propôs definir o arranjo ideal entre fontes renováveis de energia (FER) e combustíveis fósseis para a matriz elétrica mexicana. 0 objetivo da combinação era que o grid local chegasse a ter 35\% de participação de FER em 2024. Para tanto, elementos como valores horários da produção de FER, e demanda de eletricidade foram analisados.

Nos últimos anos, a Avaliação do Ciclo de Vida (ACV) tem chamado a atenção por conta do potencial para avaliar a dimensão ambiental em estudos multicritério voltados para sistemas de energia. Isso ocorre devido à capacidade da técnica de realizar análises sistêmicas e quantitativas. Por meio de ACV, Turconi et al. (2013) compararam diferentes fontes de geração de eletricidade, e perceberam que para tecnologias que fazem uso de ativos fósseis, a maioria das emissões ocorre na operação da usina. Por outro lado, para sistemas operados com biomassa e urânio, o fornecimento do combustível será o gerador das principais emissões, e, portanto, também de impactos, desse ciclo de vida. 
Stamford e Azapagic (2014) avaliaram o ciclo de vida de cenários futuros (2070) de geração de eletricidade para o Reino Unido. Ao aplicarem ACV nessa investigação os autores notaram que os melhores desempenhos foram obtidos em cenários composto de fontes nucleares e renováveis, de muito baixo carbono, apesar do aumento de impactos como Ecotoxicidade Terrestre que essas fontes também acarretavam.

Aplicando uma perspectiva de ACV, Dinato e Kulay (2015) avaliaram os impactos ambientais associados a oferta de eletricidade no Brasil entre 2006 - 2013. Os resultados mostraram ter havido crescimento de efeitos adversos sobre o ambiente no período, que foram imputados à crescente participação de combustíveis fósseis no grid brasileiro.

Gueller e Meneses (2016) determinaram via ACV quais os impactos ambientais associados à construção, operação e desativação de uma usina hidrelétrica. De maneira distinta do que se poderia supor, os autores constataram ser a fase de construção aquela de maior contribuição para as categorias analisadas, de Mudanças Climáticas e Depleção de Recursos Fósseis, em muito devido aos usos de aço e concreto.

Paralelamente a isso, a ACV também vem sendo usada para solução de problemas de otimização, aumentando a robustez de modelos e, por conseguinte, dos resultados que forem obtidos (ARGASKI et al., 2016; HACATOGLU et al., 2015; MAXIM, 2014; SANTOS et al., 2017; STAMFORD e AZAPAGIC, 2014). No entanto, exceto pelo estudo realizado por Portugal-Pereira et al. (2016), que discutiu implicações do uso da técnica para avaliação de GEE (ACV-GEE) na otimização do grid energético brasileira até 2050, outras análises de mesma natureza, ou teor, não foram encontradas na literatura técnico-acadêmica.

A fim de preencher, mesmo que em parte, essa lacuna este estudo busca oferecer uma proposta de matriz elétrica brasileira para 2030 levando em consideração critérios técnicos, econômicos e ambientais. Modelos de otimização baseados em Programação Linear (PL) foram utilizados para obter o custo mínimo do sistema brasileiro de geração de eletricidade, considerando restrições ambientais definidas através de ACV, bem como as necessidades de geração e suprimento da demanda no período em referência. A ACV foi usada ainda para determinar o desempenho ambiental do cenário projetado, sendo os resultados obtidos através dela, comparados com os correspondentes para os anos 2005 e 2015. Espera-se que os resultados fornecidos por esta investigação possam subsidiar ações futuras de gestão relacionadas ao planejamento energético brasileiro. 


\subsection{Metodologia}

A metodologia de trabalho estabelecida para atender aos objetivos previstos para esse estudo compreendeu as seguintes etapas: (i) obter o melhor arranjo para a Matriz Elétrica Brasileira em 2030; (ii) estimar os impactos ambientais para esse cenário tendo em conta a perspectiva sistêmica da ACV; (iii) comparar tais resultados aos congêneres obtidos para os anos de 2005 e 2015; e (iv) fazer recomendações quanto ao processo de estruturação do grid. Segue-se a esse preâmbulo uma descrição melhor detalhada dessas ações, acompanhada de dados e premissas que foram usados durante o desenvolvimento do estudo.

\subsubsection{Projeção da Matriz Elétrica Brasileira}

Assim como fora estabelecido em 2015 durante a Conferência das Partes COP21 da Convenção-Quadro das Nações Unidas sobre Mudança do Clima (UNFCCC), 195 países se comprometeram a reduzir suas emissões de GEE e, com isso, limitar o Aquecimento Global e mitigar Mudanças Climáticas. Para atender esse objetivo, os governos definiram publicamente seus compromissos pós-2020, os quais passaram então a ser chamados de Contribuição Nacionalmente Determinada (iNDC) (MRE, 2015). 0 iNDC proposto pelo governo brasileiro compreendia a redução das emissões de GEE em 37\% até 2025, e 43\% até 2030 com relação às alcançadas em 2005, ano em que 2,35 Gt $\mathrm{CO}_{2 \text { eq }}$ foram emitidos pelo pais devido, sobretudo, à ações de mudança no uso da terra, atividades agrícolas, e a produção de energia (SEEG, 2014). Uma das medidas estabelecidas para alcançar esses patamares consiste em elevar a taxa de bioenergia no grid nacional para cerca de $18 \%$ até o prazo limite para validade do acordo.

De acordo com estimativas oficiais realizadas pelo Ministério de Minas e Energia em 2006, a geração de eletricidade teria a maior taxa de crescimento de emissões de GEE no período (25 anos) - cerca de 5,0\%aa -, com um aumento da participação do setor de 9,0\%, em 2005, para pouco menos de 14\% em 2030 (MEE, 2007).

Partindo-se dessas condições, a matriz elétrica de 2030 foi definida como aquela em que: (i) o custo total de geração - considerando diferentes fontes energéticas -, fosse mínimo; (ii) o impacto anual decorrente das emissão de GEE não excedesse $185 \mathrm{Mt} \mathrm{CO}_{2 \text { eq, }}$ valor correspondente ao desempenho de 2005; e, que (iii) a demanda elétrica projetada para o período - de $1030 \mathrm{TWh}$ - pudesse ser atendida. 
Esse problema de otimização pode ser resolvido através da Programação Linear (PL). Para tanto, é possível descrever a situação em análise a partir de um sistema que compreende a Equação (1), e as Inequações (2) - (5), que representam restrições a serem atendidas pelo modelo

$$
\operatorname{Min}\left(C_{T}\right)=\sum\left(X_{i} \times C_{i}\right)
$$

Sujeito a:

$$
\begin{aligned}
& \sum X_{i}-1,03 E 09=0 \\
& \sum\left(X_{i} \times I_{i}\right)-1.85 E 11 \leq 0 \\
& X_{i}-G C_{i, \text { máx }} \leq 0 \\
& G C_{i, \text { mín }}-X_{i} \leq 0
\end{aligned}
$$

Sendo:

$C_{T}$ : Custo total de geração de eletricidade (USD/yr)

$X_{i}$ : Geração de eletricidade a partir da fonte (i) (MWh/yr)

$C_{i}$ : Custo da geração de eletricidade a partir da fonte (i) (USD/MWh)

$I_{i}$ : Impacto da geração de eletricidade a partir da fonte (i) $\left(\mathrm{kg} \mathrm{CO}_{2}\right.$ eq $\left./ \mathrm{MWh}\right)$

$G C_{i, m a ́ x}$ : Máxima capacidade de geração de eletricidade a partir da fonte (i) (MWh/yr)

$G C_{i, m i n}$ : Mínima capacidade de geração de eletricidade a partir da fonte (i) (MWh/yr)

Os custos individuais de geração de eletricidade por fonte $\left(C_{i}\right)$ foram estimados a partir de dados e informações fornecidos pela Agência Internacional de Energia (IEA) (IEA, 2015). Já os impactos por fonte $\left(I_{i}\right)$ - expressos em $\mathrm{kg} \mathrm{CO}_{2}$ eq $/ \mathrm{MWh}$ - são originários de Sims et al. (2007). Restrições adicionais, relacionadas à capacidade de geração $\left(G C_{i}\right)$ e os limites técnicos por fonte, também foram considerados durante a otimização.

Os valores adotados para esses parâmetros são apresentados na Tabela 7.2. A solução do sistema de equações ocorreu com auxílio do software Optimization Modeling Software for Linear, Nonlinear, and Integer Programming - LINGO v. 17.0.0.52 (LINDO 2017) que é próprio para realização de estimativas dessa natureza. 
Tabela 7.2 - Valores considerados para $\mathrm{C}_{\mathrm{i}}$, $\mathrm{I}_{\mathrm{i}}$, e restrições de capacidade de geração

\begin{tabular}{lcccc}
\hline \multirow{2}{*}{ Fonte } & \multicolumn{1}{c}{$C_{i}$} & $I_{i}$ & \multicolumn{2}{c}{$G C_{i}$} \\
\cline { 2 - 5 } & $(\mathrm{USD} / \mathrm{MWh})$ & $\begin{array}{c}\left(\mathrm{kg} \mathrm{CO}{ }_{2}\right. \\
\mathrm{eq} / \mathrm{MWh})\end{array}$ & Min (TWh) & Max (TWh) \\
\hline Hidreletricidade & 64,1 & 153 & 678 & 678 \\
$\begin{array}{l}\text { Biomassa }= \\
\text { bagaço) }\end{array}$ & 166 & 25,0 & 46,5 & 64,3 \\
Eólica & 112 & 11,2 & 11,7 & 195 \\
Gás Natural & 107 & 1040 & 75,0 & 116 \\
$\begin{array}{l}\text { Derivados de } \\
\text { petróleo }\end{array}$ & 300 & 880 & 0,00 & 57,6 \\
Nuclear & 98,1 & 7,66 & 14,0 & 49,4 \\
Solar & 168 & 75,2 & 0,00 & $5,81 \mathrm{E}-02$ \\
Carvão e derivados & 99,1 & 1090 & 0,00 & 31,2 \\
\hline
\end{tabular}

Fonte: IEA (2015); ANEEL (2017)

\subsubsection{Modelagem de ACV}

Este estudo seguiu as diretrizes e requisitos descritas na norma ISO 14044 (ISO, 2006b). ACV foi aplicada segundo enfoque atribucional, e escopo "do berço-ao-portão". Isso significa que foram considerados apenas estágios da cadeia de produção das fontes de geração de energia que integram a Matriz Elétrica Brasileira. As emissões dos GEE foram determinadas para a produção de 1,0 MWh de eletricidade. A Figura 7.1 resume os elementos que compõem o modelo avaliado no estudo.

A modelagem da geração elétrica foi estruturada a partir de dados secundários obtidos junto ao Banco de Dados Ecoinvent (DONES et al. 2007) que foram adaptados às condições praticadas no Brasil de operação de cada fonte ao longo dos períodos avaliados nesta investigação. Para a geração hidrelétrica, os dados coletados incluem os materiais utilizados na construção das usinas (casos de cimento, areia, cascalho, aço e explosivos) além do consumo de energia, emissões de GEE e material particulado, transporte, uso da terra, e uso de óleo lubrificante durante a operação da planta.

Para os sistemas termoelétricos movidos a gás natural (FAIST EMMENEGGER et al. 2007) e derivados de petróleo (JUNGBLUTH 2007) os modelos abrangem a exploração em campo de gás natural bruto e óleo cru, suas extrações, operações para purificação e refino, bem com os transportes, tanto dos recursos fósseis, como dos produtos acabados, nesse caso, até as usinas de energia. 
Figura 7.1 - Sistema de Produto para a produção de 1,0 MWh de eletricidade

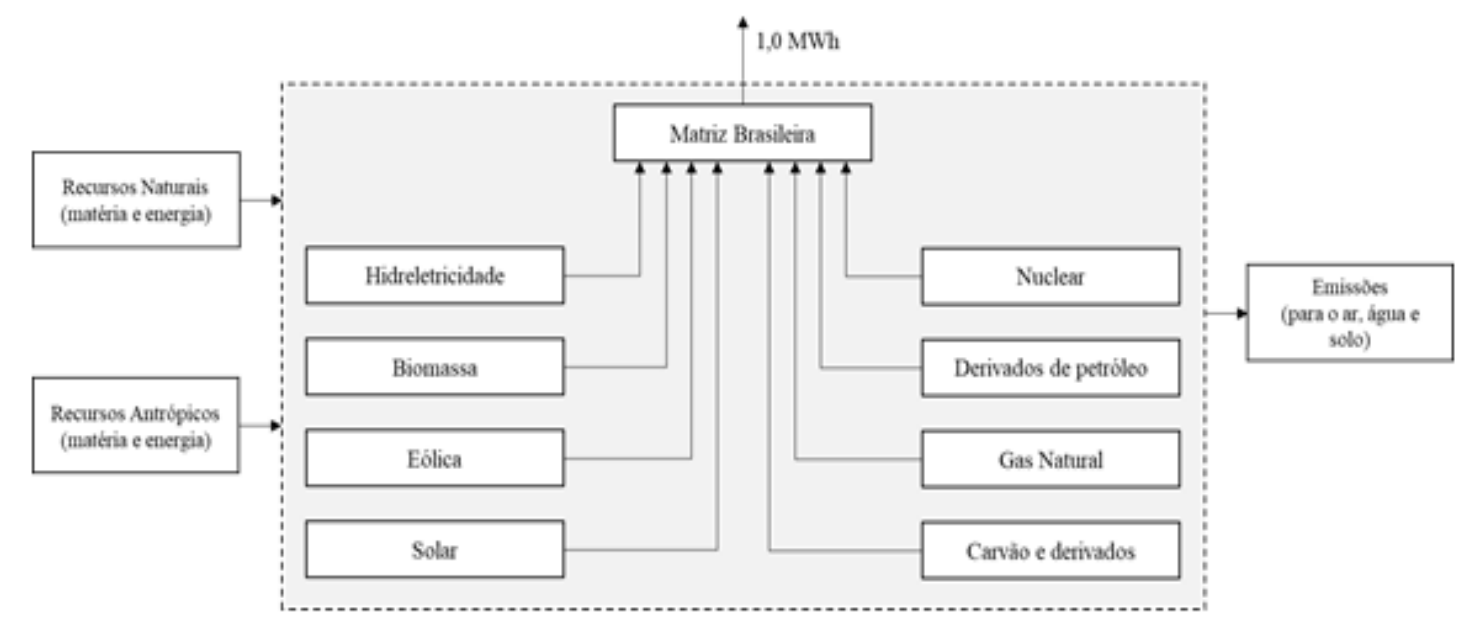

A biomassa usada para cogeração de eletricidade foi representada nessa situação por bagaço de cana, por se tratar do combustível mais usado no país para esse fim. Com isso, o sistema que descreve essa fonte de geração de energia tem início pelas operações agrícolas de semeadura, cultivo e colheita cana-de-açúcar, ao que se segue sua moagem para extração do bagaço. Fazem parte também do sistema os elementos componentes do ciclo de cogeração: caldeira, turbina, gerador elétrico, condensador e bomba. Materiais auxiliares, aspectos de infraestrutura e transportes completam o arranjo.

Ao ser realizada dessa forma, a geração de eletricidade se transforma em um processo multifuncional uma vez que etanol hidratado (ou mesmo, anidro) é produzido concomitantemente com a energia. No estudo, a situação foi tratada pelo procedimento de alocação a partir de critério energético (ISO 2006b). Por fim, o arranjo que descreve a geração termoelétrica a partir da queima de carvão e derivados considerou, além do ciclo termodinâmico, também os processos de mineração, beneficiamento e transporte dos combustíveis. Os dados foram obtidos junto a Röder et al., (2004) e, assim como nos demais casos, sofreram tratamentos que os adaptaram às condições brasileiras.

A geração de energia nuclear baseou-se na tecnologia que opera com reatores de água pressurizada, que bastante difundida no mundo e típica das usinas termonucleares brasileiras. 0 sistema se completa com as inclusões das etapas de mineração, moagem, conversão e enriquecimento (por difusão) de urânio. Aspectos de infraestrutura para seu armazenamento intermediário, condicionamento de combustível irradiado, assim como os repositórios geológicos finais também foram considerados. Os dados que quantificam as interações desses processos com o ambiente foram levantados junto a Dones (2007a). 
Os sistemas de geração eólica se restringiram a construção e manutenção das peças fixas e móveis das turbinas. Assim, o conjunto de dados responde por diferentes materiais de construção - como concreto e aço para peças fixas, e plástico, fibra de vidro, alumínio e cobre para peças móveis -, seu processamento e transporte. 0 uso da terra para instalação da usina, além de eventuais requerimentos energéticos também foram incluídos no modelo, cujos dados originais procedem de Burger e Bauer (2007). Por fim, as usinas fotovoltaicas para geração de energia solar incluem em sua modelagem as operações de redução do quartzo, purificação de silício, produção de painéis e laminados, fabricação do conversor e da estrutura de suporte. 0 transporte desses materiais, assim como as ações de tratamento de resíduos de fim de vida do sistema estão incluídas. Os consumos e emissões associados ao processo foram obtidos de Jungbluth e Tuchschmid (2007) e usado praticamente sem ajustes no modelo global para o estudo. Essa decisão deveu-se ao fato destas tecnologias serem quase que integralmente importadas pelo Brasil.

\subsubsection{Inventário do Ciclo de Vida (ICV)}

Os ICVs consolidados que representam a Matriz Elétrica Brasileira derivam dos seguintes conjuntos de dados: (i) Hidreletricidade: 'Electricity, hydropower, at reservoir power plant/BR $U$ '; termoeletricidade via (ii) Biomassa: 'Electricity, bagasse, sugarcane, at fermentation plant/BR $U$ '; (iii) Gás Natural: 'Electricity, natural gas, at power plant/BR $U$ '; (iv) Diesel e derivados de petróleo: 'Electricity, oil, at power plant/BR $U$ '; (v) Carvão e derivados: 'Electricity, hard coal, at power plant/BR U'; (vi) Nuclear: 'Electricity, nuclear, at power plant/CH U'; (vii) Eólica: 'Electricity, at wind power plant/RER U'; (vi) e, Solar: 'Electricity, production mix photovoltaic, at plant/CH U. As proporções de cada fonte de geração para os grids de 2005 e 2015 foram coletadas do Balanço Energético Nacional para esses períodos (EPE, 2005, 2015).

\subsubsection{Avaliação de Impacto de Ciclo de Vida (AICV)}

A AICV foi realizada em dois níveis. No primeiro nível, os impactos derivados do consumo de recursos foram calculados a partir do método Demanda Acumulada de Energia (CED) v. 1.09 (FRISCHKNECHT et al. 2007). Essa abordagem permite estimar a Demanda de Energia Primaria (DEP) para diferentes fontes não-renováveis (fóssil: NRF; nuclear: NRN; e biomassa: NRB) e renováveis (biomassa: RB; eólica: RWD; e água: RWA). 
O segundo nível de análise quantificou impactos provenientes de emissões que ocorreram ao longo da cadeia produtiva. Para essa avaliação aplicou-se o método ReCiPe - Midpoint (H) v. 1.12 (GOEDKOOP et al., 2013) a fim de determinar contribuição para categorias de: Mudanças Climáticas (MC), Formação de Material Particulado (FMP), Radiação Ionizante (RadI), Acidificação Terrestre (AT), Ecotoxicidade Terrestre (ET), Toxicidade Humana (TH) e Depleção de Água (DA).

\subsection{Resultados e Discussão}

A Tabela 7.3 apresenta a proposta de Matriz Elétrica Brasileira para 2030, obtida via processo de otimização. Esses resultados indicam que para atender aos requisitos estabelecidos, a geração de eletricidade a partir de fontes renováveis deve representar $88 \%$ do total da produção nacional naquele período. A taxa de hidreletricidade supera em muito as registradas em 2005 e 2015, de 272 e 281 TWh respectivamente. A geração de energia eólica é a segunda maior na oferta de 2030, mostrando uma expansão quase plena (183 TWh) em comparação à participação de 2005, e de 163 TWh quanto a aquela registrada em 2015. Ainda no tocante às fontes renováveis, a participação da biomassa no cenário projetado diminuiu em 4,30 TWh em relação ao praticado em 2015.

Tabela 7.3 - Proposta de composição da Matriz Elétrica Brasileira para 2030

\begin{tabular}{lcc}
\hline \multirow{2}{*}{ Fonte } & \multicolumn{2}{c}{ Contribuição individual por fonte } \\
\cline { 2 - 3 } & $\begin{array}{c}\text { Valores absolutos } \\
\text { (TWh/ano) }\end{array}$ & $\begin{array}{c}\text { Valores Relativos } \\
(\%)\end{array}$ \\
\hline Hidreletricidade & 675 & 65,5 \\
Biomassa (= bagaço) & 46,5 & 4,51 \\
Eólica & 184 & 17,9 \\
Gás Natural & 75,0 & 7,28 \\
Derivados de petróleo & 0,00 & 0,00 \\
Nuclear & 49,4 & 4,80 \\
Solar & 0,00 & 0,00 \\
Carvão e derivados & $1,12 \mathrm{E}-01$ & 0,01 \\
\hline Total & 1030 & 100 \\
\hline
\end{tabular}


Em termos de fontes fósseis, a participação esperada para 2030 é de 7,30\%, uma geração em $166 \%$ maior que em 2005 , devido principalmente ao aumento do uso de gás natural, mas menor em cerca de $45 \%$ que a de 2015 , por conta de reduções nos consumos de carvão e derivados de óleo. Os sistemas a gás natural se expandiram em 61 TWh se comparados ao de 2005, mas ficariam atrás do resultado praticado em 2015, em cerca de 4,5 TWh. Outro resultado expressivo remete a energia nuclear que deveria aumentar respectivamente em 40 TWh e 35 TWh com relação aos desempenhos alcançados pelas referências para atender aos compromissos definidos para 2030.

Considerando os resultados indicados na Tabela 7.2 o custo mínimo para a matriz elétrica de 2030 é de US\$ 84,5 bi/ano, valor em 47\% maior do que o praticado em 2015 e superior em $169 \%$ ao de 2005 . Esses resultados foram determinados assumindo-se os mesmos custos unitários por fonte de fornecimento de eletricidade em todos os casos. Esse comportamento se deve em grande parte a que as fontes renováveis, (p.ex. eólica), de custos superiores às fontes não renováveis tradicionais (carvão e gás natural), terão maior participação na redução das emissões de GEE, ao mesmo tempo em que asseguram o fornecimento de eletricidade. Em termos relativos, essa tendência se inverte, uma vez que a quantidade de eletricidade produzida aumenta no período 2005-2030; nesse caso, os custos unitários das matrizes elétricas para os anos de 2005, 2015 e 2030 perfazem os totais de 113 USD/MWh, 93 USD/MWh e 82 USD/MWh.

Tabela 7.4 - Desempenho ambiental da oferta elétrica brasileira para produção de 1,0 MWh

\begin{tabular}{lllll}
\hline Categoria de Impacto & $\begin{array}{l}\text { Unidades } \\
\text { (/MWh) }\end{array}$ & 2005 & 2015 & 2030 \\
\hline Demanda de Energia Primária (DEP) & $\mathrm{GJ}$ & 4,59 & 6,04 & 4,94 \\
Mudanças Climática (MC) & $\mathrm{kg} \mathrm{CO}_{2}$ eq & 204 & 326 & 180 \\
Acidificação Terrestre (AT) & $\mathrm{kg} \mathrm{SO}_{2}$ eq & $2,40 \mathrm{E}-01$ & $9,00 \mathrm{E}-01$ & $4,40 \mathrm{E}-01$ \\
Formação de Material Particulado & $\mathrm{kg} \mathrm{PM}_{10} \mathrm{eq}$ & $6,89 \mathrm{E}-02$ & $2,17 \mathrm{E}-01$ & $1,11 \mathrm{E}-01$ \\
(FMP) & $\mathrm{kg} \mathrm{1.4-DB} \mathrm{eq}$ & 8,23 & 28,9 & 14,6 \\
Toxicidade Humana (TH) & $\mathrm{kg} \mathrm{1.4-DB} \mathrm{eq}$ & $4,78 \mathrm{E}-03$ & $3,84 \mathrm{E}-01$ & $2,13 \mathrm{E}-01$ \\
Ecotoxicidade Terrestre (ET) & $\mathrm{kBq} \mathrm{U235} \mathrm{eq}$ & 25,4 & 28,7 & 52,9 \\
Radiação Ionizante (RadI) & $\mathrm{m}^{3}$ & 2,79 & 7,30 & $7,80 \mathrm{E}-01$ \\
\hline Depleção de água (DA) & & & & \\
\hline
\end{tabular}

Os resultados do desempenho ambiental da Matriz Elétrica Brasileira associados à geração de 1,0 MWh de eletricidade para os anos 2005, 2015 e 2030 estão indicados na Tabela 7.4. Os impactos de DEP, foram influenciados pelo consumo de água necessário para os sistemas hidrelétricos, e pelo esgotamento de fósseis. 
Esses efeitos projetam um impacto intermediário em relação aos registrados pelos grids do passado, que é 7,6\% mais elevados que o obtido em 2005, mas $18 \%$ inferior ao obtido em 2015. A água usada para movimentação das turbinas na geração de hidreletricidade representa a maior parcela de contribuição de DEP em 2005, de 75\%, sendo reduzida para 50\% em 2030, e alcançando 'apenas' 40\% do total de impacto como DEP de 2015. A parcela consiste da segunda contribuição mais importante para o grid, sendo superada apenas pelo esgotamento de fósseis (46\%). A matriz de 2015 apresenta maior taxa de recursos fósseis dentre as opções avaliadas, condição que explica a supremacia dos nãorenováveis em termos de aportes para DEP. A demanda de recursos nucleares tem uma influência maior no resultado total do DEP de 2030 do que para os outros anos, devido a estratégia adotada para reduzir emissões de GEE, que se vale dessa fonte para substituir os combustíveis fósseis.

A análise mostrou também que ao adotar aquela composição de grid os impactos para MC de 2030 seriam inferiores em 12\% aos obtidos em 2005, e em 45\% com relação a 2015. Em todos esses casos, as principais contribuições para MC estão relacionadas aos lançamentos atmosféricos de $\mathrm{CO}_{2}$ advindo da transformação do solo $\left(\mathrm{CO}_{2, \mathrm{LT}}\right)$ e de origem fóssil $\left(\mathrm{CO}_{2, \mathrm{f}}\right)$, e ao metano biogênico $\left(\mathrm{CH}_{4, \mathrm{~b}}\right)$. $\mathrm{O} \mathrm{CO}_{2, \mathrm{LT}}$ corresponde as emissões derivadas da conversão da floresta primária em áreas agricultáveis ou de pastagem (SCHMIDINGER e STEHFEST 2012; BECK 2013). Em relação à Matriz Elétrica Brasileira, predominam as emissões de $\mathrm{CO}_{2, \mathrm{LT}}$ em hidrelétricas, por conta da transformação de florestas, ou mesmo, de empreendimentos rurais nos lagos das usinas. Para o grid proposta para 2030, esperase que essas emissões sejam em 28\% menores do que suas correspondentes para 2005.

Os lançamentos de $\mathrm{CH}_{4, \mathrm{~b}}$ resultam de processos metanogênicos, em que bactérias anaeróbias geram metano a partir de decomposição de biomassa, ou até, de redução de $\mathrm{CO}_{2, \mathrm{~b}}$ (BEECY et al. 2001). A metanogênese ocorre em ambientes em que a concentração de $\mathrm{O}_{2}$ e a incidência de luz solar são mínimas ou virtualmente inexistentes. A inundação de áreas de vegetadas para instalação dos lagos de barragens é um ambiente propício ao desenvolvimento de reações metanogênicas. Assim sendo, as usinas hidrelétricas devem permanecer como focos importantes de geração de $\mathrm{CH}_{4, \mathrm{~b}}$ no grid brasileiro futuro, ainda que, estimativamente esses efeitos sejam também atenuados ( $\sim 27 \%)$ em relação ao que ocorreu em 2005. Isso porque, muito embora a geração hidrelétrica estimada para 2030 seja bastante superior àquela registrada em 2005, estima-se que a biomassa disponível para decomposição microbiológica anaeróbia tenha alcançado seus níveis mínimos. Por fim, atrelada a proposta de grid está também uma redução de 9,0\% nas emissões de $\mathrm{CO}_{2, \mathrm{f}}$ originados da queima de fósseis, como resultado da desobrigação do consumo de carvão, e derivados de petróleo. 
Excetuando-se DPE, MC e DA, todas as demais categorias de impacto analisadas, mostraram impactos ambientais mais elevados em 2030 do que os registrados em 2005. No entanto, um comportamento diferente pode ser observado quando tais resultados são comparados aos obtidos em 2015, quando percebe-se redução de impacto para todas as categorias analisadas, com exceção de RadI.

AT e FMP têm nas emissões gasosas de dióxido de enxofre $\left(\mathrm{SO}_{2}\right)$ que ocorreram durante o processamento do gás natural, e nos óxidos de nitrogênio $\left(\mathrm{NO}_{\mathrm{x}}\right)$ originados da queima de combustíveis fósseis, seus principais precursores. Ao comparar os desempenhos de 2030 e 2005 para AT observam-se elevações nas emissões específicas de $\mathrm{SO}_{2}$ e $\mathrm{NO}_{\mathrm{x}}$, da condição futura, respectivamente de $187 \mathrm{~g} / \mathrm{MWh}$ e $900 \mathrm{mg} / \mathrm{MWh}$. Esses incrementos se devem a maior participação do gás natural na matriz elétrica de 2030 e resultam em expressivos $83 \%$ a mais de impacto do que ocorreu em 2005. Por outro lado, em relação aos índices de 2015, as liberações futuras daqueles gases se reduziriam em 383 g/MWh e $132 \mathrm{~g} / \mathrm{MWh}$, produzindo um déficit de 51\% nos impactos da categoria em relação àquela referência. Os impactos para FMP derivam de alguns dos mesmos precursores que estão associados a AT. Nesse caso, porém, as magnitudes das contribuições são distintas. Por conta disso, os lançamentos de $\mathrm{SO}_{2}$ e $\mathrm{NO}_{\mathrm{x}}$ estimados para 2030 trariam 61\% a mais de impactos para FMP do que ocorreu em 2005, mas seriam menos agressivas do que o desempenho de 2015 para a categoria em 49\%.

Os resultados do TH são influenciados pelas emissões de bário (Ba), manganês (Mn) e arsênio (As) para a água, decorrentes da extração de gás natural, e dos descartes de resíduos da mineração de carvão e urânio. No cenário para 2030, as disposições de Ba e As aumentam em $10 \mathrm{~g} / \mathrm{MWh}$ e $32 \mathrm{mg} / \mathrm{MWh}$, à medida em que crescem os consumos de gás e urânio em relação aos alcançados em 2005. Já as emissões hídricas de Mn diminuem (343 mg/MWh) uma vez que a participação do carvão é bastante restrita na hipotética matriz futura. De maneira geral, o balanceamento desses aportes resultaria em elevação de 77\% no impacto futuro de TH. Por outro lado, como as emissões de Ba e Mn sofrem redução (16 g/MWh e 8,0 g/MWh), o desempenho do grid brasileiro de 2030 tenderia a ser melhor que o de 2015 em 49\% em termos de Toxicidade Humana.

As perdas de bromo (Br) para a água, decorrentes da extração de gás natural, são responsáveis por $81 \%$ do impacto total do ET para 2030 e $48 \%$ no de 2015 , ao passo que em 2005 era tão somente de 4,0\%. Tais emissões ocorrem no cultivo da cana-de-açúcar em função do uso de herbicidas, e impactam o grid por intermédio da bioeletricidade. 0 resultado residual de 2005 para ET se deve ao fato de a cana não ser usada à época como fonte de geração de eletricidade. 
Em relação a RadI, perdas de $\mathrm{Rn}_{222}$ e $\mathrm{C}_{14}$ em usinas nucleares, representam quase $90 \%$ do total de impacto da categoria em 2030. Nesse cenário otimizado, essas emissões aumentariam em $18 \mathrm{MBq} / \mathrm{MWh}$ e $600 \mathrm{~Bq} / \mathrm{MWh}$ se comparadas às de 2005, por conta da maior participação das termonucleares na matriz. Esse movimento torna os impactos de RadI em 108\% mais intensos do que o desempenho de 2005. Um resultado semelhante em termos de tendência, com incremento de 84\%, seria alcançado com relação a 2015.

Finalmente, a matriz proposta para 2030 teria baixos impactos quanto a DA, se comparada com os índices de 2005 e 2015 para a categoria. Os ganhos, respectivamente de $72 \%$ e 89\%, são devidos à importante redução de envolvimento das termelétricas na oferta interna futura de eletricidade. Vale ainda destacar que geração termonuclear, que participa com 4,8\% da matriz 2030 (Tabela 7.3) inibe ganhos adicionais em relação a DA, devido ao consumo de água nas torres de resfriamento.

A estratégia adotada para redução de emissões de GEE fica ainda mais clara ao se confrontarem os grids (hipotético) para 2030 e (real) de 2015. Uma saída encontrada para reduzir a incidência de termeletricidade não-renovável - desde 22\% em 2015, para 7,3\% em 2030 -, foi ampliar a cota de participação das usinas eólicas $(3,4 \% \rightarrow \sim 18 \%)$ no grid. Muito embora expressiva em valores relativos, a ação não seria suficiente para atender ao salto de demanda que o país requererá no futuro. Com isso, outro movimento natural nessa direção seria potencializar a geração de bioeletricidade; isso, no entanto, não ocorreu em virtude dos custos que a ela estão associados. Restou, como alternativa, portanto, intensificar a geração de energia nuclear, que nessa projeção dobraria o aporte de 2015 (2,4\%) para 2030 (4,8\%). Uma vantagem adicional das termonucleares reside nos baixos custos de geração da eletricidade, que são, em geral, inferiores aos de outras fontes, e comparáveis apenas aos de hidrelétricas. 0 desempenho ambiental obtido pelas termonucleares ratifica as conclusões de Beal (2016) e Gralha et al. (2017), de que essa é a alternativa de geração de energia mais adequada para mitigação do Aquecimento Global já que suas emissões de GEE são, naturalmente, menores que as de outras fontes por todo o ciclo de vida.

No entanto, o uso de energia nuclear é ainda uma questão controversa, inclusive em termos ambientais, em virtude das muitas transformações que integram sua cadeia de suprimentos, desde a extração de urânio, até o descarte final dos rejeitos radioativos, passando pela segurança operacional. Ao se somar aos impactos que acarreta em termos de RadI e TH, tal conjuntura precipitou uma revisão da participação nuclear na proposta de Matriz Elétrica Brasileira para 2030. 
Um rearranjo daquele cenário hipotético foi proposto com o propósito de reduzir impactos ambientais. Para tanto, otimizou-se novamente o grid, usando como restrição apenas um valor de capacidade limite de geração de energia nuclear $G C_{N U, m a ́ x}^{\prime}<G C_{N U \text {,máx }}$. $\mathrm{O}$ valor de $\left(G C_{N U, m a ́ x}^{\prime}\right)$ foi obtido por processo iterativo, exercitado até que fosse atingida a mínima de participação dessa fonte no grid, capaz de atender aos requerimentos de impacto e demanda fixados para a análise (seção 7.2.1). Dessa intervenção resultou uma participação de 34 TWh (3,3\%) como o limite superior do aporte nuclear. A tabela 7.5 apresenta a composição dessa matriz alternativa para 2030.

Tabela 7.5 - Variant da Matriz Elétrica Brasileira (2030") com restrição de geração nuclear

\begin{tabular}{lcc}
\hline \multirow{2}{*}{ Fonte } & \multicolumn{2}{c}{ Contribuição individual por fonte } \\
\cline { 2 - 3 } & $\begin{array}{c}\text { Valores absolutos } \\
\text { (TWh/ano) }\end{array}$ & $\begin{array}{c}\text { Valores Relativos } \\
(\%)\end{array}$ \\
\hline Hidreletricidade & 675 & 65,5 \\
Biomassa (= bagaço) & 51,2 & 4,97 \\
Eólica & 195 & 18,9 \\
Gás Natural & 75,0 & 7,28 \\
Derivados de petróleo & 0,00 & 0,00 \\
Nuclear & 33,9 & 3,29 \\
Solar & 0,00 & 0,00 \\
Carvão e derivados & $1,24 \mathrm{E}-03$ & $\rightarrow 0,00$ \\
\hline Total & 1030 & 100 \\
\hline
\end{tabular}

Para reduzir a participação nuclear $(4,8 \% \rightarrow 3,3 \%)$ foi necessário elevar o aporte da fonte eólica até seu limite superior possível de geração anual, 195 TWh (Tabela 7.2). A biomassa completa a lacuna deixa pelas termonucleares na matriz até que a demanda fosse atendida. Os resultados de desempenho ambiental para ambos os cenários (2030 e 2030”) são apresentados na Tabela 7.6. A alteração do grid 2030 para a variante 2030" reduziu em 2,4\% os impactos de DEP já que o consumo de recursos nucleares diminuiu de 31\%. Para TH, o ganho foi de 2,0\% em função da redução, em 16\%, de emissões de As para água por conta do menor descarte de rejeitos de urânio. No entanto, os benefícios associados à proposição da matriz 2030" se manifestaram, de fato, através da redução dos impactos de Radl, chegando a 31\% devido a contenção das perdas de $\mathrm{Rn}_{222}$ e $\mathrm{C}_{14}$. Como efeito colateral dessa ação, a DA foi também amortecida em 16\% em relação à calculada para 2030. Por outro lado, os impactos para ET aumentaram de 9,5\% devido ao incremento da participação da biomassa no cenário 2030". 
Tabela 7.6 - Desempenho ambiental de propostas para o grid elétrico brasileiro: cenários 2030 e 2030"

\begin{tabular}{llll}
\hline Categoria de Impacto & $\begin{array}{l}\text { Unidades } \\
\text { (/MWh) }\end{array}$ & 2030 & 2030” \\
\hline Demanda de Energia Primária (DEP) & GJ & 4,94 & 4,82 \\
Mudanças Climática (MC) & $\mathrm{kg} \mathrm{CO}_{2}$ eq & 180 & 180 \\
Acidificação Terrestre (AT) & $\mathrm{kg} \mathrm{SO}_{2} \mathrm{eq}$ & $4,40 \mathrm{E}-01$ & $4,4 \mathrm{E}-01$ \\
Formação de Material Particulado & $\mathrm{kg} \mathrm{PM}_{10}$ eq & $1,11 \mathrm{E}-01$ & $1,11 \mathrm{E}-01$ \\
(FMP) & $\mathrm{kg} \mathrm{1.4-DB} \mathrm{eq}$ & 14,6 & 14,3 \\
Toxicidade Humana (TH) & $\mathrm{kg} 1.4-\mathrm{DB}$ eq & $2,13 \mathrm{E}-01$ & $2.30 \mathrm{E}-01$ \\
Ecotoxicidade Terrestre (ET) & $\mathrm{kBq} \mathrm{U235} \mathrm{eq}$ & 52,9 & 36,6 \\
Radiação Ionizante (RadI) & $\mathrm{m}^{3}$ & $7,80 \mathrm{E}-01$ & $6,53 \mathrm{E}-01$ \\
\hline Depleção de água (DA) & & & \\
\hline
\end{tabular}

Os resultados obtidos demonstram que nem todos os sistemas de geração elétrica são capazes de atender satisfatória a simultaneamente a todos os critérios econômicos, ambientais que foram estabelecidos. Se por um lado a proposta para 2030 alcançou as esperadas reduções de impacto em termos de MC com relação a 2005, por outro, quase todas as demais categorias tiveram seus índices majorados por conta dessa sugestão. As adequações realizadas com a expectativa de equacionar a ascendência da energia nuclear sobre o grid, trouxeram de fato melhorias de desempenho em Radl e TH, mas, para isso, amplificaram os efeitos adversos da matriz na forma de ET.

\subsection{Conclusões}

O presente estudo projetou uma Matriz Elétrica Brasileira para 2030, em que três requisitos deveriam ser atendidos: (i) um arranjo que tivesse custo mínimo de geração; (ii) limite de impacto para Mudanças Climáticas de $185 \mathrm{Mt} \mathrm{CO}_{2}$ eq, que correspondia ao desempenho de 2005; e (iii) o atendimento da demanda projetada (1030 TWh) para o período. Os resultados mostraram que a geração de eletricidade a partir de fontes renováveis representa 88\% da produção nacional em 2030, sendo a energia hidrelétrica responsável pela maior parte $(\sim 75 \%)$ desse total. Além disso, a eletricidade proveniente de fontes eólicas deveria ter uma participação importante na oferta nacional (18\%), ao que se seguiria a de gás natural (7,3\%). Por fim, para cumprir com aqueles compromissos as fontes derivadas de petróleo não poderiam integrar o suprimento elétrico em 2030. 
O custo mínimo anual da geração elétrica em 2030 atingiria US\$ 84,5 bilhões devido à presença intensificada de fontes renováveis (eólica), em geral mais caras que as não-renováveis convencionais (carvão e gás natural). Em termos específicos, esse custo seria de 82,00 US\$/MWh.

Como esperado, os impactos ambientais em termos de Mudança Climática (MC) mostraram reduções de 12\% e 45\% com relação aos desempenhos de 2005 e 2015. A Depleção de Água (DA) seguiu pelas mesmas tendências, ao diminuir, respectivamente, de $72 \%$ e $89 \%$ em relação aos resultados obtidos para os mesmos períodos. No entanto, a proposta apresentou desempenhos adversos para outras categorias analisadas (DEP: Demanda de Energia Primária; AT: Acidificação Terrestre; FMP: Formação de Material Particulado; TH: Toxicidade Humana; ET: Ecotoxicidade Terrestre; e Radl: Radiação Ionizante), também em relação ao cenário de 2005. Foram destaques negativos nesse âmbito os desempenhos do grid 2030 para ET - cujo resultado é em mais quarenta vezes superior ao de 2005 -, e de RadI, maior em 108\% do que a referência. 0 uso de pesticidas no cultivo da cana-de-açúcar, e o descarte de rejeitos da moagem de urânio podem ser responsabilizados por esses reveses. Por outro lado, o perfil ambiental do grid de 2030 é superior ao de seu homólogo para 2015 em todas as categorias avaliadas.

A realização de um ajuste que reduziu a participação da energia nuclear no grid surtiu efeito na maior parte das categorias de impacto, com destaque para as reduções observadas em DEP $(2,4 \%)$, TH $(\sim 2,0 \%)$ e Radl ( 31\%). No entanto, as contribuições para ET acabaram sendo amplificadas em 9,5\%.

Os resultados obtidos demonstram que nem todos os sistemas de geração elétrica são capazes de atender satisfatória a simultaneamente a todos os critérios econômicos, ambientais que foram estabelecidos. Isso reforça a importância de incluir abordagens como a proporcionada pela ACV em ações de planejamento e tomada de decisão do setor energético. Além disso, a gestão ambiental não deve se limitar a análise de GEE, sob pena de deixar de considerar impactos significativas que ocorram em âmbito local ou regional.

\subsection{Referências}

Abbaspour M., Monavari M., Karbassi R., Kargari, N., 2011, Nuclear power and its role in $\mathrm{CO}_{2}$ emissions from the electricity generation in Iran. Energy Sources, 34: 43-52. DOI: 10.1080/15567036. 2010.483532. 
Agarski B., Budak I., Vukelic D., Hodolic J., 2016, Fuzzy multi-criteria-based impact category weighting in life cycle assessment. Journal of Cleaner Production, 112: 3256-3266. DOI: 10.1016/j.jclepro.2015. 09.077.

Alam M. M., Murad M. W., Norman A. H. M., Ozturk I., 2016, Relationships among carbon emissions, economic growth, energy consumption and population growth: testing environmental Kuznets Curve hypothesis for Brazil, China, India and Indonesia. Ecological Indicators, 70: 466-479. DOI: 10. 1016/j.ecolind.2016.06.043.

Almer C., Winkler R., 2017, Analyzing the effectiveness of international environmental policies: The case of the Kyoto Protocol. Journal of Environmental Economics and Management, 82: 125-151. DOI: $10.1016 /$ j.jeem.2016.11.003

Baek J, 2016, Do nuclear and renewable energy improve the environment? Empirical evidence from the United States. Ecological Indicators, 66: 352-356. DOI: 10.1016/j.ecolind.2016.01.059.

Beck T. Principles of Ecological Landscape Design. Island Press. Washington DC. US. 2013. Beecy D. J., Ferrell F. M., Carey J. K., 2001, Biogenic Methane: A Long-Term $\mathrm{CO}_{2}$ Recycle Concept. The US Department of Energy Carbon Sequestration Research Program. Disponível em: <https://www.netl.doe.gov/publications/proceedings/01/carbon_seq/5a1.pdf>.

Blok V., Long T. B, Gaziulusoy A. I, Ciliz N., Lozano R., Huisingh D., Csutora M., Boks C., 2015, From best practices to bridges for a more sustainable future: advances and challenges in the transition to global sustainable production and consumption. Journal of Cleaner Production, 108: 19-30. DOI: 10.1016/ j.jclepro.2015.04.119.

Burger B., Bauer C., 2007, Windkraft. In: Sachbilanzen von Energiesystemen: Grundlagen für den ökologischen Vergleich von Energiesystemen und den Einbezug von Energiesystemen in Ökobilanzen für die Schweiz, ecoinvent report n. 6-XIII, v2.0 (ed. Dones R.). Paul Scherrer Institut Villigen, Swiss Centre for Life Cycle Inventories, Dübendorf, Switzerland.

Chen C., Long H., Zeng X., 2017, Planning a sustainable urban electric power system with considering effects of new energy resources and clean production levels under uncertainty: A case study of Tianjin, China. Journal of Cleaner Production, 173: 67-81. DOI: 10.1016/j.jclepro.2017.01.098.

Costa O.L.V., Ribeiro C.O., Rego E.E., Stern J. M, Parente V., Kileber S., 2017, Robust portfolio optimization for electricity planning: An application based on the Brazilian electricity mix. Energy Economics, 64:158-169. DOI: 10.1016/j.eneco.2017.03.021.

Dantas G.A., Castro N.J., Brandão R., Rosental R., Lafranque A., 2017, Prospects for the Brazilian electricity sector in the 2030s: Scenarios and guidelines for its transformation. Renewable and Sustainable Energy Reviews, 68: 997-1007. DOI: 10.1016/j.rser.2016.08.003.

Dinato R., Kulay L., 2015, The fossilization of the Brazilian electric matrix under the Life Cycle Assessment perspective. Paper presented at the 2nd Discussion Forum on Industrial Ecology and Life-Cycle Management, Coimbra. Disponível em:

http://bibliotecadigital.fgv.br/dspace/handle/10438/18468

Dones R., 2006, Kernenergie. In: Sachbilanzen von Energiesystemen: Grundlagen für den ökologischen Vergleich von Energiesystemen und den Einbezug von Energiesystemen in Ökobilanzen für die Schweiz (Ed. Dones R.). Final report Ecoinvent. n. 6-VII. Paul Scherrer Institut Villigen, Swiss Centre for LCI, Dübendorf, Switzerland. 
Dones R., 2007a, Life Cycle Inventories of Energy Systems: Results for current systems in Switzerland and other UCTE countries. Ecoinvent Report m.5. Swiss Centre for LCI, Dübendorf, Switzerland. Disponível em: www.ecoinvent.org

Elum Z. A., Momodu A.S., 2017, Climate change mitigation and renewable energy for sustainable development in Nigeria: A discourse approach. Renewable and Sustainable Energy Reviews, 76: 72-80. DOI: 10.1016/j.rser.2017.03.040.

EPE (Empresa de Pesquisa Energética), 2006, Balanço Energético Nacional 2006. (Ano Base: 2005). Relatório Final. Disponível em: <http://http://www.mme.gov.br

EPE (Empresa de Pesquisa Energética), 2016, Balanço Energético Nacional 2016. (Ano Base: 2015). Relatório Final. Disponível em: <http://http://www.mme.gov.br

Faist Emmenegger M., Heck T., Jungbluth N., 2007, Erdgas. In: Sachbilanzen von Energiesystemen: Grundlagen für den ökologischen Vergleich von Energiesystemen und den Einbezug von Energiesystemen in Ökobilanzen für die Schweiz, ecoinvent report n. 6-V, v2.0 (ed. Dones R.). Paul Scherrer Institut Villigen, Swiss Centre for Life Cycle Inventories, Dübendorf, Switzerland.

Foley A., Smyth B.M., Pukšec T., Markovska N., Duić N, 2017, A review of developments in technologies and research that have had a direct measurable impact on sustainability considering the Paris agreement on climate change. Renewable and Sustainable Energy Reviews, 68: 835839. DOI: 10.1016/j.rser.2016.11.215.

Frischknecht R., 2017 Implementation of Life Cycle Impact Assessment Methods. Final report Ecoinvent v2. Swiss Centre for LCI. Dübendorf, Switzerland.

Goedkoop M., Heijungs R., Huijbregts M., Schryver A., Struijs J., 2017, Description of the ReCiPe methodology for Life Assessment Impact Assessment. Disponível em: <http://www.lcia-recipe.net

Gralla F., Abson D.J., Møller A.P., Lang D.J., von Wehrden H., 2017, Energy transitions and national development indicators: A global review of nuclear energy production. Renewable and Sustainable Energy Reviews, 70: 1251-1265. DOI: 10.1016/j.rser.2016.12.026.

Grilli G., Balest J., De Meo I., Garegnani G., Paletto A., 2016, Experts' opinions on the effects of renewable energy development on ecosystem services in the Alpine region. Journal of Renewable and Sustainable Energy, 8: 1-13. DOI: 10.1063/1.4943010.

Grilli G., De Meo I., Garegnani G., Paletto A., 2017, A multi-criteria framework to assess the sustainability of renewable energy development in the Alps. Journal of Environmental Planning and Management, 60: 1-20. DOI: 10.1080/09640568.2016.1216398.

Gueller M.T.B., Meneses A.A.M., 2016, Life Cycle Assessment of a small hydropower plant in the Brazilian amazon". Journal of Sustainable Development of Energy, Water and Environmental Systems, 4, 379-391. DOI:10.13044/j.sdewes.2016.04.0029.

Guerra J.B.S.O. A, Dutra L., Schwinden N.B.C., Andrade S. F, 2015, Future scenarios and trends in energy generation in Brazil: supply and demand and mitigation forecasts. Journal of Cleaner Production, 103: 197-210. DOI: 10.1016/j.jclepro.2014.09.082.

Hacatoglu K., Dincer I., Rosen M.A, 2015, A new model to assess the environmental impact and sustainability of energy systems. Journal of Cleaner Production, 103: 211-218. DOI: 10.1016/ j.jclepro.2014.06.050. 
Hardisty P.E., Clark T.S., Hynes R.G., 2012, Life Cycle Green House Gas emissions from electricity generation: a comparative analysis of Australian energy sources. Energies, 5: 872-897. DOI: 10. $3390 /$ en5040872.

IEA (International Energy Agency), 2015, Projected Costs of Generating Electricity OECD Publishing, Paris. Disponível em: <https://www.oecd-nea.org/ndd/pubs/2015/7057-proj-costselectricity -2015.pdf

ISO (International Organization for Standardization). ISO 14044, 2006, Environmental Management-Life Cycle Assessment-Requirements and Guidelines, $1^{\text {st }}$ Ed. International Organization for Standardization: Genève, Switzerland, 46p

Jacobi P. R., Cibim J., Leão R. S., 2015, Crise hídrica na Macrometrópole Paulista e respostas da sociedade civil. Estudos Avançados, 29: 27-42. DOI: 10.1590/S0103-40142015000200003

Jungbluth N., 2007, Erdöl, In R. Dones (ed.), Sachbilanzen von Energiesystemen: Grundlagen für den ökologischen Vergleich von Energiesystemen und den Einbezug von Energiesystemen in Ökobilanzen für die Schweiz. Ecoinvent report No. 6-IV. Swiss Centre for LCI. Dübendorf, Switzerland.

Jungbluth N., Tuchschmid M., 2007, Photovoltaics. In: Sachbilanzen von Energiesystemen: Grundlagen für den ökologischen Vergleich von Energiesystemen und den Einbezug von Energiesystemen in Ökobilanzen für die Schweiz, ecoinvent report n. 6-XII, v2.0 (ed. Dones R.). 180p. Paul Scherrer Institut Villigen, Swiss Centre for LCI, Dübendorf, Switzerland.

Jungbluth N., Chudacoff M., Dauriat A., Dinkel F., Doka G., Faist Emmenegger M., ... Sutter J., 2007, Life Cycle Inventories of Bioenergy. Ecoinvent report n. 17. Swiss Centre for LCI. Dübendorf, Switzerland.

Kileber, S., Parente, V., 2015, Diversifying the Brazilian electricity mix: Income level, the endowment effect, and governance capacity. Renewable and Sustainable Energy Reviews, 49:1180-1189. https://doi.org/10. 1016/j.rser.2015.04.109

Lau, L.C., Lee, K.T., Mohamed, A.R., 2012. Global warming mitigation and renewable energy policy development from the Kyoto Protocol to the Copenhagen Accord - A comment. Renewable and Sustainable Energy Reviews, 16: 5280-5284. https://doi: doi.org/10.1016/j.rser.2012.04.006

Lima, C.C., Carvalho, L.M.O., 2016, A produção de Energia Elétrica, a exaustão ambiental da fonte hídrica e a opção proveniente da base eólica renovável. Revista Brasileira de Energias Renováveis, 5:65-90. (in Portuguese)

https://doi.org/10.5380/rber.v5i1.43558

LINGO (Optimization Modeling Software for Linear, Nonlinear, and Integer Programming) v. 17.0.0.52. 2017, computer program, LINDO Systems Inc. Chicago. US. Retrieved April 2017, from http://www.lindo.com

Maxim, A., 2014, Sustainability assessment of electricity generation technologies using weighted multi-criteria decision analysis. Energy Policy, 65:284-297. https://doi.org/10.1016/i.enpol.2013.09.059

MME (Ministry of Mines and Energy). 2007. National Energy Grid 2030. Brasília, 2007, 254 p. Retrieved March, 2017, from http://www.mme.gov.br 
Moreira, J.M.L., Cesaretti, M.A., Carajilescov, P., Maiorino, J.R., 2015. Sustainability deterioration of electricity generation in Brazil. Energy Policy, 87: 334-346. https://doi.org/10.1016/j.enpol.2015.09.021

Mossalanejad, A., 2012, Evaluating the developed countries policy making toward environmental cases. International Journal of Environmental Research, 6:71-80. https://doi.org/10.22059/IJER.2011.473

MRE (Ministry of Foreign Affairs) 2015. Pretendida Contribuição Nacionalmente Determinada para consecução do objetivo da Convenção-Quadro das Nações Unidas sobre Mudança do Clima. 10 p. Brasília Available at: http://www.itamaraty.gov.br/images/ed desenvsust/BRASIL-iNDC-portugues.pdf

Pao, H. T., \& Fu, H.C., 2013, Renewable energy, non-renewable energy and economic growth in Brazil. Renewable and Sustainable Energy Review, 25:381-392. https://doi.org/10.1016/j.rser.2013.05.004

Patel, M., Zhang, X., \& Kumar, A., 2016, Techno-economic and life cycle assessment on lignocellulosic biomass thermochemical conversion technologies: A review.

Renewable and Sustainable Energy Review, 53:1486-1499.

https://doi.org/10.1016/i.rser.2015.09.070

Pereira, M. G., Camacho, C. F., Freitas, M. A. V., \& Silva, N.F., 2012, The renewable energy market in Brazil: Current status and potential. Renewable and Sustainable Energy Review, 16:3786-3802. https://doi.org/0.1016/j.rser.2012.03.024

Portugal-Pereira, J., Köberle, A. C., Soria, R., Lucena, A. F. P., Szklo, A., \& Schaeffer, R., 2016, Overlooked impacts of electricity expansion optimisation modelling: The life cycle side of the story. Energy, 115:1424-1435.

https://doi.org/10.1016/j.energy.2016.03.062

Rocha, G. O., Dos Anjos, J. P., \& Andrade, J. B., 2015, Energy trends and the water-energy binomium for Brazil. Annals of the Brazilian Academy of Sciences, 87: 569-594. https://doi.org/10.1590/0001-3765201520140560

Röder, A., Bauer, C., \& Dones, R., 2004. In: Sachbilanzen von Energiesystemen: Grundlagen für den ökologischen Vergleich von Energiesystemen und den Einbezug von Energiesystemen in Ökobilanzen für die Schweiz (Ed. Dones R.). Final report Ecoinvent. n. 6-VI. Paul Scherrer Institut Villigen, Swiss Centre for LCI, Dübendorf, Switzerland.

Sáez-Martínez, F. J., Lefebvre, G., Hernández, J.J., Clark, J. H., 2016, Drivers of sustainable cleaner production and sustainable energy options. Journal of Cleaner Production, 138: 1-7. https://doi.org/10.1016/ j.jclepro.2016.08.094

Santos, M. J., Ferreira, P., Araújo, M., Portugal-Pereira, J., Lucena, A. F. P., \& Schaeffer, R., 2017, Scenarios for the future Brazilian power sector based on a multi-criteria assessment. Journal of Cleaner Production (in press).

https://doi.org/10.1016/i.jclepro.2017.03.145

Santoyo-Castelazo, E., Azapagic, A., 2014, Sustainability assessment of energy systems: integrating environmental, economic and social aspects. Journal of Cleaner Production, 80: 119-138. https://doi.org/10. 1016/j.jclepro.2014.05.061 
Schmidinger, K., \& Stehfest, E., 2012, Including $\mathrm{CO}_{2}$ implications of land occupation in LCAs - method and example for livestock products. International Journal of Life Cycle Assessment, 17: 962-972. https://doi.org/10.1007/s11367-012-0434-7

ShafiepourMotlagh, M., Ashrafi, Kh., \& Dalir, F., 2016. LCA frameworks integration in Carbon Footprint modelling of simple cycle and combined cycle power plant for sustainable planning in Iran. International Journal of Environmental Research, 10: 645-654. https://doi.org/10.22059/IJER.2016.59969

Sims, R. E. H., 2007. Energy supply. In Climate Change 2007: Mitigation. Contribution of Working Group III to the $4^{\text {th }}$ Assessment Report of the Intergovernmental Panel on Climate Change. Cambridge University Press, Cambridge, United Kingdom and New York, NY, USA. 2007. 72 p. Retrieved May 2017, from https://www.ipcc.ch/pdf/assessment-report/ar4/wg3/ar4-wg3-chapter4.pdf

Stamford, L., \& Azapagic, A., 2014, Life cycle sustainability assessment of UK electricity scenarios to 2070. Energy for Sustainable Development, 23:194-211.

https://doi.org/10.1016/j.esd.2014.09.008

Turconi, R., Boldrin, A., \& Astrup, T., 2013,. Life Cycle Assessment (LCA) of electricity generation technologies: overview, comparability and limitations. Renewable and Sustainable Energy Reviews, 28:555-565.

https://doi.org/10.1016/j.rser.2013.08.013

Vahl, F. P., \& Casarotto Filho, N., 2015, Energy transition and path creation for natural gas in the Brazilian electricity mix. Journal of Cleaner Production, 86: 221-229. https://doi.org/10.1016/j.jclepro.2014.08.033

Vidal-Amaro, J. J., Østergaard, P. A., Sheinbaum-Pardo, C., 2015, Optimal energy mix for transitioning from fossil fuels to renewable energy sources - The case of the Mexican electricity system. Applied Energy, 150: 80-96.

https://doi.org/10.1016/j.apenergy.2015.03.133

Von Sperling, E., 2012, Hydropower in Brazil: overview of positive and negative environmental aspects. Energy Procedia, 18:110-118.

https://doi.org/10.1016/j.egypro.2012.05.023

Zbicinski, I., Stavenuiter, J., Kozlowska, B., \& van de Coevering, H. 2006. Product Design and Life Cycle Assessment (pp. 88-89). The Baltic University Press, Usppsala. Sweden. 2006. 


\section{Considerações Finais}

Após circular por todos esses casos em que a ACV foi aplicada em sua função mais original e imediata, de produzir diagnósticos ambientais, espera-se que o objetivo a que essa tese se propôs tenha sido atingido. A Avaliação de Ciclo de Vida pode ser vista como um recurso, meio, ou artifício para o aprimoramento de processos e transformações que se desenvolvem no âmbito da Indústria Química. Os capítulos que a estes se sucederam demonstram isso para situações objetivas, algumas delas triviais a IPQ, e outras que a ela são correlatas. Além disso, as aplicações que poderiam parecer semelhantes, ou talvez, meras variações de um mesmo tema, a um olhar menos perscrutador, são em verdade próprias dentro de suas aplicações.

O mesmo ocorre com os diagnósticos - que se na maioria dos casos apresentados se ativeram a desempenhos energéticos, expressos por Demanda de Energia Primária, e ambientais, que se fixaram em Mudanças Climáticas - trouxeram resultados distintos, e únicos, dentro das especificidades de cada situação.

Posto isso, cabem apenas mais três comentários. A ACV não faz, nem nunca fará, parte dos conteúdos conceituais que conferem identidade à Engenharia Química. Não é esse o tema em pauta nessa reflexão. No entanto, ela pode trabalhar em colaboração a esta habilitação, e por conseguinte, com o universo extenso de aplicações sobre o qual o profissional formado na área pode atuar.

A ACV também não trata soluções para problemas cotidianos da IPQ, mas sempre poderá ser usada - e com tantos níveis de rigor quanto as circunstâncias assim o exigirem - para gerar processos mais eficientes, que ao mesmo tempo (e invariavelmente) serão menos custosos e impactantes. E talvez seja nessa adaptabilidade que reside o cerne de confluências entre processos químicos e ACV. Ambos predispõem um conhecimento preciso, robusto de processo, dos fenômenos que o regem, e das ligações estabelecidas com outros estágios do ciclo de vida, sejam eles industriais, ou não.

E será apenas dessa forma que o benefício de ter um diagnóstico de envergadura sistêmica poderá ser bem aproveitado e, assim, gerar os resultados que dele se esperam. Esses predicados são inerentes (mas não exclusivos) à formação do engenheiro, e talvez, com mais propriedade de causa por conta das funções que desempenha - de análise de processo, e de projeto de plantas e sistemas - do engenheiro químico. 
Além disso, a integração da ACV com abordagens típicas da Engenharia Química é, mais do que possível, necessária, oportuna e bem-vinda. Dessas sinergias podem surgir resultados tão conclusivos e bem fundamentados, quanto as abordagens puderem ser exploradas na plenitude de suas facetas. Para que isso ocorra, porém, é fundamental que o praticante da ACV tenha conhecimentos de engenharia química, ou que na equipe de engenheiros existam um praticionaire, quando não houver um especialista, em ACV. Ou seja, este segundo comentário conflui naturalmente para o primeiro.

Por fim, espera que tenha ficado claro um ponto essencial de toda essa reflexão: exatamente por tratar (apenas) de uma técnica de diagnóstico, a ACV pode transcender, inclusive com boa eficiência, os limites das abordagens mais convencionais - restritas as dimensões técnica e econômica e encerradas tão somente no intra murus do processo e buscar correlações entre desempenho ambiental e parâmetros, condições ou mesmo, tipologias de processos.

E vale a pena reiterar uma máxima apontada há alguns parágrafos atrás neste mesmo capítulo: processos com desempenho ambiental satisfatórios são também mais tecnicamente consistentes e economicamente lucrativos. Isso porque, suas conversões de matérias-primas e insumos em produtos são elevadas, e há baixa geração de rejeitos, já que uma parte do (pouco) que foi gerado dessas perdas podem ser (re)valorizado a ponto de ser aproveitado no processo de origem (reciclo fechado), ou mesmo tornar-se um subproduto, e com esses status seguir para outra cadeia produtiva (reciclo aberto), gerando assim receitas para a organização.

Conforme sucedem as experiências em que a ACV mostra as habilidades de que dispõe na interface estabelecida entre processos antrópicos da indústria química e o meio ambiente, a ideia de que essa é uma tese a ser comprovada deixa de ter sentido, para dar lugar a uma certeza, um dogma, um ideal, ou talvez até, uma crença. 
